\title{
Analysis of Removal Alternatives for the Heavy Water Components Test Reactor at the Savannah River Site
}

by

M. B. Owen

Westinghouse Savannah River Company

Savannah River Site

Aiken, South Carolina 29808

us Energv Corporation

DOE Contract No. DE-AC09-89SR18035

This paper was prepared in connection with work done under the above contract number with the U.S. Department of Energy. By acceptance of this paper, the publisher and/or recipient acknowledges the U.S. Government's right to retain a nonexclusive, royalty-free license in and to any copyright covering this paper, along with the right to reproduce and to authorize others to reproduce all or part of the copyrighted paper. 


\section{DISCLAMMER}

Portions of this document may be illegible in electronic image products. Images are produced from the best available original document. 


\section{DISCLAIMER}

This report was prepared as an account of work sponsored by an agency of the United States Government. Neither the United States Government nor any agency thereof, nor any of their employees, makes any warranty, express or implied, or assumes any legal liability or responsibility for the accuracy, completeness, or usefulness of any information, apparatus, product, or process disclosed, or represents that its use would not infringe privately owned rights. Reference herein to any specific commercial product, process, or service by trade name, trademark, manufacturer, or otherwise does not necessarily constitute or imply its endorsement, recommendation, or favoring by the United States Government or any agency thereof. The views and opinions of authors expressed herein do not necessarily state or reflect those of the United States Government or any agency thereof.

This report has been reproduced directly from the best available copy.

Available to DOE and DOE contractors from the Office of Scientific and Technical Information, P. O. Box 62, Oak Ridge, TN 37831; prices available from (423) 576-8401.

Available to the public from the National Technical Information Service, U. S. Department of Commerce, 5285 Port Royal Road, Springfield, VA 22161. 


\section{Table of Contents}

Note that a more-detailed table of contents begins on the following page.

\section{Analysis of Removal Alternatives} for the

Heavy Water Components

Test Reactor at the

Savannah River Site

April 1997

Department of Energy Savannah River Site Aiken, South Carolina

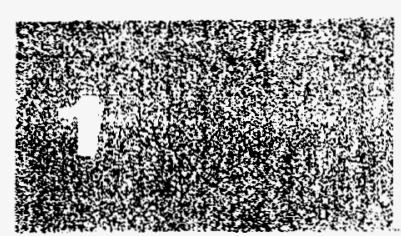

ANALYSIS OF REMOVAL ALTERNATIVES

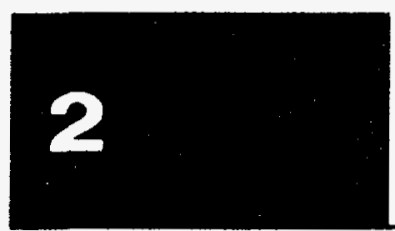

APPENDIX A

ILLUSTRATIONS AND PHOTOGRAPHS

\section{APPENDIX B}

LIST OF HWCTR EQUIPMENT
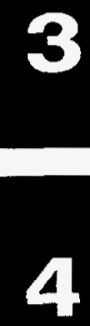

APPENDIX C

SCHEDULE FOR DISMANTLEMENT

\section{APPENDIX D}

SChEDUle for Partial Dismantlement aND INTERIM SAFE STORAGE

\section{APPENDIX E}

SCHEDULE FOR CONVERSION TO BENEFICIAL REUSE

\section{APPENDIX F}

SCHEDULE FOR ENTOMBMENT

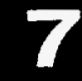

\section{APPENDIX G}

REFERENCES

\section{APPENDIX $\mathrm{H}$}

GLOSSARY

\section{APPENDIX 1}

PuBlic COMMENTS AND DEPARTMENT OF

ENERGY RESPONSES 


\section{Contents}

About Revision 1 ix

\subsection{EXECUTIVE SUMMARY}

2.0 INTRODUCTION

2.1 Purpose 3

2.2 Scope 3

2.3 Public Participation ? 4

2.4 Regulator Involvement 4

2.5 The Decontamination and Decommissioning Project Plan 5

2.6 Relationship to the Site Ten Year Plan 5

2.7 Organization of this Document 5

3.0 FACILITY CHARACTERIZATION 6

3.1 Site Description 6

3.2 Facility Description and Brief History 7

3.2.1 Description of the HWCTR Facility 7

3.2.2 Brief History of the Facility 9

3.3 Summary of Existing Conditions - 10

3.4 Transition/Deactivation Process and End Condition Achieved 10

3.5 Surveillance and Maintenance Program 10

3.6 Previous Removal Actions and Cleanup 11

3.6.1 The 1976 Decommissioning Plan 11

$\begin{array}{lll}3.6 .2 & \text { Since } 1976 & 12\end{array}$

3.7 Source, Nature and Extent of Contamination 13

$\begin{array}{lll}3.7 .1 & \text { Summary } & 13\end{array}$ 
3.7.2 Basis for Estimates of Contamination

3.7.3 Induced Radioactivity

3.7.4 Radiation Levels

3.7.5 Radioactive Contamination

3.7.6 Lead

3.7.7 Mercury

3.7.8 Asbestos

3.7.9 PCBs

3.7.10 Waste Oils and Hydraulic Fluids

3.7.11 Additional Detailed Characterization

3.8 Facility Safety Analysis Documentation in Effect

\subsection{IDENTIFICATION OF REMOVAL ACTION OBJECTIVES}

4.1 Objectives of Decommissioning

4.2 General End Condition Criteria

4.3 Related Remedial Actions Involving Soil or Water in the Vicinity

4.4 Potential Future Uses of the Property

4.5 Historical Significance of the HWCTR Facility

5.0 REMOVAL ALTERNATIVES

5.1 Potential Alternatives

5.1.1 Safe Storage

5.1.2 Alternatives Studied in Detail

5.1.3 Dismantlement

5.1.4 Partial Dismantlement and Interim Safe Storage

5.1.5 Partial Dismantlement and Beneficial Reuse

5.1.6 Entombment 
5.3 Specific End Condition 32

$\begin{array}{lll}\text { 5.3.1 Dismantlement } & 32\end{array}$

5.3.2 Partial Dismantlement and Interim Safe Storage 32

5.3.3 Partial Dismantlement and Beneficial Reuse 33

5.3.4 Entombment 33

5.4 Risks and Safety Issues $\quad 34$

$\begin{array}{lll}5.4 .1 & \text { Summary } & 34\end{array}$

5.4.2 The Nature of Radiological Risks 34

5.4.3 HWCTR Radiological Risks 35

5.4.4 Pathways for Radiation Exposure 36

$\begin{array}{lll}\text { 5.4.5 Risks of External Exposure } & 36\end{array}$

5.4.6 Risks Associated With Ingestion of Radioactive Materials 37

5.4.7 Risks From Inhaling Airborne Radioactivity 38

$\begin{array}{lll}\text { 5.4.8 Risks From Waterborne Radioactivity } & 38\end{array}$

5.4.9 Risks Associated With Nonradiological Pollutants 38

5.5 Potential Impacts of Each Alternative 38

$\begin{array}{lll}\text { 5.5.1 Ecological Impacts } & 38\end{array}$

5.5.2 Socioeconomic Impacts 42

5.5.3 Off-Site Impacts $\quad 42$

5.5.4 Cumulative Impacts $\quad$ - 44

5.6 Effectiveness of Each Alternative 44

5.7 Environmental Protection $\quad 45$

$\begin{array}{lll}\text { 5.7.1 Policy } & 45\end{array}$

5.7.2 Implementation 45

5.7.3 Dismantlement 45

5.7.4 Partial Dismantlement and Interim Safe Storage 45

5.7.5 Partial Dismantlement and Beneficial Reuse 46 
5.7.6 Entombment $\quad 46$

5.8 Health and Safety of Workers and the Public 46

5.8.1 Physical Security 46

5.8.2 Occupational Safety and Health 47

5:8.3 Radiation Protection $\quad \cdot 47$

5.8.4 Minimizing Worker Radiation Exposure $\quad 48$

$\begin{array}{lll}\text { 5.8.5 Emergency Preparedness } & 48\end{array}$

5.9 The Applicable or Relevant and Appropriate Requirements $\quad 48$

5.10 The Achievement of Removal Objectives $\quad 49$

5.10.1 Dismantlement . 49

5.10.2 Partial Dismantlement and Interim Safe Storage 50

5.10.3 Partial Dismantlement and Beneficial Reuse $\quad 50$

5.10.4 Entombment 51

5.11 Ease of Implementation $\quad$ • 51

5.11 .1 Technical Feasibility _.. 51

5.11.2 Equipment, Personnel and Support Services Availability 52

5.11.3 Administrative Feasibility of Licenses and Easements 52

5.12 Nature and Amount of Waste Generated 53

5.12.1 Types of Waste $\quad 53$

5.12.1 The Form of the Waste Materials 53

5.12.2 Waste Packaging $\quad 54$

5.12.4 Waste Disposal Sites $\quad 55$

5.12.5 Waste Minimization Program 55

5.12.6 Dismantlement $\quad 55$

5.12.7 Partial Dismantlement and Interim Safe Storage 56

5.12.8 Partial Dismantlement and Beneficial Reuse . 57

$\begin{array}{ll}5.12 .9 \text { Entombment } & 57\end{array}$ 
5.13 Material Recycle and Reuse Opportunities 58

$\begin{array}{ll}5.13 .1 & \text { Reuse Opportunities } \\ \end{array}$

5.13.2 Recycle Opportunities $\quad 58$

5.14 Cost $\quad 59$

5.14.1 Methodology For Cost Estimates $\quad 59$

5.14.2 Cost Estimates for Each Alternative $\quad 59$

5.14.3 Assumptions Used in Making Cost Estimates 61

$\begin{array}{lll}5.15 \text { Schedule } & 61\end{array}$

$\begin{array}{ll}\text { 5.15.1 Dismantlement } & 61\end{array}$

5.15.2 Partial Dismantlement and Interim Safe Storage 62

5.15.3 Partial Dismantlement and Building Reuse 62

5.15.4 Entombment $\quad 63$

6.0 REMOVAL ALTERNATIVE COMPARATIVE ANALYSIS 63

6.1 Protecting the Environment 64

6.2 Minimizing Risks to the Public 65

6.3 Minimizing Risks to Workers 65

6.4 Meeting Requirements 65

6.5 Flexibility in Use of the Property 65

6.6 Ease of Implementation 66

6.7 Minimizing Capital Costs $\quad 66$

6.8 Surveillance and Maintenance Costs $\quad 66$

$\begin{array}{lll}6.9 & \text { Schedules } & 67\end{array}$

6.10 Value as a Demonstration Project $\quad .67$

$\begin{array}{lc}6.11 \text { Recycling Materials } & 68\end{array}$

7.0 RECOMMENDED REMOVAL ALTERNATIVE 68

7.1 The Highest Ranking in the Comparative Analysis 68 
7.2 The Best Prototype for Reactor Decommissionings 68

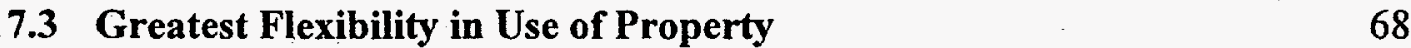

7.4 Most Compatible with SRS Property Reuse plans 69

7.5 Impact on the Environment Is Small 69

7.6 Risks to the Public Are Low 69

7.7 Risks to the Workers Are Low 69

7.8 Adequate Funding Should Be Available 69

7.9 The Partial Dismantlement and Interim Safe Storage Option Leaves 70 Most Radioactivity in the Facility

7.10 The Beneficial Reuse Option Is Not Cost-Effective 70

7.11 The Entombment Approach Has Major Disadvantages 70

8.0 PROCEEDING WITH THE DECOMMISSIONING

8.1 HWCTR Unconditional Release Criteria and Radionuclide $\begin{array}{ll}\text { Guidelines } & 71\end{array}$

8.2 The RESRAD and RESRAD-BUILD Computer Codes 71

8.3 The HWCTR RESRAD Study 72

8.4 Exposure Pathways Used in the Study $\quad 72$

8.5 The Conceptual-Models of Radioactivity in the Facility 73

8.6 Assumptions Used in the Study 74

8.7 The Study Results $\quad \ldots \quad \ldots .75$

8.8 Application of the Study Results to the HWCTR Project 75

Appendix A - Illustrations and Photographs $\quad$ A1

Appendix B - List of HWCTR Equipment B1

Appendix C - Schedule for Dismantlement $\quad$ C1

Appendix D - Schedule for Partial Dismantlement and Interim Safe D1 Storage

Appendix E - Schedule for Conversion for Beneficial Reuse E1 
Appendix F - Schedule for Entombment F1

Appendix G - References $\quad$ G1

Appendix H - Glossary HI

Appendix I - Public Comments and Department of Energy Responses II

\section{List of Figures}

1 The HWCTR Facility $\quad 7$

2 Location of the HWCTR on the Savannah River Site A1

3 The HWCTR Property $\quad$ A2

4 Cutaway View of the HWCTR Facility A3

5 The HWCTR Model $\quad$ A4

6 The HWCTR Model - Underground View A5

7 The HWCTR Model - Right Cyclone Room at the -52-Foot Level A6

8 The HWCTR Model - Left Purification Room at -52-Foot Level A6

9 Part of the 0-Level Main Floor $\quad$ A7

10 Detail of 0-Level Floor Beside Spent Fuel Basin $\quad$ A7

11 The Reactor Vessel Head $\quad$ A8

12 The Refueling Machine $\quad$ A8

13 Right Pump Room at the -16-Foot Level A9

14 Main Coolant Piping A9

15 Shielded Casks $\quad \therefore 10$

16 Radiation Hot Spot A10

17 The Monitor Room at the -52-Foot Level A11

18 The Steam Muffler $\quad$ A11

19 Construction Photograph Showing Base Mat A12

20 The New HWCTR Reactor Vessel $\quad$ A12

21 Construction Photograph Showing Reactor Vessel Outside of Building A13

22 Construction Photograph Showing Outside of Dome A13 
23 Construction Photograph Showing Reactor Vessel Being Moved Into Position A14

24 . Construction Photograph Showing Inside of Biological Shield

25 Construction Photograph Showing Reactor Vessel Being Lowered Into Position

26 Construction Photograph Showing Interior of Reactor Vessel

27 The Reactor Vessel Head

28 Alternatives Considered

29 Concepts of Alternatives

30 The Shippingport Decommissioning

31 The EBWR Containment Building

32 Engineered Trench for Low-Level Radioactive Waste

33 E-Area Vaults

34 Schedule Comparison

35 Conceptual Models for RESRAD Claculations

\section{List of Tables}

11976 Decommissioning Plan Alternatives

2 Significant Radioactive Contaminants

3 Reactor Component Approximate Induced Activity, in Curies, in 1996

4 Cooling System Approximate Activity in Total Millicuries, in 1996

5 HWCTR Radioactivity in Curies After 100 Years

6 Costs of Different Alternatives

7 Ranking of Alternatives Studied

8 Exposure Pathways for Scenario A

9 Exposure Pathways for Scenario B 


\begin{abstract}
About Revision 1
Revision 1 was issued primarily to incorporate public comments on the study, which were received by the Department of Energy (DOE) in December of 1996. A total of 65 comments were received from nine different individuals. A record of these comments along with the DOE responses appears in Appendix I.

Each comment was carefully reviewed and changes to the study made accordingly. These changes improved the readability and technical accuracy of the study. They did not change DOE's preferred alternative of dismantlement.

To explain how DOE plans to proceed with the decommissioning, a new Section 8 was added to the study. Note also that a document number (WSRC-TR-96-0268) was assigned.

Changes associated with revision 1 to the study are marked with a vertical line in the right margin.
\end{abstract}




\title{
WSRC-TR-96-0268
}

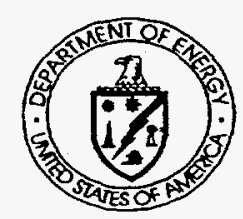

\section{Analysis of Removal Alternatives for the} Heavy Water Components Test Reactor at the Savannah River Site

\author{
Prepared for the \\ Westinghouse Savannah River Company \\ Under Subcontract No. AB72522N \\ By \\ U S ENERGY Corp. of Aiken, S.C. \\ In Association With \\ Life Cycle Environmental of Charleston, S. C.
}

Revision 1

April 1997

Department of Energy - Savannah River Site Aiken, South Carolina 


\subsection{EXECUTIVE SUMMARY}

This engineering study evaluates different alternatives for decontamination and decommissioning of the Heavy Water Components Test Reactor (HWCTR).

The HWCTR lies within a fenced two-acre property located in the northwest quadrant of the Savannah River Site, approximately 2.5 miles from the nearest major nuclear materials production facility and about three miles from the nearest site boundary. Cooled and moderated with pressurized heavy water, this uranium-fueled nuclear reactor was designed to test fuel assemblies for heavy water power reactors. It was operated for this purpose from March of 1962 until December of 1964.

The reactor is housed in a steel-domed containment building. The lower part of this building, made of reinforced concrete, extends approximately 61.5 feet below ground level. The 98-ton steel reactor vessel, two steam generators and related process equipment reside underground.

In 1965, all nuclear fuel was removed from the HWCTR site and the heavy water removed from plant systems. Since that time, the containment building has remained in a condition that amounts to protective confinement, that is, effectively mothballed. In recent years, small auxiliary structures on the property have been demolished leaving only the containment building itself (770-U) and a smaller connecting health physics building (735-U), along with the ventilation exhaust stack (792-U), the deluge control bunker (788-B) and Building 704-B, which contained HWCTR administrative, technical support and storage areas.

With the passage of the years, most of the radioactivity inside of the facility has decayed. Today, more than 99 percent of the residual radioactivity - estimated to be in the range of 3000 curies - is within the reactor vessel, effectively imbedded within the activated metal components. Some of the concrete radiation shielding which surrounds the reactor vessel is also radioactive, as is steel reinforcing bar and imbedded piping within the concrete shielding. Low level radioactive contamination pervades piping and process equipment inside of the reactor building. And traces of radioactive contamination spilled during the operating period are still detectable inside of the building in places such as crevices and drain pipes in the concrete floors.

Radioactive contaminants are predominately nickel-63 and cobalt-60. Also present are low levels of cesium-137 and other fission products along with uranium and transuranic radionuclides, such as plutonium-239. These materials came from failures of ten fuel assemblies which occurred during reactor operation. Also present, as in any older industrial facility, are small amounts of hazardous materials such as lead, mercury and asbestos.

The HWCTR facility is slowly deteriorating, gradually increasing the potential for exposure of site workers to its radioactive and hazardous materials. Because it is smaller and simpler in design than the weapons materials production reactors at the site, its decommissioning will serve as an effective prototype to begin the site reactor decommissioning program. Consequently, the 
Department of Energy (DOE) is moving forward with decommissioning of the facility. A broad range of possible alternative approaches has been considered. Four alternatives studied in detail include:

(1) Dismantlement, in which all radioactive and hazardous contaminants would be removed, the containment dome dismantled and the property restored to a condition similar to its original preconstruction state,

(2) Partial dismantlement and interim safe storage, where radioactive equipment except for the reactor vessel and steam generators would be removed, along with hazardous materials, and the building sealed with remote monitoring equipment in place to permit limited inspections at fiveyear intervals,

(3) Conversion for beneficial reuse, in which most radioactive equipment and hazardous materials would be removed and the containment building converted to another use such as a storage facility for radioactive materials, and

(4) Entombment, which involves removing hazardous materials, filling the below-ground structure with concrete, removing the containment dome and pouring a concrete cap on the "tomb".

Also considered was safe storage, where the decommissioning would be deferred while radioactive contaminants decay to safer levels. But this approach, which has, in effect, been followed for the past 30 years, did not warrant detailed evaluation.

The four other alternatives were evaluated, taking into account factors such as potential effects on the environment, risks, effectiveness, ease of implementation and cost. The preferred alternative was determined to be dismantlement. This approach is recommended because it ranks highest in the comparative analysis, would serve as the best prototype for the site reactor decommissioning program and would be most compatible with site property reuse plans for the future.

This removal alternative analysis for the HWCTR decommissioning was developed following guidelines contained in DOE's Decommissioning Resource Manual, reference 1.

In December of 1996, public comments on the study were received from nine individuals. Revision 1 includes changes made in response to those comments, which did not change the preferred alternative of dismantlement. 


\subsection{INTRODUCTION}

\subsection{Purpose}

This engineering study was developed to evaluate different options for decommissioning of the HWCTR at the Savannah River Site (SRS).

The decommissioning is being undertaken to reduce risks to workers and the public from the radioactive and hazardous contaminants associated with the HWCTR. The HWCTR project is one of many cleanup projects being undertaken as part of the environment restoration program at SRS. The experience gained will eventually be applied to the decommissioning of facilities such as the site's five nuclear materials production reactors, which are substantially larger than the HWCTR and have a much larger radioactive material inventory.

This decision for decommissioning of the HWCTR is reflected in the Savannah River Site Waste Management Final Environmental Impact Statement of July 1995 which states that:

"The Heavy Water Components Test Reactor is the prototype for this program. [The decommissioning program for nuclear reactor facilities.] By starting with a small reactor, DOE can learn from experience and develop methods and procedures which will then be applied to the larger reactors."

The HWCTR project is also serving as a prototype for application of the Comprehensive Environmental Response, Compensation and Liability Act, known as CERCLA, to decommissioning activities at SRS. The CERCLA process is being followed on the project in accordance with a May 1995 agreement between the DOE and the U. S. Environmental Protection Agency. This agreement is embodied in the DOE's Decommissioning Resource Manual, reference 1 .

\subsection{Scope}

This study considers a broad range of options for decommissioning of the HWCTR. It focuses on four which are representative and feasible. Each option is developed in sufficient detail to facilitate meaningful comparisons. Additional detailed planning will be necessary for the approach actually undertaken. Such planning will be incorporated into the HWCTR project Decommissioning Plan which is expected to be completed in Fiscal Year 97.

This study was prepared in accordance with the May 1995 agreement between the DOE and the U. S. Environmental Protection Agency. The agreement includes following the process of CERCLA in evaluation of decommissioning alternatives.

CERCLA, a federal statute also known as Superfund, provides the statutory authority for cleanup of hazardous substances that could endanger the public health, public welfare or the environment. Facilities such as the HWCTR contain nuclear materials which are included in the CERCLA definition of hazardous substances. In CERCLA parlance, the 
decommissioning of the HWCTR is being undertaken as a "non-time critical removal action." This study is, therefore, entitled an analysis of removal action alternatives and embodies the applicable provisions of the CERCLA process.

The evaluations in this document address the potential environmental impacts of different alternatives, the potential and actual risks, the implementation costs, the time to complete the major steps for each option, flexibility in future use of the property, ease of implementation and value as a demonstration project, as well as other factors. Consequently, in accordance with reference 1 , there will be no separate environmental assessment or environmental impact statement for the HWCTR decommissioning, as would normally be the case under the National Environmental Policy Act. The DOE and the U. S. Environmental Protection Agency have agreed that for decommissioning projects such as the HWCTR an environmental assessment or environmental impact statement is unnecessary because the CERCLA removal action process being followed incorporates the appropriate elements of the National Environmental Policy Act regarding environmental values and potential impacts.

\subsection{Public Participation}

The DOE and the Westinghouse Savannah River Company (WSRC) solicited comments from the public on this study. On November 19, 1996, announcements appeared in five area newspapers asking for public comments. A total of 65 comments were received from nine individuals. Copies of these comments are contained in Appendix I, along with responses from the DOE.

Each comment was taken into account before the decision was made on the alternative selected for the decommissioning. Changes to this study were made in Revision 1 to incorporate many of the comments, which improved the readability and technical accuracy of the document. The comments did not affect the selection of dismantlement as the preferred alternative.

\subsection{Regulator Involvement}

Regulatory agency roles in decommissioning of DOE facilities are described in the Decommissioning Resource Manual, reference 1, which notes that the specific roles at a particular DOE site are subject to local agreements. The two regulatory agencies involved with the SRS are the U. S. Environmental Protection Agency, Region IV, and the South Carolina Department of Health and Environmental Control. Representatives of these two agencies met with representatives of DOE-SR in February of 1996 to discuss the roles that the agencies would play in the HWCTR project. It was agreed that the regulators would become involved at the time of the site evaluation which would follow completion of the decommissioning activities. 


\subsection{The Decontamination and Decommissioning Project Plan}

In March of 1996, WSRC issued the Heavy Water Components Test Reactor Decontamination and Decommissioning Project Plan, reference 2. This document establishes initial cost, schedule and technical baselines for the project. It also describes the general approach to be taken to protect the safety and health of the workers and the public and to protect the environment, to the extent that such matters can be determined in the early stages of the project. The Project Plan will eventually evolve into the Decommissioning Plan, the principal planning document for the HWCTR decommissioning.

The HWCTR Decommissioning Project Plan recognizes that the actual end state of the facility will depend upon the outcome of this study. In turn, this study is consistent with the Project Plan and incorporates in later sections appropriate information from that document.

\subsection{Relationship to the Site Ten Year Plan}

In early 1997, the Savannah River Site was finalizing an Environmental Management Ten Year Plan. This document lays out plans for environmental restoration at the site over the next decade, which are focused on accelerating elimination of the most urgent risks and reducing the high surveillance and maintenance costs of many site facilities. The decommissioning of the HWCTR appears in the plan as the only facility decommissioning project scheduled to be undertaken during the ten-year time period.

\subsection{Organization of this Document}

This study is organized, as recommended in reference 1 , in the following manner:

- It begins with a discussion of facility characterization, which describes the HWCTR facility and the radioactive and hazardous contaminants associated with it,

- The objectives of the removal action are identified,

- The four different alternatives to be evaluated in detail are described,

- Each alternative is then evaluated in detail,

- A comparative analysis of the four alternatives is presented, and

- The recommended alternative is identified, along with the rationale for its selection.

Details such as equipment lists, schedules and references appear as appendices, along with a glossary of terms. 


\subsection{FACILITY CHARACTERIZATION}

\subsection{Site Description}

The HWCTR facility is located on approximately two acres in the northwest quadrant of the SRS, on property known as U-Area. U-Area lies three miles from the nearest SRS property boundary and about two and one-half miles from any major nuclear materials production facilities on the site.

The federally-owned SRS reservation is located near Aiken, South Carolina. The DOE Savannah River Operations Office manages the SRS. The Westinghouse Savannah River Company operates the site under contract to DOE.

When considering different approaches to decommissioning a facility such as the HWCTR, factors taken into account include the nature of the surrounding property, how it is presently used and possible uses for it in future years.

The SRS occupies an area of approximately 310 square miles in western Southern Carolina in a mostly rural area of Aiken, Barnwell and Allendale counties, about 25 miles southeast of Augusta, Georgia. The Savannah River borders the site on the southwest side. Land bordering the SRS is chiefly forest and agricultural. The closest towns to the site are New Ellenton and Jackson, both in South Carolina. The closest residences stand about 200 feet from the site perimeter on the west, north and southeast sides.

The area east of the HWCTR facility is wooded. Adjoining the HWCTR property to the west is the site security force headquarters. Other administrative buildings of B-Area lie nearby.

The HWCTR property has an elevation of approximately 288 feet above sea level. No stream runs near the property. The water table at the site is some 50 feet below the lowest point in the reactor containment building. Figure 1 shows the reactor containment building. The location of the HWCTR on the federally-owned site is shown in Figure 2. Figure 3 shows the HWCTR property. Please note that Figures 2 and 3 and most other figures in this report are located in Appendix $A$.

The SRS was built in the early 1950s to produce basic materials for nuclear weapons. Five large nuclear production reactors were built to produce these materials, as were various other supporting facilities for purposes such as fabricating reactor fuel, recovering the plutonium and tritium, and processing waste materials. The production reactors are no longer in service. Today, the mission of the SRS focuses on the environmental legacy of the Cold War, with processing for storage or disposal the radioactive and chemical wastes associated with operation of these reactors and their related facilities. Another prime mission is environmental restoration of the site, which includes projects such decommissioning of the HWCTR. 


\subsection{Facility Description and Brief History}

\subsubsection{Description of the HWCTR Facility}

The HWCTR was a pressurized heavy water test reactor used to test candidate fuel designs for heavy water power reactors. It was not a defense-related facility like the materials production reactors on the site. The nominal reactor power of 50 megawatts (thermal) was dissipated to the atmosphere through a muffler which lies approximately 110 yards east of the reactor building.

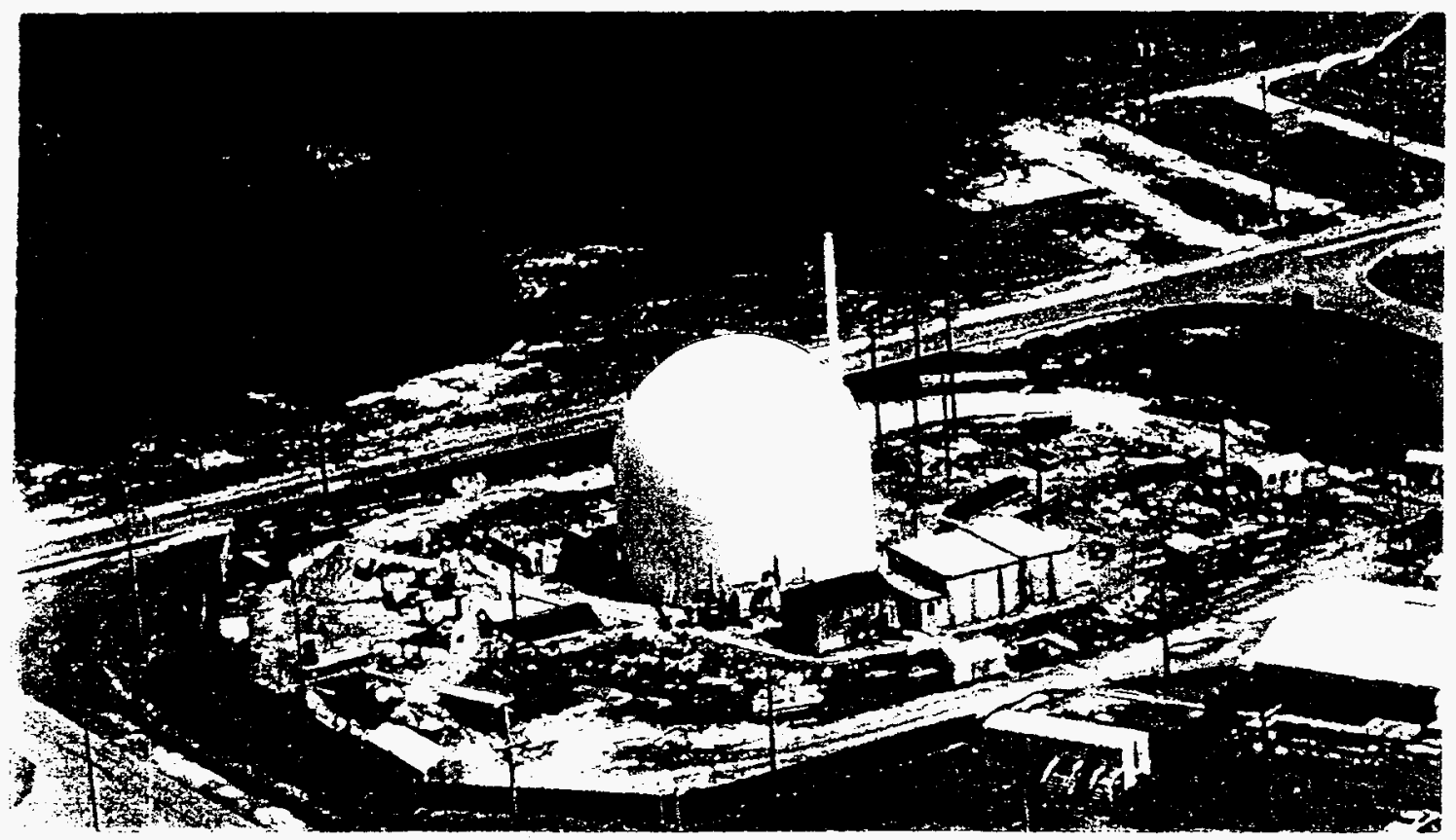

Figure 1. The HWCTR Facility

Details of the reactor containment building and its contents are shown in a series of illustrations and photographs in Figures 4 through 27 of Appendix A.

The containment building is 70 feet in diameter. The structure rises approximately 65 feet above the ground; the floor of the lowest level is approximately 52 feet below grade. The below-grade part was constructed of pre-stressed concrete. The hemispherical dome was fabricated from 0.75 inch thick carbon steel plate to a level of 30 feet above the ground. The upper part of the dome was made of 0.375 inch carbon steel. The dome shell contains approximately 170 tons of steel. The building was designed to withstand an internal pressure of 24 pounds per square inch and was pneumatically tested to five pounds per square inch.

The containment building houses the reactor and coolant systems, the refueling machine. the spent fuel basin and the reactor instrumentation. Arrangement of the reactor within the containment building is shown in Figure 4 . The reactor core consisted of a central region of 12 test assemblies surrounded by a ring of 24 driver fuel assemblies, enriched in Iranium- 
235. Control rods, safety rods and instrument thimbles were interspersed throughout the core.

The reactor vessel has an overall height of 30 feet, a diameter of about eight feet and weighs approximately 100 tons. The vessel is made of carbon steel, three to five inches thick, clad internally with 0.25 inch stainless steel.

The reactor main cooling system operated at 1200 pounds per square inch (gage) and 250 degrees Centigrade. Two test loops, isolated from the primary cooling system, provided special test conditions. These loops contained four inch diameter stainless steel piping.

Components in the main circulating system include two steam generators, nine pumps, two gas recompressors, a filter, a deionizer and a large main storage tank. The steam generators are about 23 feet high and weigh about 19 tons. The two largest pumps in the primary system are approximately 13 feet tall. The primary loop piping is made of 10 inch diameter carbon steel, coated internally with an adherent magnetite film. This film, produced during initial operations, was considered effective in reducing corrosion buildup during plant operation.

Auxiliary fluid systems include those typically associated with water-cooled reactors, such as steam, a stainless steel purification system with filters and deionizers, and pressure relief systems. A 7165 gallon heavy water $\left(\mathrm{D}_{2} \mathrm{O}\right)$ storage tank which fed various systems is located in the left purification room at the -52-foot level. A 15,000 gallon emergency deluge system water tank is located inside the top of the dome. This emergency water supply was never used.

Other equipment in the reactor building includes a small spent fuel basin, made of reinforced concrete lined with stainless steel. This basin, 9 feet by 13 feet wide, extends from the ground floor to the -27 -foot level. It contains a 54 inch by 54 inch shipping cask pit that extends 16 feet below the basin floor.

A system of floor drains leads to a 350 gallon sump tank located in the monitor room at the 52-foot level.

A comprehensive list of HWCTR equipment appears in Appendix B.

In addition to the containment building, the following HWCTR structures remain standing:

- The health physics building (735-U). This sheet metal building has a concrete floor and lower wall. Connected to the containment building by a short passageway, it is approximately 20 feet by 24 feet by 11 feet high. It was used for personnel access to the containment building. 
- The ventilation exhaust stack (791-U). The 30-inch-diameter, 80 -foot-high exhaust stack stands just east of the reactor building. It is made of $5 / 16$ inch carbon steel plate. The containment building ventilation system vented through the stack.

- The deluge control bunker (788-B). This small reinforced concrete structure stands some 150 yards north of the fenced HWCTR property. It is approximately 10 feet by 11 feet by eight feet high. It was designed as an emergency operating station for the emergency water supply housed in a 15,000 gallon tank at the top of the containment dome.

- Building 704-B. This building is one of six original wings of a star-shaped building which once served as administrative offices for du Pont in the early years of the site. It adjoins the fence on the west side of the HWCTR property. It was used on the HWCTR project for administrative, technical support and storage areas.

\subsubsection{Brief History of the Facility}

The HWCTR was operated from March 1962 to December 1964 to test fuel elements and other reactor components of potential use in heavy water moderated and cooled power reactors. The total power history of the HWCTR was 13,882 megawatt-days. During operation, 36 different fuel assemblies were tested. Ten of these experienced cladding failures as operational capabilities of the different designs were being established.

The fuel assembly failures released fission products, uranium and transuranic radionuclides into the main cooling system and the isolated liquid loop. Even though the boiling loop was never used to test fuel assemblies, it, too, became contaminated with radioactivity as a result of a leak which developed in the "bayonet" fixture designed to isolate a test element in this system from the rest of the reactor vessel.

During the entire operating period the steam generators leaked heavy water into the steam system, which caused that system to become radioactively contaminated. The total heavy water loss from the plant during operation amounted to approximately 22,000 pounds, approximately one-third of which entered the steam system through the steam generators.

Spills of radioactive heavy water occurred frequently in most areas of the reactor building during the operating period. Residual contamination from such spills is described in section 3.7 below.

In December of 1964 , operations were terminated and the facility was placed in a standby condition, as a result of the decision by the U. S. Atomic Energy Commission to redirect research and development work on heavy water power reactors to reactors cooled with organic materials. For about one year, site personnel maintained the facility in a standby status, then retired the reactor in place. 


\subsection{Summary of Existing Conditions}

Although it is slowly deteriorating, the HWCTR facility is presently in relatively good condition. The reactor building is structurally sound and weather tight. The interior is reasonably clean and orderly, although the 0-level main floor is being used for equipment storage. Rusting is evident on carbon steel piping and components where insulation has been removed. The paint is still tightly adherent except in the stairwells and on equipment such as the refueling machine platform where it is flaking. (The refueling machine is a heavy, lead-shielded container also known as the transfer coffin.) Present conditions can be seen in photographs of Figures 9 through 18. A complete photographic record of the facility was produced in connection with preparation of the 1996 Facility Screening Characterization Report, reference 3.

Accessible radiation levels are low. Radioactive and hazardous contaminants associated with the facility are described in section 3.7.

\subsection{Transition/Deactivation Process and End Condition Achieved}

Conditions in the HWCTR facility at the end of its operating period were well documented as described in reference 3. After the final reactor shutdown in December of 1964, all of the fuel assemblies and the two neutron sources were removed from the reactor and transported to the Receiving Basin for Off-site Fuel located in H-Area at the SRS. All other reactor components including control and safety rods, long term corrosion coupons, and a rod containing gamma ion chambers were left in the core, as were all housings and guide tubes.

After the heavy water was drained from the reactor systems, both the high and low pressure systems were vacuum dried and filled with nitrogen to minimize corrosion. The secondary coolant system was drained and left at ambient conditions. The shell sides of the steam generators and purge coolers were filled with nitrogen. A positive pressure on the reactor vessel and primary side systems was maintained from nitrogen filled cylinders until this operation was abandoned in November of 1971.

Very few changes have been made in the HWCTR systems since shutdown. Some equipment has been removed, such as the boiling loop surge tank and heat exchanger. General area radiation levels have decayed to low values (less than one millirem per hour) with only a few isolated hot spots remaining. The physical location and status of the HWCTR systems are essentially the same as after the final shutdown, except for penetrations required to completely drain the residual fluid from system components, and, of course, lower radiation levels due to radioactive decay.

\subsection{Surveillance and Maintenance Program}

Since the retirement of the HWCTR, the facility has undergone periodic surveillance. Access has been controlled by the locked security fence surrounding the HWCTR site. 
Little maintenance has been required since the reactor retirement and draining of the systems were completed.

In 1975, HWCTR was placed in condition approximating safe storage or protective confinement. Radiation levels from cobalt 60 , the principal radionuclide of concern, have decayed by a factor of approximately 16 since that time, significantly reducing the radiological hazards associated with the facility.

The outside of the containment dome was painted in 1991.

\subsection{Previous Removal Actions and Cleanup}

\subsubsection{The 1976 Decommissioning Plan}

Approximately 20 years ago, the U. S. Energy Research and Development Administration made preparations to decommission the HWCTR. To support planning for the decommissioning, a characterization study was accomplished in 1975 to determine the location and amounts of radiological contaminants in the facility. The results of this study are described in section 3.7. The study showed that radiation and radioactive contamination levels are low and that most of the radioactivity is contained within the reactor vessel.

A decommissioning plan, reference 4, also was prepared. Although this plan was not carried out due to lack of funding, certain aspects of the plan remain relevant in today's circumstances.

The 1976 decommissioning plan included an analysis of different alternatives for the decommissioning. They were dismantlement, entombment and protective confinement. These alternatives were defined as follows:

- Dismantlement. All radioactivity was to be removed to permit release to the general public. In addition, the dome would also be removed along with steel and concrete structures down to 16 feet below grade, the cavity below this level backfilled with earth and capped with a concrete pad at the -16-foot level and the remaining cavity backfilled with earth to grade level to clear the site for future construction.

- Entombment. All radioactive equipment above grade would be placed below grade. The reactor vessel and its head would be sealed, the dome removed and the entire below-ground structure filled with compacted earth or concrete. A reinforced concrete pad would also be poured on top of this and a waterproof barrier installed. The objectives of this approach were (1) to provide long-term security (100 years or longer) for the radioactivity to reduce risks to the public and (2) to minimize surveillance and maintenance of the facility. 
- Protective Confinement. This approach would involve sealing and locking the building, painting the dome, installing moisture detectors to detect water leaking into the structure and establishing ground water monitoring wells around the building. (This approach is similar to safe storage.)

For each of these alternatives several different options were considered. Estimated costs and worker radiation exposure appeared in the 1976 decommissioning plan as follows:

\section{Table 11976 Decommissioning Plan Alternatives}

\begin{tabular}{|l|c|c|c|}
\hline Alternative & Estimated cost & $\begin{array}{c}\text { Radiation } \\
\text { exposure }\end{array}$ & Aesthetic \\
\hline $\begin{array}{l}\text { Dismantlement, removal of } \\
\text { structure to -16'level }\end{array}$ & $\$ 5.4$ million & 20 person-rem & Best \\
\hline $\begin{array}{l}\text { Dismantlement, removing no } \\
\text { underground structure }\end{array}$ & 4.4 million & 20 person-rem & Best \\
\hline Entombment & 1.7 million & 5 person-rem & Good \\
\hline Protective confinement & $\mathbf{0 . 1 9}$ million & $<1$ person-rem & Least attractive \\
\hline
\end{tabular}

The cost estimates were in 1975 dollars. The aesthetic judgment concerned the appearance of the decommissioned site, with more weight being given to absence of man-made structures.

Risks associated with these different approaches were also evaluated. These focused on the potential for exposure of members of the public to radiation from the reactor vessel. Two pathways were considered: direct radiation and ingestion of water contaminated with radioactivity. Risks were shown to be low for each alternative. Potential direct radiation exposures were to be controlled by physical security arrangements. The highest potential exposure to the public from contaminated ground water in any scenario was estimated to be one one-thousandth of the federal guideline radioactivity concentration or lower.

The authors of the 1976 decommissioning plan concluded that "all three alternatives are feasible and involve a very low risk of near-term public exposure".

\subsubsection{Since 1976}

Although the 1976 plan was never carried out, the facility condition for the past twenty years has approximated the protective confinement approach. Additional work on the HWCTR decommissioning project began several years ago. In Fiscal Year 94, four auxiliary buildings on the HWCTR site were demolished and disposed of as clean waste. In early Fiscal Year 95 detailed radiological contamination surveys of the reactor building were performed. The results of these are reflected in the next section.

In 1995, asbestos thermal insulation was removed from the piping and components located inside the reactor containment. At the beginning of Fiscal Year 96, in addition to the reactor containment building, only two other small buildings remained on the property. One, the 
control building, was demolished in Fiscal Year 96. The other building is the health physics building, which is connected to the reactor building by a short passageway. Also still in place are the ventilation stack (Building 791-U) and the steam muffler, which lies outside of the security fence, 110 yards east of the reactor containment building.

\subsection{Source, Nature and Extent of Contamination}

\subsubsection{Summary}

Radioactivity from operation and maintenance of the reactor and its associated systems remains inside of the containment building. The total amount of radioactivity has been estimated to be in the range of 3000 curies in 1996. More than 99 percent of this amount is contained within the reactor vessel in the form of neutron-activated metals. The radionuclides present are chiefly nickel-63 and cobalt- 60 .

Low levels of radioactive contamination are present inside of the reactor vessel and in various plant systems and equipment. Cobalt-60 from neutron-activated corrosion and wear products predominates. Also present are traces of tritium from heavy water, along with low levels of fission products, uranium and transuranic radionuclides from the fuel assembly failures. Traces of these radioactive materials also exist in cracks and crevices on the outside of equipment and in building floors, and inside of the spent fuel basin.

\section{Table 2 Significant Radioactive Contaminants}

\begin{tabular}{|l|r|l|l|}
\hline Radionuclide & Half Ilfe & \multicolumn{1}{|l|}{ Radiation } & Source \\
\hline Iron-55 (Fe-55) & $2.7 \mathrm{yr}$ & X-rays & Activation of steel \\
\hline Cobalt-60(Co-60) & $5.27 \mathrm{yr}$ & Beta-gamma & Activation of steel \\
\hline Nickel-63 (Ni-63) & $100 \mathrm{yr}$ & Beta & Activation of steel \\
\hline Strontium-90(Sr-90) & $28.6 \mathrm{yr}$ & Beta & Fuel failures \\
\hline Cesium-137(Cs-137) & $30 \mathrm{yr}$ & Beta-gamma & Fuel failures \\
\hline Plutonium-239 (Pu-239) & $24,110 \mathrm{yr}$ & Alpha & Fuel failures \\
\hline Plutonium-241 (Pu-241) & $14.4 \mathrm{yr}$ & Beta & Fuel failures \\
\hline Americium-241 (Am-241) & $433 \mathrm{yr}$ & Alpha & Fuel failures \\
\hline
\end{tabular}

The HWCTR reactor building also contains small amounts of hazardous contaminants common to older industrial structures. These include lead, mercury and traces of asbestos. Polychlorinated biphenyls (PCBs) are expected to be present also.

More detail on the radioactive and hazardous contaminants appears in paragraphs 3.7 .3 through 3.7.11 below.

\subsubsection{Basis for Estimates of Contamination}

The following information formed the basis for conclusions about the contaminants in the facility: 
- The radiological characterization study performed in 1975, the results of which are reflected in the 1976 decommissioning plan, reference 4 . Characterization data included radiation and contamination levels on accessible surfaces, contamination levels inside of the spent fuel basin and several piping systems and radiation levels inside of the lower part of the reactor vessel. Tables 3 and 4 show radiological data from the 1975 study extrapolated to 1996 to account for radioactive decay.

- Detailed radioactive contamination surveys performed in 1994 when most of the reactor building was downgraded to radiological buffer area status. Approximately 1300 smear surveys for removable radioactivity were taken in 1994.

- Radiological scan surveys performed by WSRC in early 1996 on the 0 -level floor and inside of the steam muffler.

- An in-depth study of facility drawings and historical records associated with the operational period. These records, which are summarized in the Facility Screening Characterization Report, reference 3, included radiological survey forms, log books, technical reports and reports documenting conditions after the final shutdown of the reactor.

- Visual inspections of the facility in early 1996.

\subsubsection{Induced Radioactivity}

More than 99 percent of the radioactivity in the HWCTR facility is associated with induced radioactivity in the vessel and its internal structure, chiefly the thermal shields.

Induced radioactivity is also present in the concrete biological shield surrounding the reactor vessel. The highest levels are present in the region around the point of peak axial neutron flux, which was about four feet from the vessel bottom. The levels diminish with radial distance from the reactor vessel and with changes in elevation from the point of peak axial flux.

Table 3 Reactor Component Approximate Induced Activity, in Curies, in 1996

\begin{tabular}{|l|c|c|c|c|}
\hline Component & Fe-55 & Co-60 & Ni-63 & Total \\
\hline Thermal shield & 50 & 550 & 2100 & 2700 \\
\hline Monitor pin plate & 1.9 & 20 & 78 & 100 \\
\hline Reactor vessel & 1.8 & 15 & 9 & 26 \\
\hline Control, safety rods & 0.5 & 5 & 16 & 22 \\
\hline Zircaloy housing tubes & - & $<1.5^{*}$ & - & $<1.5$ \\
\hline Totals & 54.2 & 590 & 2203 & 2850 \\
\hline
\end{tabular}

* Only Co-60 is significant in the zirconium alloy housing tubes. 


\subsubsection{Radiation Levels}

Radiation levels in the HWCTR containment building are low. Most accessible areas have levels under one millirem per hour. The highest accessible level measured in recent years is 110 millirem per hour on a sample line in the right cyclone room at the -52 foot level.

The highest radiation levels in the facility exist within the reactor vessel. Levels of several hundred rem per hour are expected at the point of highest activation, which is on the inner wall of the thermal shield approximately four feet from the bottom of the vessel. Radiation levels from control and safety rods in the vessel are also expected to fall within this range.

No areas with radiation levels above natural background are known to exist on the HWCTR property outside of the reactor building. But detectable radioactive contamination is present inside of the steam muffler.

\subsubsection{Radioactive Contamination}

Radioactive contamination levels inside of the HWCTR facility are low. No detectable removable radioactive contamination is present in most accessible areas. One exception is the 0-level, where approximately one-half of the floor is posted as a radioactive contamination area.

Inside of the posted area are the reactor vessel head and the spent fuel basin. Within the spent fuel basin are low levels of radioactivity which include traces of fission products, uranium and transuranics.

Radioactive contamination is present in cracks and crevices in the concrete floors throughout the reactor building. Floor drains and the building sump also contain low levels of radioactive contamination, as does the imbedded piping that connects the floor drains to the sump tank.

Low levels of radioactive contamination are also present inside of the reactor vessel and various fluid and gas systems connected to the reactor. The following systems are known to be radioactively contaminated:

- Boiling-cooled isolated loop

- Coolant sampling

- Floor drains and building sump

- Liquid-cooled isolated loop

- Main circulating (main coolant)

- Purification
- Reactor gas pressure relief

- Reactor gas purge

- Seal supply

- Spent fuel basin purification

- Steam

- Water relief 
Table 4 Cooling System Approximate Activity in Total Millicuries, in 1996

\begin{tabular}{|l|c|c|c|}
\hline System & Co-60 & Transuranics & $\begin{array}{c}\text { Fission } \\
\text { Products }\end{array}$ \\
\hline Main Process Water System & 32 & 0.2 & $<0.1$ \\
\hline Liquid loop & 3 & 0.2 & $<0.1$ \\
\hline Boiling loop & 20 & 0.4 & $<0.1$ \\
\hline
\end{tabular}

Traces of radioactive contamination are expected to be present in the underground waste water storage tank located on the HWCTR property and in the underground piping which connects this tank to the reactor building system. Low levels of radioactivity are also present in the steam muffler and the underground steam line which leads to it, as previously noted.

Radioactive contamination in soil on the HWCTR property is expected to be minimal. This conclusion is based primarily on the results of three soil samples taken near the outlet of the steam muffler in April of 1996. These samples, which were taken by the WSRC Environmental Restoration organization, showed no detectable radioactivity above natural background in an area with a relatively high potential for contamination, given the presence of radioactive contamination in the muffler itself. There is some possibility of soil contamination on the HWCTR property from sources such as possible leakage of the underground tank. But no records showing soil contamination have been uncovered except for the January 1966 final radiological survey, which showed one small contaminated area, which was subsequently decontaminated, at the outfall of the ventilation stack condensate drain line.

\subsubsection{Lead}

Lead used for radiation shielding is present in the reactor building in numerous locations. Lead-shielded casks also remain in the building, along with the refueling machine which contains lead shielding. Lead may be present in paint on metal surfaces and in brass and bronze parts of piping systems. Some of the lead may be radioactively contaminated, which could produce a mixed waste.

\subsubsection{Mercury}

Small amounts of mercury are expected to be present in electrical equipment such as fluorescent lights.

\subsubsection{Asbestos}

Asbestos piping insulation was removed from the reactor building in 1995 . But some asbestos insulation remains in place on two piping lines and asbestos debris is still present in 
several locations. Asbestos also may be present in electrical cable insulation, gasket materials and wall penetration boots.

\subsubsection{PCBs}

PCBs are expected to be present at low levels in materials such as paint, electrical equipment and oils.

\subsubsection{Waste Oils and Hydraulic Fluids}

Oils which must be treated as regulated waste are present in the building in a number of locations. Some may contain hazardous constituents as defined by the Resource Conservation and Recovery Act and the Toxic Substances Control Act.

\subsubsection{Additional Detailed Characterization}

In paragraph 3.7.2, the basis for conclusions about radioactive and hazardous contaminants in the HWCTR facility was laid out. In mid-1996, additional characterization work was performed to provide a more-detailed knowledge of the contaminants in the facility, its ventilation exhaust stack and the steam muffler. This work was undertaken to support detailed planning for the decommissioning. The results did not significantly influence the analyses of decommissioning alternatives presented in this document.

The additional characterization confirmed that the estimates of induced radioactivity in the reactor vessel and the biological shield were accurate. It also confirmed that radiation levels were low in the facility, as expected, and that levels of radioactive contamination were also low. The results of the characterization for hazardous contaminants also bore out expectations with two exceptions. No lead-based paint was found, though some was anticipated. And levels of PCBs in paint and electrical cabling insulation turned out to be somewhat higher than expected.

In planning the additional characterization work, lessons learned in other site decommissioning projects were factored into the HWCTR characterization program. For example, in decommissioning of the old tritium facility, Building 232-F, it was found that the concrete structure was not adequately characterized for tritium which had penetrated into the concrete. The HWCTR Facility Characterization Plan therefore included analyzing samples of concrete in a laboratory for the presence of tritium, which could have been associated with the heavy water coolant. The tritium levels in the HWCTR facility were found to be low, as would be expected given the design of the reactor and its operating history.

\subsection{Facility Safety Analysis Documentation in Effect}

The present safety basis documentation for the HWCTR is the Hazards Assessment Document - Heavy Water Components Test Reactor, Building 770-U, Report WSRC S- 
HAD-00001 of January 1997. The evaluation described in this report resulted in classification of the HWCTR as an "industrial facility." This report, combined with the HWCTR Health and Safety Plan currently in effect, satisfies the applicable requirements of DOE Order 5480.4, Environmental Protection, Safety, and Health Protection Standards.

Accident analyses performed in connection with preparation of the HWCTR Decommissioning Plan show that there would be no significant consequences to the general public from hypothetical accidents which could possibly occur during the decommissioning.

Note that information on risk and safety issues associated with the four decommissioning alternatives appears in section 5.4.

\subsection{IDENTIFICATION OF REMOVAL ACTION OBJECTIVES}

\subsection{Objectives of Decommissioning}

The following primary objectives have been established for the HWCTR decommissioning:

- Minimizing the risks to workers and to the public. This objective is a basic tenet of site environmental restoration and facility decommissioning work, and other work at the SRS.

- Providing flexibility in future uses of the property. This objective is considered important for the long term when missions and circumstances of the Savannah River Site may change. Although present site future-use plans call for the property to remain in the hands of the federal government, this situation may eventually change, especially since the HWCTR is not located on the central portion of the site near other nuclear facilities which are more highly contaminated.

- Minimizing the capital costs of the decommissioning work. This objective is basic to efficient operation of the site and execution of its environmental restoration program.

- Minimizing required maintenance and surveillance of the facility in future years. This goal is consistent with the site-wide efforts to reduce the mortgage costs of DOE's weapons complex facilities. Surveillance and maintenance costs of nuclear facilities such as the HWCTR are substantial. Cost saved in this area will make more money available for cleanup work.

- Recycling materials in the facility to the extent practicable. This goal is consistent with DOE headquarters and DOE-SR policy on recycling materials in facility decommissioning work. Recycling of materials generally produces long-term environmental benefits. 
- Providing valuable information for follow-on decommissioning projects at the $S R S$. This goal is important because the HWCTR will the first nuclear facility at the SRS to be decommissioned under the DOE decommissioning framework and the first site nuclear reactor to undergo decommissioning.

- Minimizing radioactive waste stream volumes where economically justifiable. This objective is consistent with DOE headquarters and DOE-SR policies to minimize the volumes of waste streams to save money and help protect the environment.

\subsection{General End Condition Criteria}

- Increased physical security of radioactive equipment and building materials,

- Reduced or eliminated risk of radionuclide migration from the HWCTR property, and

- Improvement in the ability to release most or all the HCTWR site for unrestricted future use.

\subsection{Related Remedial Actions Involving Soil or Water in the Vicinity}

Although not a part of the detailed 1996 characterization, soil samples are being taken on the HWCTR property for laboratory analysis for radioactive contaminants, carbon tetrachloride, PCBs and total metals. These samples are being taken following guidelines of the site Environmental Restoration Program. Contaminants found will be removed as appropriate for worker protection and environmental restoration purposes.

\subsection{Potential Future Uses of the Property}

One goal of the HWCTR decommissioning project, as noted in Section 4.1, is to provide flexibility in future uses of the property. Considering the present vision for the future of the Savannah River Site will help place this goal into context.

The January 1996 Savannah River Site Future Use Project Report provides this vision. It expresses recommendations by various stakeholders on their preferences for future use of the federally-owned property. The report resulted from the efforts of a DOE-WSRC team that solicited ideas from interested organizations and individuals, holding a series of six public meetings in the region. The SRS Citizens Advisory Board participated, as did numerous other diverse organizations, including environmental advocacy groups.

The Future Use Report notes that while no general consensus was reached, several common themes emerged from the project. The project team embraced these themes as recommendations. Recommendations which could be relevant to the HWCTR project include: 
- SRS boundaries should remain unchanged, and the land should remain under the ownership of the federal government, consistent with the site's 1972 designation as the first National Environmental Research Park.

- All SRS land should be available for multiple use, except for residential use, (e.g., industry, ecological research, natural resource management, research and technology demonstration, recreation and public education) whenever appropriate and nonconflicting.

- $\quad$ Residential uses of SRS land should be prohibited.

- Some of the land should continue to be available for nuclear and non-nuclear industrial uses, and commercial industrialization should be pursued.

- Future use planning should consider the full range of worker, public and environmental risks, benefits and costs associated with remediation.

Also relevant to the HWCTR project are site maps in the Future Use Report which show recommended uses of different parts of the property. The U-Area, where the HWCTR is located, and the B-Area, which encompasses U-Area, are designated for administrative facilities, a position endorsed by the Citizens Advisory Board.

The report states that the "recommendations will be considered by the DOE as it weighs ongoing and future mission needs, technical capabilities, legal requirements and funding throughout future planning and decision-making activities."

As time passes and conditions at the site and in the surrounding area change in the coming years, different ideas may prevail. But in the meantime, the Future Use Project Report offers the best available predictions of SRS land use that pertain to the HWCTR decommissioning project.

An important factor taken into account in the Future Use Project Team's recommendations is the proximity of U-Area and B-Area to other facilities on the site. Information on this subject appears in the site's Land-Use Baseline Report of June 1995.

This report shows that:

- B-Area, which encompasses the HWCTR property, is a primary administrative area,

- The HWCTR lies about 2.5 miles from the nearest nuclear industrial facility, F-Area with its high-level waste storage tanks and chemical processing facility, and

- The HWCTR lies outside of the radiological risk zone associated with the central nuclear facilities. This zone is defined by safety analyses which consider possible but extremely unlikely accidents which could release radioactivity. 
- Outside of the zone the maximum amount of radiation exposure a person could receive in the event of an accident would fall below guidelines used by the DOE and the Nuclear Regulatory Commission for such accident scenarios.

The Land Use Baseline Report was available in draft form to those participating in the future use study, and is consistent with the Future Use Project Report.

\subsection{Historical Significance of the HWCTR Facility}

Another factor taken into account by the DOE was the historical significance of the facility. Accordingly, the HWCTR was evaluated using the criteria of evaluation for the National Register of Historic Places, which is found in the Federal Code of Regulations, 36 CFR 60.4. The facility was found not to be historically significant.

\subsection{REMOVAL ALTERNATIVES}

\subsection{Potential Alternatives}

Five different alternatives were considered for the HWCTR decommissioning. Included were those utilized in past nuclear reactor decommissioning projects and those methods presently considered to be industry standards. Of the five, four were found to warrant detailed study. These alternatives are shown in Figure 28 below, illustrated in Figure 29 of Appendix $\mathrm{A}$ and explained in the following paragraphs.

\subsubsection{Safe Storage}

The DOE Decommissioning Handbook and the American Nuclear Society's American National Standard for Decommissioning of Research Reactors, identify this alternative as SAFSTOR. This term means to defer decommissioning for a prolonged period of storage during which the facility is maintained so that the risk to public health and safety is acceptable. While in this condition, radioactive contaminants decay, reducing the radiological hazards associated with the facility. Under the American Nuclear Society's standard, SAFSTOR entails the following actions:

- A characterization study for radioactive materials,

- Removal of all fuel assemblies,

- Removal of all radioactive fluids and wastes,

- Removal or stabilization of radioactive contamination,

- Operation of appropriate support systems such as ventilation and fire prevention systems, 
- Isolating and providing access control to remaining radioactive areas, and

- Instituting routine maintenance and surveillance measures.

The HWCTR facility has remained essentially in this state since the 1975 characterization study was performed. Radiation levels have decayed during that time, substantially reducing the hazards associated with dismantlement and other decommissioning methods. Little is to be gained by continuing this condition, nor would it meet the objectives set for the decommissioning project. And experience in the nuclear industry has shown that proceeding without delay with decommissioning will often save costs in the long run, given the uncertainty associated with changing regulations and rising waste disposal costs. Therefore, the safe storage method does not warrant detailed analysis.

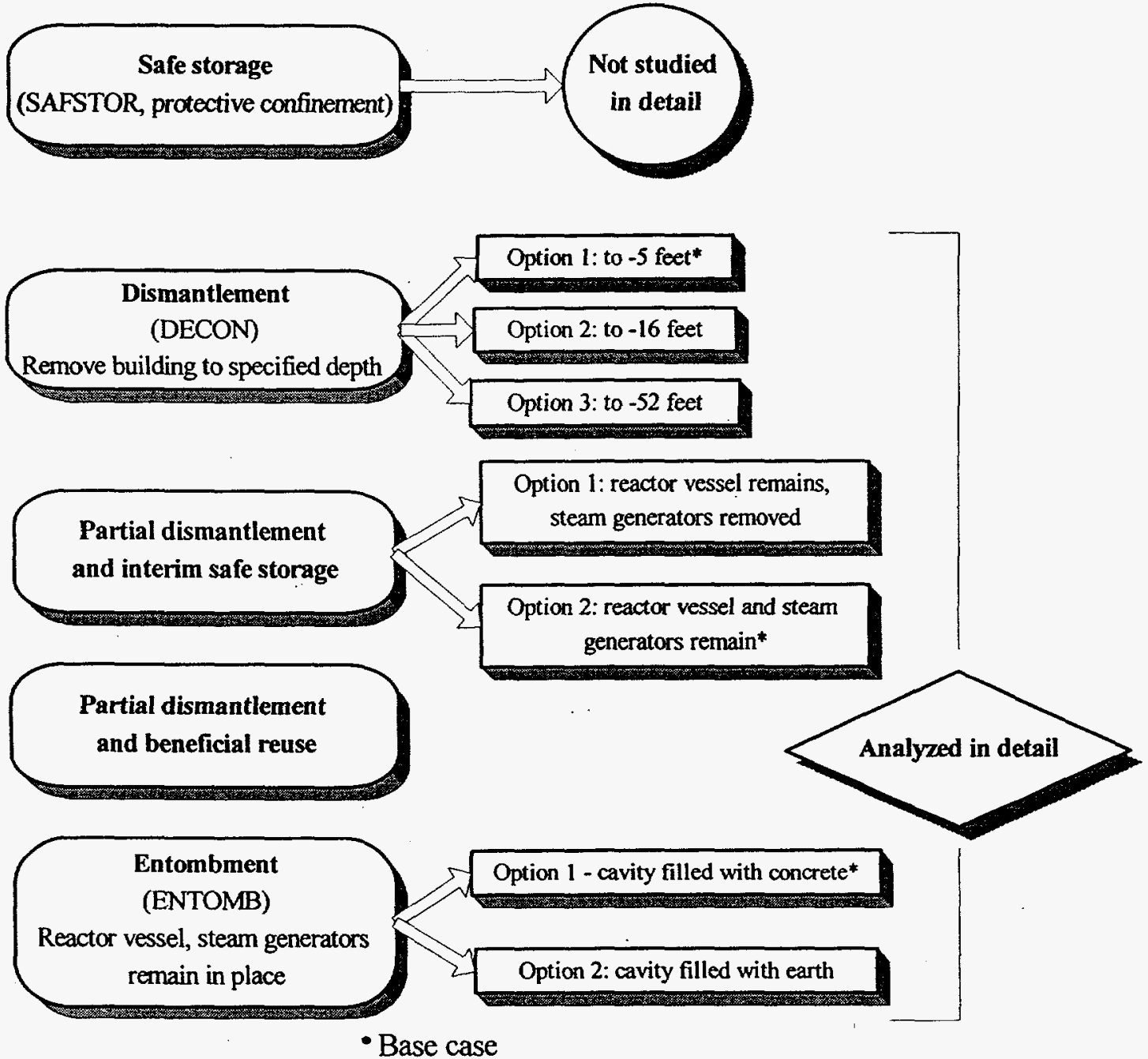

Figure 28. Alternatives Considered 


\subsubsection{Alternatives Studied in Detail}

The four removal alternatives analyzed in detail are described in the following paragraphs. Major tasks associated with each alternative are identified, recognizing that variations within each alternative can produce a viable end condition. For example, in the partial dismantlement and interim safe storage process, all equipment with the exception of the reactor vessel and steam generators would be removed. If this alternative were to be selected, a viable variation could be considered that limited the removal of other equipment. As another example, the entombment process requires the removal of recyclable metals. This could prove to be too costly and therefore, a variation might be chosen that would delete this task without affecting the overall end result of this alternative. Such options for the alternatives are discussed where they may have substantial merit.

Figure 29 of Appendix A provides a simple illustration of each of these alternatives.

\subsubsection{Dismantlement}

The Doe Decommissioning Handbook and the American Nuclear Society's American National Standard for Decommissioning of Research Reactors, call this approach DECON and note that it consists of removal of fuel assemblies, radioactive fluids, waste and other materials having activities above accepted unrestricted release levels, consistent with the principles of ALARA (maintaining personnel radiation exposure $\underline{\text { As }}$ Low As Reasonably Achievable). A good example of this approach is the decommissioning of the Shippingport Atomic Power Station in Pennsylvania, a summary of which appears on the next page.

This alternative merits evaluation in detail. Removing underground structures to five feet below grade level will be the primary case studied. This depth will permit removal of the entire ground floor (the 0-level), which has radioactivity in cracks and floor drain lines.

The dismantlement process would include the following major tasks:

- Modify the containment dome to facilitate removal of large components, e.g., the refueling machine, reactor vessel and steam generators.

- Remove all process piping, pumps and motors, cable trays, duct work, and installed components, including the reactor vessel and steam generators.

- Remove all hazardous waste and mixed waste.

- Recycle equipment and materials as practicable.

- Remove activated and contaminated concrete.

- Remove building to below grade.

- Remove the ventilation exhaust stack.

- Remove steam muffler and associated underground steam line.

- Remove underground waste water tank and associated piping.

- Dispose of all waste.

- Backfill with earth and grade the site.

- Perform final radiological survey. 
- Release for unrestricted use.

\section{The Shippingport Decommissioning Project}

The decommissioning of the Shippingport Atomic Power Station serves as a good example of the dismantlement alternative, although this facility was much larger than the HWCTR facility.

The world's first large-scale nuclear power plant, the Shippingport station was located in Beaver County, Pennsylvania. It was built by the Atomic Energy Commission to demonstrate for commercial use the pressurized water reactor technology of the U. S. Navy's nuclear-powered submarines. The plant operated from 1957 until 1984. Its decommissioning, which was completed in December of 1989, was the first complete decontamination and decommissioning of a power-producing reactor in the nation.

Some facts about the Shippingport decommissioning project:

- Structures demolished: All to three feet below grade,

- Actual total cost of project: $\$ 91.3$ million,

- Cost of removing piping and equipment: $\$ 8.5$ million,

- Cost of removal and shipment of reactor pressure vessel: $\$ 7.4$ million,

- Cost of removal of structures and chambers: $\$ 6.2$ million,

- Cost of solid waste disposal: $\$ 2.0$ million,

- Cost of waste burial at DOE Hanford, Washington Site: $\$ 2.2$ million,

- Volume of low-level radioactive waste: 214,000 cubic feet,

- Duration of physical work: 40 months,

- Personnel radiation exposure: 152 person-rem.

Technology transfer was a prime objective of the project. Hundreds of reports, presentations, technical papers and videotapes were made available to widely disseminate the lessons learned. These documents, which are listed in the Final Project Report of the Shippingport Station Decommissioning Project, are available from DOE's Remedial Action Program Information Center in Oak Ridge, Tennessee.
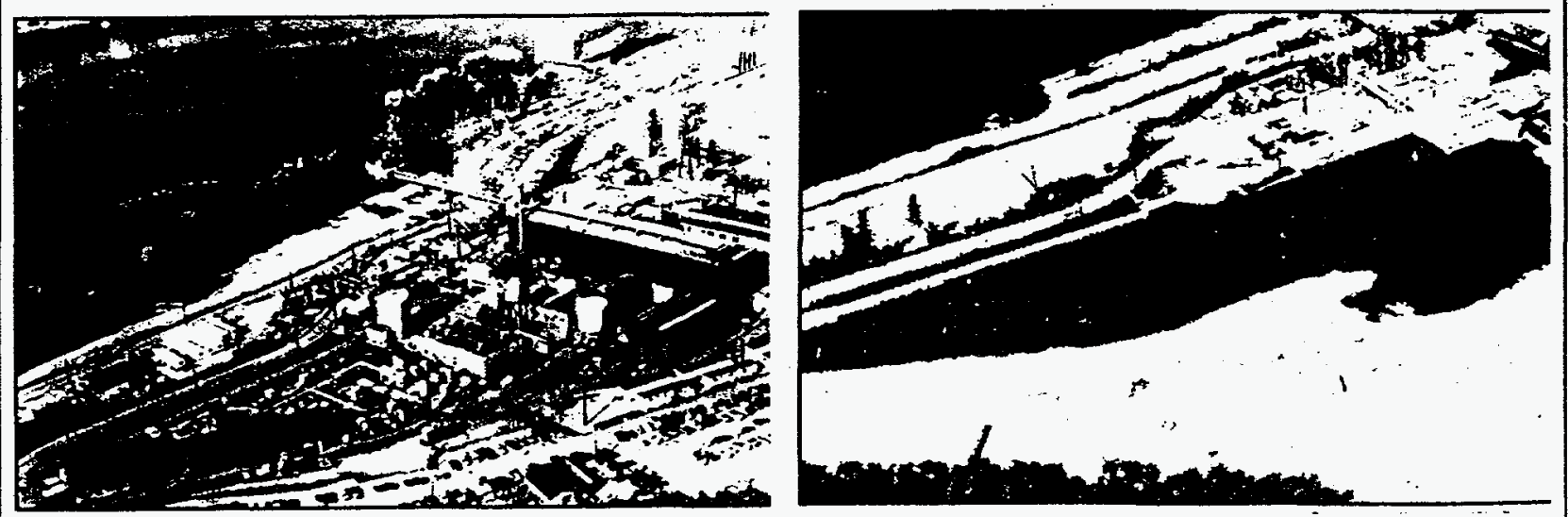

Figure 30. The Shippingport Decommissioning. These before and after views of the 7.5 acre property illustrate what is meant by the "greenfields" complete dismantlement type of nuclear reactor facility decommissioning. 
Three options associated with this alternative are discussed later in this document and included in the costs estimates. These are (1) removing the concrete structure down to the 5-foot- level, the primary approach, (2) removing the concrete structure down to the -16-foot level and (3) removing all of the concrete structure.

\subsubsection{Partial Dismantlement and Interim Safe Storage}

This approach entails removal of all radioactive equipment except for the reactor vessel and steam generators. It is a variation of the decommissioning approach being used for the 105 $\mathrm{C}$ plutonium production reactor at DOE's Hanford Site in the state of Washington. The Hanford 105-C reactor approach is summarized on the following page. In the case of the HWCTR, all radioactivity would be removed except for that in the reactor vessel, the reactor vessel biological shield and the steam generators, which would be sealed and left in place. The imbedded piping in the biological shield and in the floor drain system would remain in place. The containment dome would remain standing. The site would be left in a condition where the vessel and steam generators could be removed at some later time.

Such an approach could prove advantageous should funding for complete dismantlement not be forthcoming.

The partial dismantlement and interim safe storage process includes the following major tasks:

- Modify carbon steel dome to facilitate removal of large components, e.g., the refueling machine.

- Remove all process piping, pumps and motors, cable trays, duct work, and installed components with the exception of the reactor and two steam generators.

- Seal weld caps on vessel nozzles (outside of the biological shield) and on steam generator nozzles.

- Remove all hazardous materials and mixed waste.

- Recycle equipment as practicable.

- Remove the ventilation exhaust stack.

- Remove steam muffler and associated underground steam line.

- Remove underground waste water tank and associated piping.

- Dispose of all waste.

- Restore the carbon steel portion of the containment structure as necessary.

- Weld closed all containment building openings.

- Install remote monitoring equipment and establish periodic monitoring requirements, e.g., every five years. 


\section{The Interim Safe Storage of the 105-C Production Reactor at Hanford}

Even though the Hanford 105-C reactor is much larger and different in design from the HWCTR, a variation of its "cocooning" concept merits consideration.

The 105-C reactor is one of nine large weapons materials production reactors located at the DOE's Hanford Site in the state of Washington. The reactor operated from 1952 to 1969 . Shortly after the final shutdown, the used nuclear fuel was removed. Only minimal surveillance and maintenance has been accomplished since that time.

The reactor core consists of a block of graphite weighing 9,000 tons. It is surrounded by a reinforced concrete shield wall, three to four feet thick. The reactor building is a light industrial structure, 346 feet long, 150 feet wide and 120 feet high. Several areas of the building are in advanced stages of deterioration.

The DOE has determined that the reactor will be "cocooned" for safe storage until ultimate disposal. This process will entail sealing the reactor block in plastic. Openings in the shield wall will be sealed also. A new stainless steel roof will be installed over the shield wall. Radioactive equipment will be removed from the remainder of the building and the spaces decontaminated. This part of the structure will be razed, leaving only the cocooned reactor. Provisions will be made for remote monitoring and inspections at five year intervals. After a period of 50 to 75 years, the reactor block will be removed and buried in the site's radioactive waste disposal facility.

The 105-C interim safe storage program has been designated a large-scale demonstration project by the DOE's Morgantown Energy Technology Center.

\subsubsection{Partial Dismantlement and Beneficial Reuse}

This approach would follow the partial dismantlement and interim safe storage alternative, except that (1) reactor vessel and steam generators would be removed and (2) the structure would be set up for a purpose such as storage of radioactive material or equipment. The decommissioning of the Experimental Boiling Water Reactor (EBWR) at Argonne National Laboratory near Chicago, lllinois is a good example of such an approach. The containment building for that reactor, which bears similarities to the HWCTR building, was turned into a storage facility for transuranic wastes. A summary of the EBWR project appears on the next page. 
The Decommissioning of the Experimental Boiling Water Reactor (EBWR)

This project is an example of a nuclear reactor building much like the HWCTR containment building being converted to a storage facility for transuranic waste materials.

Located at Argonne National Laboratory near Chicago. Illinois, EBWR was the first boiling water type nuclear power plant to produce electricity. It produced up to 100 megawatts of heat during operation. After ten years of operation, it was shutdown in 1967

Decommissioning work began in 1986 and was completed in 1996. Radioactive equipment was removed. The reactor vessel was cut into pieces for disposal. Radioactive concrete biological shielding surrounding the reactor vessel was taken out. Because of the planned use as a storage facility for radioactive materials, the facility was not released for unrestricted use; low levels of radioactivity were allowed to remain inside imbedded piping in the biological shield, inside sealed floor drains and in parts of the building bridge crane.

Some figures associated with this project:

- Total cost - $\$ 19,586,000$ (include three characterization studies, engineering, etc.)

- Total worker radiation exposure - 20.87 person-rem (18.1 person-rem for reactor vessel complex removal)

- Low-level radioactive waste generated - 14,841 cubic feet (The cost of transportation and disposal of approximately two-thirds of this amount was $\$ 50$ per cubic foot; the remainder cost $\$ 90$ per cubic foot.)

- Mixed waste (both radioactive and hazardous) - 564 cubic feet

Note that the $\$ 19,586,000$ cost applies to the decontamination and decommissioning work only. Setting up the facility for storing transuranic wastes will cost approximately $\$ 2,629,000$.

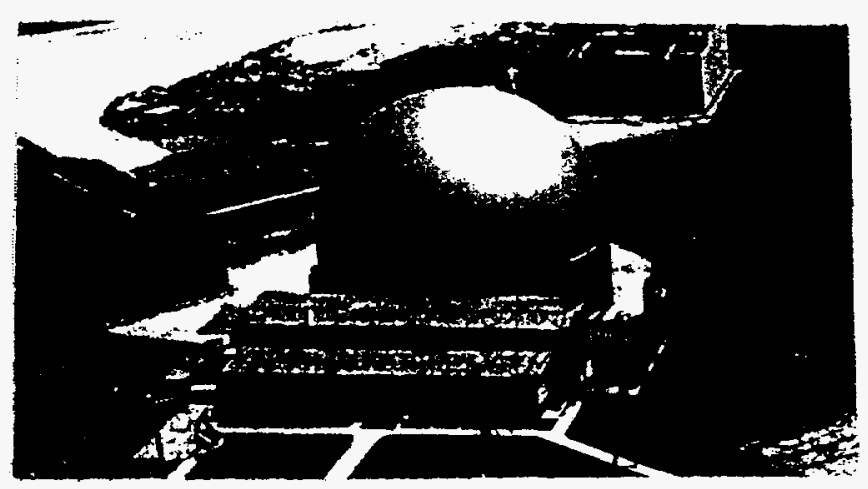

Figure 31. The EBWR Containment Building 
At the present time, no specific purpose for reuse of the HWCTR building has been identified. Hence, the analysis of this alternative assumes a generic waste storage scenario, with only infrequent access by personnel.

The beneficial reuse process would include the following major tasks:

- Develop and obtain necessary approvals for a waste storage plan.

- Modify carbon steel dome to facilitate removal of large components, e.g., refueling machine, reactor vessel and steam generators.

- Identify internal building waste storage areas desired.

- Remove the refueling machine.

- Cut piping from the reactor vessel and steam generators. Seal openings to the pressure vessels by welding steel plugs in openings.

- Remove the reactor vessel and steam generators.

- Remove activated concrete in the biological shield.

- Remove any interfering process piping, pumps and motors, cable trays, duct work, and installed components.

- Remove all hazardous waste and mixed waste.

- Recycle equipment as practicable.

- Remove the ventilation exhaust stack.

- Remove steam muffler and associated underground steam line.

- Remove underground waste water tank and associated piping.

- Dispose of all waste.

- Modify deck structure as necessary to support waste storage requirements.

- Restore the carbon steel portion of the containment structure.

- Upgrade building to meet current codes and requirements for intended use.

\subsubsection{Entombment}

The DOE Decommissioning Handbook and the American Nuclear Society's American National Standard for Decommissioning of Research Reactors describes the in-place entombment approach, which they call ENTOMB, as sealing all of the remaining highly radioactive or contaminated components (e.g., reactor structural components) within a structure integral with the biological shield. First, all fuel assemblies would be removed, along with all radioactive fluids and waste and selected components. (Fuel, radioactive fluids and waste have already been removed from the HWCTR.) Concrete would typically be poured into the below-ground building cavity to produce a monolithic structure. The radioactivity would remain entombed until it decayed to harmless levels. This time period would depend on the type and amount of radioactive contaminants. It would typically be longer than a century.

One nuclear reactor which was entombed in the early 1970s is located at Wright-Patterson Air Force Base in Dayton, Ohio. Information on this project appears on page 28.

The entombment process for the HWCTR would include the following major tasks: 
- Modify carbon steel dome to facilitate removal of large components, e.g., the refueling machine.

- Remove all site equipment, above the zero reference point, that is located external to the biological shield, including the refueling machine.

- Remove all hazardous waste and mixed waste.

- Store the removed radioactive and contaminated equipment, if practicable, inside the containment building below the 0-level, as long as it is not mixed waste.

- Identify and remove, if practicable, all recyclable metals.

- Cut piping from reactor vessel and steam generators.

- Seal reactor vessel, and steam generator openings with welded steel plugs.

- Dispose of all waste.

- Secure the remaining radioactive components within a structure that will meet the criteria of prevention of access to the facility and maintaining structural integrity over an extended period of time, i.e., fill existing voids in containment building with concrete to a level of plus three feet.

- Remove the steel dome portion of the containment building.

- Remove the ventilation exhaust stack.

- Remove steam muffler and associated underground steam line.

- Remove underground waste water tank and associated piping.

- Cover the entire concrete surface with a waterproof barrier and seal with a waterproof membrane similar to that planned for the SRS low-level waste burial grounds.

The existing walls of the underground reinforced concrete structure are 18 inches thick; the bottom floor - referred to as the "base mat" - is five or more feet thick. Filling the cavity with concrete will produce a large monolithic concrete structure of high durability.

Consideration was given to filling the reactor vessel, steam generators and large piping with concrete grout to immobilize the radioactivity within this equipment. It was determined that use of this technique was unnecessary because of the high integrity of the equipment, especially the reactor vessel which contains most of the radioactivity, and the fact that the radioactivity inside of the equipment would be contained well within the monolithic structure.

After 100 years, the approximate amounts of radioactivity inside of this entombment, using the estimates of Table 3 and Table 4 adjusted to account for radioactive decay, would be:

Table 5. HWCTR Radioactivity in Curies After 100 Years

\begin{tabular}{|c|c|c|c|c|}
\hline Iron-55 & Cobalt-60 & Nickel-63 & $\begin{array}{c}\text { Plutonium-239, and } \\
\text { other transuranics }\end{array}$ & Fission products \\
\hline- & 0.001 & 1000 & $<0.001$ & $<0.0001$ \\
\hline
\end{tabular}




\section{The Entombment of the Air Force Nuclear Engineering Center (AFNEC) Reactor}

The AFNEC was a small 10 megawatt water-cooled reactor. Located at the Air Force Institute of Technology at Wright-Patterson Air Force Base in Dayton, Ohio, it was built to conduct studies related to nuclear propulsion of aircraft. It was operated from 1967 to 1970.

The reactor and its associated experimental facilities are enclosed in a steel-domed structure that looks much like the HWCTR containment building. The AFNEC containment shell stands 110 feet above grade and extends about 50 feet below the ground. The structure is 82 feet in diameter.

During 1970 and 1971, the reactor was entombed. First, non-structural radioactive components were removed. Radioactive cavities such as the reactor tank and test cells were filled with sand. Penetrations in the concrete biological shield were sealed by welding. Finally, additional concrete shielding was constructed to reduce radiation levels to less than 0.2 millirem per hour. The design lifetime of the entombment was 50 years.

In 1987, Oak Ridge National Laboratory performed a study for the Air Force of options to decommission the entombed reactor. The four options and their projected capital cost in 1987 dollars are:

(1) A facility upgrade with continuing surveillance of the entombed structure ( $\$ 1$ million),

(2) Removing radioactive equipment from the tomb (\$26.4 million),

(3) Removing radioactive equipment and removing the concrete monolith itself (\$27.9 million), and

(4) Removing radioactive equipment, removing the monolith and razing the structure $(\$ 42.2$ million)

A decommissioning plan was eventually developed for the fourth option. But the plan was not carried out, chiefly because the Barnwell Low Level Radioactive Waste Disposal Site closed to waste generators outside the Southeast Compact, leaving no place to dispose of low level waste from the decommissioning work.

The Air Force finally decided to adopt option (1), and upgraded the entombed facility. In connection with this, all radioactive materials external to the structure were removed, including underground tanks.

The iron-55 radioactivity, with its 2.7 year half-life, would have decayed away. Virtually all of the cobalt-60 activity remaining would be inside of the reactor vessel, effectively imbedded in the metal components.

Virtually all of the nickel-63 activity also would reside inside of the reactor vessel, effectively imbedded in the metal. With its 100 year half-life, the nickel- 63 would still be present in amounts in the range of one curie even after 1000 years. But given the nature of its radioactive emissions - low-energy beta and no gamma - it is less hazardous than most other radioisotopes and can result in radiation exposure only if ingested or inhaled. 
The transuranic radioisotopes referred to in Table 5 include plutonium-239, americium-241 and others. Owing to their long half-lives they would not decay significantly in a century. Pieces of HWCTR hardware, such a valve from the main cooling system, would still be radioactive in the year 2096. Fission products such as cesium-137 also would be present in amounts exceeding current limits.

Besides these radioisotopes, others are present in the HWCTR in smaller quantities, but they are less important than those just discussed.

In summary, given its present radioactive inventory, an entombed HWCTR would still contain low-levels of radioactivity above current limits even after a century. Of course, limits for acceptable levels of radioactivity may change over the years.

\subsection{Radiological Release Criteria}

The radiological release criteria for the HWCTR project have not yet been established. The criteria could involve an "unrestricted" or a "restricted" release, depending on the approach followed, or no release from radiological controls at all.

The dismantlement approach would entail an unrestricted release of the property. The property would then be available for any suitable use. The partial dismantlement and interim safe storage approach and the entombment approach would both entail restricted releases, with continuing institutional controls on the property. The partial dismantlement and beneficial reuse approach would entail continued institutional controls, the nature of which would depend on the actual use of the facility. The institutional controls would involve such things as radiological warning signs, controlled access and periodic radiological surveys and inspections.

The criteria for restricted release would be established based on the particular decommissioning scenario. They would include specifications for permissible radiation levels on accessible surfaces of the facility.

The unrestricted release criteria have not yet been established either, but they would likely follow DOE Order 5400.5, Radiation Protection of the Public and the Environment. These criteria entail limiting personnel radiation exposure from residual radioactivity at the site to less than 100 millirem per year, and applying the ALARA principle to ensure that the actual exposure is as low as reasonably achievable. (When the original version of this study was issued, it was expected that a new radiation cleanup standard being developed by the $U$. S. Environmental Protection Agency would apply to the project. But work on this new standard was suspended.)

In the past, unrestricted release criteria for DOE decommissioning projects have been set on a case by case basis. The criteria for the Shippingport Atomic Power Station in Pennsylvania serve as a good example since this was a DOE project which involved unrestricted release of the property following removal of radioactive material, with some below-ground parts of the structure remaining in place. These criteria included the following elements: 
- A basic limit of “...100 millirem per year total committed effective dose equivalent to the maximum exposed individual of the general public under the worse case scenario...".

- Use of the surface radioactivity limits of the Nuclear Regulatory Commission's Regulatory Guide 1.86 long a nuclear industry standard,

- An average concentration of cobalt- 60 , the limiting radionuclide, of less than 6 picocuries per gram in the top three meters of soil, and

- An average exposure rate of less than 0.05 millirem per hour one meter from the wall of a buried underground structure which could conceivably be occupied in the future.

\subsection{Specific End Condition}

This section addresses how well each of the four alternatives satisfies the end condition criteria described in section 4.2 above.

\subsubsection{Dismantlement}

The facility would be brought to a condition where (1) the equipment and components are removed, (2) activated and contaminated concrete is removed, (3) the facility is decontaminated to acceptance levels for unrestricted release, (4) all structures have been demolished to below-grade level and (5) the site has been backfilled, graded and landscaped. This condition would be similar to the condition attained during the decommissioning of the Shippingport Atomic Power Station. It would readily satisfy the criteria of section 4.2.

Any of the three options associated with this alternative - removal of the concrete structure to the -5-foot level, to the -16-foot level or removal of all of the below-ground structure would satisfy the criteria.

\subsubsection{Partial Dismantlement and Interim Safe Storage}

The facility would be brought to a condition where all radioactive equipment but the reactor, steam generators and biological shield would be removed from the building. The upper portion of the containment building would be restored and all openings welded shut in order for the facility to function as the top of the cocoon. Remote monitoring equipment to detect 
excessive moisture and other potential problems would be installed. Plans would be in place for entry into the building at five year intervals for inspections.

This condition satisfies two of the three criteria of section 4.2. It increases the physical security of the radioactive equipment and building materials by effectively sealing the building. By removing all of the radioactive equipment except for the reactor vessel and steam generators, it improves the ability to eventually release the HWCTR site for unrestricted use. But it does not significantly reduce the risk of radionuclide migration from the property, because most radioactivity would remain inside the reactor vessel. The matter of radionuclide migration is discussed in section 5.4 below.

\subsubsection{Partial Dismantlement and Beneficial Reuse}

Equipment removed would include the reactor vessel, steam generators and other large components. The activated portion of the biological shield and contaminated concrete would be removed. Process piping items and other installed components interfering with designated storage areas would be removed. Given the planned use as a radioactive materials storage facility, the building would not be completely released from radiological controls. Imbedded radioactive piping, such as floor drains and that inside of the biological shield, would remain in place.

Upon completion of the equipment removal, the containment building would be restored to suitable condition for use as a storage area. Decks and other structural components would be reinforced as required to support the approved waste storage plan. This condition would be similar to the end condition of the EBWR at the Argonne National Laboratory.

This approach improves the physical security of radioactive equipment and building materials to some degree by relocating nearly all of the radioactivity to the SRS low-level waste disposal facilities. Consequently, there is also reduced risk of radionuclide migration from the HWCTR property. And the ability to release most or all of the property for unrestricted use also improves.

\subsubsection{Entombment}

The facility would be brought to a condition where all equipment above the 0 -level reference point has been removed. The underground structure would be removed down to -5 feet or lower, depending on the option chosen. The containment building would be filled with concrete to a level of three feet above the 0 -level reference point. The carbon steel portion of the containment building would then be removed. Landscaping to improve aesthetics could be executed if desired.

This approach meets the section 4.2 criteria as follows: The physical security of the radioactivity is increased by containing it within a buried concrete vault. The risk of radionuclide migration is diminished for the same reason. The ability to eventually release 
most or all of the site for unrestricted future use is not improved. Even after 100 years of entombment, much of the equipment would remain radioactive by today's standards. And removing the equipment from the monolithic structure would be costly as the Air Force found during its study of one of its old nuclear reactors at Wright-Patterson Air Force Base.

\subsection{Risks and Safety Issues}

In this section, risks and safety issues associated with the HWCTR decommissioning alternatives are discussed, with the focus on workers and the public. Potential environmental impacts from the decommissioning work are addressed in the next section.

Radiological risks associated with external radiation exposure are addressed quantitatively. Other risks are addressed in a qualitative fashion. The results of previous studies such as those associated with the SRS Waste Management Final Environmental Impact Statement are utilized as applicable. This approach is consistent with the graded approach for applying the requirements of the Comprehensive Environmental Response, Compensation and Liability Act to nuclear decommissioning work expressed in reference 1.

\subsection{Summary}

Risks associated with the HWCTR decommissioning, regardless of the approach selected, would be low. No unusual safety issues would be involved. A detailed Health and Safety Plan will ensure that the safety of workers is protected.

The most significant radiological risks are associated with worker radiation exposure. This exposure would be relatively low for each alternative, compared with that on other nuclear reactor facility decommissioning projects.

Insofar as nonradiological risks associated with the decommissioning work are concerned, these are similar to those involved with modifying or dismantling a nonnuclear commercial or industrial building of similar size and age. There are no special workplace hazards. Controls commonly used in industry and on SRS to ensure occupational safety will ensure that the nonradiological risks associated with the HWCTR decommissioning are small.

\subsubsection{The Nature of Radiological Risks}

Everyone, from the moment of conception, is exposed to ionizing radiation naturally present in the environment. This ionizing radiation is known as background radiation. It comes from radioactive materials in the earth and within our bodies. It also appears as cosmic radiation from outer space. The amount of background radiation that one receives in the United States averages about 0.3 rem per year. This amount varies significantly from place to place .

Decommissioning a nuclear facility such as the HWCTR entails radiation exposure to workers above natural background levels. The public could also be exposed to radiation 
levels above background, especially from shipments of radioactive metals to off-site recycling facilities.

Scientists agree that exposure of people to high levels of ionizing radiation can cause some forms of cancer. Risk factors have been developed that relate radiation exposure to the increased rate of fatal cancers, based on studies of groups of people accidentally or occupationally exposed to relatively high levels of radiation. The International Commission on Radiological Protection identifies risk factors for fatal cancers of 0.0005 per person-rem for the general population and 0.0004 per person-rem for workers. (Risk factors are lower for workers because most of them are adults.)

Many scientists believe that these risk factors are conservative because they entail extrapolating cancer rates associated with high radiation exposures to low exposure levels where there is no direct evidence that radiation exposure causes cancer.

The following examples illustrate how these factors are used in estimating cancer risk.

- If a group of 10 people received an average individual dose of 0.3 rem per year exposure over a 70-year lifetime, their collective risk of dying from cancer is increased by a factor of about 1 in 10 from this radiation exposure. (This value comes from multiplying ten persons by 0.3 rem by 70 years by the 0.0005 risk factor, which equals 0.105 , or about $1 / 10^{\text {th }}$.) Note that the average person receives about 0.3 rem per year from background radiation.

- A group of 100 radiation workers who each receive occupational exposure of one rem over a ten-year career - a typical exposure in the nuclear industry - has an increased risk of fatal cancer from this exposure of one chance in 25 or 0.04 . (From multiplying 100 by one by 0.0004 .)

The use of accepted risk factors therefore provides an estimate of increased cancer risk from radiation exposure to workers and the general population. Note that risks in the range of $1 \times 10^{-4}$ or 0.0001 are small compared to others that most people accept, such as dying in motor vehicle accidents $(0.013)$ or drowning $(0.0026)$.

Another way to help place the additional cancer risks into perspective is to consider statistics on cancer mortality in the United States. According to the U.S. Centers for Disease Control and Prevention 23.5 percent of human deaths in this country are caused by some form of cancer.

\subsubsection{HWCTR Radiological Risks}

Four factors combine to make the radiological risks low. First, only moderate amounts of radioactivity are present in the facility. Second, the vast majority of this radioactivity is in the form of activated steel, with the radioactivity effectively imbedded in the metal inside of the reactor vessel. Third, once the decommissioning is completed, the radioactivity will either be removed from the facility or sealed in place so that the probability of exposure to 
workers or to the public is not significant. Fourth, extensive controls will be used to handle radioactive material and minimize radiation exposure to workers and the public during the course of the decommissioning work and in shipment of radioactive materials from the HWCTR site.

\subsubsection{Pathways for Radiation Exposure}

In the decommissioning of the HWCTR, several possible pathways exist for exposure of workers and members of the general public to radioactivity from the facility. The most significant are:

- External exposure. Workers will receive external exposure to gamma radiation during the course of the decommissioning work. Amounts would vary with the alternatives. Members of the public could be exposed to gamma radiation from radioactive metals transported to off-site recycling facilities. People on the property after the decommissioning could receive some radiation exposure from residual radioactivity at the site.

- Ingestion of radioactive materials. Workers could ingest radioactive particles during the course of the work, and receive internal radiation exposure as a result. After the facility is decommissioned, people on the property could possible ingest materials containing trace amounts of residual radioactivity.

- Inhalation of airborne radioactivity. Workers could breathe airborne radioactive particles during decommissioning work.

- Waterborne radioactivity. If radioactivity from the facility were to get into surface water or ground water, radiation exposure to humans could eventually result.

\subsubsection{Risks of External Exposure}

Estimates of the worker radiation exposure associated with the four decommissioning alternatives appear in section 5.8.4. The estimates range from four person-rem for dismantlement and partial dismantlement and beneficial reuse, to one person-rem for entombment. Worker radiation exposure will be maintained as low as reasonable achievable using techniques summarized in reference 2 .

Using the risk factors described in section 5.4.2, the estimated risk of an additional cancer death among all of the workers who receive this exposure would be $0.0016\left(1.6 \times 10^{-3}\right)$ for four person-rem and $0.0004\left(4 \times 10^{-4}\right)$ for one person-rem.

Note that the HWCTR exposure estimates are low for nuclear reactor facility decommissioning work. Worker radiation exposure for the larger-scale Shippingport decommissioning project was 152 person-rem. On the Experimental Boiling Water Reactor decommissioning project the worker exposure was 20.87 person-rem. 
Radiation exposure to workers from transportation of radioactive waste to SRS disposal facilities is estimated to be much less than one person-rem. The risk of an additional cancer death among a group exposed to one person-rem would be $0.0004\left(4 \times 10^{-4}\right)$.

The most credible way that members of the public could receive external radiation exposure from the decommissioning would be exposure to radiation from packaged metal piping and components transported to off-site recycling facilities. This material would be shipped by truck in large steel containers. Department of Transportation regulations allow radiation levels up to 0.2 rem per hour on the outside of the package and at the outer point of the transport vehicle in such shipments. The actual radiation levels would be substantially lower than those permitted by the regulations; they are expected to fall below 0.001 rem per hour.

Risks associated with transportation of radioactive and hazardous waste from SRS were evaluated in detail in the SRS Waste Management Final Environmental Impact Statement. Projected shipments evaluated included those from nuclear decommissioning projects such as HWCTR. Accident impacts were taken into account as well as incident-free shipments. Conservative assumptions were used. The results showed that risks from transportation of the material were small, a conclusion validated by extensive experience.

In the dismantlement alternative, adherence with the radiation cleanup standard would ensure that people on the property after the decommissioning do not receive significant radiation exposure from residual radioactivity. Compliance with the cleanup standard would be independently verified so that there is good assurance that the criteria have been met. With the entombment alternative, significant radiation exposure to those on the property after the decommissioning would likewise be prevented by adherence to a cleanup standard which would ensure that accessible radiation levels are insignificant. With the other alternatives, physical security measures such as those presently in place as outlined in reference 2 would limit access to authorized personnel who would be monitored for radiation exposure.

\subsubsection{Risks Associated With Ingestion of Radioactive Materials}

Risks from ingestion of radioactive materials are negligible both to workers and the general public.

Workers risks are minimized by controls over radioactive materials handled during the decommissioning work. These controls are summarized in reference 2 .

The most credible pathway for members of the general public to ingest radioactivity from the HWCTR would occur after the decommissioning, from residual radioactivity at the cleanedup site. The radiation cleanup standard used to determined that the property is suitable for unrestricted release from radiological controls would ensure that possible radiation exposures from ingestion of materials on the property are negligible. 


\subsubsection{Risks From Inhaling Airborne Radioactivity}

As with ingestion of radioactive material, risks to workers from this pathway would be avoided by the protective measures outlined in reference 2 .

And, as with possible ingestion of radioactive materials, risks to those on the property after the decommissioning is completed would also be negligible because the cleanup standard used would take this pathway into account.

\subsubsection{Risks From Waterborne Radioactivity}

Risks from radioactivity associated with the HWCTR decommissioning contaminating nearby surface water or ground water under the property would be extremely small. This matter is addressed further in section 5.5.1.

\subsubsection{Risks Associated With Nonradiological Pollutants}

Nonradiological contaminants associated with the HWCTR facility were described in section 3.7. They include lead, mercury, asbestos and PCBs.

All four decommissioning alternatives call for removing such materials from the facility. Therefore, the risks associated with these materials apply to the decommissioning workers. Worker risks will be minimized by protective measures which will be detailed in the Health and Safety Plan. The nonradiological contaminants in the HWCTR facility are similar to those found in nonnuclear building of similar age and construction. Such contaminants are commonly encountered in building modification and demolition work. Appropriate protective measure for workers are well established.

The potential ecological impacts of nonradiological pollutants in the HWCTR facility are addressed in section 5.5.1.

\subsection{Potential Impacts of Each Alternative}

In accordance with reference 1, separate National Environmental Policy Act documents, such as an environmental assessment or an environmental impact statement, are not required for decommissioning performed under the Comprehensive Environmental Response, Compensation and Liability Act. In such a case, as the HWCTR project, the alternatives analysis is to address the ecological, socioeconomic, off-site and cumulative impacts of the alternatives being considered.

\subsubsection{Ecological Impacts}

The potential ecological impacts of the HWCTR decommissioning project fall into four areas: (1) water quality, (2) air quality, (3) soils and (4) terrestrial biota and endangered and threatened species. 


\subsubsection{Water Quality}

The decommissioning work will involve remediation of hazardous pollutants and radioactivity and the possibility of releases of these materials to the surrounding waters and groundwater supplies.

Nonradiological pollutants. For nonradiological pollutants, there is equal risk involved with each of the decommissioning alternatives as each alternative involves removal of all regulated wastes, wastes which fall under the Resource Conservation and Recovery Act, wastes controlled by the Toxic Substances Control Act and other hazardous materials.

While the possibility of water pollution from contaminant migration during decommissioning work exists, a number of factors make this risk extremely small. The nearest stream, Upper Three Runs Creek, runs approximately a mile southeast of the property. Thus, the possibility of pollutants getting to and being transported by streams as a result of the decommissioning work is negligible.

The ground water table lies 90 to 100 feet below the surface of the HWCTR property, over 30 feet below the lowest point of the structure. The containment structure is essentially impervious to water. Since the structure would remain intact during hazardous pollutant remediation work, the possibility of contaminants from the work getting through the structure and into the ground water is extremely remote.

Another factor which minimizes the potential for releases of waterborne pollution involves the types and quantities of the contaminants - primarily solids with only small amounts of liquids - which will be remediated under strict controls. Simply put, the pollutants involved would not migrate during the type of work required for their removal.

To put the potential impacts associated with removal of nonradiological pollutants during decommissioning work into perspective, they are no greater than those involved with the remediation of a typical, commercial nonradiological facility of similar age and construction.

There is no risk of migration of nonradiological environmental pollutants from the HWCTR site following completion of decommissioning work because all of the decommissioning alternatives call for removal of regulated wastes, those covered under the Resource Conservation and Recovery Act, those covered under the Toxic Substances Control Act, and other hazardous materials. (Asbestos remediation is addressed in section 5.5.1.2.)

Radiological pollutants. The potential impacts associated with radiological contamination releases to the environment during the decommissioning work are also very small. Minute amounts of radioactivity may be released to the environment during the demolition work. The releases will be almost exclusively in the form of airborne radioactive particles and very low levels of radioactivity contained in concrete dusts. The radioactivity involved will not 
migrate far from the source and will be deposited on ground surfaces in the vicinity of the HWCTR site. But given the controls which will be in use, these releases will be so small that they will not be measurable when compared to natural background radioactivity. Thus, the probability of measurable quantities of radioactivity getting to streams, rivers or ground water is negligible.

Following decommissioning work, the possibility of migration of radioactivity from the HWCTR site will vary from very small to zero, depending on the alternative chosen. For the dismantlement alternative, since all radioactivity will be removed from the site, there remains no further risk of migration. Even the entombment alternative, which leaves the greatest amount of radioactivity at the site, offers only a slight chance for radioactive material migration. This is because of the integrity of the entombment structure coupled with the fact that the water table is approximately 30 feet below the bottom of the structure. The potential of radionuclide migration for the two remaining alternatives falls between the dismantlement and entombment alternatives since each involves removal of more of the radioactive material than does the entombment alternative.

It is expected that the radioactive wastes from the decommissioning work will be disposed of on-site at the Solid Waste Disposal Facility and the E-Area Vaults. The HWCTR low-level radioactive waste will constitute only a small fraction of the waste in these facilities. The potential impacts of radionuclide migration from these facilities on water quality have been shown to be small (reference 3 ).

\subsubsection{Air Quality}

Very small and probably negligible quantities of air pollutants would be released by the decommissioning work. Given the amounts and types of releases, long term air quality would not be effected.

Nonradiological Air Pollutants. Most of the asbestos containing materials have already been remediated at the HWCTR site. However, some small quantities of asbestoscontaining materials (e.g., insulation in electrical wires and gaskets) are expected to be removed during decommissioning work. As with other hazardous materials, this material will be removed prior to any large-scale structural demolition work. This sequence allows the structure to provide a secondary containment for the work, virtually eliminating the possibility of releases of asbestos to the environment. Therefore, the only hazards involved will be to those individuals carrying out the asbestos removal work. Given that this work will be performed by trained workers using appropriate controls, the potential for asbestos exposure to these people is low.

No volatile organic compounds are known to be present at the HWCTR site and it is planned that none would be introduced during or after the decommissioning work. Also, no chlorinated fluorocarbons are known to be present and it is expected that none will be released during or after the decommissioning work. 
The only degradation in air quality which will be realized during the decommissioning process would come from dust-generating work, primarily concrete demolition and earth moving. While such dust-producing work is necessary to some extent with any of the alternatives, dismantlement involves the most demolition and thus will produce the most dust. Proven methods for dust suppression will be employed to reduce the amount of dust generated. Standard methods of dust control including the use of equipment such as dust masks will be use to minimize worker exposures. The dust produced during demolition work will be no greater than that typically produced by razing a small to moderate size commercial or industrial facility.

Radiological Air Pollutants. Very small quantities of airborne radioactive contaminants are expected to be released during the decommissioning work. This is primarily the result of trace levels of radioactivity adhering to concrete and being released with the dust produced by demolition work. Proven techniques will be used to contain the radioactivity. The quantities of radioactivity released would so small and would be dissipated so quickly that they would be undetectable. No radioactivity releases approaching the airborne release limits of 40CFR61 Protection of the Environment are expected.

\subsubsection{Soils}

As previously noted, very small quantities of radionuclides could be released to soils in the vicinity of the HWCTR facility during demolition work. However, the radioactivity levels would be so small as to be undetectable, even with sensitive laboratory instrumentation. There is very little possibility of soil contamination from nonradiological pollutants as a result of the decommissioning work. This is because of the nature of the pollutants and the controls which will be employed for the remediation work.

As stated in Section 4.3, soil samples will be taken and analyzed in a laboratory for radioactivity and other hazardous constituents. Contaminants found will be removed as appropriate.

\subsubsection{Terrestrial Biota and Endangered and Threatened Species}

No long-term ecological consequences are expected from the decommissioning work. There are no known endangered or threatened species on the HWCTR property, according to the Land-Use Baseline Report - Savannah River Site, Report WSRC-TR-95-0276 of June 1995. The plant habitat at the site consists almost exclusively of various wild grasses and weeds indigenous to the area. The only wooded area is the muffler site. Small trees, brush and native grasses are present in this area.

The decommissioning work will damage or destroy native grasses on the property along with some plants and small trees in the area near the muffler. However, given the plant life which currently exists at the site, the area can be expected to recover naturally within several years of the decommissioning. While the dismantlement alternative provides for the largest disturbance, this alternative includes site restoration, part of which includes replanting the affected areas after fill and grading. 
Limited disturbance of animal life in the area is expected. In a very small number of cases, injury or death to animal inhabitants may occur. This includes small animals, rodents and amphibians. Bird life is not expected to be affected. However, since the site encompasses only two acres of the 310-square-mile federal reservation, long term damage to the animal populations in the vicinity is not expected and recovery from any damage would occur in a short while.

\subsubsection{Socioeconomic Impacts}

It is estimated that less than 50 people will be involved with the HWCTR decommissioning effort at any one time. Given the current average employment level at SRS of about 16,000, the socioeconomic impact of the work would be negligible. It is expected that part of the workforce involved in the decommissioning work would come from the local area.

No increased social or economic risks to minorities or low-income populations as a result of the decommissioning work are expected.

Regarding land use, as discussed previously, only the dismantlement alternative would make the property available for unrestricted uses. The other alternatives would require that the area remain under some type of radiological controls.

There are no known or suspected cultural resources which could be disturbed or destroyed by the decommissioning activities at the HWCTR site.

Depending upon the alternative chosen, decommissioning could improve the appearance of the site. The best alternative from the aesthetic standpoint would be dismantlement, which would restore the site to conditions similar to those which existed prior to construction. Entombment provides the next best condition, in that it eliminates the dome and limits the amount of above-grade material present after the decommissioning work is complete. The partial dismantlement and beneficial reuse alternatives provide little change from the current condition because the dome, which is the most prominent feature on the site, would remain in place. The partial dismantlement and interim safe storage approach would be similar.

\subsubsection{Off-Site Impacts}

\subsubsection{Waste Materials}

The HWCTR decommissioning effort will generate moderate quantities of waste materials. This includes both hazardous and non-hazardous waste. A significant portion of this waste will also be radioactive.

Of the four alternatives, dismantlement, because it involves removing all of the equipment and a portion of the structure below grade, will generate the most waste. Entombment, which entails removal of the dome, and the partial dismantlement and interim safe storage 
and the beneficial reuse approaches, in which the dome remains intact, would generate smaller quantities of waste materials.

Nonradioactive, Non-Hazardous Waste. Nonradioactive, non-hazardous waste generated by the decommissioning work will consist chiefly of building rubble (concrete and reinforcing steel), some limited amounts of piping and equipment and structural steel. In either the dismantlement or entombment alternatives, the dome will be demolished and become nonradioactive waste. Nonradioactive steel and other metal waste materials would likely be sold as scrap and recycled. Material that can not be recycled, such as building rubble, will be disposed of in an onsite sanitary landfill.

Nonradioactive, Hazardous Waste. Decommissioning work would generate small quantities of nonradioactive, hazardous waste. Since each alternative calls for removal of all hazardous waste and materials, the amounts generated will be the same for each of the four removal alternatives. The waste streams include asbestos-containing materials, along with wastes associated with the Resource Recovery Conservation Act - primarily lead, brass, bronze, mercury-containing components and small amounts of waste oils. Also, wastes controlled by the Toxic Substances Control Act - lubricants, electrical components and small amounts of waste oils containing PCBs - will be generated. Most of these wastes would be temporarily stored in permitted storage facilities at SRS prior to shipment to permitted treatment, storage and disposal facilities. Given the nature and quantities of the hazardous waste materials which will be shipped to the off-site contractor, there would be negligible potential environmental impact.

Radioactive, Non-Hazardous Waste. Significant quantities of non-hazardous, radioactive waste will be generated during decommissioning work. The quantities of this waste vary with each alternative, with dismantlement providing the most. Since all of this waste will be disposed of on-site, no off-site effects would be expected.

Radioactive, Hazardous Waste. Radioactive hazardous waste, with similar hazardous constituents to those in nonradioactive hazardous waste discussed previously, will also be generated. The quantities in these waste streams are not dependent on the removal alternative because all of the alternatives require that these wastes be removed from the facility. A small amount of radioactive asbestos-containing material will have to be removed. Significant quantities of mixed waste (wastes which are both hazardous under the Resource Conservation and Recovery Act and radioactive) will be generated. Small quantities of radioactive wastes controlled by the Toxic Substances Control Act are also expected.

Some of these waste materials will be sent off site. The mixed waste may first be sent to the Savannah River Site mixed waste storage facility pending the availability of treatment or permanent disposal options. Some of this waste may be amenable to recycling, for example the lead in the transfer coffin may be able to be extracted from the steel shell and recycled as scrap metal. Off-site shipments of hazardous, radioactive wastes are unlikely to have any environmental impact. 
Job Control Waste. In addition to the equipment and waste materials removed from the facility during the decommissioning, there will be "job control waste". This waste will include things such as plastic sheets, cloths, protective clothing and small tools which are used during the course of the work. Most of this material will fall into the categories of radioactive, non-hazardous waste or nonradioactive, non-hazardous waste. Quantities will be small compared to other waste materials generated during the work.

Merits of Off-Site Disposal of Wastes. The foregoing discussion indicates that most waste materials would be disposed of on-site. In some cases off-site disposal could prove to be more economical. Should the DOE realize a cost savings for off-site disposal - either in terms of direct project costs or the life cycle cost of waste disposal and management - then off-site disposal may be undertaken. If this is done, the off-site shipments would be unlikely to have any environmental impact.

\subsubsection{Cumulative Impacts}

The total potential environmental impacts which would be associated with the HWCTR decommissioning are small. Each alternative entails negligible potential impacts on water quality, air quality, soils, terrestrial biota and endangered or threatened species. The socioeconomic impacts of each alternative would also be minor. Off-site impacts would be minimal and limited to those associated with transportation of radioactive materials and wastes of types and quantities which are routinely shipped around the country.

Cumulative impacts result from the incremental impact of the HWCTR decommissioning when added to other past, present and foreseeable future actions at SRS. Considered in the context of such actions, the principal cumulative effects of the HWCTR decommissioning are positive ones - to eliminate or reduce a radiological hazard in a part of the site designated for administrative use in future years and to serve as a pilot program for decommissioning of other nuclear reactors at the site. The impacts associated with transportation and disposal of wastes from the decommissioning have already been taken into account in reference 3 .

\subsection{Effectiveness of Each Alternative}

In sections 5.7 through 5.10 , the effectiveness of each removal alternative is addressed. Effectiveness is considered in terms of:

- Environmental protection,

- The health and safety of workers and the public,

- The Applicable or Relevant and Appropriate Requirement, or ARARs, and

- The achievement of the removal objectives of section 4.1 . 


\subsection{Environmental Protection}

\subsubsection{Policy}

The HWCTR Decommissioning Project Plan, reference 2, summarizes the policy of DOE and WSRC regarding compliance with all environmental laws and regulations and all national environmental goals.

As noted previously, the HWCTR decommissioning will be carried out as a non-time critical removal action under the Comprehensive Environmental Response, Compensation and Liability Act. HWCTR will be the first decommissioning project at SRS carried out in this fashion. Section 5.9 identifies the Applicable or Relevant and Appropriate Requirements associated with environmental laws which will apply to the HWCTR project.

\subsubsection{Implementation}

Compliance with both federal and state regulations will be implemented through a series of programs and procedures specifically written to address the regulatory requirements. The principal document used to ensure that this policy is carried out will be the HWCTR Decommissioning Plan.

\subsubsection{Dismantlement}

Potential environmental impacts of the dismantlement approach include those associated with (1) the removal of radioactive equipment and structural materials and dismantlement of the structure, (2) the transportation of the radioactivity to waste disposal or recycling facilities and (3) the disposal of radioactive waste in the SRS disposal facilities. Once the dismantlement is completed, and final radiological surveys verify that the applicable cleanup standards have been met, there would be no significant environmental impact on the site property since it will have been effectively restored to its pre-construction state.

In section 5.5, the potential environmental impacts which could be associated with the decommissioning were considered in detail and found to be small.

\subsubsection{Partial Dismantlement and Interim Safe Storage}

Potential environmental impacts associated with this decommissioning alternative include (1) those connected with removal of radioactive equipment, (2) those from transporting radioactive materials, (3) those at the waste disposal facilities and (4) those from radioactive materials which remain inside of the reactor building.

The review described in section 5.5 of potential environmental impacts which could be associated with the decommissioning showed that the potential impacts of this alternative would be small. 


\subsubsection{Partial Dismantlement and Beneficial Reuse}

Potential environmental impacts associated with this approach include (1) those related to equipment removal, (2) those from transportation of radioactive material, (3) those at the waste disposal facilities, (4) those from the radioactivity remaining in the facility and (5) those related to storage of the waste in the building.

The discussion in section 5.5 shows that the potential environmental impacts which could be associated with the decommissioning work would be small.

The potential environmental impact associated with storage of material in the facility would obviously depend on the type and amount of material. Since this study addresses a generic waste storage scenario, assumptions must be made to estimate the potential environmental impact of storing waste materials in the HWCTR containment building. If one makes the assumption that transuranic wastes would be stored in the building, similar to the EBWR plan, an estimate can be made of the potential environmental impact, drawing on the EBWR experience.

An evaluation of the potential environmental impacts of the EBWR transuranic waste storage plan was performed as part of an environmental assessment of proposed upgrading of waste storage facilities at Argonne National Laboratory. This study indicated that the proposed actions would not adversely affect the surrounding environment. It concluded that the environmental consequences of the related construction work would be localized to the building site and that the environmental impact of operations would be minimal.

\subsubsection{Entombment}

With the entombment approach, all of the radioactivity would be fixed in a concrete structure and the external dose rate would be essentially background. The tomb would be approximately 60 feet deep and 70 feet in diameter. Approximately three feet of the tomb would protrude above grade.

As indicated in section 5.5, the potential environmental impacts which could be associated with this alternative would be small.

\subsection{Health and Safety of Workers and the Public}

Measures to be taken to protect the health and safety of workers and the public during the HWCTR decommissioning are outlined in reference 2. In this section, these measures are summarized, then differences related to health and safety among the four alternatives are discussed.

\subsubsection{Physical Security}

Physical security for the HWCTR facility is provided at several levels. First, the general public is excluded because the facility is on the SRS government reservation, with armed 
guards providing access control to the site. Second, the HWCTR property is surrounded by a chain link fence with appropriate security measures such as locks, warning signs, and key control by the facility custodian. These arrangements prevent access except by authorized project personnel or by visitors escorted by authorized personnel. Third, the entrances to each of the buildings at the HWCTR are secured by door locks, which are under the control of the custodian. Fourth, access by authorized personnel is administratively controlled by WSRC Procedure RP 18.0201, Inactive/Surplus Facilities Access Control.

\subsubsection{Occupational Safety and Health}

Health and safety of site project personnel would be controlled by adherence to WSRC Manuals 4Q, Industrial Hygiene, and 8Q, Employee Safety Manual. A Health and Safety Plan specifically for the HWCTR would be in effect. Also, 29 CFR 1926 Occupational Safety and Health Administration Standards for Construction, and 29 CFR 1910 Occupational Safety and Health Administration Standards for General Industry would apply. Where variances to these requirements are necessary, they will be pursued in accordance with DOE Order 5483.1A, Occupational Safety and Health Program for DOE Contractor Employees at Government-Owned and Contractor-Operated Facilities.

Occupational safety and health of decommissioning subcontractor personnel will also be controlled by adherence to standards similar to those listed above.

Industrial hygiene and safety support will be provided by the decommissioning subcontractor. Safety oversight will be provided by the WSRC Occupational Safety and Hygiene Department.

\subsubsection{Radiation Protection}

All radiological work at HWCTR will be performed in accordance with the SRS radiological protection program, as specified in the WSRC 5Q Manual, Radiological Control, or equivalent standards used by the decommissioning subcontractor. The WSRC program complies with the following requirements:

- 10 CFR 835 - Occupational Radiation Protection,

- DOE/EH-0256T - US DOE Radiological Control Manual,

- DOE Order 5400.5 - Radiation Protection of the Public and the Environment, and

- DOE Order 5480.11 - Radiation Protection for Occupational Workers.

Elements of the SRS radiological control program include careful planning of the work, using only skilled and trained workers, briefing the workers, following detailed procedures and oversight by qualified radiological control personnel. 


\subsubsection{Minimizing Worker Radiation Exposure}

The HWCTR project will have a formal program to ensure that radiation exposure associated with decommissioning operations is kept as low as reasonably achievable. Elements of this program will include establishing a Radiological Awareness Committee, conducting formal pre-job reviews and monitoring actual radiation exposure to identify trends and needed improvements.

Estimates of the approximate personnel radiation exposure associated with the different approaches are as follows:

- Dismantlement: 4 person-rem,

- Partial dismantlement and interim safe storage: 2 person-rem,

- Partial dismantlement and beneficial reuse: 4 person-rem, and

- Entombment: 1 person-rem.

These estimates are consistent with those of Table 1 which were made in 1976, when radioactive decay of cobalt- 60 , the chief source of external radiation exposure, is taken into account.

\subsubsection{Emergency Preparedness}

The WSRC SCD-7 Manual, SRS Emergency Plan, describes the SRS emergency response program. The HWCTR Facility Custodian will be responsible for the implementation of this plan.

\subsection{The Applicable or Relevant and Appropriate Requirements}

These requirements referred to as ARARs, consist of those cleanup standards, standards of control, and other substantive requirements, criteria or limitations promulgated under federal environmental, state environmental or SRS siting laws that specifically address a hazardous substance, pollutant, contaminant, remedial action, location or other circumstance found at a CERCLA site.

The Applicable or Relevant and Appropriate Requirements for the HWCTR project include:

- The Comprehensive Environmental Response, Compensation and Liability Act (CERCLA)

- The Clean Air Act of 1970 (CAA),

- The Clean Water Act of 1977 (CWA), 
- The Safe Drinking Water Act of 1974 (SDWA),

- The Resource Conservation and Recovery Act (RCRA),

- The Toxic Substances Control Act of 1976 (TSCA), and

- The Superfund Amendment and Reauthorization Act of 1986 (SARA).

Other federal regulations and DOE Orders which apply to the HWCTR project are listed in the DOE Decommissioning Handbook. In addition to federal regulations, the state of South Carolina has promulgated regulations that, in many cases, augment or exceed the requirements of the federal regulations. In such instances, the state regulations will govern the HWCTR project along with any required federal regulation. And, as noted previously, the U. S. Environmental Protection Agency's new radiation cleanup standard will apply to the HWCTR project when it goes into effect.

In accordance with DOE and WSRC policy, these regulations will be complied with, no matter which alternative is selected for the HWCTR decommissioning.

\subsection{The Achievement of Removal Objectives}

The HWCTR removal objectives are described in paragraph 4.1. Briefly, the seven objectives are: (1) minimizing risks, (2) providing flexibility for future uses of the property, (3) minimizing capital costs, (4) minimizing future surveillance and maintenance, (5) recycling materials as much as practicable, (6) providing information for the follow-on reactor decommissioning work at SRS, and (7) minimizing radioactive waste stream volumes where economically feasible.

\subsubsection{Dismantlement}

(1) The dismantlement approach would entail low risks to both the workers and the public, as explained in section 5.4 .

(2) It would provide maximum flexibility for future uses of the property by releasing the site for unrestricted use.

(3) The capital costs would be relatively high, as discussed in section 5.14 .

(4) Future surveillance and maintenance would be eliminated.

(5) Recycling of materials would be maximized since all equipment would be removed from the facility and available for recycling.

(6) This approach would provide extensive information for follow-on projects because it entails complete dismantlement, including removal of the reactor vessel. Procedures 
used and methods developed for the HWCTR could be adapted to the larger SRS production reactors in many cases.

(7) This approach would generate more waste stream volume than the others.

\subsubsection{Partial Dismantlement and Interim Safe Storage}

(1) This approach also would entail low risks to both the workers and the public, as explained in section 5.4 .

(2) It would provide less flexibility for future uses of the property than the dismantlement approach because the site would not be released for unrestricted use.

(3) The capital costs would be less than for complete dismantlement, as discussed in section 5.14.

(4) Future surveillance and maintenance would be minimal, with inspections inside of the facility at approximately five-year intervals.

(5) Recycling of materials would be significant since most equipment would be removed from the facility and available for recycling.

(6) This approach would provide extensive information for follow-on projects. Many of the procedures used and methods developed could be adapted to the larger SRS production reactors.

(7) The waste stream volumes with this approach is lower than with dismantlement.

\subsubsection{Partial Dismantlement and Beneficial Reuse}

(1) This approach also would entail low risks to both the workers and the public, as explained in section 5.4 .

(2) It would provide no flexibility for future uses of the property other than storage.

(3) The capital costs would be substantial, as discussed in section 5.14.

(4) Future surveillance and maintenance costs would be significant, since the facility would still be in use.

(5) Recycling of materials would be significant as with the dismantlement approach, since all equipment would be removed from the facility and available for recycling.

(6) This approach would provide extensive information for follow-on projects. Many of the procedures used and methods developed could be adapted to the larger SRS production reactors. 
(7) The volumes of waste streams with this approach would be lower than with dismantlement but higher than with the other alternatives.

\subsubsection{Entombment}

(1) Like the others, this approach also would entail low risks to both the workers and the public, as explained in section 5.4 .

(2) It would provide some flexibility for future uses of the property, even though the entombment would require minimal controls.

(3) The capital costs would be less than for the other approaches, as discussed in section 5.14 .

(4) Future surveillance and maintenance would be minimal.

(5) Recycling of materials would be less significant as with the other approaches, since most of the equipment would not be available for recycling.

(6) This approach would provide less information for follow-on projects than would the other alternatives, although some of the procedures used and methods developed could be adapted to the larger SRS production reactors.

(7) The waste stream volumes would be low with this approach.

\subsection{Ease of Implementation}

\subsubsection{Technical Feasibility}

Experience has shown that all alternatives are technically feasible. Ample precedents exist, including the examples cited in section 5.1.

Detailed information on decontamination and decommissioning technologies appears in a number of sources, such as the DOE Decommissioning Handbook. The national and international literature on this subject is available through DOE's information clearinghouse the Remedial Action Program Information Center in Oak Ridge, Tennessee.

The development of innovative technologies for nuclear decontamination and decommissioning work is sponsored by DOE through several initiatives, including its Morgantown Energy Technology Center in Morgantown, West Virginia, which is presently sponsoring two nuclear reactor decommissioning projects in the DOE weapons complex. These are the 105-C Reactor decommissioning at Hanford, Washington and the CP-5 Reactor decommissioning at the Argonne National Laboratory in Illinois. Experience gained from both of these projects will become available for the HWCTR project. 


\subsubsection{Equipment, Personnel, and Support Services Availability}

Special equipment needed to decommission the HWCTR is available, regardless of the option chosen. Such equipment includes:

- A 125-ton minimum capacity mobile crane,

- Special lifting and handling equipment for components such as the reactor vessel and steam generators,

- Concrete removal equipment,

- Metal segmenting equipment to cut up structural steel, piping, tanks, etc.

- Surface decontamination equipment for purposes such as removing paint containing lead or PCBs.

There are a number of firms in the United States that are experienced in nuclear facility decontamination and decommissioning work.

Support services needed for the decommissioning work are readily available. These include:

- Analytical laboratory services,

- Radiological control technician services,

- Rigging and handling services,

- Radioactive piping cutting services,

- Radioactive concrete cutting services, and

- Radioactive facility demolition services.

\subsubsection{Administrative Feasibility of Licenses and Easements}

There are no known licenses that currently apply to SRS that would influence this alternatives study or its implementation during decommissioning of the HWCTR facility. Nor has any future licensing need which would impact the decommissioning been found.

Likewise, there are no known easements that currently apply at SRS which would influence this alternatives study or its implementation. And no future easement been found which would impact the decommissioning. 


\subsection{Nature and Amount of Waste Generated}

\subsubsection{Types of Wastes}

Different types of waste materials that will be generated during the decommissioning work include:

- Low-level radioactive waste,

- Hazardous waste such as that containing lead, PCBs and asbestos,

- Mixed waste that is both hazardous and radioactive,

- Nonradioactive solid waste.

Although transuranic radionuclides such as plutionium-239 are present in the HWCTR in trace amounts, the concentrations are low enough to preclude having to classify any waste materials as transuranic waste.

\subsubsection{The Form of the Waste Materials}

The HWCTR project waste will include:

- Various pieces of equipment such as the reactor vessel assembly, steam generators, pumps, tanks, heat exchangers, lead-shielded casks, etc. Appendix B lists approximately 75 different items, along with their location, size, weight and other information. Nearly all of this equipment is expected to be radioactive. Decontamination to permit unrestricted release will likely not be cost effective. Note that much of this equipment can be recycled to recover usable metals as explained in section 5.13.

- Radioactive concrete. The inside of the biological shield is radioactive from neutron activation. Concrete on the floors is contaminated, especially in crevices.

- Radioactive imbedded piping. Piping that pierces the concrete biological shield is radioactive. It would be removed in the dismantlement alternative. Piping associated with floor drains is also radioactive. Some of this runs through the spent fuel basin shield wall. All radioactive imbedded piping would be removed with the dismantlement approach.

- Radioactive ventilation equipment. It is anticipated that all of the building ventilation ducting and other ventilation equipment will prove to be radioactive. 
- Radioactive structural steel. Some structural steel in the facility is radioactive. Most of this material can be recycled. The dome itself contains approximately 170 tons of structural steel. With the dismantlement and entombment approaches, the dome would be taken apart.

- Job-control waste. These waste materials will be produced during the decommissioning work. They will include things such as rags, plastic radiological containments and small tools.

No contaminated soil is included in estimates related to the HWCTR decommissioning because soil remediation, should any become necessary, will be handled as a separate environmental restoration activity.

\subsubsection{Waste Packaging}

The radioactive and mixed waste will be packaged in accordance with the WSRC IS Manual Waste Acceptance Criteria. It is expected that much of this material will be packaged in B25 boxes, standard carbon steel containers which are six feet long, four feet wide and four feet high. Each B-25 box will hold up to 98 cubic feet of waste. The maximum allowable weight of 5000 pounds per box will be a limiting factor for some materials. For example, only 33 cubic feet of concrete weighing 150 pounds per cubic foot could be put into a single B-25 box. Figure 32 shows B-25 boxes.

Other large containers such as "sea-land containers" would be used as practicable to minimize segmenting of equipment and structural steel for recycling. These containers are typically 20 or 40 feet long. Such containers would be use to transport the material to the recycling facility, but they cannot be used for disposal of radioactive waste.

Medium-sized equipment such as heat exchangers, coolers and small tanks would be segmented as necessary and placed in containers for disposal or recycling. Large equipment such as the reactor vessel and steam generators, if removed under the dismantlement or partial dismantlement and beneficial reuse alternatives, are expected to be sealed by welding steel blanks over nozzle openings, so that they, in effect, serve as their own strong, tight containers.

An important factor related to packaging of waste is to ensure that it has been accurately characterized. The detailed characterization program completed in 1996 provided data for this purpose. Additional characterization of waste materials will be performed in accordance with a Waste Stream Characterization Plan. Lessons learned in site decommissioning programs, such as in the decommissioning of Building 232-F, were factored in the 1996 HWCTR detailed characterization effort and the HWCTR Waste Stream Characterization Plan. 


\subsubsection{Waste Disposal Sites}

Present plans call for the low-level radioactive waste associated with the HWCTR project to go to SRS disposal facilities. All low-level waste except for large equipment would go into the E-Area Vaults. This facility is shown in Figure 33.

Large radioactive equipment would likely be sent to the SRS Solid Waste Disposal Facility for shallow land burial in engineered trenches, such as the one shown in Figure 32.

Note that plans for on-site disposal of waste are subject to change if off-site disposal proves to be more economical.

Mixed waste would be stored at SRS in an approved mixed waste storage facility pending disposition under the Federal Facility Compliance Act. It is expected that the HWCTR mixed waste will be processed under the SRS Mixed Waste Approved Site Treatment Plan. Hazardous waste would be disposed of by a hazardous waste contractor at a suitable treatment-storage-disposal facility.

These plans are consistent with those expressed in the SRS Waste Management Final Environmental Impact Statement of July 1995. This document contains more information on waste disposal options.

\subsubsection{Waste Minimization Program}

A variety of methods will be used to minimize waste associated with the HWCTR decommissioning, among them:

- Material taken into the facility which might become waste during the decommissioning work will be kept to a minimum,

- Waste materials will be segregated into different waste types as much as practicable as they are generated,

- Commercially available size reduction techniques such as supercompaction, metal melting and incineration will be used to reduce waste volume, and

- Metals such as stainless steel, carbon steel and lead will be recycled as much as practicable.

These methods are consistent with waste management practices described in reference 3 .

\subsubsection{Dismantlement}

Approximate waste volumes for the dismantlement alternative would be in the range of: 
- Low-level radioactive waste: 19,250 cubic feet. Radioactive concrete from the biological shield would make up approximately 3800 cubic feet of this amount. Approximately 540 cubic feet of contaminated concrete would be removed from floors in the facility

- Mixed waste (both hazardous and radioactive): 280 cubic feet,

- Non-radioactive solid waste: 24,800 cubic feet with the underground structure removed to minus five feet, 40,300 cubic feet with the structure removed to minus 16 feet and 72,400 cubic feet if all of the underground structure were removed.

These estimates are based on the following assumptions:

- Eighty percent of equipment and piping in the facility, by volume, is radioactive.

- Radioactive equipment includes the reactor vessel assembly, the steam generators, the entire steam system including the muffler, the underground tank, and most piping and equipment in fluid systems.

- An average depth of eight inches of concrete in the biological shield surrounding the core region is radioactive,

- Concrete floors are radioactive to an average depth of two inches,

- Estimates for concrete are based on disposal volume in B-25 boxes considering the 5000 pound per box weight limit, except for the lower axial biological shield,

- The 170-ton steel dome is not radioactive,

- An average of approximately seven cubic feet of incidental low level radioactive waste would be generated each day during removal of radioactive equipment (a type of waste commonly called job control waste), and

PCB waste and other hazardous wastes would also be generated.

These estimated waste volumes can be accommodated in the SRS disposal facilities planned for use. They are consistent with estimates for future site facility decontamination and decommissioning work contained in the SRS Waste Management Final Environmental Impact Statement. More detailed information on these estimates, and the ones which follow, will be available from WSRC.

\subsubsection{Partial Dismantlement and Interim Safe Storage}

This alternative would entail removing all of the equipment except the reactor vessel and the two steam generators. The dome would remain in place. 
Approximate waste volumes for this alternative would be in the range of:

$\because \quad$ Low-level radioactive waste: 5,400 cubic feet,

- Mixed waste: 280 cubic feet,

- Non-radioactive solid waste: 2,850 cubic feet.

These estimates are based on assumptions similar to those used in the dismantlement alternative estimate, taking into account differences between the two approaches. PCB waste and other hazardous wastes would also be generated.

These estimated waste volumes, less than for the dismantlement alternative, can be accommodated in the SRS disposal facilities planned for use on the HWCTR project.

\subsubsection{Partial Dismantlement and Beneficial Reuse}

This option would entail approximately 60 percent of the equipment removal associated with the complete dismantlement alternative. The dome would remain in place, along with embedded radioactive piping. Decontamination of areas such as concrete floors would be limited to that necessary to establish radioactive material storage area controls.

Approximate waste volumes for this alternative would be in the range of:

- Low-level radioactive waste: 11,600 cubic feet,

- Mixed waste: 280 cubic feet,

- Non-radioactive solid waste: 2,200 cubic feet.

These estimates are based on assumptions similar to those used in the dismantlement and partial dismantlement and interim safe storage waste estimates, taking into account difference between the approaches.

PCB waste and other hazardous wastes would also be generated.

These estimated waste volumes, less than for the dismantlement alternative, can be accommodated in the SRS disposal facilities planned for use on the HWCTR project.

\subsubsection{Entombment}

This alternative generates the least amount of waste to be removed and disposed of. Only the hazardous materials and mixed waste, and equipment above the 0 -level floor would be removed, along with the containment dome.

Approximate waste volumes for this alternative would be in the range of: 
- Low-level radioactive waste: 2,380 cubic feet,

- Mixed waste: 280 cubic feet,

- Non-radioactive solid waste: 8,800 cubic feet.

These estimates are based on assumptions similar to those used in the other waste estimates, taking into account differences between the approaches.

PCB waste and other hazardous wastes would also be generated.

\subsection{Material Recycle and Reuse Opportunities}

\section{S.13.1 Reuse Opportunities}

There are no significant opportunities for reuse of the HWCTR equipment, given its age and condition. Possible reuse of the building itself for another purpose is addressed in the partial dismantlement and beneficial reuse alternative.

\subsubsection{Recycle Opportunities}

Potential metal recycling opportunities include:

- Carbon steel and stainless steel piping,

- Structural steel including the containment dome,

- The steam generators,

- The refueling machine (transfer coffin),

- Heat exchangers and coolers,

- Lead-shield casks,

- Stainless steel deionizer and filter vessels,

- Some lead bricks and lead sheet,

- The 7165-gallon heavy water tank, the 15,000-gallon emergency deluge tank, the 8000gallon underground waste water tank and smaller tanks,

- The steam muffler, and 
- The ventilation exhaust stack.

This list is not all inclusive; other equipment could be recycled as well. Note that the radioactive equipment and material, which includes most items listed, would have to be recycled by a commercial vendor licensed for such work.

The most opportunities for recycling would be realized if the dismantlement alternative were chosen. The entombment alternative would offer the fewest opportunities for recycling.

Note that in mid-1996, disposal of radioactive recyclable metals at SRS as low level radioactive waste was less costly than recycling them.

\subsection{Cost}

\subsubsection{Methodology For Cost Estimates}

An activity-based cost approach was used. Each major task was divided into its individual cost components. Where appropriate, tasks were further divided into subtasks. Crew labor composition, equipment necessary and material costs were detailed on each task estimate worksheet.

Markups were applied to the estimates for overhead, profit, bonds and contingencies. Percentages for markups were: overhead 20 percent, profit 10 percent, bond three percent and contingency 20 percent. These figures were based on cost engineering judgment and experience.

The estimates, which are in 1996 dollars, are considered conceptual because work plans for the project are not yet developed.

\subsubsection{Cost Estimates for Each Alternative}

Table 6 on the next page shows the costs of the four different alternatives.

The dismantlement alternative costs are estimated to be:

- Option 1 - structure removal to minus five feet: $\$ 15,000,000$,

- Option 2 - structure removal to minus 16 feet: $\$ 16,000,000$,

- Option 3 - removal of entire underground structure: $\$ 23,000,000$.

The cost of the partial dismantlement and interim safe storage alternative is estimated to be:

- Option 1 - steam generators removed: $\$ 8,500,000$,

- Option 2 - steam generators remain in place: $\$ 8,200,000$.

WSRC-TR-96-0268 
The partial dismantlement and beneficial reuse alternative is estimated to cost $\$ 14,000,000$. This figure does not include the expenses associated with establishing the facility as a storage area. These costs would add an amount in the range of $\$ 2.6$ million, based on the cost of setting up the former EBWR containment building as a storage facility for transuranic waste.

\section{Table 6 Costs of Different Alternatives}

\begin{tabular}{|c|c|c|c|c|}
\hline Task & Dismantle & PD\&ISS* & Reuse & $\overline{\text { Entomb }}$ \\
\hline Mobilization at site & $\$ 95,746$ & $\$ 95,746$ & $\$ 95,746$ & $\$ 95,746$ \\
\hline Refurbish polar crane and place in service & 122,428 & 122,428 & 122,428 & N/A \\
\hline Remove radioactive equipment & 765,877 & 538,291 & 197,504 & 152,780 \\
\hline Remove all equipment above 0 -level & 72,315 & N/A & N/A & 72,315 \\
\hline Modify dome for large equipment removal & 17,560 & 17,560 & 17,560 & 17,560 \\
\hline Remove steam generators & 263,626 & $\bar{N} / \mathrm{A}$ & 263,626 & N/A \\
\hline Seal steam generators by welding & 87,876 & 87,876 & 87,876 & 87,876 \\
\hline Remove reactor vessel & 507,808 & N/A & 507,808 & N/A \\
\hline Seal reactor vessel by cutting and welding & 217,769 & 217,769 & 217,769 & 217,769 \\
\hline Remove lead-based paint & 0 & 0 & 0 & 0 \\
\hline Remove PCBs & $\overline{174,314}$ & 174,314 & 174,314 & 174,314 \\
\hline Remove other hazardous material & $\overline{174,314}$ & 174,314 & 174,314 & 174,314 \\
\hline Decontaminate concrete & 157,807 & 23,476 & 104,334 & N/A \\
\hline Remove activated concrete in bioshield & 132,616 & N/A & 132,616 & $\overline{N / A}$ \\
\hline Remove structure to -5 feet & 449,953 & $\mathrm{~N} / \mathrm{A}$ & N/A & N/A \\
\hline Remove structure to -16 feet & 835,889 & N/A & N/A & N/A \\
\hline Remove structure to -52 feet & $2,879,642$ & N/A & N/A & N/A \\
\hline Remove underground tank & 51,110 & 51,110 & 51,110 & 51,110 \\
\hline Remove muffler and underground steam line & 212,562 & 212,562 & 212,562 & 212,562 \\
\hline Remove ventilation exhaust stack & 230,103 & 230,103 & 230,103 & 230,103 \\
\hline Remove radioactive imbedded piping & 335,451 & N/A & 335,451 & N/A \\
\hline Remove containment dome & 688,837 & $\bar{N} / \mathrm{A}$ & N/A & 688,837 \\
\hline Restore patch in containment dome & N/A & 199,741 & 199,741 & $\overline{N / A}$ \\
\hline Seal all building openings & N/A & 12,001 & N/A & N/A \\
\hline Establish remote monitoring equipment & $\bar{N} / \mathrm{A}$ & 256,320 & $\mathrm{~N} / \mathrm{A}$ & $\mathrm{N} / \mathrm{A}$ \\
\hline Bring building up the latest codes for reuse & N/A & $\bar{N} / \mathrm{A}$ & $3,525,813$ & N/A \\
\hline Modify building to support reuse & $\bar{N} / \mathrm{A}$ & N/A & N/A & $\mathrm{N} / \mathrm{A}$ \\
\hline Waste disposal - option $1,-5$ feet (baseline) & $5,518,009$ & $1,849,912$ & $3,358,162$ & $2,560,411$ \\
\hline Waste disposal - option $2,-16$ feet & $6,453,123$ & $\bar{N} / \mathrm{A}$ & N/A & N/A \\
\hline Waste disposal - option $3,-52$ feet & $11,525,428$ & $\bar{N} / \mathrm{A}$ & N/A & N/A \\
\hline Backfill cavity with concrete & $\mathrm{N} / \mathrm{A}$ & N/A & N/A & 597,105 \\
\hline Backfill cavity with earth & 121,829 & N/A & N/A & 121,829 \\
\hline Seal entombment with waterproof membrane & $\mathrm{N} / \mathrm{A}$ & $\overline{N / A}$ & N/A & 18,952 \\
\hline Final radiological survey & $2,162,519$ & $1,621,998$ & $1,621,998$ & 261,549 \\
\hline
\end{tabular}




\begin{tabular}{|l|r|r|r|r|}
\hline Task & Dismantle & PD\&ISS $^{\star}$ & Reuse & Entomb \\
\hline SRS engineering and planning support & $2,066,355$ & $2,066,355$ & $2,066,355$ & $2,066,355$ \\
\hline Other costs & 630,257 & 643,795 & 630,257 & 706,074 \\
\hline & & & & \\
\hline Total cost for each alternative* & $\mathbf{\$ 1 5 , 0 0 0 , 0 0 0}$ & $\mathbf{\$ 8 , 5 0 0 , 0 0 0}$ & $\mathbf{\$ 1 4 , 0 0 0 , 0 0 0}$ & $\mathbf{\$ 8 , 5 0 0 , 0 0 0}$ \\
\hline
\end{tabular}

*PD\&ISS is Partial Dismantlement and Interim Safe Storage. ${ }^{* *}$ Note that the total costs are for the baseline cases. The cost totals were rounded off to reflect the lack of precision in these conceptual estimates, which were prepared for comparison purposes, based on preliminary information.

The cost of the entombment alternative is estimated to be:

- Option 1 - cavity filled with concrete: $\$ 8,500,000$,

- Option 2 - Cavity filled with earth: $\$ 8,000,000$.

\subsubsection{Assumptions Used in Making Cost Estimates}

The following assumptions were made in preparing cost estimates for the different alternatives:

- The underground tank, the steam muffler and the steam line leading to it would be removed in each of the four alternatives studied because these actions are considered to be appropriate to achieve the general end condition criteria of Section 4.2.

- These will be no impact on the HWCTR decommissioning from possible environmental restoration activities in the vicinity,

- The 12-foot wide, 17-foot high opening in the containment building will have to be further enlarged to facilitate removal of large equipment such as the reactor vessel and steam generators

- Refurbishment of the 25-ton polar crane would prove cost effective compared to use of other lifting apparatus for removing equipment,

- Waste volumes would be as estimated in section 5.12 ,

- $\quad$ Equipment would be recycled as described in section 5.13.2.

\subsection{Schedule}

\subsubsection{Dismantlement}

The schedule for the dismantlement alternative appears in Appendix C. Please note the following points: 
- It is divided into five broad phases.

- Phase I, which entailed demolishing outbuildings, has been completed.

- Phase II is presently underway, with tasks 5 through 8 completed. It is scheduled for completion with selection of the preferred decommissioning alternative by September 30 , 1996.

- Phase III would start with the beginning of FY 97 and end 24 months later with removal of all piping and equipment completed, except for the reactor vessel, steam generators and large pumps.

- Phase IV, which would entail removal of the large equipment, would start on October 1, 1998 and complete on March 1, 2000.

- Phase V would extend from January 1, 1999 until September 30, 2002, ending with dismantlement completed and the property in a "greenfield" condition.

Overall, the planning and preparation portions of the project would take approximately three years and three months, with most of this period already completed. The execution phases would span five years and six months. This schedule is similar to the one which appears in the Decommissioning Project Plan, reference 2. It also is comparable to the actual completion schedule for the EBWR decommissioning project.

\subsubsection{Partial Dismantlement and Interim Safe Storage}

Appendix D shows the schedule for this approach. Note that:

- Phases I and II are identical to the dismantlement alternative.

- Phase III runs until October 1, 1998, as with the dismantlement alternative.

- Phase IV, which entails isolating the reactor vessel and steam generators, overlaps Phase III, proceeding from April 1, 1998 until January 1, 1999.

- Phase V, which completes the cocooning of the reactor ends on May 15, 2000.

With this alternative, the planning and preparation work schedule is similar to the schedule for dismantlement. The execution phases of the partial dismantlement and interim safe storage process would take approximately three years, one and one-half months.

\subsubsection{Partial Dismantlement and Building Reuse}

Appendix E shows the schedule for this approach. Note that: 
- Phases I and II are identical to the dismantlement alternative.

- Phase III runs until October 1, 1998, as with the dismantlement alternative.

- Phase IV, as with the dismantlement alternative, proceeds from October 1, 1998 until March 1, 2000.

- Phase V, which ends with materials stored in the facility, finishes on May 1, 2002.

With this alternative, the planning and preparation work schedule is similar to the schedule for dismantlement. The execution phases would take approximately five years and one month.

\subsubsection{Entombment.}

Appendix F shows the schedule for the entombment approach. Note that:

- As before, phases I and II are identical to the dismantlement alternative.

- Phase III runs until January 30, 1998.

- Phase IV - removing the underground tank, the muffler, the underground steam line and the dome - proceeds from February 2, 1998 until July 1, 1998.

- Phase V, which includes filling the cavity with concrete, finishes on June $1,1999$.

With this alternative, the planning and preparation work schedule is similar to the others. The execution phases would take approximately two years and two months.

\subsection{REMOVAL ALTERNATIVE COMPARATIVE ANALYSIS}

Table 7 on the next page reflects the results of the analysis, ranking the alternatives in 11 different areas. These areas include those which reference 1 recommends taking into account: effectiveness, "implementability" and cost. The highest total represents the optimum alternative. 


\section{Table 7 Ranking of Alternatives Studied}

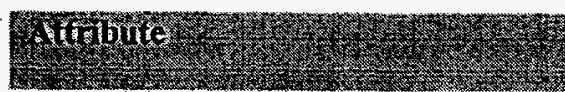

1. Protects environment

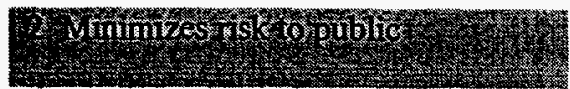

3. Minimizes risk to workers

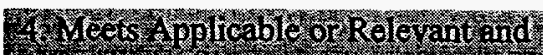

W. Apropiate Requirements

5. Flexibility in future use of property

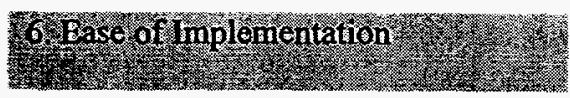

7. Minimizes capital costs

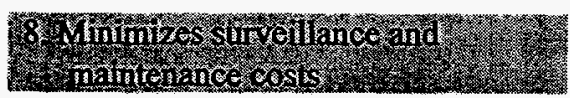

9. Minimizes scheduled time for accomplishment

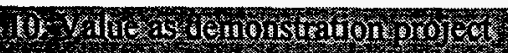

11. Recycles materials

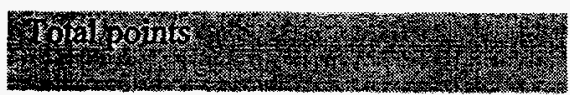

Total points (weighted)

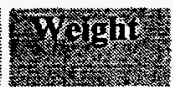

4

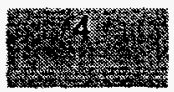

3

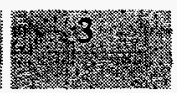

3

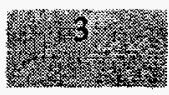

4

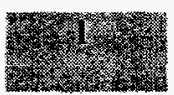

2

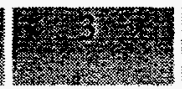

1

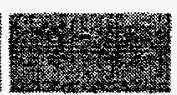

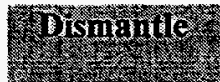

4

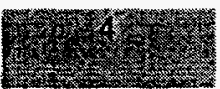

2

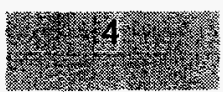

4

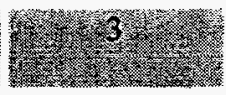

2

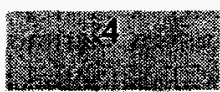

2

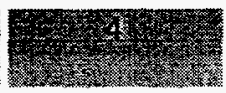

4

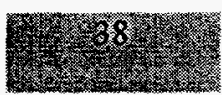

103

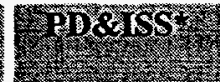

2

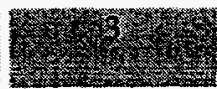

3

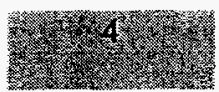

2

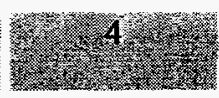

4

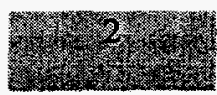

3

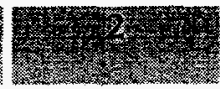

3

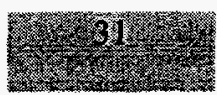

92

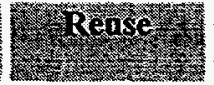

2

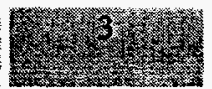

2

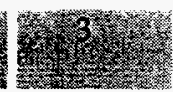

4

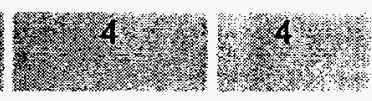

2

2

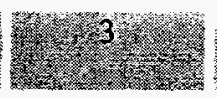

2

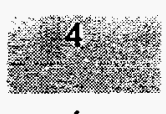

4

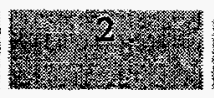

2

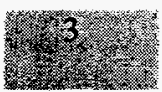

4

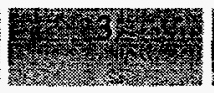

3

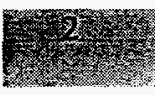

2

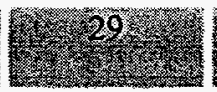

79

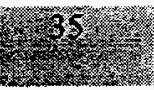

101

* PD\&ISS is Partial Dismantlement and Interim Safe Storage.

Note that this table assigns relative weights of either one, two, three or four to each attribute, depending upon its importance. The alternatives are ranked from one to four to reflect the degree to which each attribute satisfies the removal action objectives, with four being the highest value.

\subsection{Protecting the Environment}

Because only moderate amounts of radioactive materials remain in the HWCTR, and considering that handling of this material will be closely controlled as explained previously, all four approaches protect the environment well.

The dismantlement alternative, the only approach which would result in an unrestricted release of the property, ranks highest in this category. One can consider that the radioactivity in the HWCTR facility is merely being moved from one part of the SRS to another, to E-Area. But E-Area has been devoted to radioactive waste storage and the 
radioactive waste from the HWCTR project would make up only a small fraction of the amount disposed of there. The disposal of radioactive waste in E-Area has been evaluated in detail in connection with the SRS Waste Management Final Environmental Impact Statement.

The partial dismantlement and interim safe storage and the beneficial reuse options rank lowest in protecting the environment because radioactivity remains on the HWCTR property in both cases. The entombment approach was assigned a medium value because of the durability of the concrete monolith in which the radioactivity would be imbedded.

\subsection{Minimizing Risks to the Public}

Each alternative would do an effective job of minimizing risks to the public. Risk to the public would be low in every case because the HWCTR facility contains only moderate amounts of radioactive materials and it is located three miles from the nearest SRS property boundary. The results of studying risks inherent with the decommissioning work as described in section 5.4 reflect this conclusion.

Once again, the dismantlement approach ranks highest because it would leave the site with no significant residual radioactivity; radioactivity would remain on the property in each of the other cases

\subsection{Minimizing Risks to Workers}

Risks to those performing the decommissioning work would be low with any alternative as discussed in section 5.4. Such risks come chiefly from the industrial activity involved and the occupational radiation exposure to the workers.

Entombment ranks highest in this category because it would entail the least work and the lowest worker radiation exposure. The dismantlement and beneficial reuse approaches rank lowest because the opposite is true in those cases. Partial dismantlement and interim safe storage ranks in between.

\subsection{Meeting Requirements}

All alternatives would satisfy the Applicable or Relevant and Appropriate Requirements identified in section 5.9 .

\subsection{Flexibility in Use of the Property}

The dismantlement alternative ranks highest in this regard because it would leave the property effectively restored to its pre-construction state, with no restrictions on its use. In each of the other cases, restrictions would apply. The partial dismantlement and interim safe storage approach would require continuing institutional controls. The beneficial reuse 
option would as well. The entombment approach would also necessitate limited institutional controls for a long period.

One can argue that consideration of future uses of a two-acre site on a 310-square-mile federal reservation carries little importance. But the location of the HWCTR site inside of B-Area increases the importance of this factor. B-Area lies outside of the central nuclear industrial zone of SRS, as well as outside of the SRS radioactive materials storage and disposal area (E-Area), and future SRS property use plans indicate that B-Area will be utilized for administrative purposes only.

\subsection{Ease of Implementation}

Any of the four alternatives could be implemented without special difficulties. Precedents exist for each one. Necessary equipment and support services are available. A number of companies have extensive experience with such nuclear decommissioning work. There are no major differences among the different alternatives in ease of implementation.

\subsection{Minimizing Capital Costs}

The partial dismantlement and interim safe storage approach and the entombment alternative rank highest in this area, having the lowest estimated capital cost of approximately $\$ 8,500,000$. Dismantlement at $\$ 15,000,000$ ranks third. The estimated costs of the dismantlement and beneficial reuse alternative is highest at $\$ 14,000,000$ plus the expense of setting up the facility for an alternate use - approximately $\$ 2,600,000$ (for at total of $\$ 16,600,000)$ based on the EBWR experience.

\subsection{Surveillance and Maintenance Costs}

The dismantlement approach obviously ranks highest here because it would have no surveillance and maintenance associated with it. Entombment, which entails minimal costs, ranks second. The surveillance and maintenance costs associated with the partial dismantlement and interim safe storage approach would be somewhat greater but also small, since inspections of the inside of the facility would be limited to five-year intervals. The beneficial reuse approach ranks lowest in this area because the building would continue to be an active facility which would require higher costs for more frequent surveillance and maintenance. But even in this case, the costs involved would be small compared to the capital cost of the decommissioning work. 


\subsection{Schedules}

The schedule for each alternative appears below:

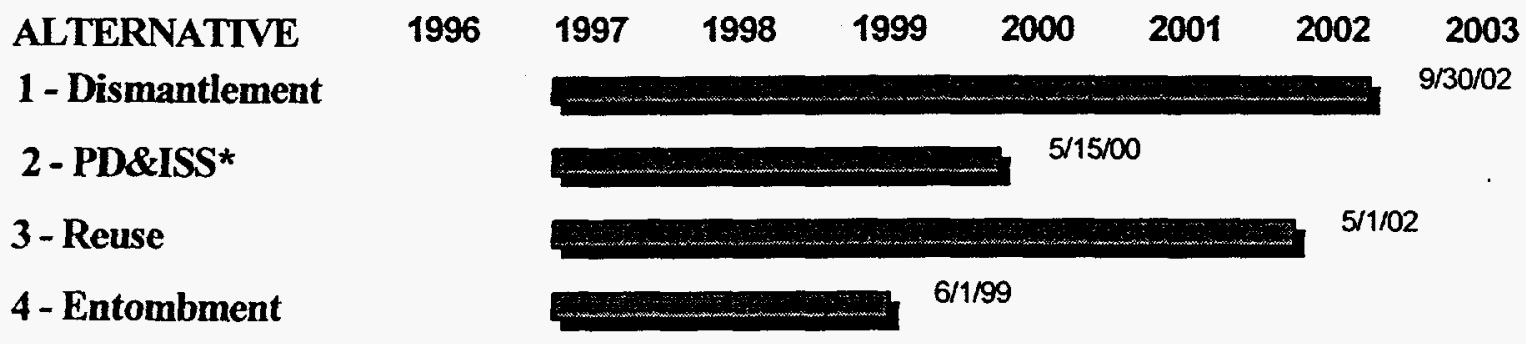

*PD\&ISS is Partial Dismantlement and Interim Safe Storage.

\section{Figure 34. Schedule Comparison}

As can be seen, entombment ranks highest in this category by having the shortest schedule. Partial dismantlement and interim safe storage is ranked second. Dismantlement and beneficial reuse both have relatively long schedules compared to the other two approaches.

\subsection{Value as a Demonstration Project}

This factor compares how well procedures, methods and experience from the HWCTR project could be applied to decommissioning of the five large nuclear weapons material production reactors at the site. As noted previously, the HWCTR decommissioning is intended by DOE to serve as a prototype for the SRS nuclear reactor decommissioning program.

Attempting to judge the different alternatives in this area is complicated by a lack of definitive plans for decommissioning of the other five reactors. That is, the best approach to follow with those facilities has not yet been determined.

But even given this situation, one can roughly estimate the relative value of the different alternatives for the HWCTR decommissioning in serving as a demonstration project for this work. All four alternatives would provide some benefit. The dismantlement approach would provide the most because it would entail a broader range of activities, including removal of the reactor vessel and total dismantlement of the facility. The entombment approach would provide the least value as a demonstration project because it would entail the least number of different activities. The other two HWCTR alternatives would rank between these two extremes. 


\subsection{Recycling Materials}

The dismantlement option ranks highest in the category because it affords the most opportunities for recycling of materials, including the 170 tons of steel in the containment dome. The entombment approach would afford the fewest opportunities to recycle materials. The other two alternatives fall in between these extremes, and are approximately equal in this area.

\subsection{RECOMMENDED REMOVAL ALTERNATIVE}

Dismantlement has been selected as the preferred removal action alternative for the HWCTR decommissioning. Option 1, which entails removal of the concrete structure five feet below grade, is preferred because of lower costs.

In making this judgment, DOE considered many factors. In Section 6, the alternatives studied were ranked in 11 different areas. Dismantlement ranked highest. It offers more value as a demonstration project and more flexibility in futures uses of the property than the other alternatives. One disadvantage of dismantlement is its higher cost, but sufficient funding, set aside for the HWCTR project, is expected to be available. All of the other options have major disadvantages, which are not offset by their merits. Risks and potential environmental impacts associated with all four alternatives are relatively low.

The primary factors in selection of dismantlement as the preferred alternative are as follows:

\subsection{The Highest Ranking in the Comparative Analysis}

As shown in Table 7, dismantlement ranked the highest of the four alternatives studied when 11 different factors were compared. These factors include those recommended by DOE in reference 1 for such comparisons. The ranking system used provided for an objective comparison between the different alternatives on a semi-quantitative basis.

\subsection{The Best Prototype for Reactor Decommissionings}

Since DOE intends for the HWCTR decommissioning to serve as the prototype for decommissioning of the other, larger SRS reactors, this factor, even though it was not afforded greater weight in the comparative analysis, remains an especially important one in the alternatives selection process. Dismantlement ranked highest in this category because it would entail a broader range of decommissioning activities than the other approaches, and, consequently, provide a better learning experience.

\subsection{Greatest Flexibility in Use of the Property}

Of the four alternatives studied, only dismantlement would result in the HWCTR property becoming available for unrestricted use. Each of the other choices would entail restrictions. Therefore, dismantlement meets the general end condition criteria of Section 4.2 better than 
the other approaches. The partial dismantlement and interim safe storage and the beneficial reuse options would result in continued radiological controls of the facility. Entombment would leave radioactivity imbedded in a concrete monolith in the middle of the HWCTR property.

\subsection{Most Compatible With SRS Property Reuse Plans}

The dismantlement approach is most compatible with reuse plans for the SRS property. These plans call for B-Area, within which HWCTR is located, to serve as an administrative area. This property is outside of the area at SRS where most nuclear facilities are located. Allowing radioactivity to remain with $\mathrm{B}$-Area is therefore counter to present plans for future use of this area.

\subsection{Impact on the Environment Is Small}

While the potential environmental impacts of all alternatives are small, removing all of the radioactivity from the HWCTR property by adopting the dismantlement alternative would leave the environment inside U-Area and B-Area in the most pristine condition. The radioactivity from the decommissioning would end up in E-Area, inside engineered trenches and the E-Area Vaults. The amount of radioactivity from the HWCTR project would be small compared to that present and planned for these facilities. It would be disposed of within the central area of SRS near other nuclear facilities. Studies documented in reference 3 show that radioactive materials in these disposal facilities do not pose a significant environmental threat.

\subsection{Risks to the Public Are Low}

As with the other alternatives, risks to the public associated with the dismantlement approach are minimal, Because all radioactivity would be removed from the HWCTR property, risks to the public after the dismantlement is completed would be somewhat lower than with the other approaches.

\subsection{Risks to the Workers Are Low}

Risks to the workers from the dismantlement process are low, as with the other alternatives.

\subsection{Adequate Funding Should Be Available}

The dismantlement alternative is estimated to cost approximately $\$ 15$ million. Sufficient funding for carrying out this alternative is expected to be available. 


\subsection{The Partial Dismantlement and Interim Safe Storage Option Leaves Most Radioactivity In the Facility}

The partial dismantlement and interim safe storage alternative would leave the reactor vessel, which contains more than 99 percent of the radioactivity in the facility, in place. Even though the vessel would be effectively sealed, this situation does not represent a longterm solution to disposition of the radioactivity. Eventually, more work would be needed to complete the decommissioning process of the HWCTR. Note that DOE plans to eventually remove the radioactive reactor block from the cocooned 105-C Reactor at Hanford, which served as a model of this concept for the HWCTR. This disadvantage far outweighs the merits of this approach.

\subsection{The Beneficial Reuse Option Is Not Cost-Effective}

The beneficial reuse option is expensive, with an estimated cost, including the expense of setting up the facility for an alternate use, of approximately $\$ 17$ million. The facility would have only about 12,000 square feet of effective floor space for storing material. Using just the \$2.6 million figure from setting up the EBWR as a storage facility for storing transuranic waste, the cost would be $\$ 217$ per square foot. If the cost of the decommissioning work were figured in as well, this amount would rise to $\$ 1,416$ per square foot.

To date, no material to be stored in the HWCTR facility has been identified. And there are other, less-expensive storage areas available at SRS.

This disadvantage of the beneficial reuse alternative far outweighs the merits of this approach.

\subsection{The Entombment Approach Has Major Disadvantages}

While entombment is considered to be a technically-viable approach with certain advantages, it also has major drawbacks. For the HWCTR project, equipment inside of the entombed structure would remain radioactive by today's standards for hundreds of years. And, as the Air Force found in its study of the entombed reactor at Wright-Patterson Air Force Base, removing radioactivity from an entombed reactor, should this ever become necessary, is an extremely costly undertaking. None of the potential benefits of this approach, including its lower costs, compensate for this major disadvantage.

\subsection{PROCEEDING WITH THE DECOMMISSIONING}

As revision 1 to this study shows, dismantlement remains DOE's preferred alternative. To determine whether the costs involved with this approach could be reduced, DOE has had a radiation exposure pathway analysis performed. This study is described in a detailed report, Residual Radioactivity Guidelines for the Heavy Water Components Test Reactor, dated April 1997. It produced guideline levels for radionuclides in the reactor containment building. The 
results also showed that it is technically acceptable for activated and contaminated concrete, embedded radioactive piping and some installed radioactive equipment to remain inside the buried structure.

In this section, the study and its results are briefly described, along with the potential application of the results to the decommissioning project.

\subsection{HWCTR Unconditional Release Criteria and Radionuclide Guidelines}

For this project, the DOE plans to use the release criteria of DOE Order 5400.5, Radiation Protection of the Public and the Environment. These criteria require that exposure to members of the public from residual radioactivity be less than 100 millirem per year for all exposure pathways, and as low as reasonably achievable below this value.

To implement the release criteria, guidelines are required that relate the amounts of different radionuclides remaining in the facility to the annual exposure limit. DOE Order 5400.5 specifies that authorized limits for each property shall be set equal to generic or derived sitespecific guidelines.

The DOE Decommissioning Resource Manual (reference 1) states that site-specific guidelines for radioactivity in soils and remaining structures are to be developed using the DOE material code RESRAD, employing a realistic pathway analysis. When a building remaining on a decommissioned site may be occupied in a realistic future scenario, a related computer code may be used to calculate site-specific guidelines. This code is RESRADBUILD. RESRAD-BUILD also may be used to establish guidelines associated with possible occupancy of a portion of a buried contaminated structure.

\subsection{The RESRAD and RESRAD-BUILD Computer Codes}

RESRAD is a computer code developed by Argonne National Laboratory that can be used to model the transport of radionuclides in soil and determine the resulting radiation exposure to humans. Outputs include tables and graphs which show annual radiation exposure for periods as long as 10,000 years. Also, radionuclide guideline levels that equate to particular annual exposures can be produced by the code.

The basic RESRAD exposure pathway scenario, and usually the most conservative one, entails a family farm. The family living on the property could receive radiation exposure from residual radioactivity through eight different pathways, such as direct exposure to contaminated soil, eating plant foods grown on the property and drinking milk from on-site livestock. The model includes provisions for contamination from soil (or for the HWCTR case, buried structures) leaching into the ground water and then reaching the environment of those living on the property.

RESRAD requires a variety of inputs. A source term that describes the concentrations of different radionuclides present is one key input. The geometry of the source, especially with 
respect to ground water, is another. Then there are numerous other inputs such as characteristics of the soil and the rates of intakes of foodstuffs.

RESRAD-BUILD is a pathway analysis model developed by Argonne National Laboratory to evaluate the potential radiological dose to an individual who lives or works in a building contaminated with radioactive material. Outputs include tables of exposures associated with building occupancy. Radionuclide guideline levels associated with a particular annual exposure can also be calculated.

In RESRAD-BUILD, six exposure pathways are considered, including external exposure from the source and inhalation of airborne radioactive particles. Like RESRAD, the program requires a variety of inputs, such as the radionuclide concentrations, the source geometry and the building description.

\subsection{The HWCTR RESRAD Study}

The study used the RESRAD and RESRAD-BUILD residual radioactivity computer codes to calculate guidelines for residual radioactivity in the HWCTR reactor containment building at the conclusion of its decommissioning. It produced residual radioactivity guidelines based on two different criteria: 100 mrem per year above background and 15 millirem per year above background to a hypothetical individual exposed to radioactivity on the site property. The 100 millirem per year value, as noted previously, is the maximum limit of the DOE unrestricted release criteria. The 15 millirem per year value corresponds to the criterion of the Nuclear Regulatory Commission's proposed radiation cleanup rule. It is considered appropriate for a reference value corresponding to as low as reasonably achievable (ALARA), given the limited amounts of radioactive contaminants in the HWCTR facility.

The study also produced two estimates of the maximum annual radiation exposure to a hypothetical individual on the property. One estimate assumed that the radioactivity associated with the biological shield, contaminated concrete and embedded radioactive piping would remain in place. The other assumed that this radioactivity would be left in place along with all radioactivity in installed equipment, with the exception of the reactor vessel assembly and the steam generators.

\subsection{Exposure Pathways Used in the Study}

Scenario A assumed residential use of the site as a family farm. A hypothetical resident was assumed to eat homegrown produce and meat and drink milk from livestock fed with forage grown onsite. Ground water drawn from a well located on the property would be the only source of water for drinking, household use and irrigation. Table 8 shows the different exposure pathways. 
Table 8 Exposure Pathways for Scenario A

\begin{tabular}{|c|l|}
\hline No. & Pathway \\
\hline 1 & Direct gamma exposure to contaminated soil \\
\hline 2 & Internal dose from inhalation of dust \\
\hline 3 & Internal dose from inhalation of radon \\
\hline 4 & Internal dose from ingestion of plant foods \\
\hline 5 & Internal dose from ingestion of meat and milk from onsite livestock \\
\hline 6 & Internal dose from drinking water \\
\hline 7 & Internal dose from ingestion of soil \\
\hline
\end{tabular}

Another plausible use for the HWCTR property would involve constructing a building on the site. Scenario B assumed that an administrative building with a basement four meters deep is built on the property.

It was assumed that the building basement incorporates as one of its walls an existing wall of the HWCTR underground structure. Under this scenario, a hypothetical individual was assumed to work eight hours per day inside the building basement, five days per week for 50 weeks per year. The exposure pathways associated with the scenario are shown in Table 9.

\section{Table 9 Exposure Pathways for Scenario B}

\begin{tabular}{|c|l|}
\hline No. & Pathway \\
\hline 1 & Direct gamma exposure to contaminated wall \\
\hline 2 & External exposure due to air submersion \\
\hline 3 & Internal dose from inhalation of airborne radioactive particulates \\
\hline 4 & Internal dose for inadvertent ingestion of radioactive material \\
\hline
\end{tabular}

DOE Order 5400.5 and the Decommissioning Resource Manual (reference 1) both indicate that a realistic pathway analysis should be employed in establishing the site-specific cleanup guidelines. The two scenarios selected for analysis may not be considered entirely realistic, given present expectations for future uses of the SRS property, but they are plausible.

The administrative building basement assumption is consistent with exposure pathway scenarios used in connection with decommissioning of the Shippingport Atomic Power Station in Pennsylvania. The Shippingport project entailed dismantlement of that facility and unrestricted release of the site property. Some underground concrete structures with low levels of residual radioactivity remained in place. These were filled with building rubble and clean earth, as will be the case for the HWCTR project.

\subsection{The Conceptual Models of Radioactivity in the Facility}

The conceptual models used in the RESRAD calculations are shown in Figure 35 . These models represent the volumes which contain radioactive material. The biological shield model in the figure would contain primarily activated concrete and metal. The contaminated 
concrete model would contain contaminated concrete, the imbedded radioactive piping in the facility and all radioactive equipment except for the reactor vessel and the two steam generators. Note that it was assumed in the calculations that contaminated concrete in the facility would be placed at the bottom of the buried structure, along with embedded radioactive piping and radioactive equipment.

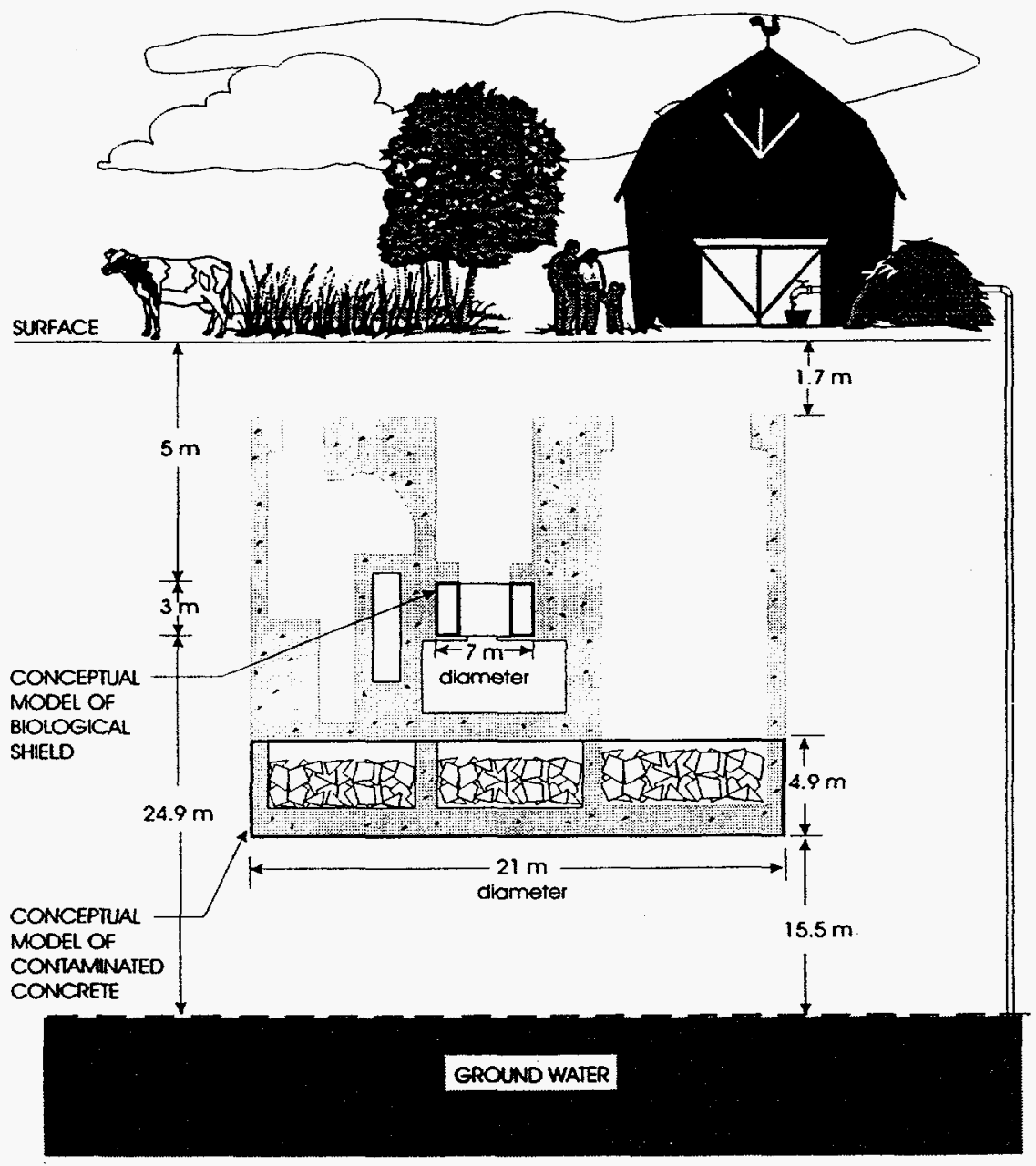

Figure 35 Conceptual Models for RESRAD Calculations

\subsection{Assumptions Used in the Study}

Assumptions used were generally realistic but on the conservative side. For example, in source term calculations (the calculated amounts of different radionuclides in the facility) the highest measured contamination levels measured during the detailed characterization study performed in 1996 were considered to be the average contamination levels. One inherent conservatism in the RESRAD process is modeling buried concrete structures as soil, which was done for the HWCTR project. Radionuclide migration from and through concrete would, of course, occur at a slower rate than through soil, allowing for more radioactive decay to take place before contaminants reached the environment. Another 
conservative assumption involves the lower axial shield below the reactor vessel. This shield, which contains most of the cobalt-60 in the facility, was assumed to remain in place. But it more likely will be removed during the dismantlement work.

\subsection{The Study Results}

The RESRAD calculation showed that radioactivity which would remain in the facility with no decontamination would produce under Scenario $A$ a maximum annual exposure to a hypothetical individual of 0.037 millirem per year. Calculated radionuclide guideline levels for residual radioactivity which would produce 15 millirem per year under scenario A (RESRAD) and Scenario B (RESRAD-BUILD) were well above actual levels measured during the 1996 characterization program.

A second RESRAD calculation, which assumed that all installed radioactive equipment except the reactor vessel and steam generators would remain in place, also showed a maximum annual exposure of approximately 0.037 millirem per year.

\subsection{Application of the Study Results to the HWCTR Project}

The study shows that it is technically acceptable for activated and contaminated concrete to remain in the facility, along with embedded radioactive piping and radioactive equipment except for the reactor vessel and steam generators. This approach is consistent with many of the public comments which appear in Appendix I.

As indicated in Section 5.1.3, previous planning for dismantlement had entailed removing all process piping pumps and motors, cable trays, duct work and installed components. Section 5.1.3 also indicates that activated and contaminated concrete would be removed.

This equipment which may remain in the facility is located below the minus five-foot level, that is, beneath the main floor. It would include such hardware as the main cooling system heavy water tank shown in Figure 8 and the sump tank located in the monitor room shown in Figure 17. It would not include the reactor vessel and steam generators, nor equipment, such as shielded casks, which are not installed. This approach may be taken if it is shown to be less expensive than removal of the installed equipment for recycling. If it is taken, low limits for radiation levels on the equipment to remain will be established. 


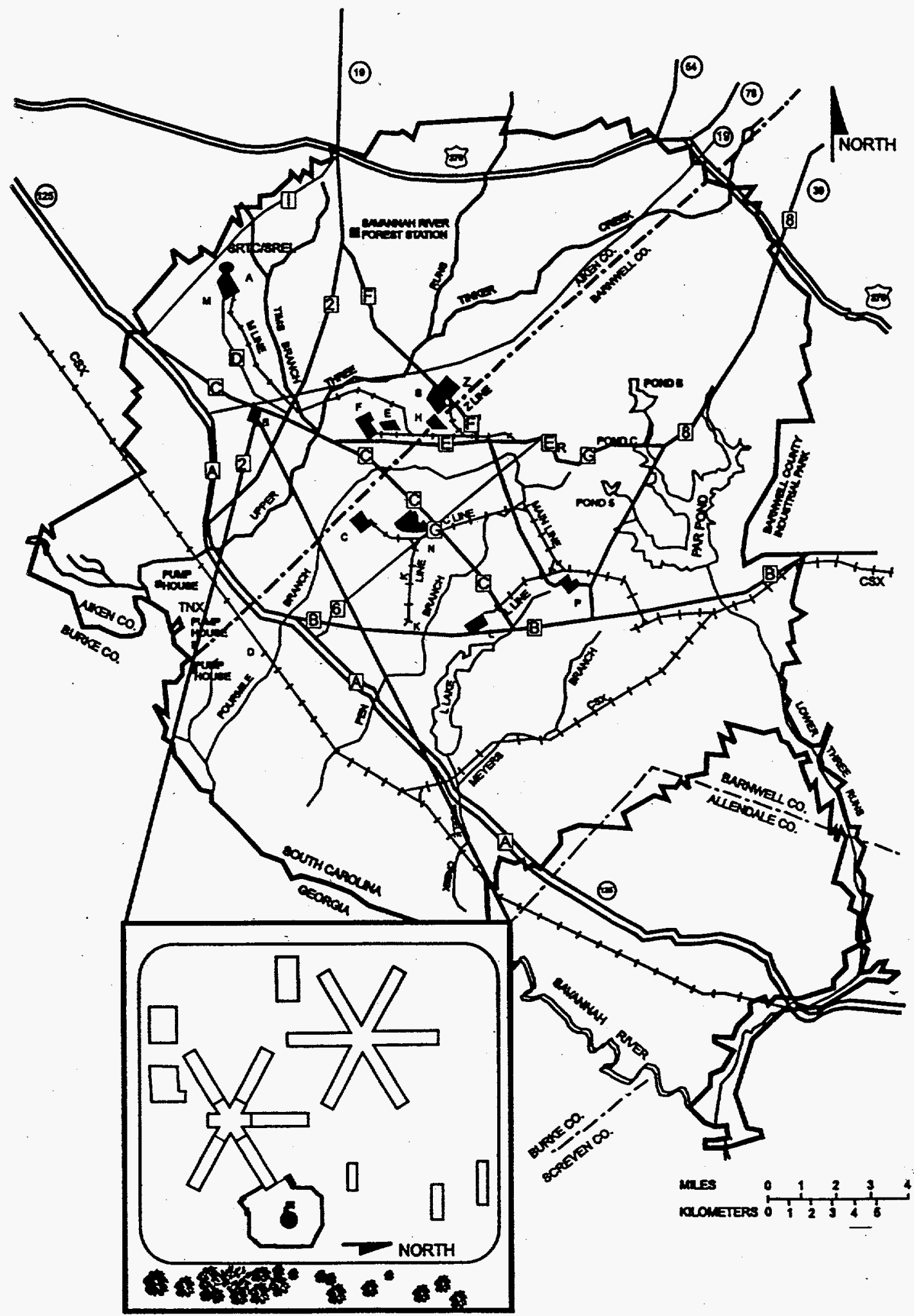

Figure 2. Location of the HWCTR on the Savannah River Site. The HWCTR property, shown in the lower part of the inset, comprises U-Area. U-Area lies within B-Area, which is designated an administrative area in long-term site property plans. 


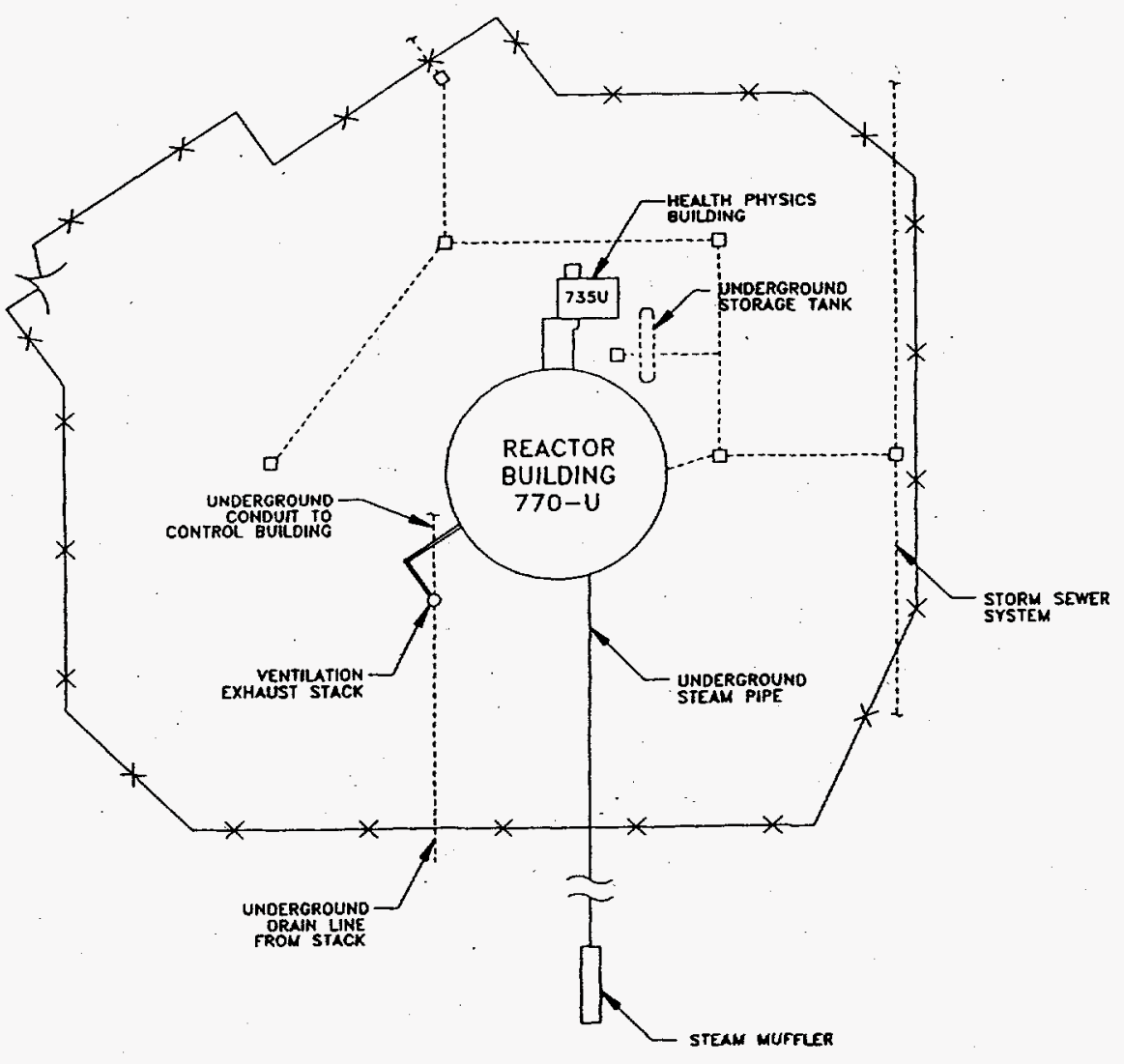

Figure 3. The HWCTR Property 


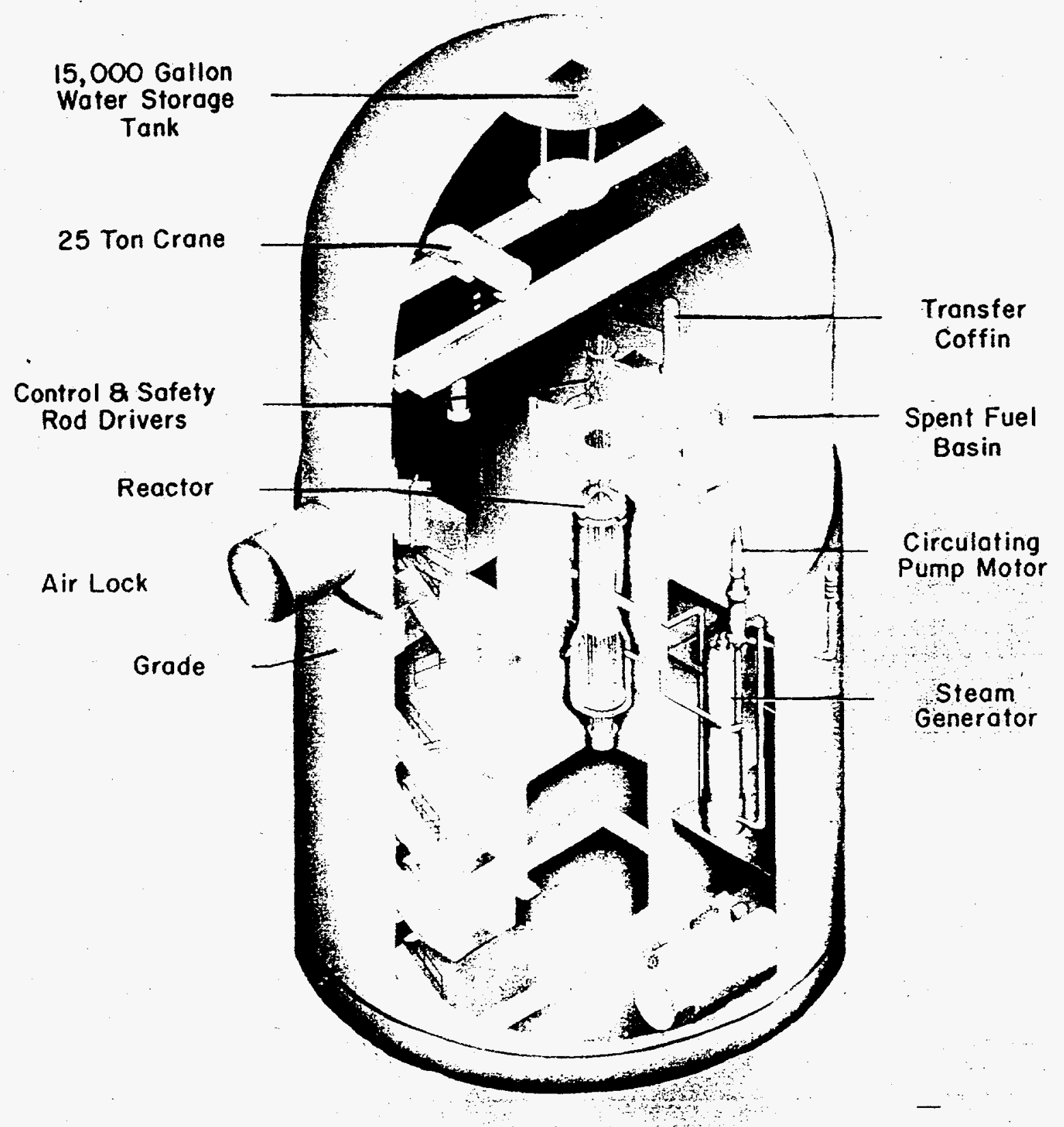

Figure 4. Cutaway View of the HWCTR Facility. The containment structure is 70 feet in diameter and 125 feet high. The steel dome rises approximately 65 feet above ground level. The below ground section is made of reinforced concrete. 


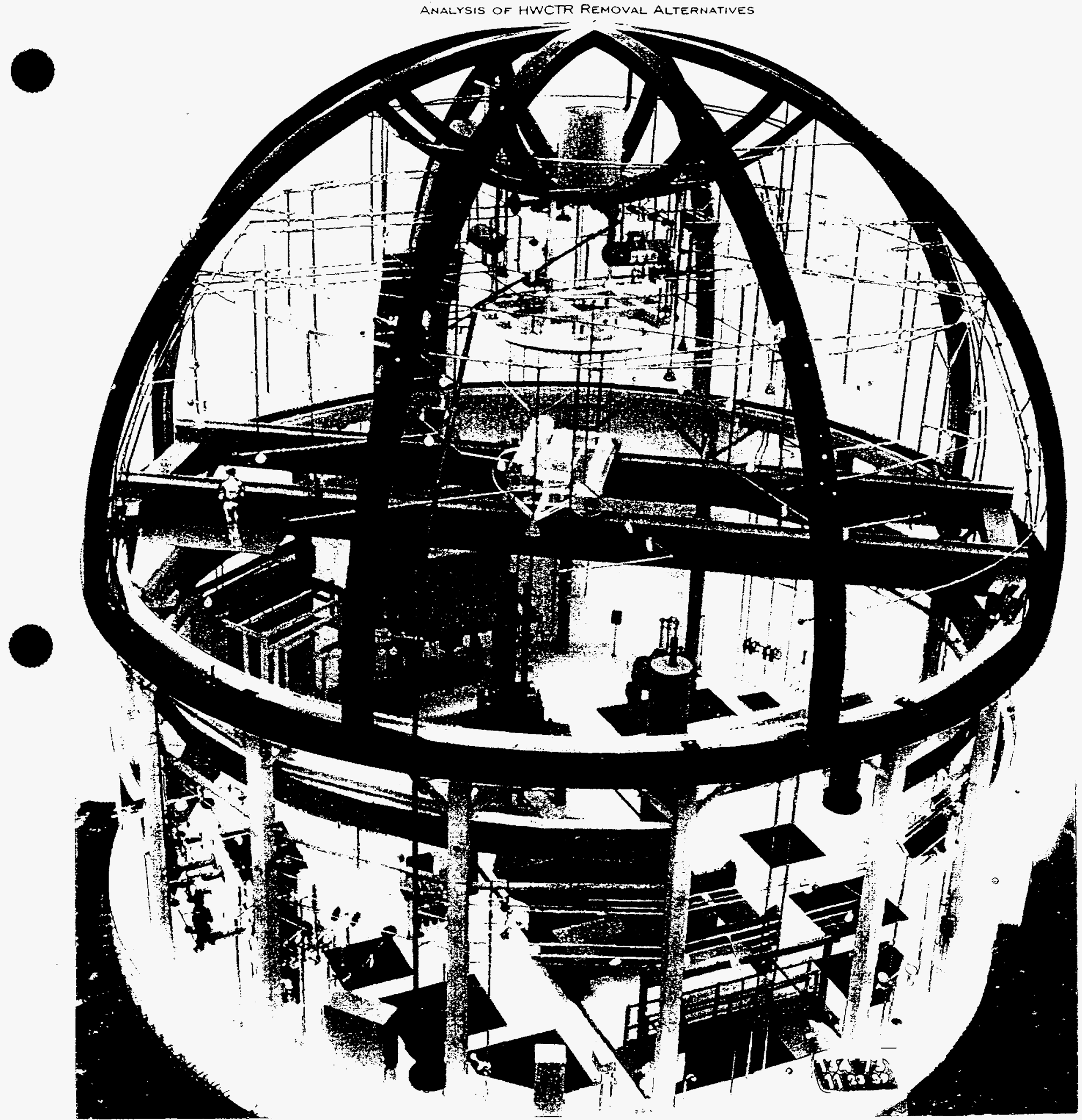

Figure 5. The HWCTR Model. This model was used in determining equipment layouts when the facility was being built. This view shows the above-ground part of the containment building with the steel shell removed. Note the 25-ton polar crane inside of the dome. The spent fuel basin is in the lower part of the picture. The black shapes on the 0-level floor are ten removable plugs, which are presently in place The reinforced concret: iloor is five feet thick. 


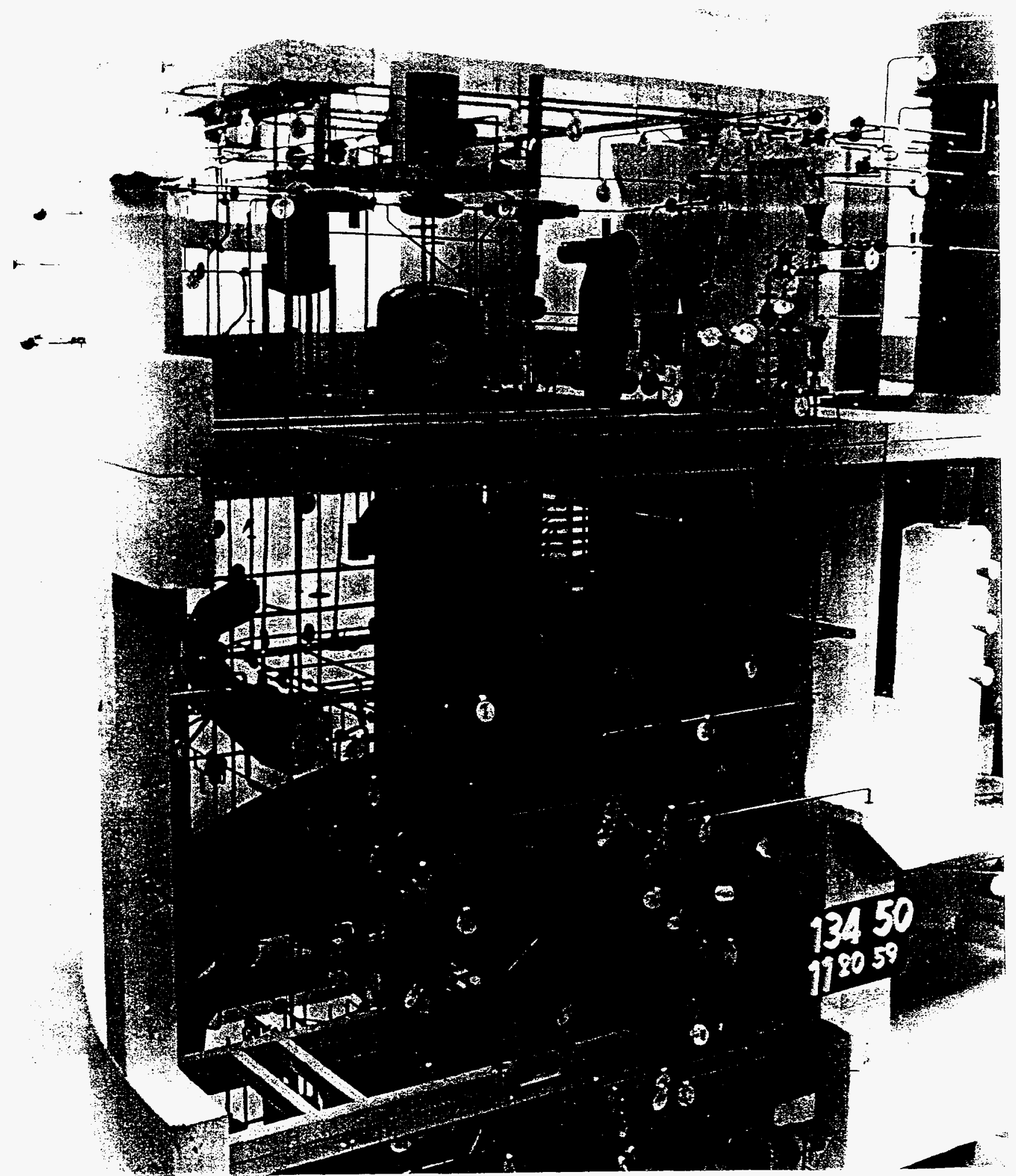

Figure 6. The HWCTR Model - Underground View. The area in the upper part of this view is the left pump room at the - 16-foot level. The room below is the left generator room at the -37-foot level Steel grating on the floors is not shown. On the right you can see the reactor vessel The stars at the bottom right lead to the pin room below the ressel You can see the left steam generator in the center of the photograph 


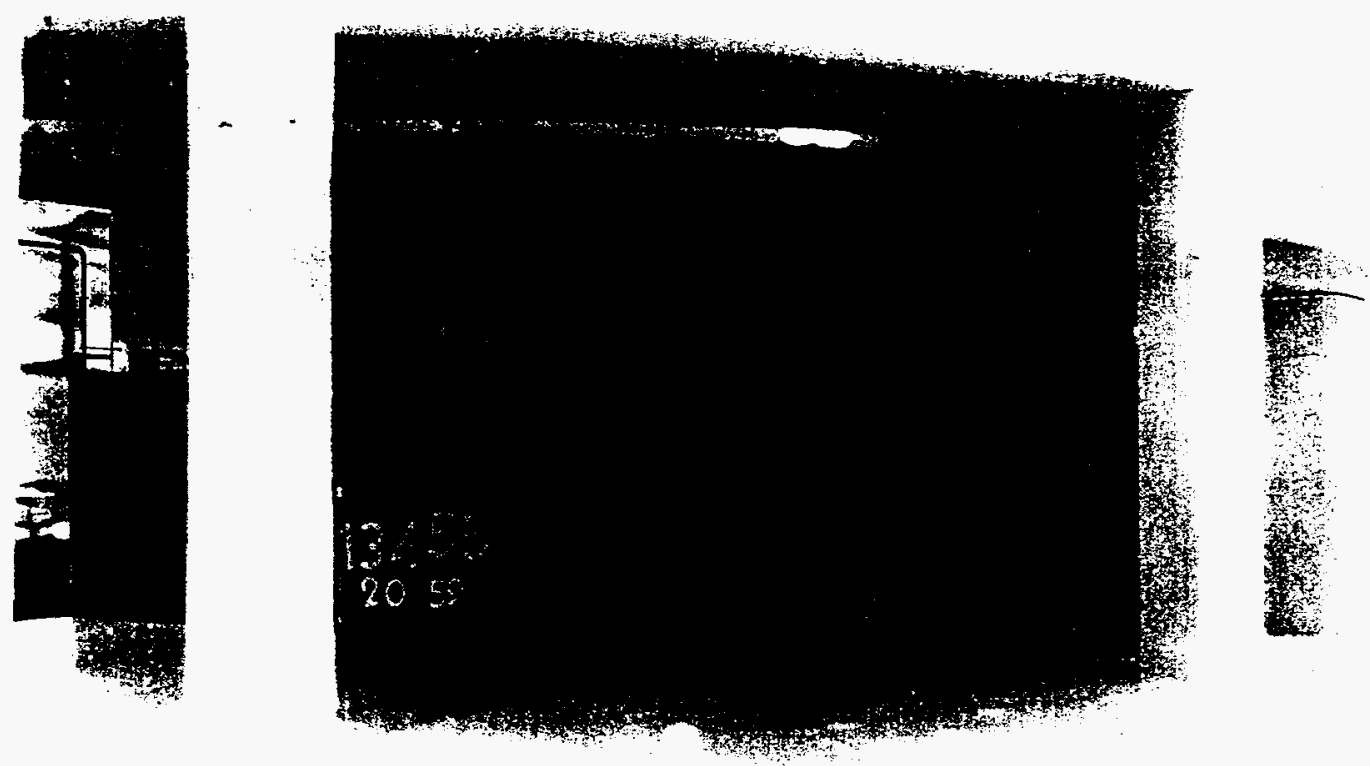

Figure 7. The HWCTR Model - Right Cyclone Room at the -52-Foot Level. Looking in from the outside of the model, you can see portions of the spent fuel basin purification system. This system was also used to process water from the building sump.

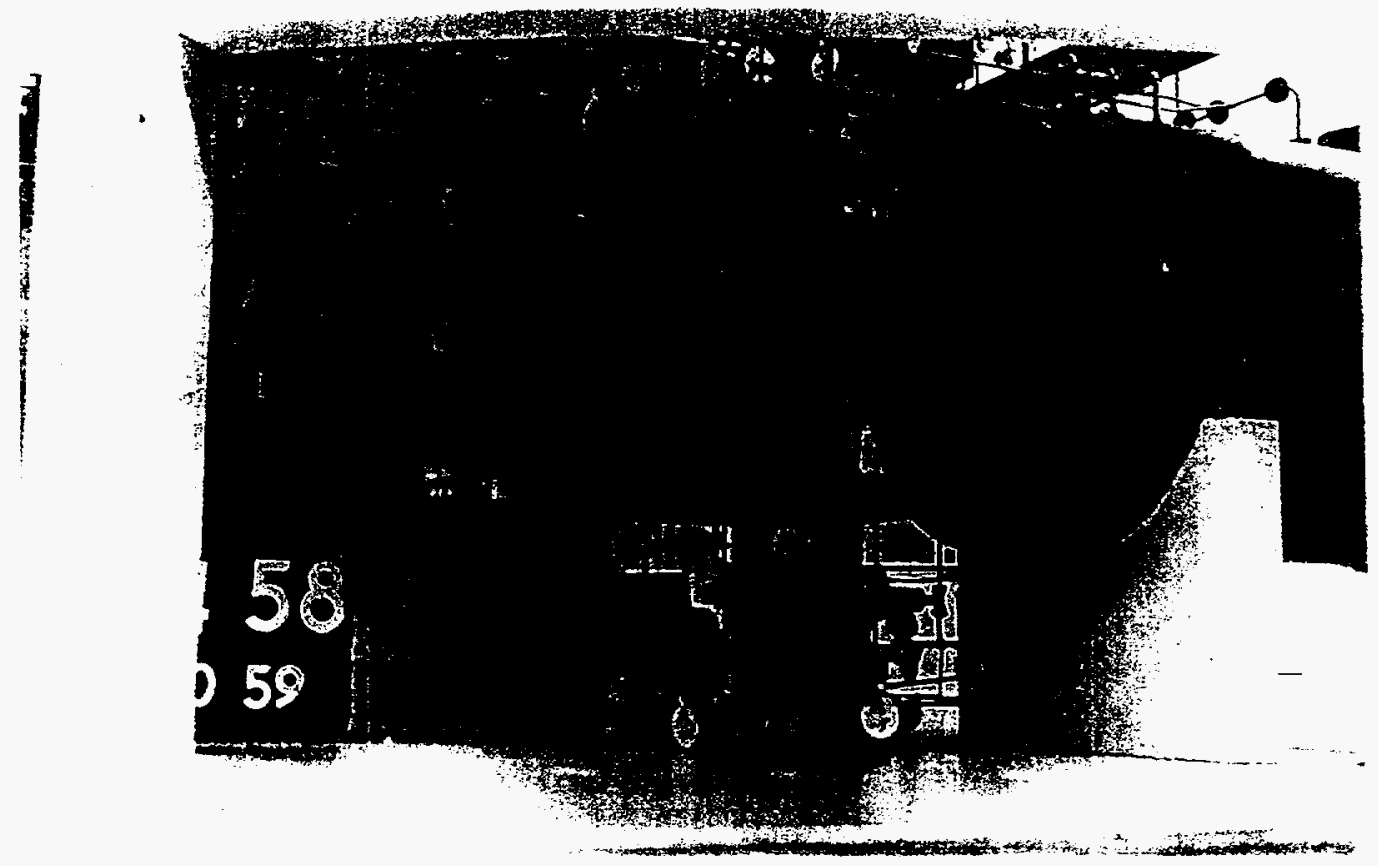

Figure 8. The HWCTR Model - Left Purification Room at -52-Foot Level. Here you can see the main cooling system heavy water storage tank, which provided makeup water to the plant and fed the hydraulic seal head tanks. The tank and all fluid systems connected to it are contaminated with radioactivity. 


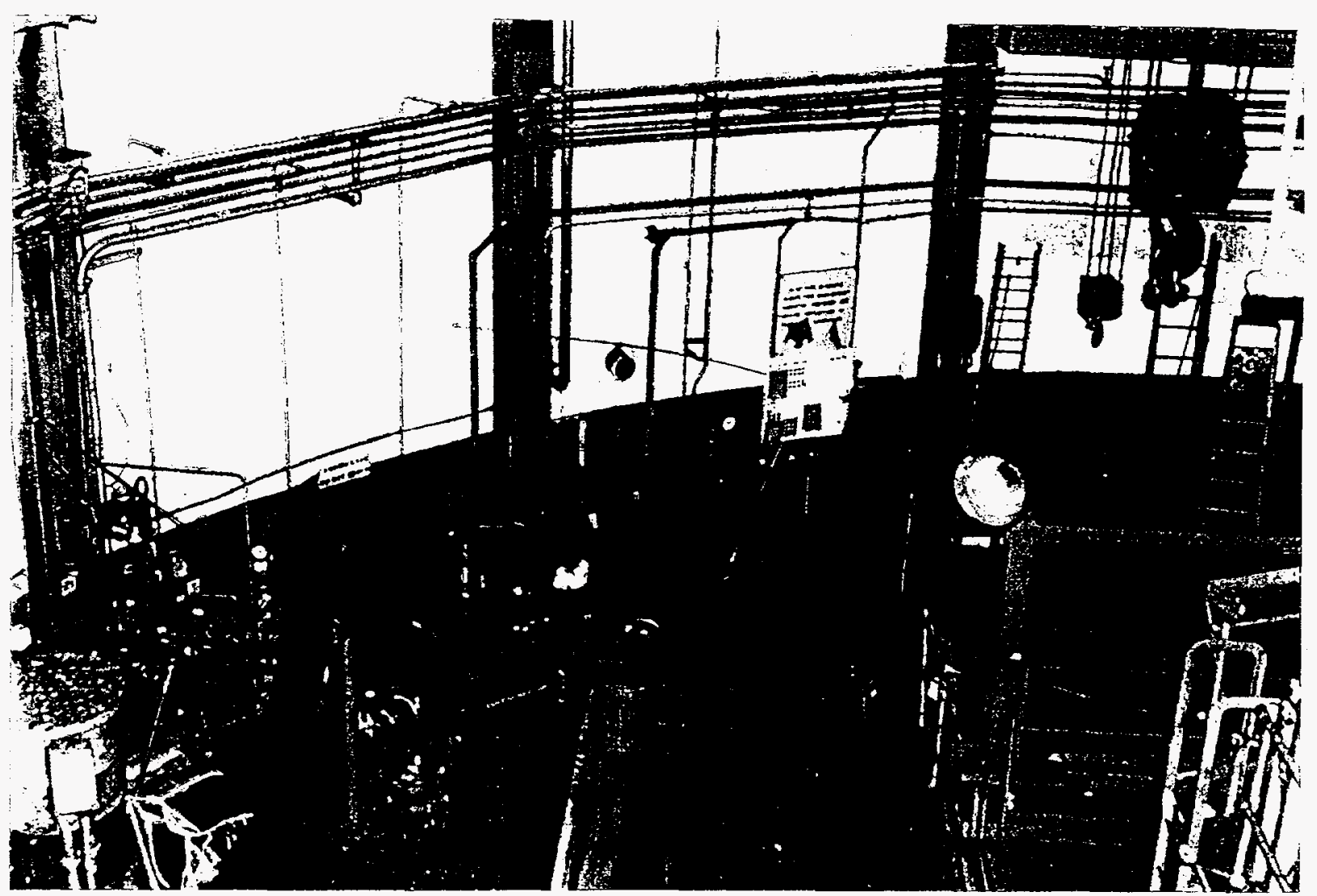

Figure 9. Part of the 0-Level Main Floor. Wooden planks covering the spent fuel basin can be seen on the right. Note the polar crane hook at upper right. During spent fuel handling in the basin, the hook was immersed in the basin water. The hook and crane cables remain radioactively contaminated.

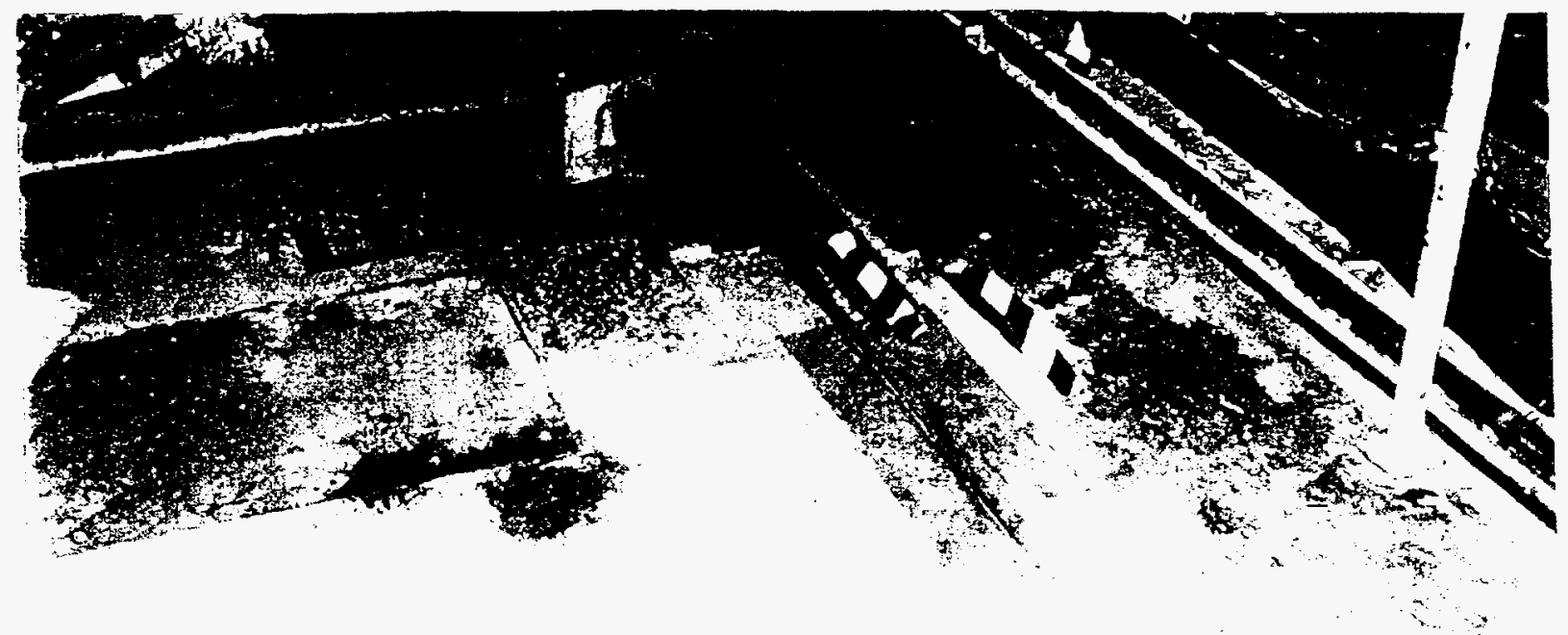

Figure 10. Detail of 0-Level Floor Beside Spent Fuel Basin. Fere wou can see one of the removable flour plugs Because the spent fuel basin overflowed. radioacrive contammaton is present in crevices in the thoor In this iew the basin is on the unper right 


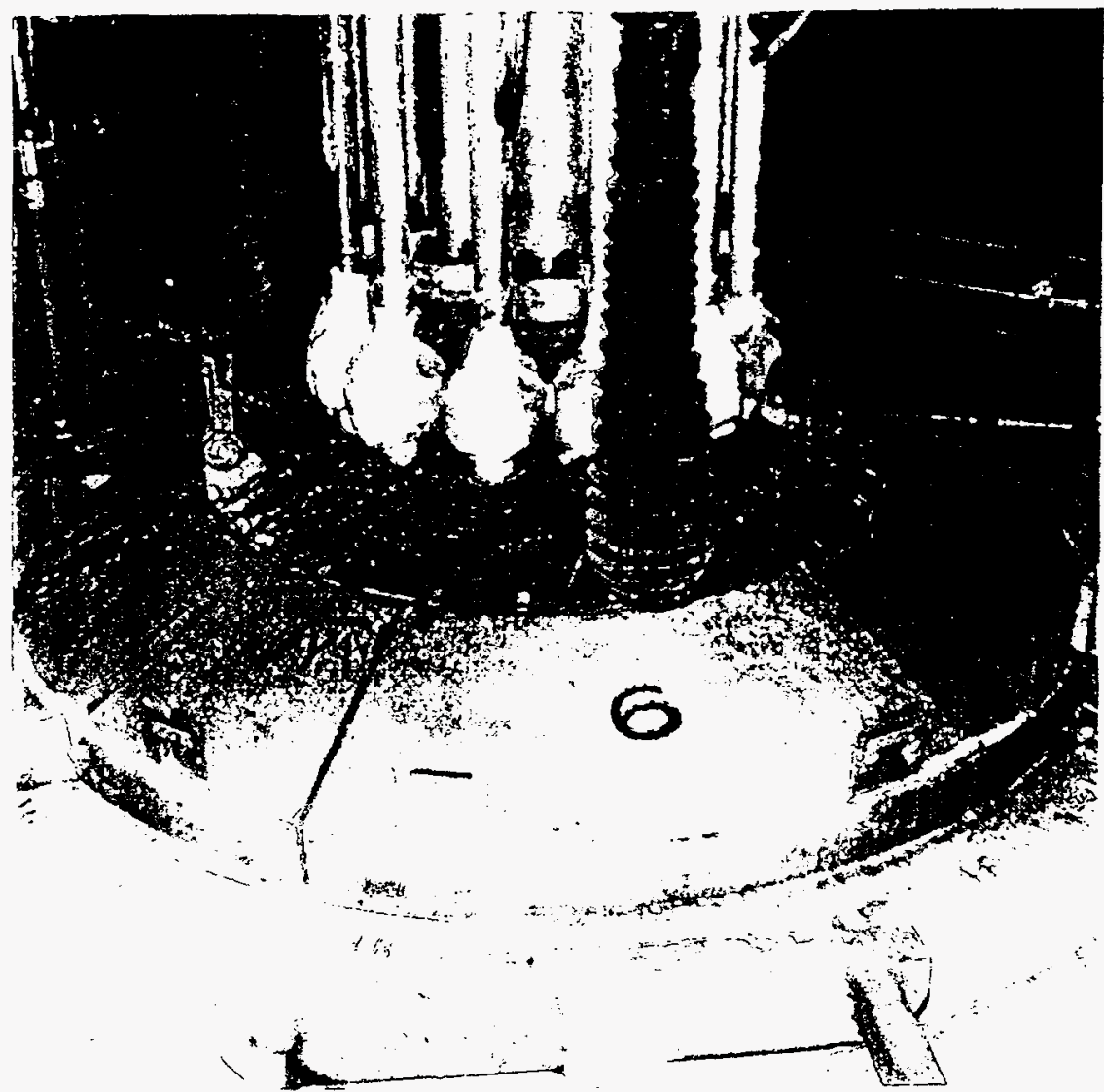

Figure 11. The Reactor Vessel Head. Covers for thermal insulation on top of the pressure vessel head can be seen here. The smaller pipes are pressure thimbles for the control rod drive mechanisms. The HWCTR operated at 1200 pounds per square inch (gauge). Pressure was maintained by a helium blanket inside of the vessel head. The reactor vessel assembly weighs 98 tons. It presently contains the control rods but no nuclear fuel, which was removed shortly after the final reactor shutdown in December of 1964.

Figure 12. The Refueling Machine. Known as the transfer coffin, this container was used about 70 times to remove fuel assemblies from the reactor and transfer them to the spent fuel basin. The refueling machine contains lead radiation shielding and weighs, with its movable support platform, approximately 80 tons. It is contaminated with radioactivity.

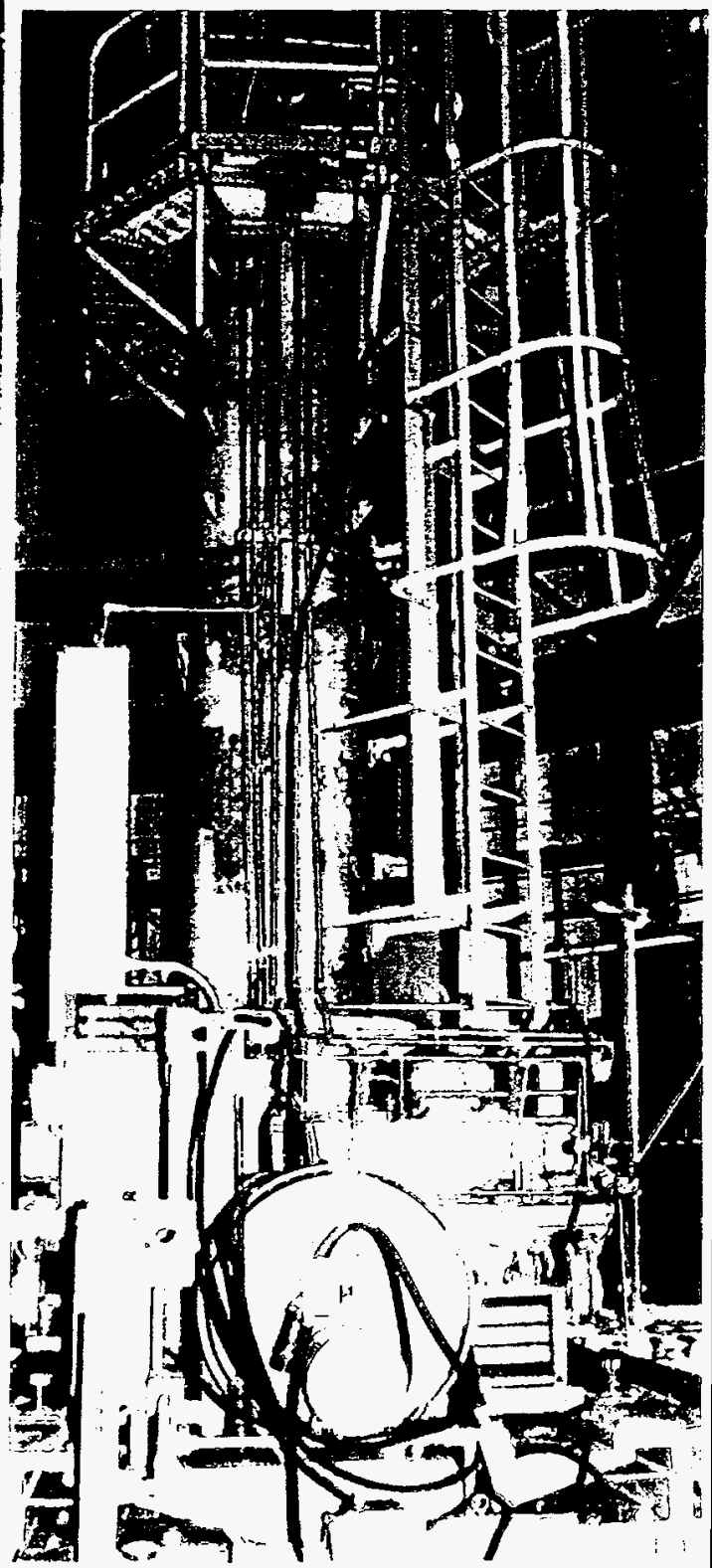




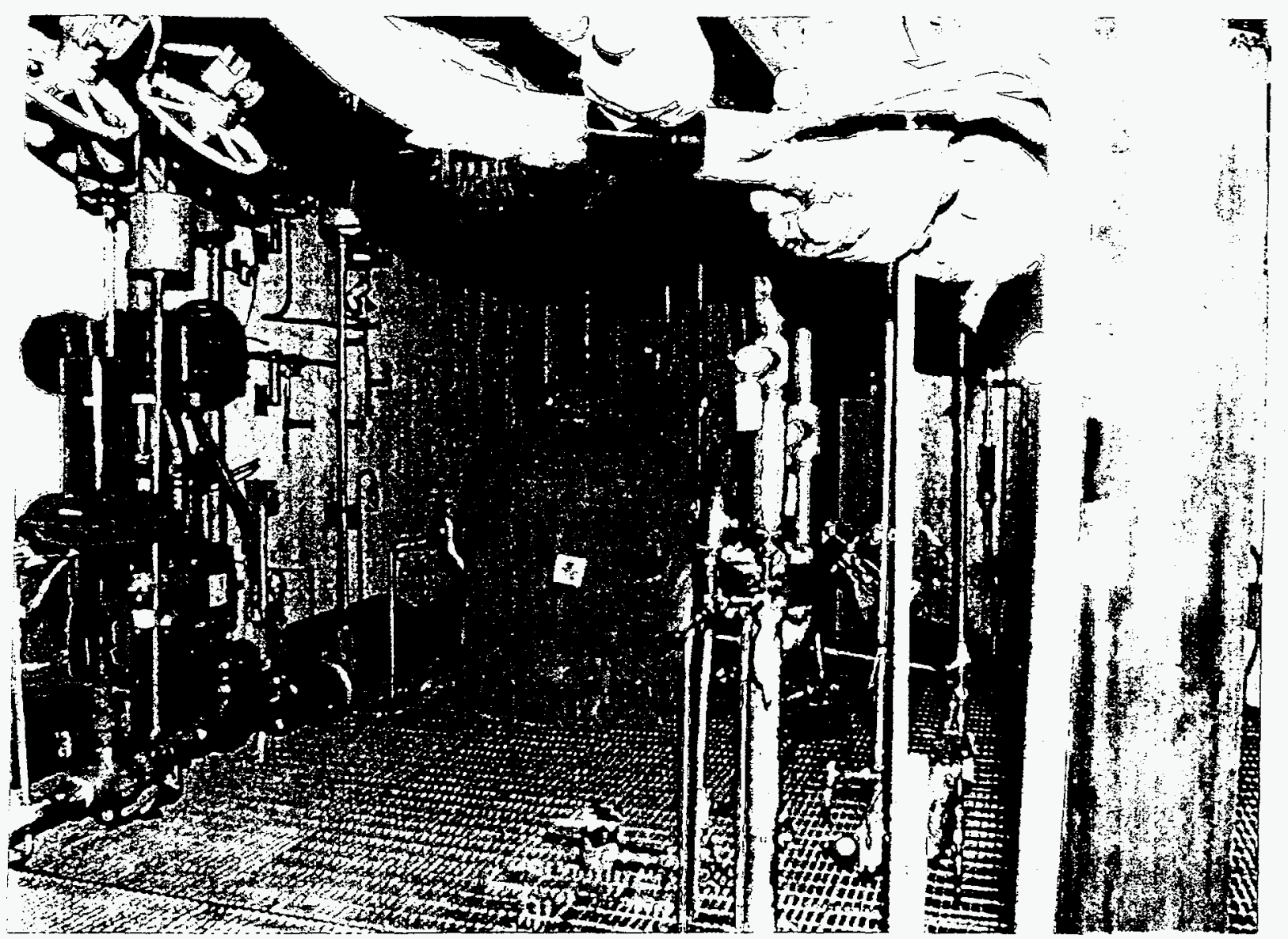

Figure 13. Right Pump Room at the -16-Foot Level. The top of the right steam generator can be seen here Each of the two steam generators stands 23 feet high and weighs approximately 19 tons. Asbestos thermal insulation has been removed from the generators and in all but a few places in the HWCTR facility

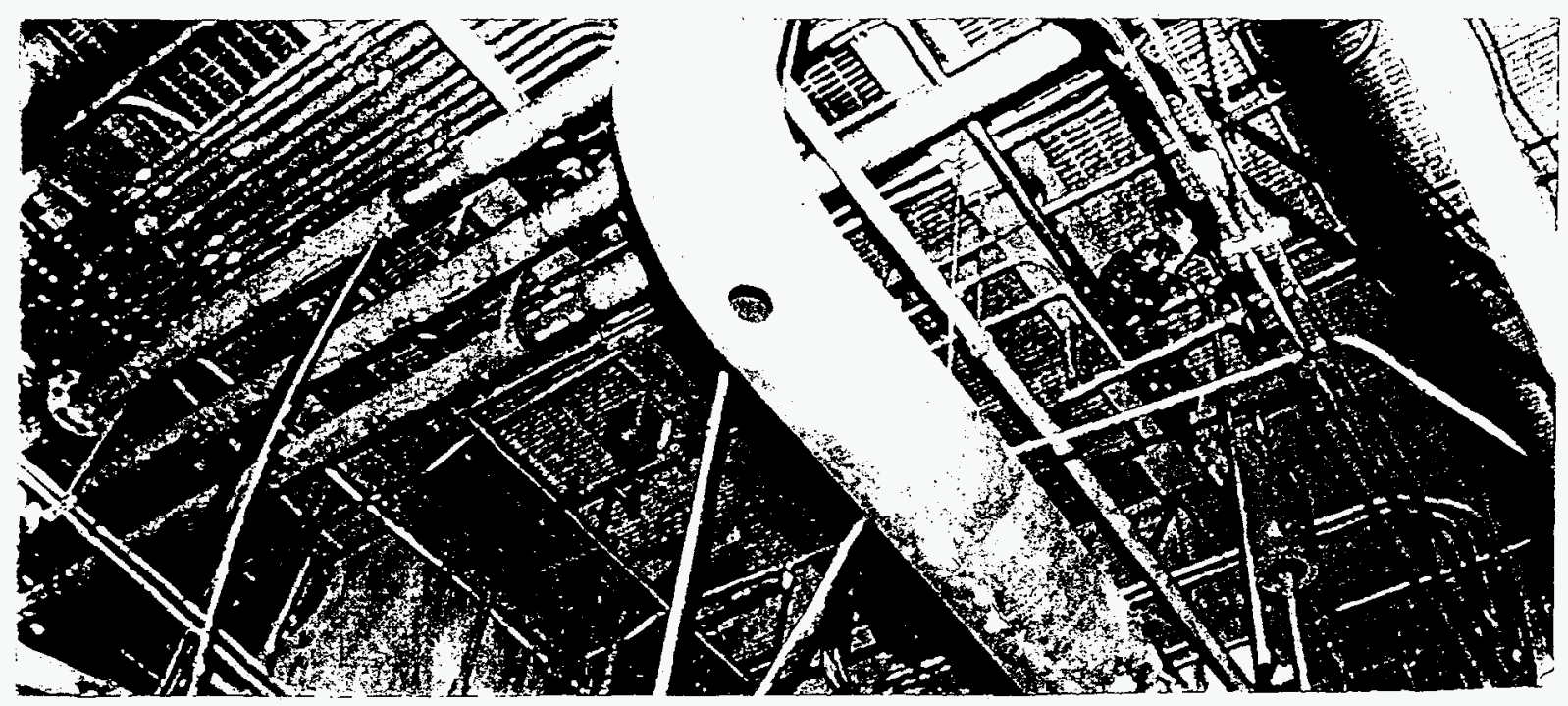

Figure 14. Main Coolant Piping. This section of ten inch diameter carbon steel piping runs ncar the ceiling in the left generator room. The hole in the pipe was cut during a 1975 radiological characterization tudy: This study showed low levels of cobalt-60, cesium- 137 and plutonium-239 in the main coolant systcin, as well as in the two isolated coolant loops 
ANALYSIS OF HWCTR REMOVAL ALTERnatives

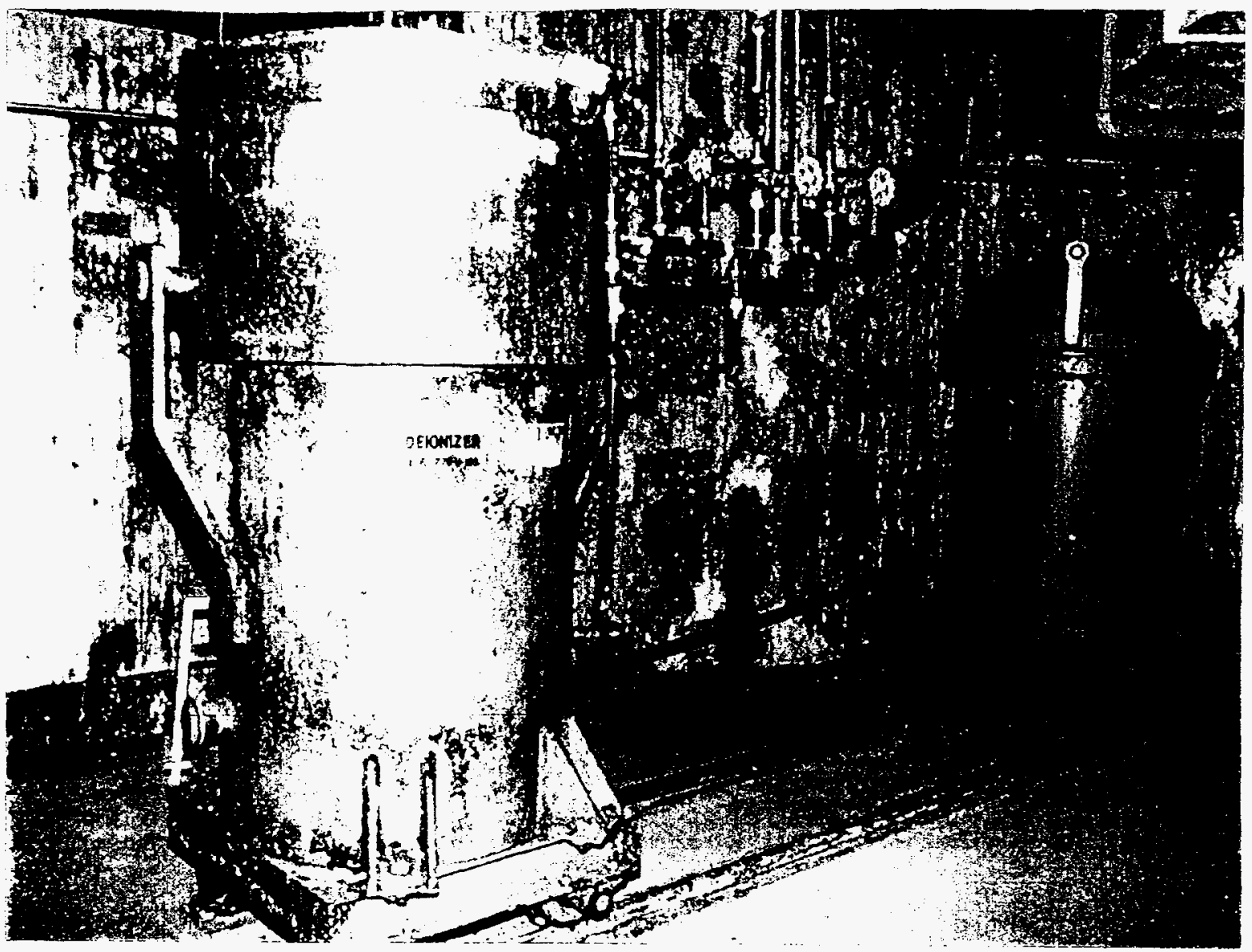

Figure 15. Shielded Casks. These two caskis in the left purtication room once held a deionizer vessel and a filter used in the spent fuel basin purification system. Because they contan lead radiation shielding. these caslis, if radioactively contaminated, could become a mixed waste. Mixed waste. which is both hazardous and radioactive, presents special disposal problems. There are five other similar shielded casks in the HWCTR facility

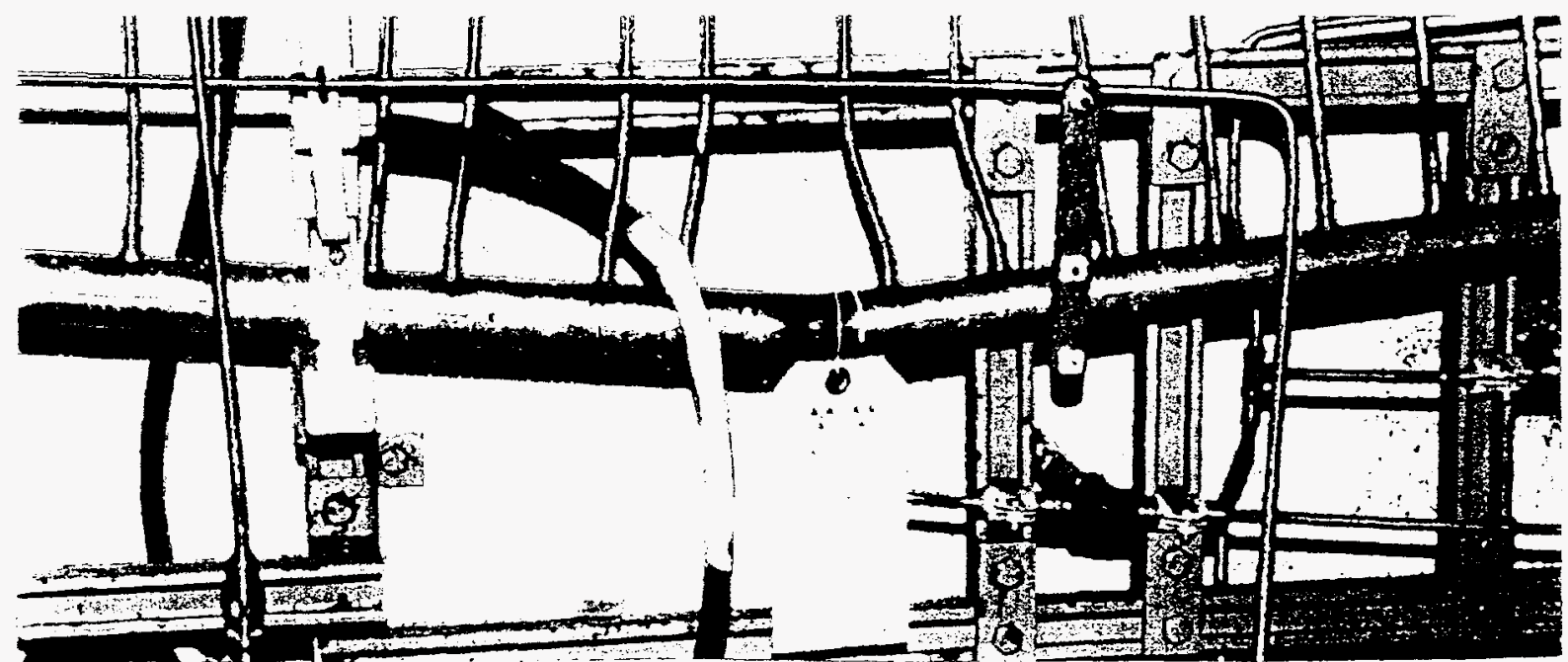

Figure 16. Radiation Hot Spot. This pipung in the righ cyclone room at the -52-foot level was determined to have a radiation level of 110 millirem per hour on contact dhe bighest accesible beta-gamma radiation lesel measured in recent vears in the HWCTR facility Radation levels un most areas are less than one millirem pot hour 
ANALYSIS OF HWCTR REMOVAL ALTERNATIVES

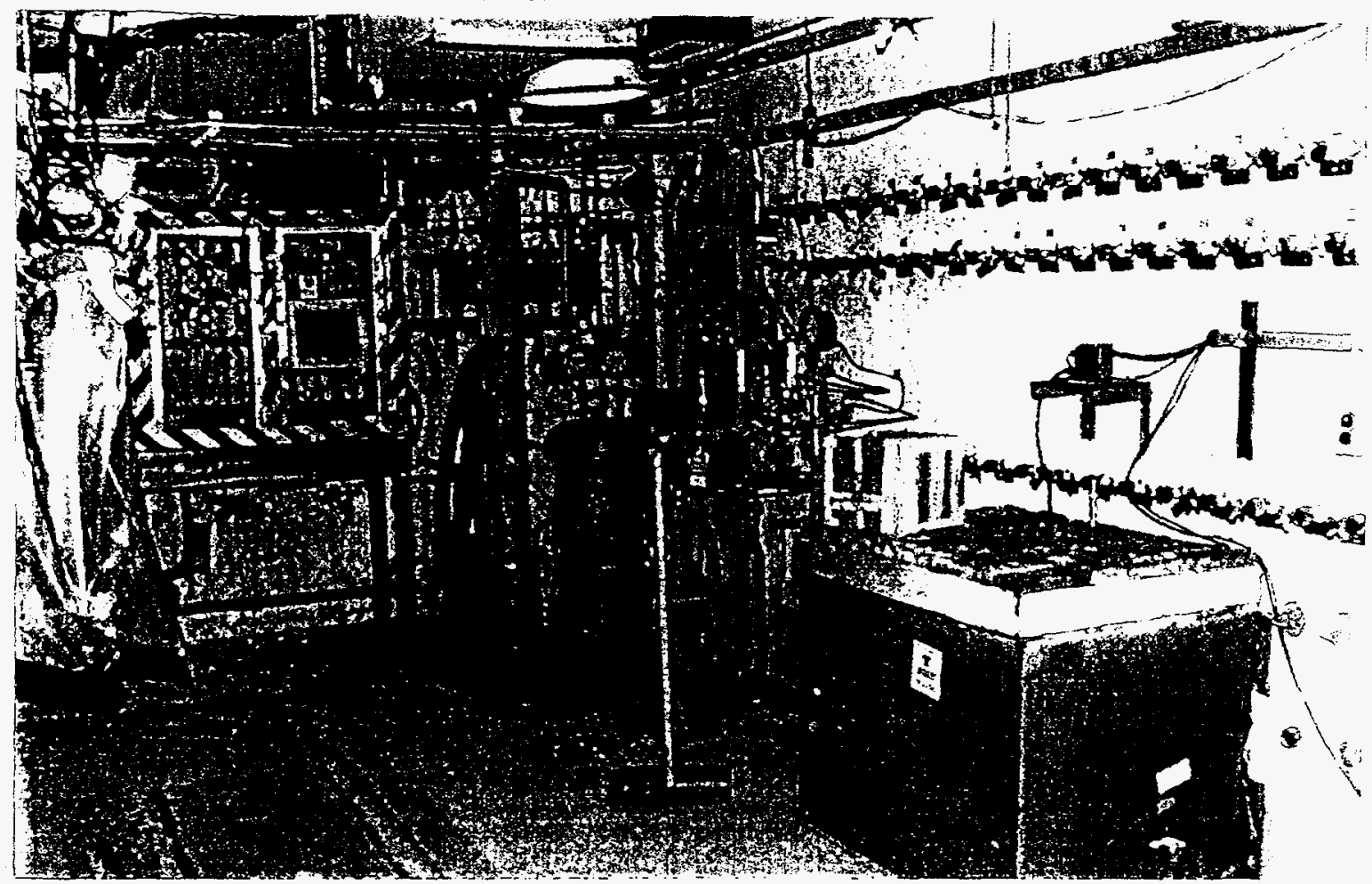

Figure 17. The Monitor Room at the -52-Foot Level. This room is located beneath the pin room. On the left you can see the sample station. In the middle stands the building sump pump, with the 350 gallon sump below. The box to the right in the picture contains delay coils for a photoneutron monitoring instrument. Lead bricks on the box could become mixed waste.

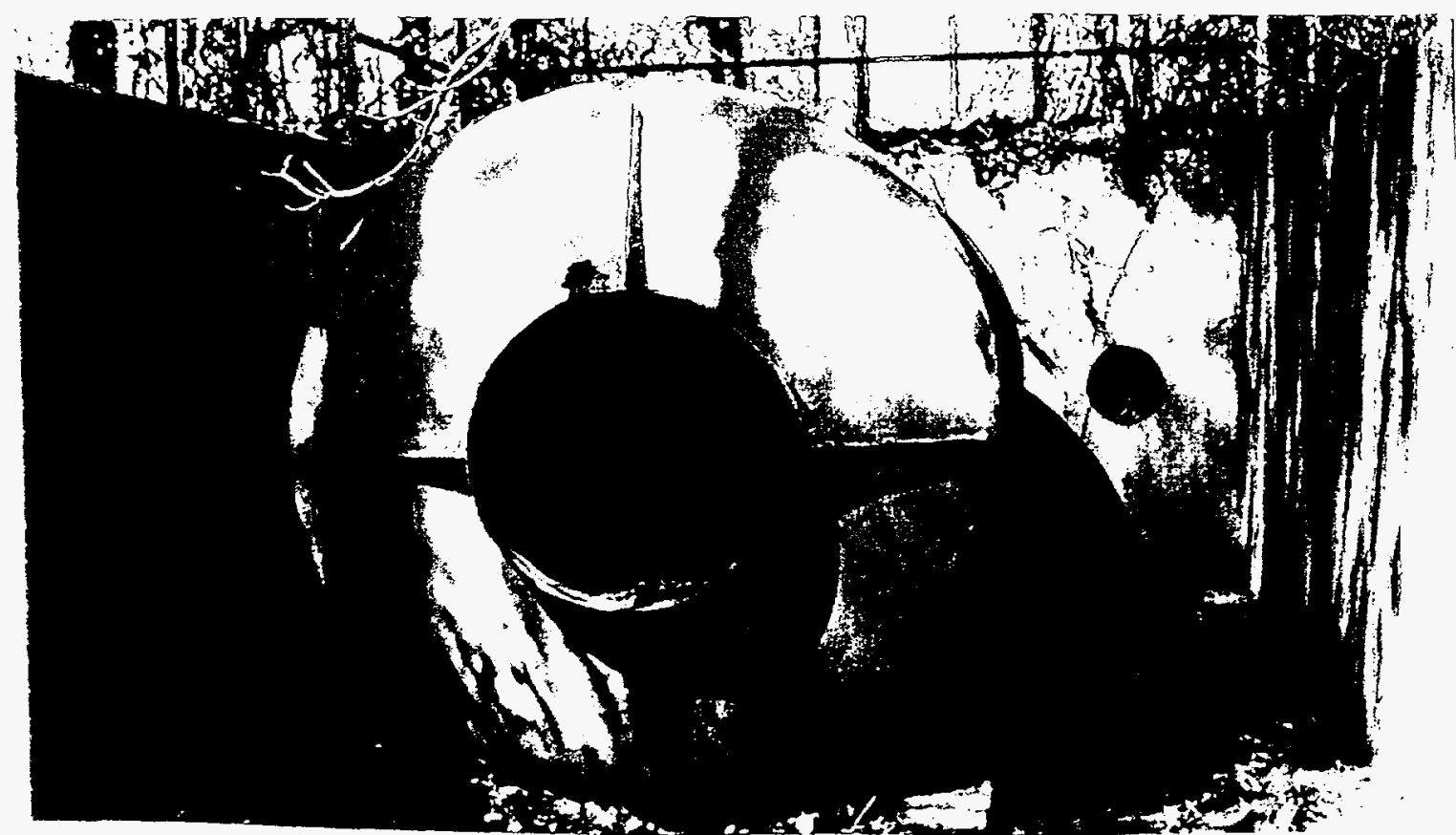

Figure 18. The Steam Muffler. This seven-foot-diameter silencer lies in a wooded area 100 meters east of the reactor building. It contains low levels of radioactive contamination which entered the steam system through leaking joints in the steam generators. 


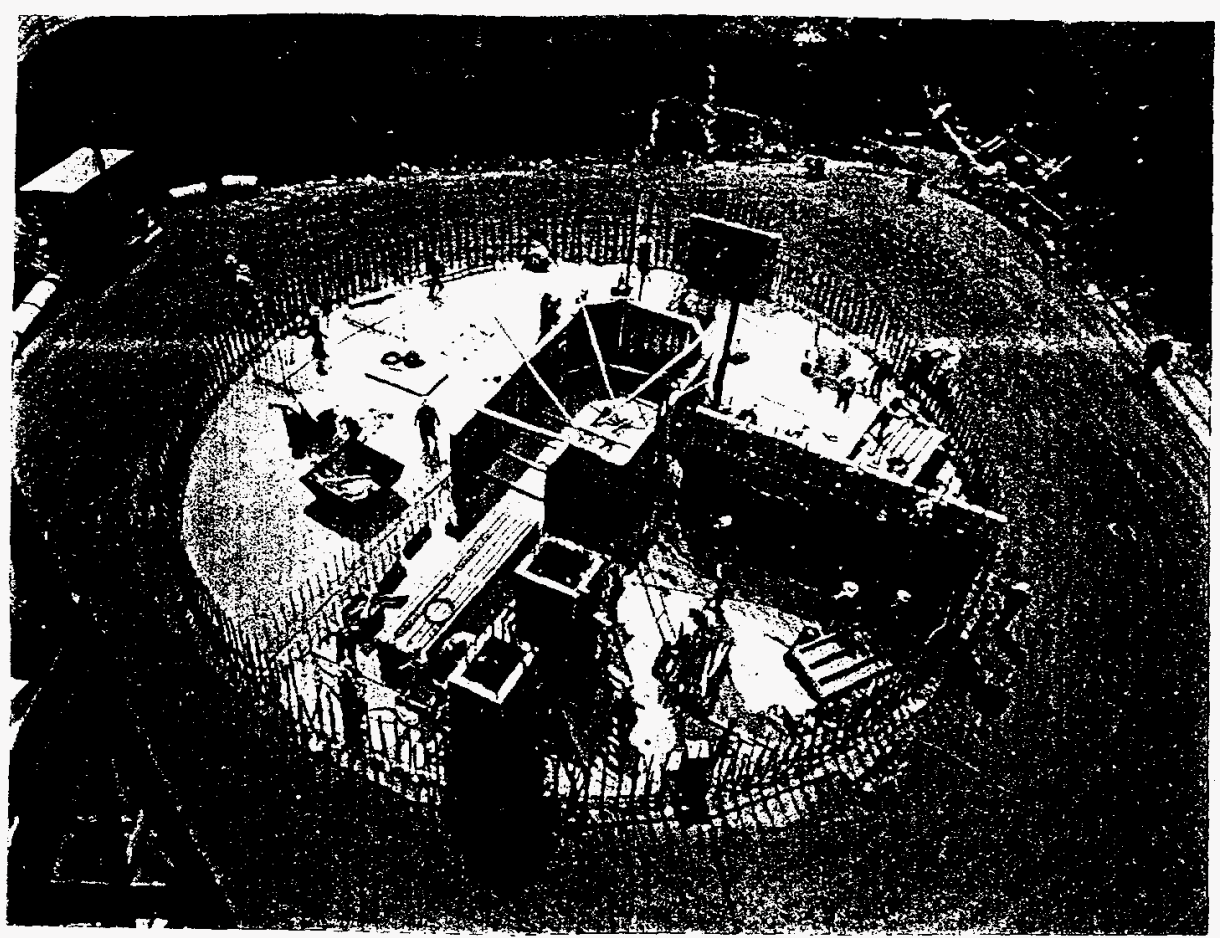

Figure 19. Construction photograph Showing Base Mat. Here you can see the base mat - the reinforced concrete floor at the-52-foot level in the center of the floor stand the monotor room walls

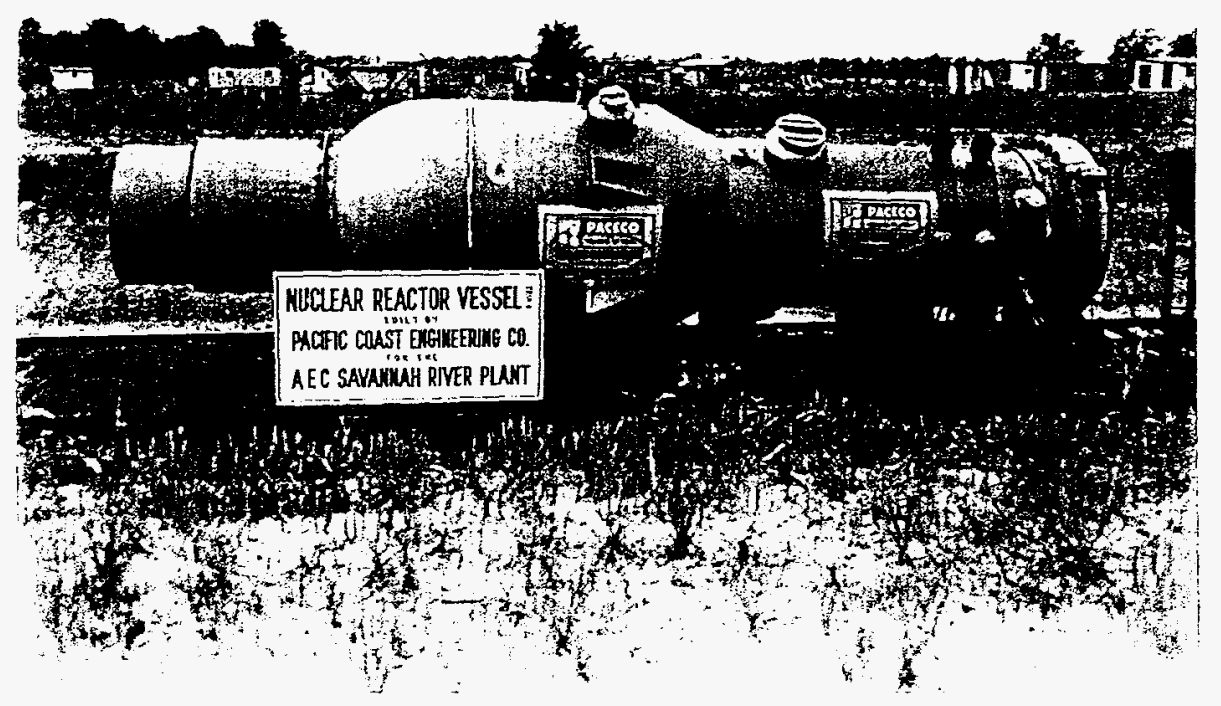

Figure 20. The New HWCTR Reactor Vessel. 


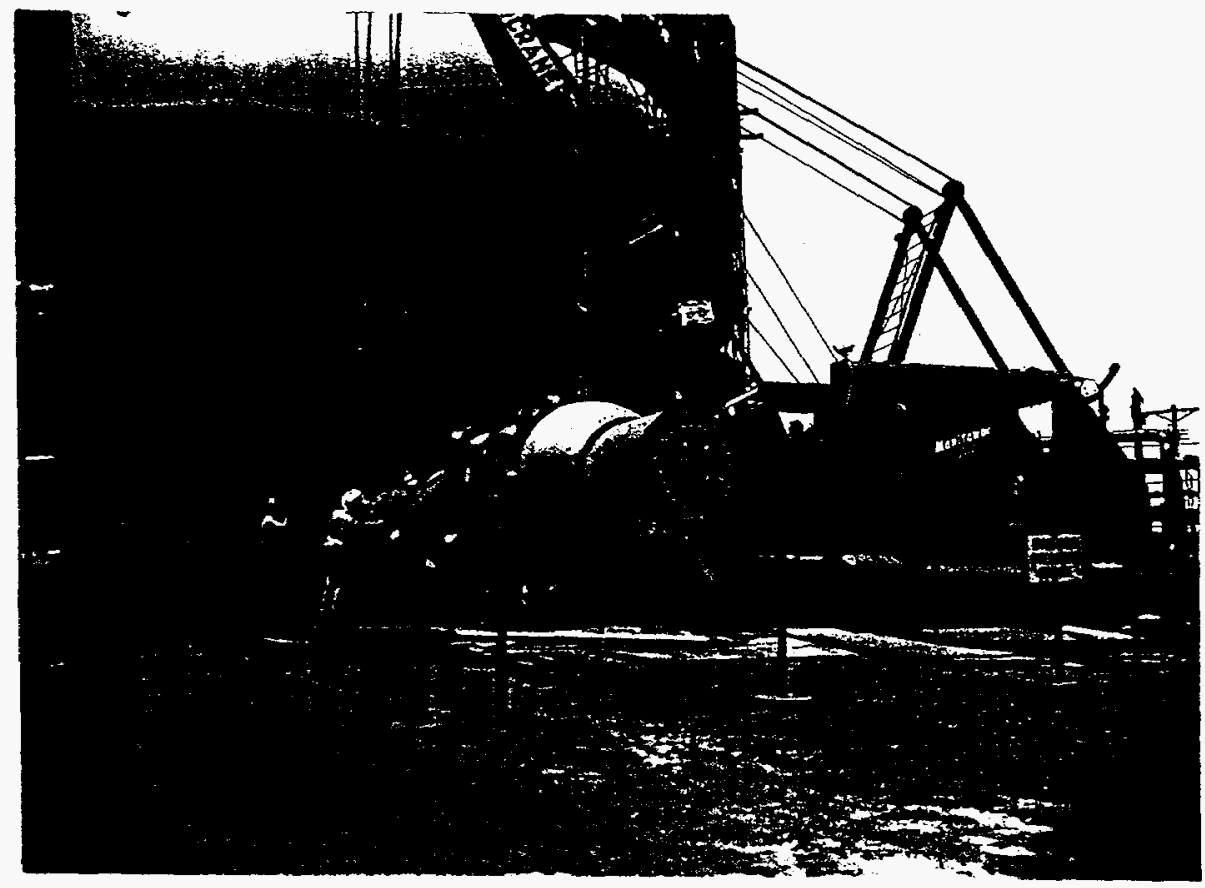

Figure 21. Construction Photograph Showing Reactor Vessel Outside of Building. On July 3, 1961, the vessel is positioned for movement into the containment building.

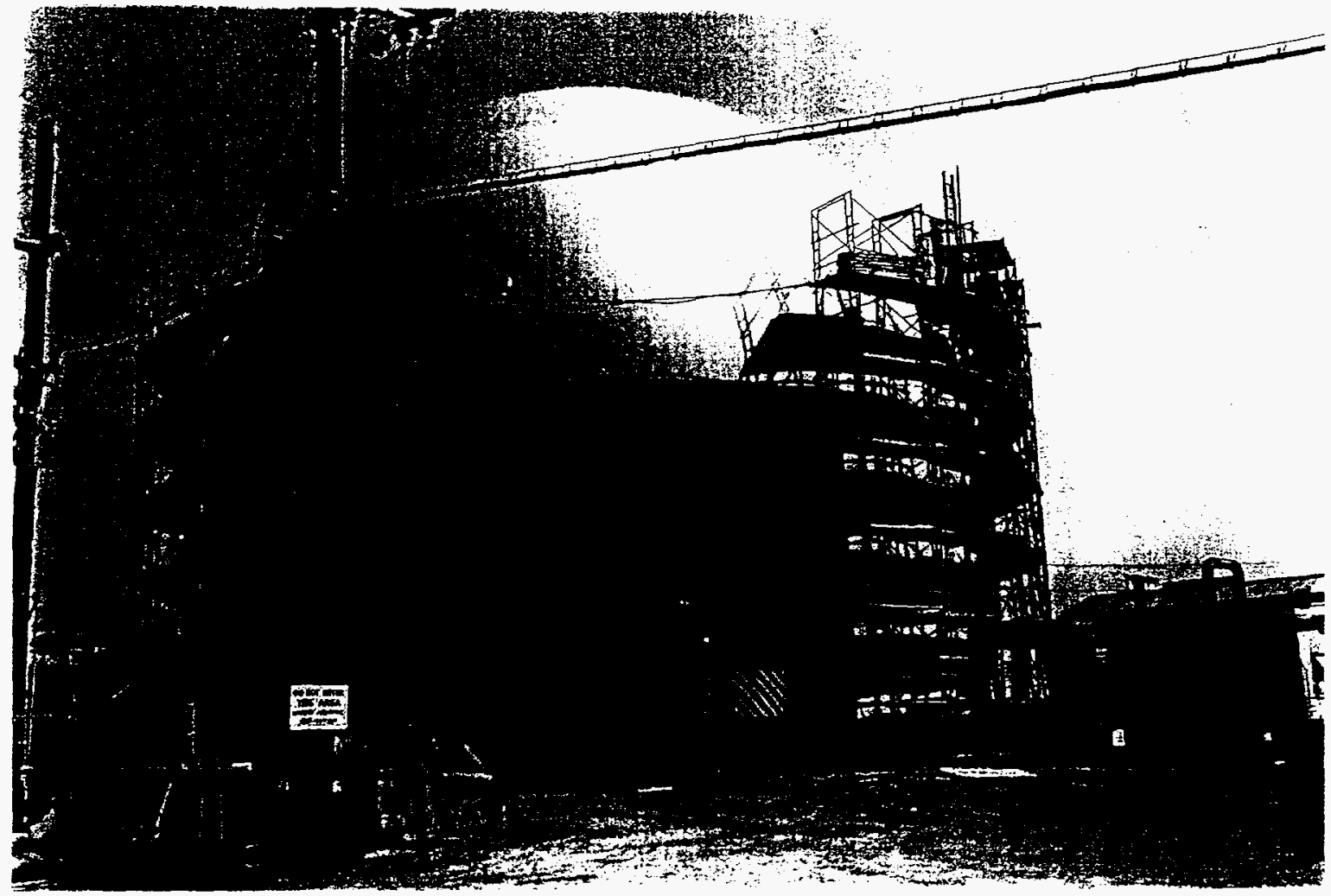

Figure 22. Construction Photograph Showing Outside of Dome. The mobile crane used to install the reactor vessel can be seen inside the opening. The equipment hatch presently in this location measures seven feet by seven feet. A larger opening will be cut to facilitate removal of large equipment during the decommissioning work. 


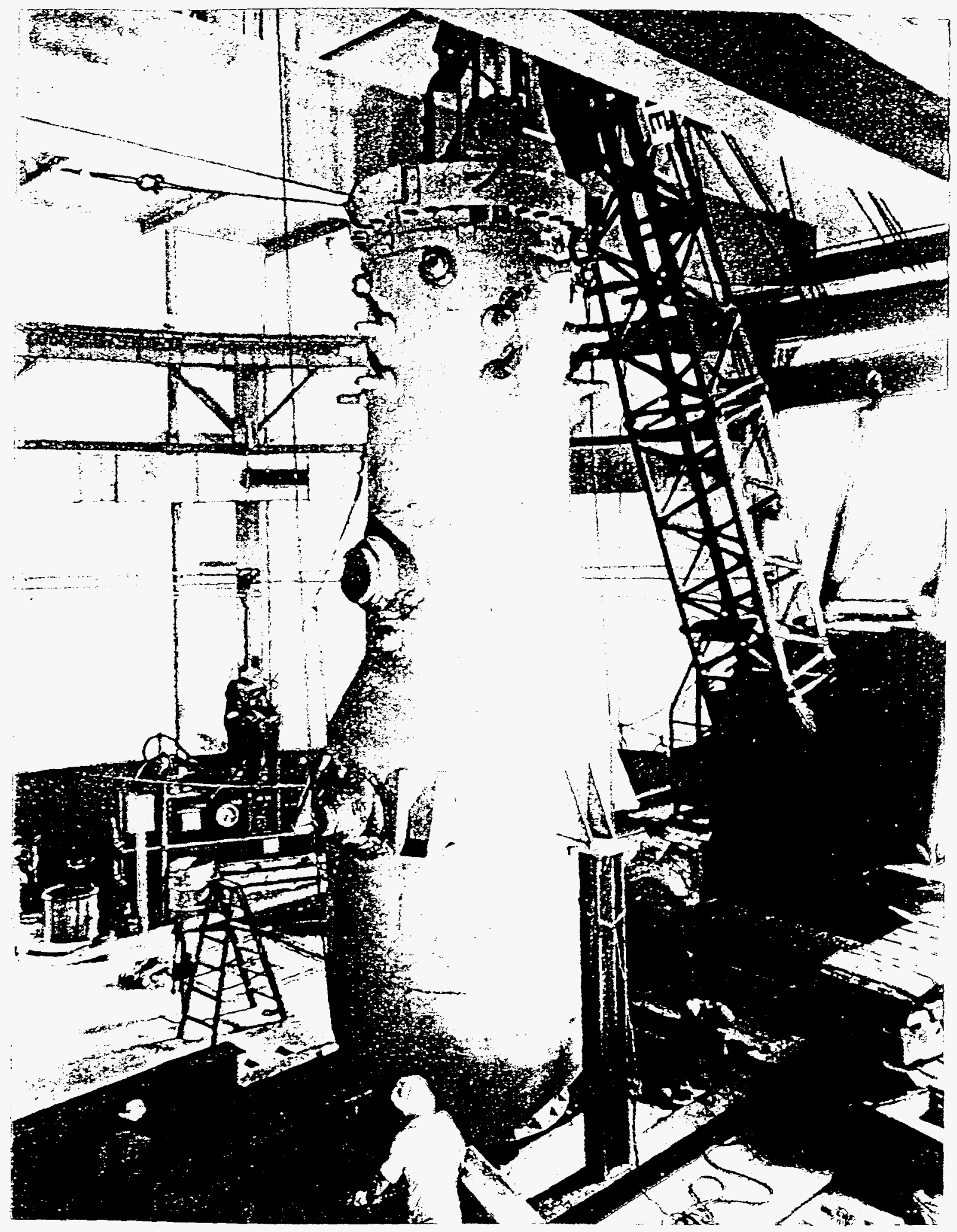

Figure 23. Construction Photograph Showing Reactor Vessel Being Moved Into Position. The vissel stands 30 feet high with a maximum inside diameter of seren feet it is made of carbon :iect clat un the

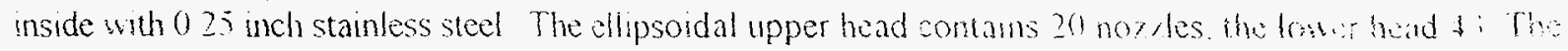
shell contans 25 nozzles ranging from 075 inch to 16 inches w dianctet 


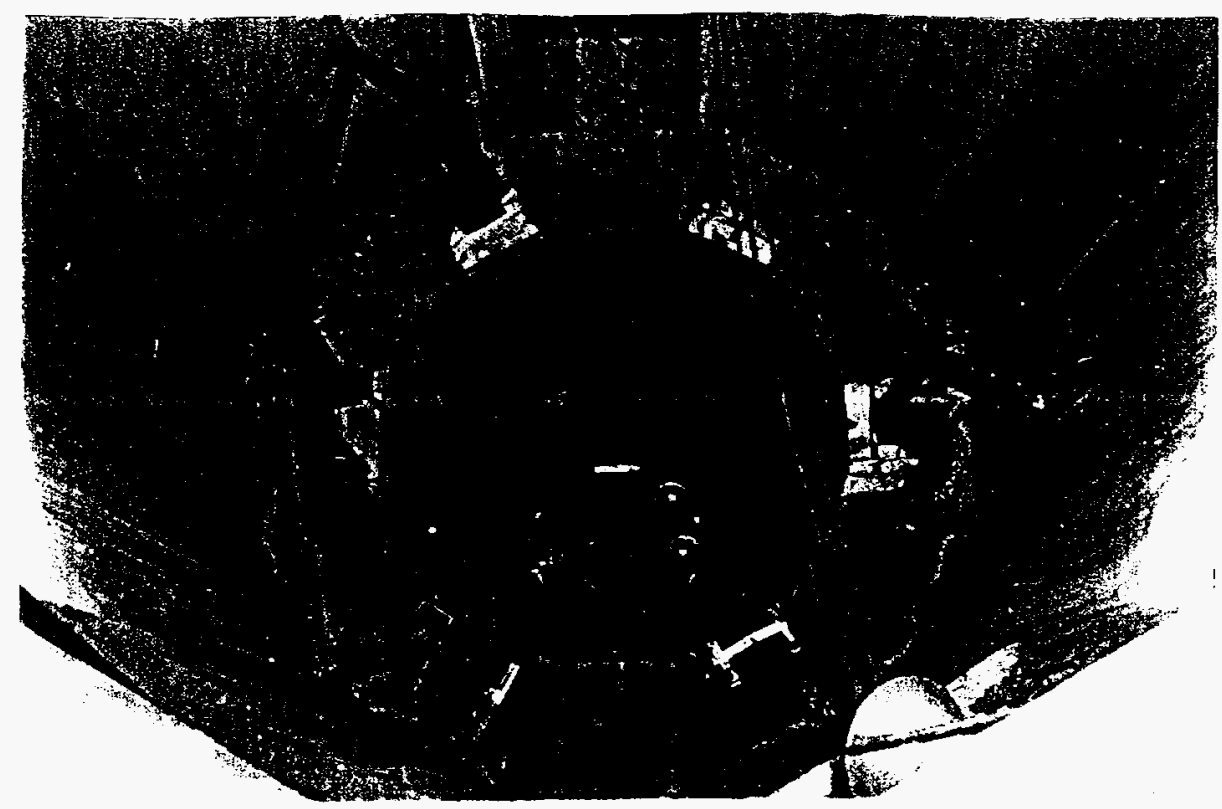

Figure 24. Construction Photograph Showing inside of the Biological Shield. This view shows the reinforced concrete shielding prior to installation of the reactor vessel. The outer walls are 42 or more inches thick. The thichness of the inner wall below the ledge is 30 inches.

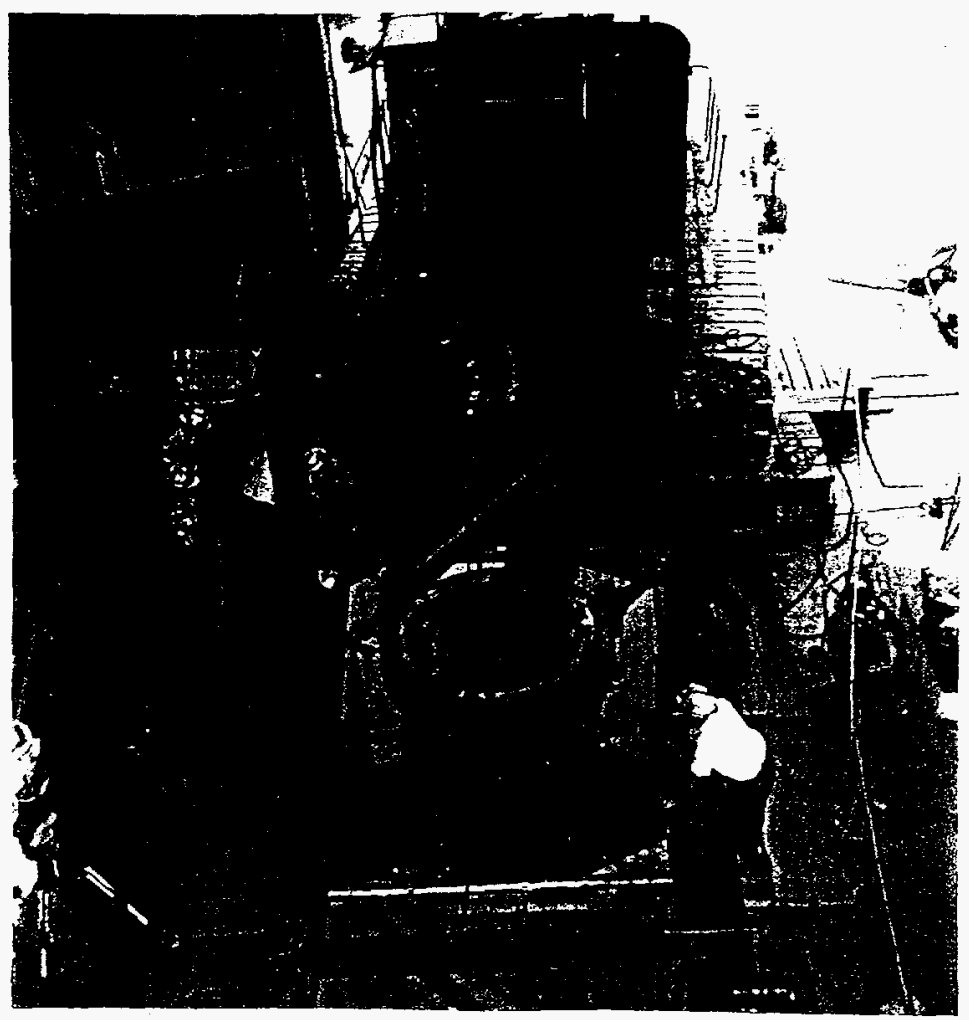

Figure 25. Construction Photograph Showing Reactor Vessel Being Lowered Into Position. 


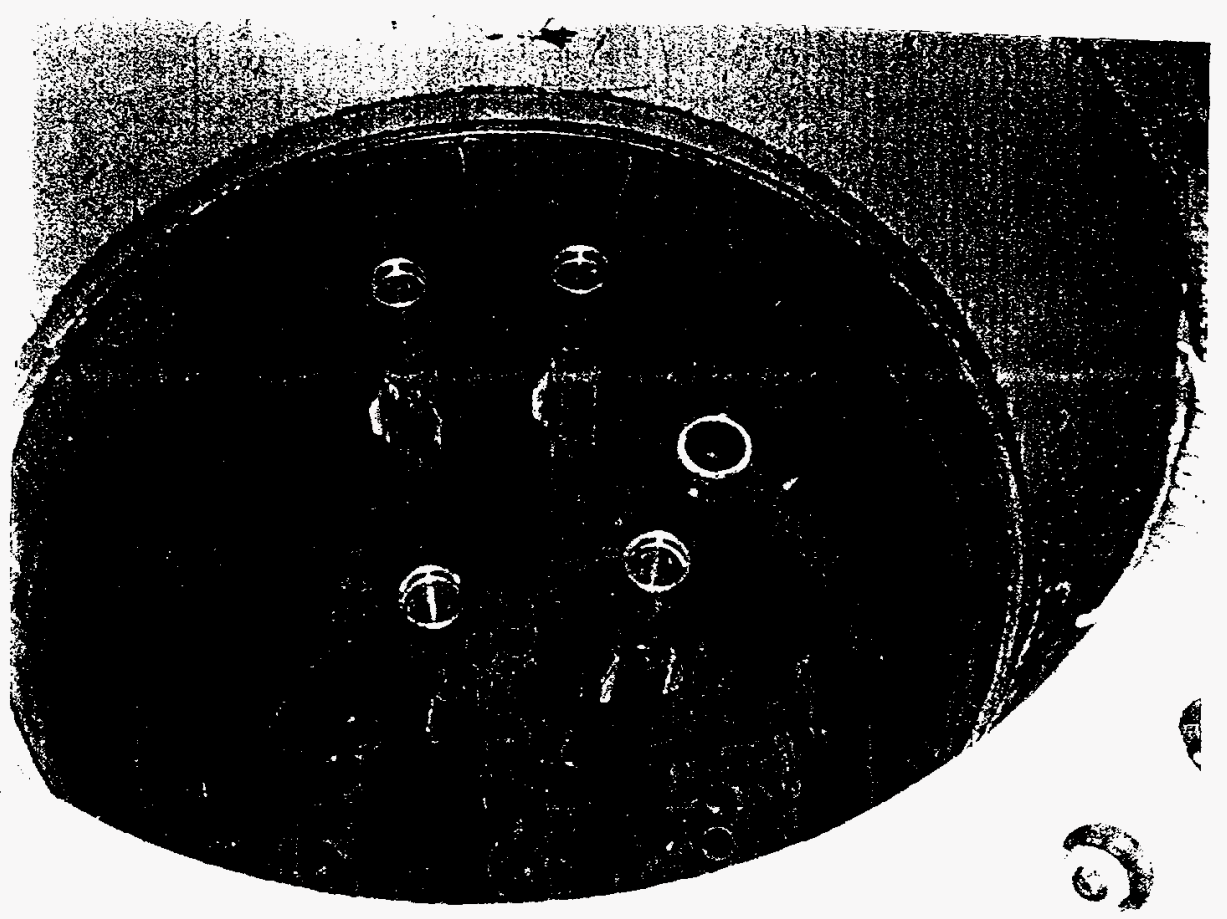

Figure 26. Construction Photograph Showing Interior of Reactor Vessel. At this point a number of vessel components were not yet installed Note the piping to the isolated coolant loop "bayonet" on the lower right. Two such bayonet fixtures were installed to test fuel assemblies under different conditions from those found in the vessel. Only one - the isolated liquid loop - was actually used

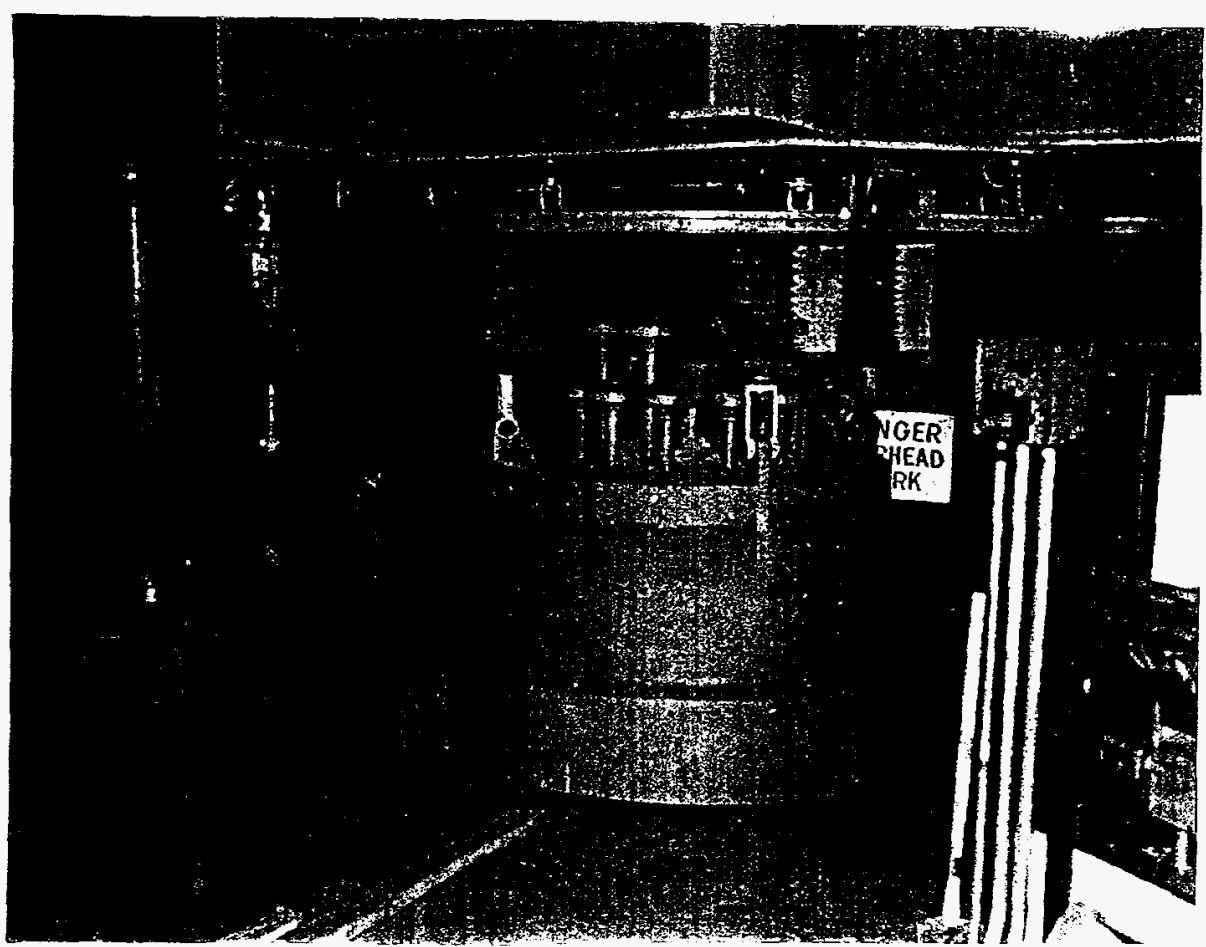

Figure 27. The Reactor Vessel Head. In this view, the ellipsoidal head is not positioned over the reactor but is located in the stored position which it occupied during fuel assembly charge-discharge operations 


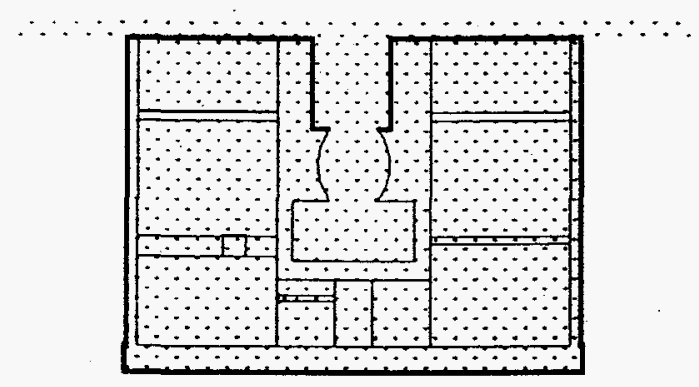

(1) Dismantlement (DECON, Greenfields)

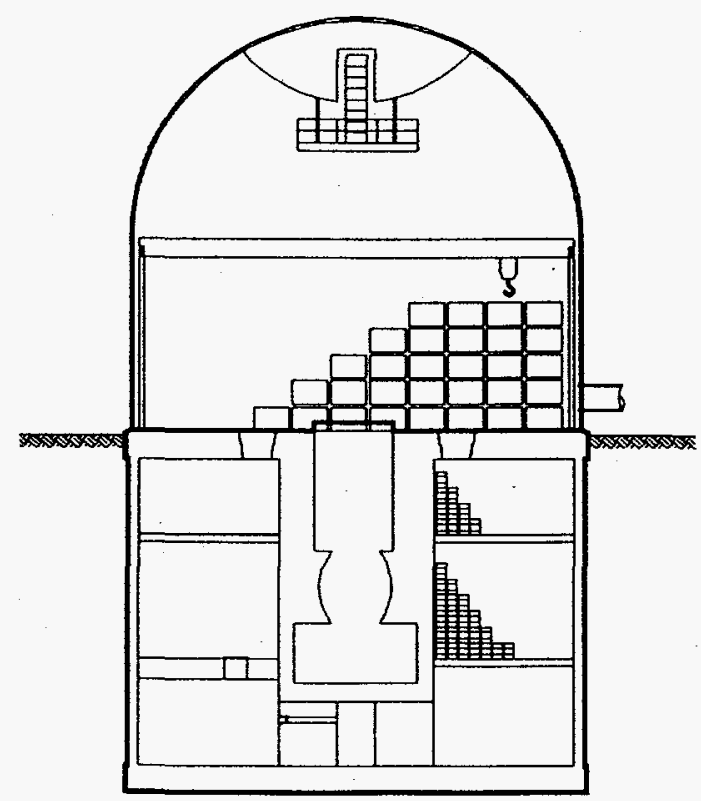

(3) Partial Dismantlement Beneficial Use

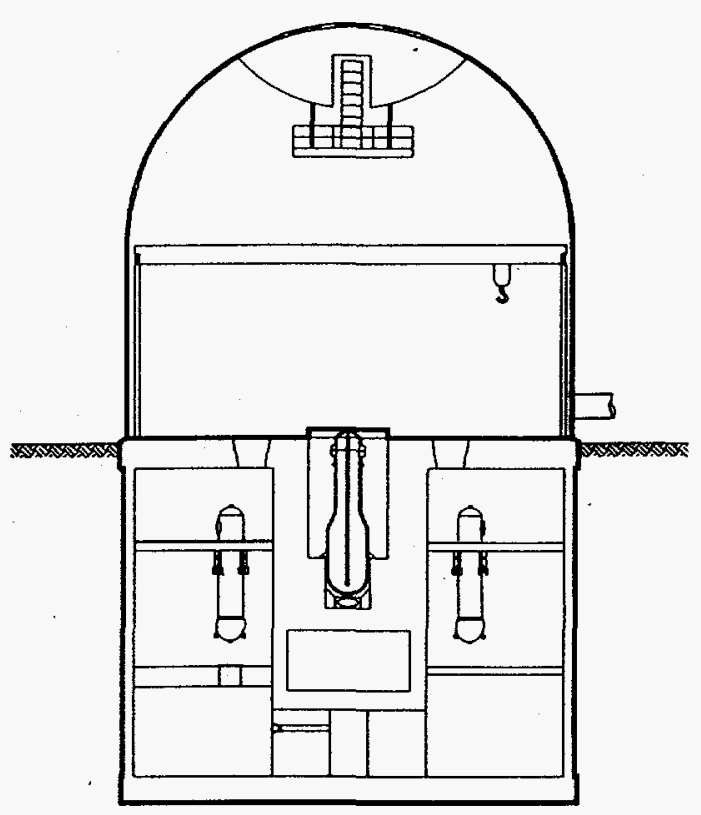

(2) Partial Dismantlement Cocooning

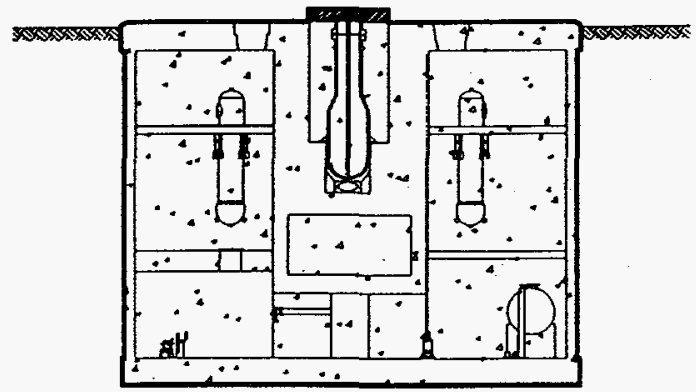

(4) Entombment (ENTOMB)

Figure 29. Concepts of Alternatives 


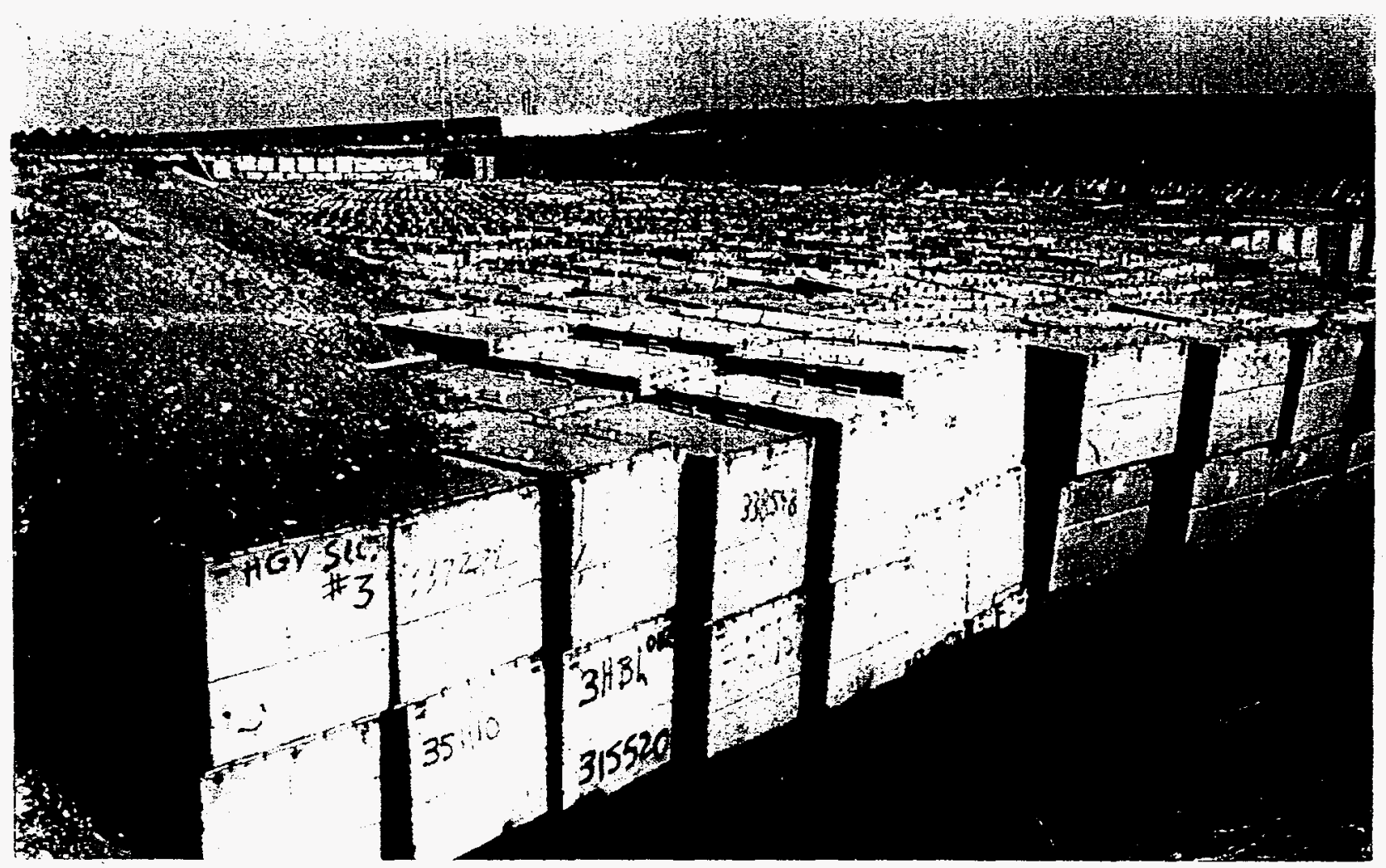

Figure 32. Engineered Trench for Low-Level Radioactive Waste. A trench like this in the Savannah River Site Solid Waste Disposal Facility may be used for disposal of the HWCTR reactor vessel and steam generators if they are removed during the decommissioning. Located in E-Area, this facility is approximately three miles from the HWCTR property

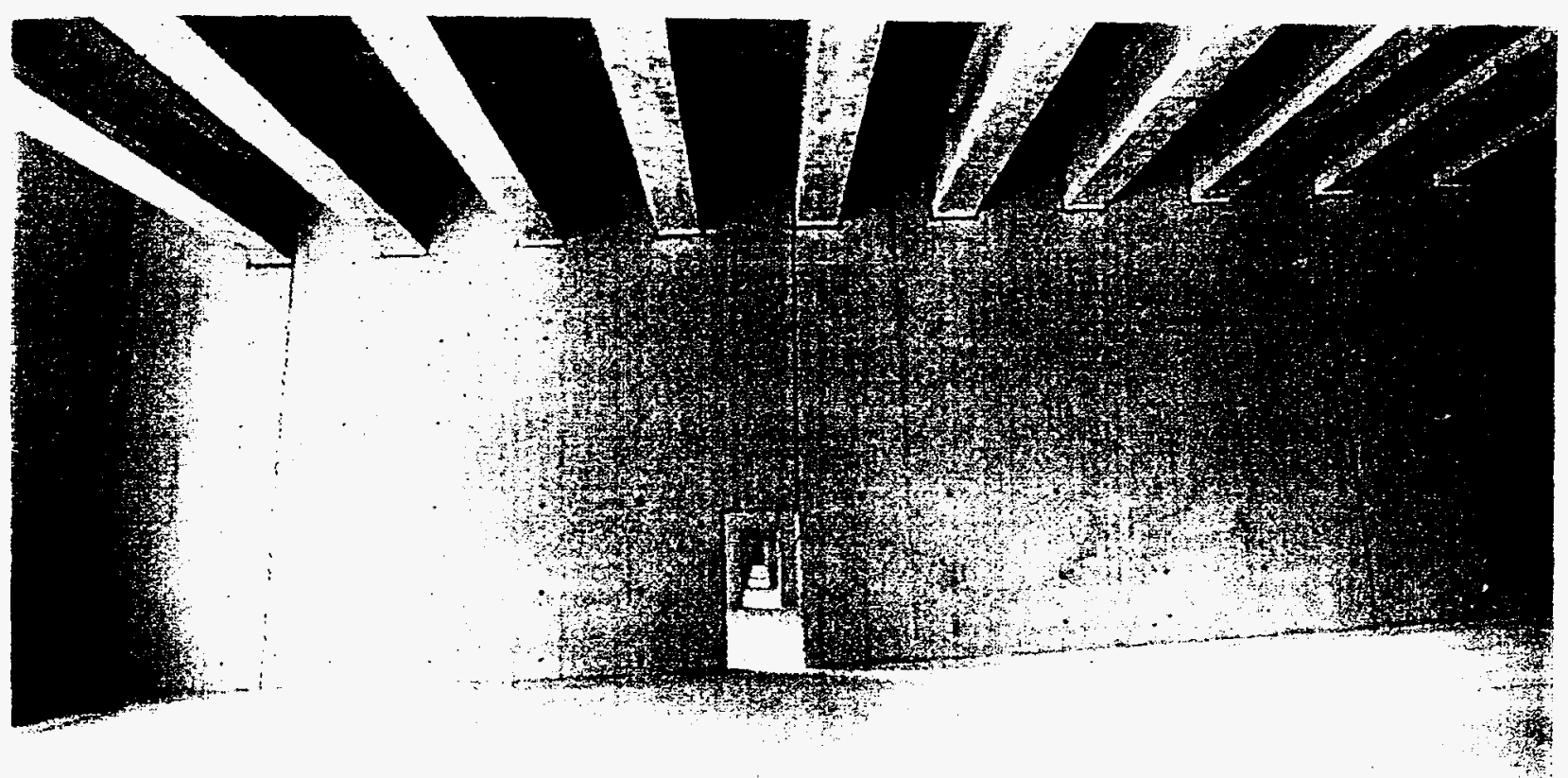

Figure 33. E-Area Vaults. Other low-level radioactive waste from the HWCTR project is expected to be disposed of in vaults like this at the Savannah River Site. Most of the waste will be packaged in steel boxes such as those in the upper photograph Each vault is 55 feet long. 150 feet wide and 30 feet high Once full, wey will be covered with clay to form a mound with a plant cover 


\section{Appendix B}

\section{List of HWCTR Equipment}


Analysis of HWCTR Removal Alternatives

\begin{tabular}{|c|c|}
\hline $\begin{array}{l}\text { EQUIPMENT } \\
\text { PIECE } \\
\text { NUMBER }\end{array}$ & COMPONENT NAME \\
\hline EP. 1 & REACTOR VESSEL \\
\hline EP-20.1 & STEAM GENERATOR \\
\hline EP-20.2 & STEAM GENERATOR \\
\hline EP-21.1 & MAIN PUMP - \\
\hline EP-21.2 & MAIN PUMP• \\
\hline EP. 22 & SEAL SUPPLY TANK \\
\hline EP-40.1 & MAIN PURGE COOLER \\
\hline EP. 40.2 & MAIN PURGE COOLER \\
\hline EP. 41 & MAIN STORAGE TANK \\
\hline EP- 42 & INTERMITTENT MAKE-UP PUMP \\
\hline EP. 43 & SEAL POT \\
\hline EP. 44.1 & MAIN SYSTEM DEIONIZER \\
\hline EP. 44.2 & MAIN SYSTEM DEIONIZER \\
\hline EP. 45 & MAIN AFTERFILTER \\
\hline$E P-46$ & PURIFICATION PUMP \\
\hline EP-47 & PURIFICATION COLLECTION TANK \\
\hline EP. 50 & PLATFORM SCALE \\
\hline EP. 51 & DRAIN TANK \\
\hline EP- 53 & HOLD TANK \\
\hline EP-54 & MAIN SYSTEM PREFILTER \\
\hline$E P-55$ & DRAIN TANK PUMP \\
\hline EP- 60 & POISON TANK \\
\hline EP-84.1 & SEPARATOR \\
\hline EP. 86 & GAS RECOMPRESSOR \\
\hline EP-87 & GAS RECOMPRESSOR \\
\hline EP- 92 & CATCH POT \\
\hline EP-101,1 & SPENT FUEL BASIN COOLER \\
\hline EP-101.2 & SPENT FUEL BASIN COOLER \\
\hline EP-102.1 & SPENT FUEL BASIN CIRC . PUMP \\
\hline EP-102.2 & SPENT FUEL BASIN CIRC. PUMP \\
\hline EP.103 & SPENT FUEL BASIN DEIONIZER \\
\hline EP-104 & SPENT FUEL BASIN FILTER \\
\hline EP-105 & HOLD TANK \\
\hline EP-106 & DISPOSAL PUMP \\
\hline EP-159 & BLDG. SUMP PUMP \\
\hline EP-176 & BOILING LOOP QUENCHER \\
\hline$E P-178.1$ & BOILING LOOP CIRC. PUMP \\
\hline EP-178.2 & BOILING LOOP CIRC. PUMP \\
\hline EP.180 & ISOLATED COOLING LOOP SEAL PUMP \\
\hline EP-181 & ISOLATED COOLING LOOP SEAL SUPPLY TANK \\
\hline EP-185 & BAYONET \\
\hline EP-186.1 & LIQUID LOOP PUMP \\
\hline EP-186.2 & LIQUID LOOP PUMP \\
\hline EP-187 & LIQUID LOOP COOLER \\
\hline EP-191 & LIQUID LOOP PURGE COOLER \\
\hline EP-192.1 & ISOLATED COOLING LOOP DEIONIZER \\
\hline EP-192.2 & ISOLATED COOLING LOOP DEIONIZER \\
\hline EP-193 & ISOLATED COOLING LOOP AFTERFILTER \\
\hline
\end{tabular}

WSRC-TR-96-0268

Revision 1

\begin{tabular}{|c|c|c|c|}
\hline LOCATION & WEIGHT & SIZE & $\begin{array}{l}\text { VOLUME } \\
\text { Cu. Ft. }\end{array}$ \\
\hline $0^{\prime} \cdot 0^{\prime \prime}$ & 98 TONS & $37^{\prime} \times 10^{\prime} 5^{\prime \prime} \times 7^{\prime} 9^{\prime \prime}$ & 3000 \\
\hline$\left(-16^{\circ}-3^{\prime \prime},(-) 37^{\prime}-6^{\prime \prime}\right.$ & 38,000 POUNDS & $23^{\prime} 3^{11} \times 6^{\prime} 1^{11} \times 6^{\prime} 1^{\prime \prime}$ & 860 \\
\hline$(-) 16^{\prime}-3^{\prime \prime},(-) 37^{\prime}-6^{\prime \prime}$ & 38,000 POUNDS & $23^{\prime} 3^{\prime \prime} \times 6^{\prime} 1^{\prime \prime} \times 6^{\prime} 1^{\prime \prime}$ & 860 \\
\hline$\left(-16^{\prime}-3^{\prime \prime}\right.$ & & $12^{\prime} 8^{\prime \prime} \times 7^{\prime} 6^{\prime \prime} \times 7^{\prime} 6^{\prime \prime}$ & 546 \\
\hline$(-)^{16^{\prime}-3^{\prime \prime}}$ & & $12^{\prime} 8^{\prime \prime} \times 7^{\prime} 6^{\prime \prime} \times 7^{\prime} 6^{\prime \prime}$ & 546 \\
\hline+52 & 1,075 POUNDS & $5^{\prime} \times 30^{\prime \prime} \times 26^{\prime \prime}$ & 27 \\
\hline$(-) 37^{\prime} \cdot 6^{\prime \prime}$ & & $18^{\prime} \times 2^{\prime} \times 2^{\prime} 6^{\prime \prime}$ & 95 \\
\hline$(-) 37^{\prime}-6^{\prime \prime}$ & & $19^{\prime} \times 2^{\prime} \times 2^{\prime} 6^{\prime \prime}$ & 95 \\
\hline$\left(-52^{\prime} \cdot 6^{n}\right.$ & 9100 POUNDS (EMPTY & $20^{\circ} 8^{\prime \prime} \times 9^{\prime} \times 9^{\prime}$ & 1660 \\
\hline$\left(-52^{\prime}-6^{\prime \prime}\right.$ & 3,000 POUNDS & $7^{\prime} \times 5^{\prime} 9^{\prime \prime} \times 2^{\prime} 10^{\prime \prime}$ & 113 \\
\hline$(-) 37^{\prime}-6^{\prime \prime}$ & 2,100 POUNDS & $13^{\prime} \times 2^{\prime} 8^{\prime \prime} \times 2^{\prime} 8^{\prime \prime}$ & 92 \\
\hline$(-) 37^{\prime}-6^{\prime \prime}$ & 29,600 POUNDS & $5^{\prime} 8^{\prime \prime} \times 4^{\prime} 8^{\prime \prime} \times 3^{\prime} 8^{\prime \prime}$ & 97 \\
\hline$\left(-37^{\prime}-6^{\prime \prime}\right.$ & 29,600 POUNDS & $5^{\prime} 8^{\prime \prime} \times 4^{\prime} 8^{\prime \prime} \times 3^{\prime} 8^{\prime \prime}$ & 97 \\
\hline$(-)^{3} 7^{\prime} \cdot 6^{\prime \prime}$ & 1,900 POUNDS & $35^{\prime \prime} \times 2 \times 2$ & 14 \\
\hline$(-) 37^{\prime}-6^{\prime \prime}$ & 250 POUNDS & $5^{\prime} 1^{\prime \prime} \times 26^{\prime \prime} \times 26^{\prime \prime}$ & 24 \\
\hline & & & \\
\hline$\left(-52^{\prime}-6^{\prime \prime}\right.$ & 275 POUNDS (EMPTM & $4^{\prime} \times 32^{\prime \prime} \times 32^{\prime \prime}$ & 28 \\
\hline$(-) 52^{\prime} \cdot 6^{\prime \prime}$ & 540 POUNDS (EMPTM & $11^{\prime} 8^{\prime \prime} \times 21^{\prime \prime} \times 21^{11}$ & 36 \\
\hline$(-)^{3} 7^{\prime}-6^{\prime \prime}$ & 11,150 POUNDS & $6^{\prime} \times 3^{1} \times 3^{1}$ & 54 \\
\hline$+52^{\prime}$ & 2050 POUNDS (EMPTY & $6^{\prime} 9^{\prime \prime} \times 2^{\prime} \times 2^{\prime \prime}$ & 27 \\
\hline $0^{0}-0^{n}$ & 344 POUNDS & $5^{\prime} 2^{\prime \prime} \times 14^{\prime \prime} \times 14^{\prime \prime}$ & $\frac{21}{7}$ \\
\hline$\left(-152^{\prime}-6^{\prime \prime}\right.$ & & $8^{\prime} 6^{\prime \prime} \times 5^{\prime} \times 4^{\prime}$ & 170 \\
\hline$\left(-52^{\prime} \cdot 8^{\prime \prime}\right.$ & & $8^{\prime} 6^{\prime \prime} \times 5^{\prime} \times 4^{\prime}$ & 170 \\
\hline$(-)^{5} 2^{\prime} \cdot 8^{\prime \prime}$ & & $46^{\prime \prime} \times 30^{\prime \prime} \times 30^{\prime \prime}$ & 24 \\
\hline$(-) 52^{\prime}-6^{\prime \prime}$ & 2,800 POUNDS & $13^{\prime} \times 26^{\prime \prime} \times 13^{\prime \prime}$ & 30 \\
\hline$(-) 52^{\prime} \cdot 6^{\prime \prime}$ & 2,800 POUNDS & $13^{\prime} \times 26^{\prime \prime} \times 13^{\prime \prime}$ & 30 \\
\hline & & & \\
\hline$\left(-152^{\prime}-6^{\prime \prime}\right.$ & 24,775 POUNDS & $5^{\prime} 7^{\prime \prime} \times 4^{\prime} 4^{\prime \prime} \times 4^{\prime} 4^{\prime \prime}$ & 11 \\
\hline $6-52^{\prime} \cdot 6^{\prime \prime}$ & 24,000 POUNDS & $5^{\prime} 7^{\prime \prime} \times 4^{\prime} 4^{\prime \prime} \times 4^{\prime} 4^{\prime \prime}$ & 105 \\
\hline$\left(-116^{\prime}-3^{\prime \prime}\right.$ & 640 POUNDS (EMPTM & $9^{\prime} 2^{11} \times 3^{1} \times 3^{\prime}$ & 83 \\
\hline & & & \\
\hline & & & \\
\hline$\left(-137^{\prime}-6^{\prime \prime}\right.$ & 4,000 POUNDS & $7^{\prime} 1^{\prime \prime} \times 4^{\prime} 4^{\prime \prime} \times 3^{\prime} 4^{\prime \prime}$ & 102 \\
\hline$\left(-237^{\prime}-6^{\prime \prime}\right.$ & 4,000 POUNDS & $7^{\prime} 1^{\prime \prime} \times 4^{\prime} 4^{\prime \prime} \times 3^{\prime} 4^{\prime \prime}$ & 102 \\
\hline$(-) 52^{\prime}-6^{\prime \prime}$ & & $35^{\prime \prime} \times 29^{\prime \prime} \times 38^{\prime \prime}$ & 22 \\
\hline$+52^{1}$ & 1,400 POUNDS & $4^{\prime} \times 24^{\prime \prime} \times 24^{\prime \prime}$ & 16 \\
\hline$\left(-16^{\prime}-3^{\prime \prime}\right.$ & 4000POUNDS (EMPTM & $7^{\prime} 1^{\prime \prime} \times 4^{\prime} 3^{\prime \prime} \times 3^{\prime} 4^{\prime \prime}$ & 102 \\
\hline$\left(-16^{\prime}-3^{\prime \prime}\right.$ & 4000POUNDS (EMPM & $7^{\prime} 1^{\prime \prime} \times 4^{\prime} 3^{\prime \prime} \times 3^{\prime} 4^{\prime \prime}$ & 102 \\
\hline$\left(-16^{\prime}+3^{\prime \prime}\right.$ & 2400POUNDS (EMPTM & $12^{\prime} 10^{\prime \prime} \times 2^{\prime} 2^{\prime \prime} \times 2^{\prime} 2^{\prime \prime}$ & 52 \\
\hline$\left(-37^{\prime} \cdot 6^{\prime \prime}\right.$ & 275 POUNDS & $32^{\prime \prime} \times 23^{\prime \prime} \times 25^{\prime \prime}$ & 11 \\
\hline & & & \\
\hline$(-) 37^{\prime}-6^{\prime \prime}$ & 1,900 POUNDS & $4^{\prime} \times 2^{\prime} 7^{\prime \prime} \times 2^{\prime}$ & $\overline{21}$ \\
\hline
\end{tabular}

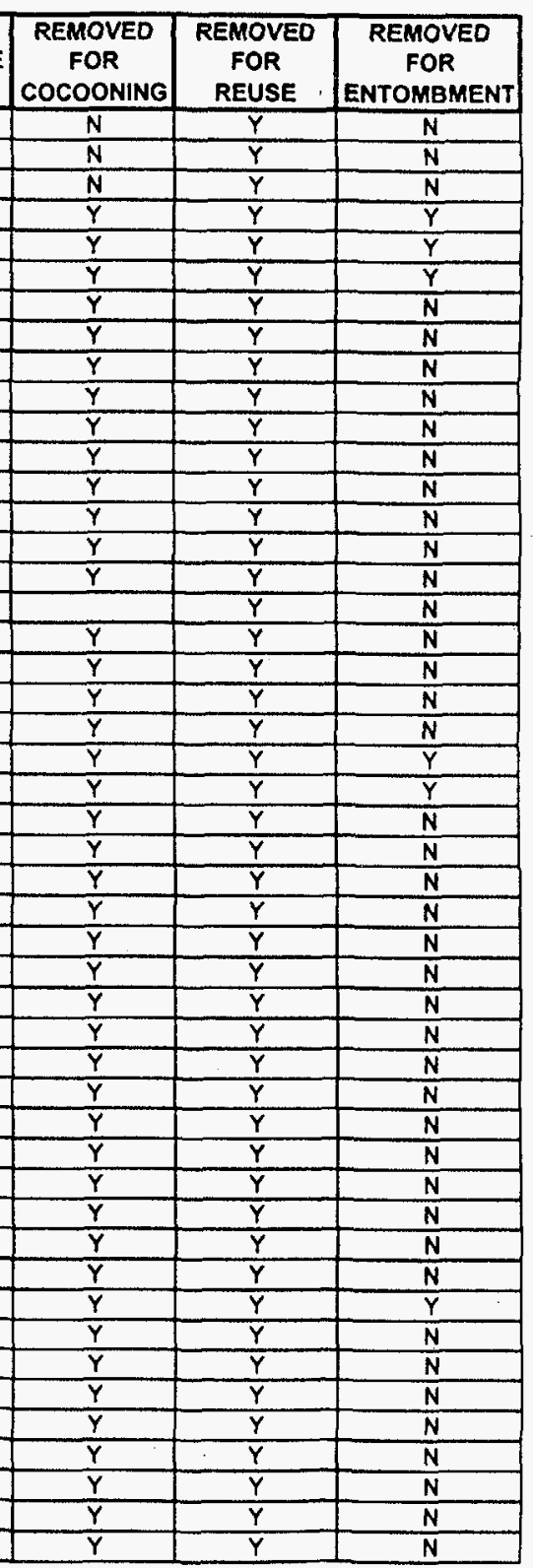

Appendix B 
Analysis of HWCTR Removal Alternatives

\begin{tabular}{|c|c|c|c|c|c|c|c|c|}
\hline $\begin{array}{l}\text { EQUIPMENT } \\
\text { PIECE } \\
\text { NUMBER }\end{array}$ & COMPONENT NAME & LOCATION & WEIGHT & SIZE & $\begin{array}{c}\text { VOLUME } \\
\text { Cu. Ft. }\end{array}$ & \begin{tabular}{|c|} 
REMOVED \\
FOR \\
COCOONING \\
\end{tabular} & $\begin{array}{c}\text { REMOVED } \\
\text { FOR } \\
\text { REUSE } \\
\end{array}$ & \begin{tabular}{|c|} 
REMOVED \\
FOR \\
ENTOMBMENT \\
\end{tabular} \\
\hline EP-194 & D2O STORAGE TANK & $\left(-152^{\prime}-8^{\prime \prime}\right.$ & & & & $Y$ & $\bar{Y}$ & $\bar{N}$ \\
\hline EP-195 & ISOLATED COOLING LOOP SEAL PUMP & $\left(-152^{\prime}-8^{\prime \prime}\right.$ & & $35^{\prime \prime} \times 29^{\prime \prime} \times 38^{\prime \prime}$ & 22 & $\bar{Y}$ & $\bar{Y}$ & $\mathrm{~N}$ \\
\hline EP.197 & PURIFICATION PUMP & & & & & $\bar{Y}$ & $\bar{Y}$ & $\bar{N}$ \\
\hline EP-198 & ISOLATED COOLING LOOP SEAL HOLO TANK & +52 & 1,400 POUNDS & $4^{\prime} \times 24^{\prime \prime} \times 24^{\prime \prime}$ & 18 & $\bar{Y}$ & $\bar{Y}$ & $\bar{Y}$ \\
\hline EP-256 & ROD DRIVE PLATFORM & $0^{\prime}-0^{n}$ & & $8^{\prime} \times 14^{\prime} 8^{n} \times 9^{\prime} 4^{\prime \prime}$ & 1090 & $\bar{Y}$ & $\bar{Y}$ & $Y$ \\
\hline EP-270 & TRANSFER COFFIN & $0^{\prime}-0^{\prime \prime}$ & & $25^{\prime} 4^{\prime \prime} \times 2^{\prime} 8^{\prime \prime} \mathrm{D}$ & 192 & $Y$ & $Y$ & $Y$ \\
\hline EP.278 & SPENT FUEL BASIN GANTRY & & & & & $\bar{Y}$ & $\bar{Y}$ & $\bar{Y}$ \\
\hline EP-519 & 25 TON BUILDING CRANE & & & & & $\bar{Y}$ & $\bar{Y}$ & $\bar{Y}$ \\
\hline EP.913.01 & TANK & +52 & & $3^{\prime} \times 24^{\prime \prime} \times 24^{\prime \prime}$ & $12^{\circ}$ & $\mathbf{Y}$ & $\mathbf{Y}$ & $\bar{Y}$ \\
\hline & LOWER AXIAL SHIELD & 1FT. BELOWRV & 6 TONS & $58^{\prime \prime} \times 37^{\prime \prime}$ & 57 & $\bar{Y}$ & $\bar{Y}$ & $\mathbf{N}$ \\
\hline & REACTOR NOZZLES & & & ABOUT 240 OF 10" PIPE & 20 & $\bar{Y}$ & $\bar{Y}$ & $\mathbf{N}$ \\
\hline & REINFORCED CONCRETE & BIOLOGICAL SHIELD & & & 500 & $\bar{Y}$ & $\overline{\mathbf{Y}}$ & $\mathbf{N}$ \\
\hline & FOUR PROCESS VALVES & $\left(-16^{1}-3^{\prime \prime},\left(-37^{\prime} \cdot 6^{\prime \prime}\right.\right.$ & & $4^{1} 8^{n} \times 3^{\prime} \times 2^{\prime}$ & 112 & $\bar{Y}$ & $\bar{Y}$ & $N$ \\
\hline & ONE PROCESS VALVE & $(-)^{1} 6^{\prime}-3^{\prime \prime}$ & & $3^{\prime} \times 2^{\prime} \times 2^{\prime}$ & 12 & $\bar{Y}$ & $\bar{Y}$ & $\mathbf{N}$ \\
\hline & 10 IN. PROCESS PIPING & $\left(-16^{\prime}-3^{\prime \prime},\left(-137^{\prime}-6^{\prime \prime}\right.\right.$ & & $250^{\prime}$ & 180 & $\bar{Y}$ & $\mathbf{Y}$ & $\mathbf{N}$ \\
\hline & 4 IN. PROCESS PIPING & $(-) 16^{\prime}-3^{\prime \prime},(-) 37^{\prime}-6^{\prime \prime},(-) 52^{\prime}-6^{\prime \prime}$ & & $1000^{\prime}$ & 110 & $\bar{Y}$ & $\bar{Y}$ & $\mathbf{N}$ \\
\hline & 12 IN. \& \& IN PROCESS PIPING & OFEET & & $100^{\prime}$ & 60 & $\bar{Y}$ & $\bar{Y}$ & $\bar{Y}$ \\
\hline & TRANSFER COFFIN PLATFORM & DFEET & & $6^{6} 8^{\prime \prime} \times 7^{\prime} 4^{\prime \prime} \times 2^{\prime}$ & 100 & $\mathbf{Y}$ & $\mathbf{Y}$ & $Y$. \\
\hline & REINFORCED CONCRETE & BIOLOGICAL SHIELD & & & 800 & $\mathbf{Y}$ & $\bar{Y}$ & $\mathbf{N}$ \\
\hline & EIGHT FAILED FUEL ELEMENT CONTAINERS & TOP OF SPENT FUEL BASIN & & $12^{n} \mathrm{D} \times 12^{\prime}$ & 64 & $\bar{Y}$ & $\bar{Y}$ & $\mathbf{N}$ \\
\hline & COMPONENT RECEPTACLE & TOP OF SPENT FUEL BASIN & & & 48 & $\bar{Y}$ & $\bar{Y}$ & $\mathbf{N}$ \\
\hline & CRANE RAILWAY & & & & & & & \\
\hline & 6 IN. MOTOR OPERATED VALVE & & & & & & & \\
\hline & 10 IN. MOTOR OPERATED VALVE & & & & & & & \\
\hline
\end{tabular}




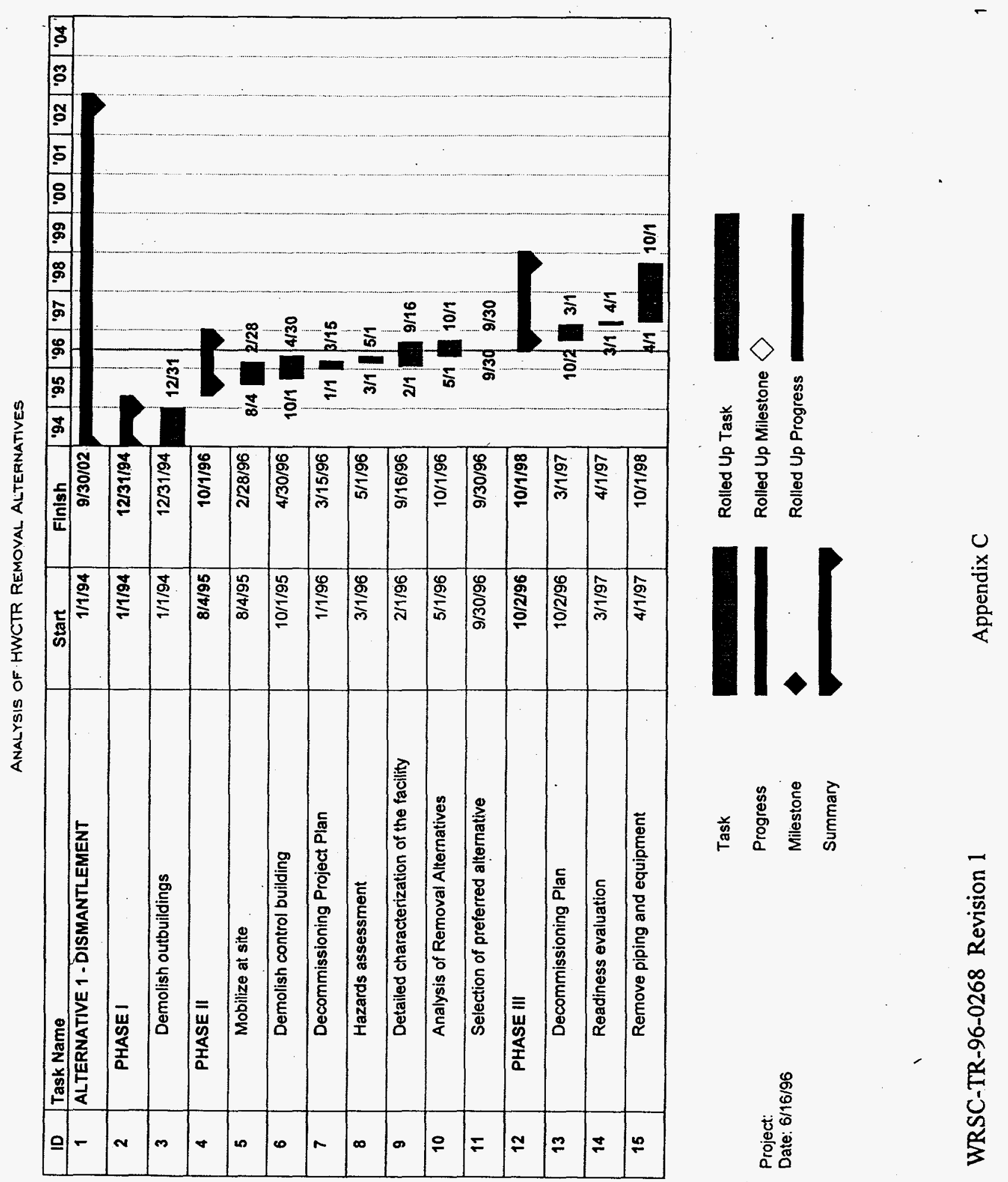


ANALYSIS OF HWCTR REMOVAL ALTERNATIYES

\begin{tabular}{|c|c|c|c|c|c|c|c|c|c|c|c|c|c|c|}
\hline ID & Task Name & Start & Finish & 94 & 95 & '96 & $' 97$ & 98 & 99 & 100 & 01 & 02 & 03 & 04 \\
\hline 16 & Remove hazardous materials & $4 / 1 / 97$ & $10 / 1 / 98$ & & & & & & & & & & & \\
\hline 17 & Remove underground tank, muffler, st. line & $1 / 1 / 98$ & 10/1/98 & & & & $1 / 1$ & & & & & & & \\
\hline 18 & PHASE IV & $10 / 1 / 98$ & $3 / 1 / 00$ & & & & & & & & & & & \\
\hline 19 & Remove large components, except vessel & $10 / 1 / 98$ & $6 / 1 / 99$ & & & & & $n$ & & & & & & \\
\hline 20 & Remove and ship reactor vessel & $6 / 1 / 99$ & $3 / 1 / 00$ & & & & & & & & & & & \\
\hline 21 & PHASEV & $1 / 1 / 99$ & 9/30/02 & & & & & & & & & & & \\
\hline 22 & Remove and dispose of radioactive concrete & $1 / 1 / 99$ & $3 / 4 / 01$ & & . & & & $1 / 1$ & & & & & & \\
\hline 23 & Remove dome & $3 / 1 / 01$ & $8 / 1 / 01$ & & & & & & & $3 / 1$ & & & & \\
\hline 24 & Remove building to below grade & $8 / 1 / 01$ & $1 / 1 / 02$ & & & & & & & & & & & \\
\hline 25 & Perform final radiological survey & $1 / 1 / 02$ & $5 / 1 / 02$ & & & & & & & & $1 / 1$ & & & \\
\hline 26 & Final Independent Verification, DHEC \& EPA & $5 / 1 / 02$ & $7 / 1 / 02$ & & & & & & & & & & & \\
\hline 27 & Backfill and grade site & $7 / 1 / 02$ & $8 / 30 / 02$ & & & & & & & & & & & \\
\hline 28 & Landscaping and project closeout & $9 / 1 / 02$ & $9 / 30 / 02$ & & & & & & & & & $9 / 1$ & $9 / 30$ & \\
\hline
\end{tabular}

Task

Project:

Date: $6 / 16 / 96$
Progress

Milestone

Summary
Rolled Up Task

Rolled Up Milestone $\diamond$

Rolled Up Progress 
ANalysis of HWCTR Removal ALternatives

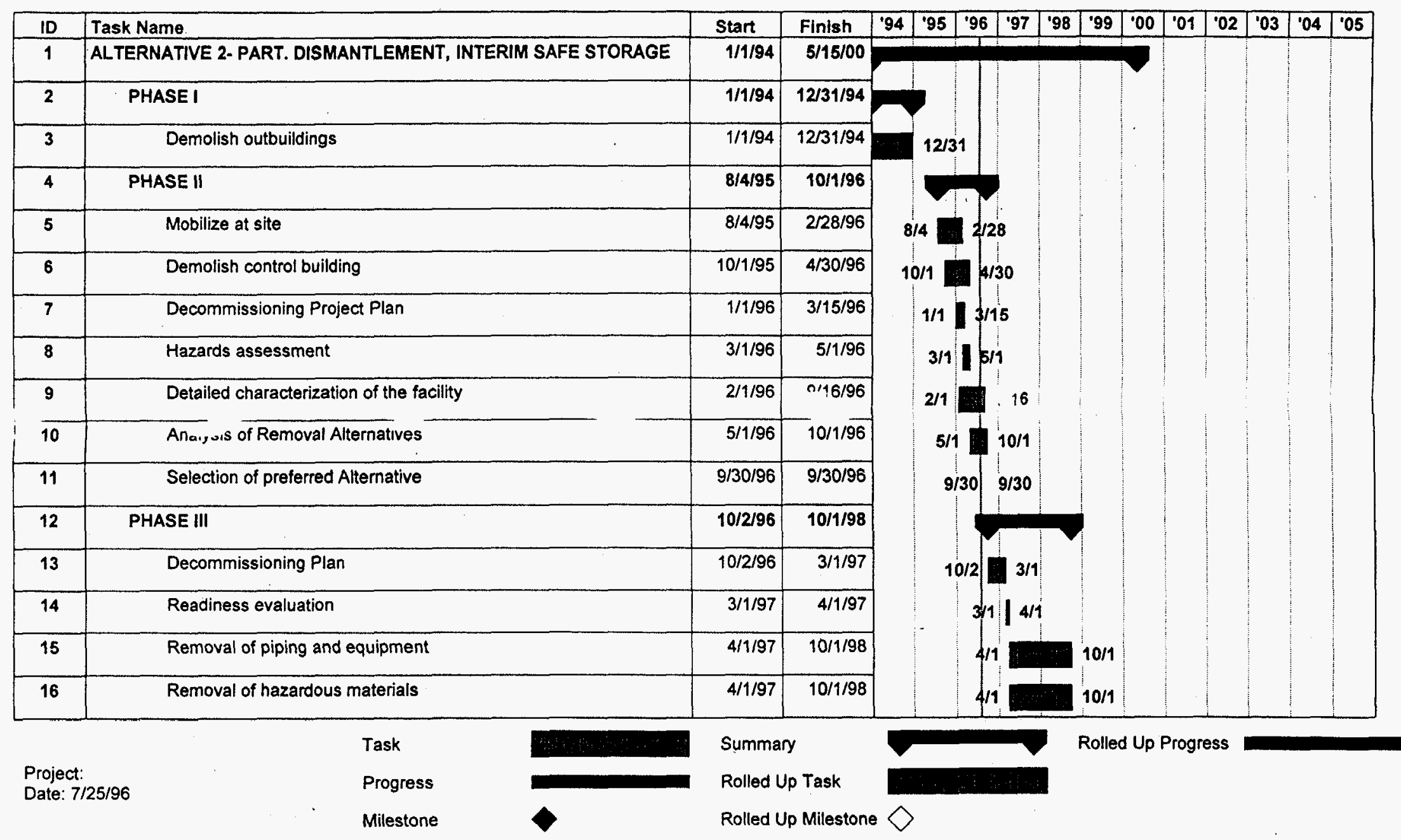



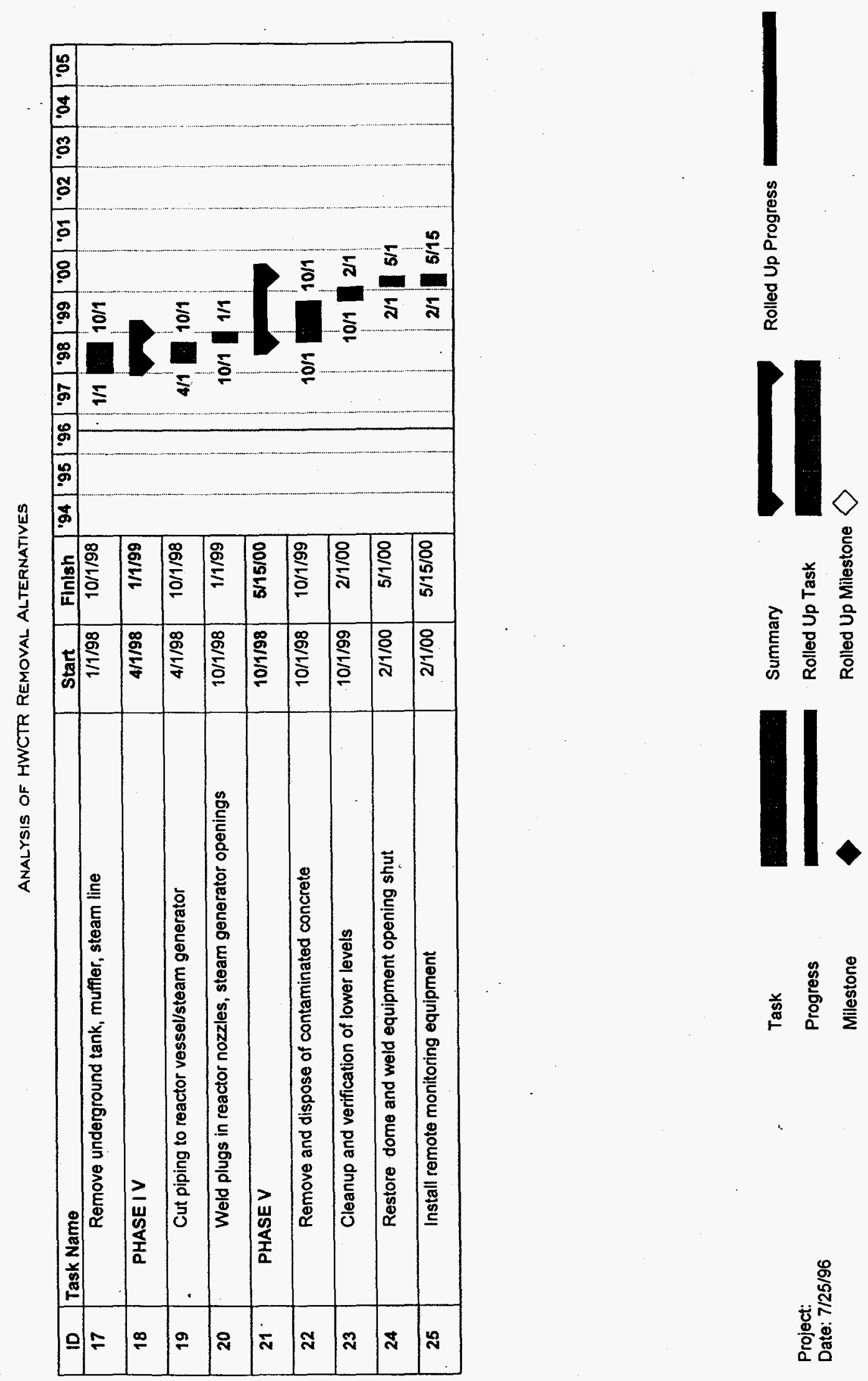

$N$

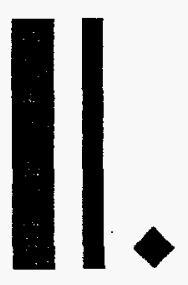

0
$\frac{x}{0}$
$\frac{0}{2}$
$\frac{2}{\alpha}$
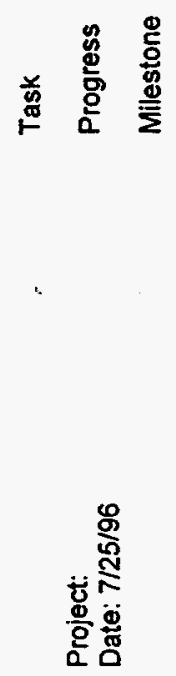

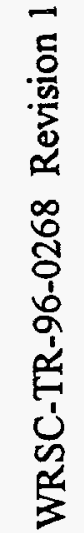


ANALYSIS OF HWCTR REMOVAL ALTERNATIVES

\begin{tabular}{|c|c|c|c|c|c|c|c|c|c|c|c|c|c|}
\hline 10 & Task Name & Start & Finish & 94 & 95 & .96 & 97 & '98 & '99 & .00 & 01 & .02 & .03 \\
\hline 1 & ALTERNATIVE 3 - BENEFICIAL REUSE & $1 / 1 / 94$ & $5 / 1 / 02$ & & & & & & & & & & \\
\hline 2 & PHASE I & $1 / 1 / 94$ & $12 / 31 / 94$ & & & & & & & & & & \\
\hline 3 & Demolish outbuildings & $1 / 1 / 94$ & $12 / 31 / 94$ & & & & & & & & & & \\
\hline 4 & PHASE II & $8 / 4 / 95$ & $10 / 1 / 96$ & & & & & & & & & & \\
\hline 5 & Mobilize at site & $8 / 4 / 95$ & $2 / 28 / 96$ & & & & & & & & & & \\
\hline 6 & Demolish control building & $10 / 1 / 95$ & $4 / 30 / 96$ & & $/ 1$ & & & & & & & & \\
\hline 7 & Decommissioning Project Plan & $1 / 1 / 96$ & $3 / 15 / 96$ & & $1 / 1$ & & & & & & & & \\
\hline 8 & Hazards assessment & $3 / 1 / 96$ & $5 / 1 / 96$ & & $3 / 1$ & & & & & & & & \\
\hline 9 & Detailed characterization of the facility & $2 / 1 / 96$ & $9 / 16 / 96$ & & $2 \sqrt{1}$ & & 116 & & & & & & \\
\hline 10 & Analysis of Removal Alternatives & $5 / 1 / 96$ & $10 / 1 / 96$ & & II & & & & & & & & \\
\hline 11 & Selection of preferred alternative & $9 / 30 / 96$ & $9 / 30 / 96$ & & & & 130 & & & & & & \\
\hline 12 & PHASE III & $9 / 30 / 96$ & $10 / 1 / 98$ & & & & & & & & & & \\
\hline 13 & Develop and obtain necessary approvals for a waste storage plan & $9 / 30 / 96$ & $4 / 1 / 97$ & & & & & & & & & & \\
\hline 14 & Decommissioning Plan & $10 / 2 / 96$ & $3 / 1 / 97$ & & & $0 / 2$ & & & & & & & \\
\hline 15 & Readiness evaluation & $3 / 1 / 97$ & $4 / 1 / 97$ & & & & & & & & & & \\
\hline
\end{tabular}

Project:

Date: $6 / 16 / 96$
Task

Progress

Milestone

Summary
Rolled Up Task

Rolled Up Milestone $\diamond$

Rolled Up Progress 


\begin{tabular}{|c|c|c|c|c|c|c|c|c|c|c|c|c|c|}
\hline ID & Task Name & Start & Finish & 94 & 95 & 96 & 197 & $' 98$ & 99 & .00 & '01 & '02 & 03 \\
\hline 16 & Remove hazardous materials & $4 / 1 / 97$ & $1 / 1 / 98$ & & & & & & & & & & \\
\hline 17 & Remove piping and equipment & $4 / 1 / 97$ & $10 / 1 / 98$ & & & & & & & & & & \\
\hline 18 & Remove underground tank, muffler, steam line & $1 / 1 / 98$ & $10 / 1 / 98$ & & & & $1 / 1$ & & & & & & \\
\hline 19 & PHASE IV & $10 / 1 / 98$ & $3 / 1 / 00$ & & & & & & & & & & \\
\hline 20 & Remove large components, except vessel & $10 / 1 / 98$ & $6 / 1 / 99$ & & & & & & & & & & \\
\hline 21 & Remove and ship reactor vessel & $6 / 1 / 99$ & $3 / 1 / 00$ & & & & & & & & & & \\
\hline 22 & PHASE V & $1 / 1 / 99$ & $6 / 1 / 02$ & & & & & & & & & & \\
\hline 23 & Remove and dispose of radioactive concrete & $1 / 1 / 99$ & $3 / 1 / 01$ & & & & & $1 / 1$ & & & & & \\
\hline 24 & Cleanup and verification of lower levels & $3 / 1 / 01$ & $6 / 1 / 01$ & & & & & & & $3 / 1$ & & & \\
\hline 25 & Strengthen floors as needed for storage & $6 / 1 / 01$ & $8 / 31 / 01$ & & & & & & & & & & \\
\hline 26 & Refurbish building, meeting current building codes & $6 / 1 / 01$ & $3 / 1 / 02$ & & & & & & & & & $3 / 1$ & \\
\hline 27 & Install ventilation system & $11 / 1 / 01$ & $3 / 1 / 02$ & & & & & & & & $1 / 17$ & $3 / 1$ & \\
\hline 28 & Restore dome to close equipment access & $9 / 3 / 01$ & $3 / 1 / 02$ & & & & & & & & & $3 / 1$ & \\
\hline 29 & Place materials to be stored Into building & $3 / 1 / 02$ & $5 / 1 / 02$ & & & & & & & & & $5 / 1$ & \\
\hline
\end{tabular}

$\begin{array}{llll} & \text { Task } & \text { Rolled Up Task } & \text { Rolled Up Milestone } \\ \text { Project: } & \text { Progress } & \text { Rolled Up Progress } \\ \text { Date: } 6 / 16 / 96 & \text { Milestone } & \text { Summary } & \end{array}$


ANALYSIS OF HWCTR REMOVAL ALTERNATIVES

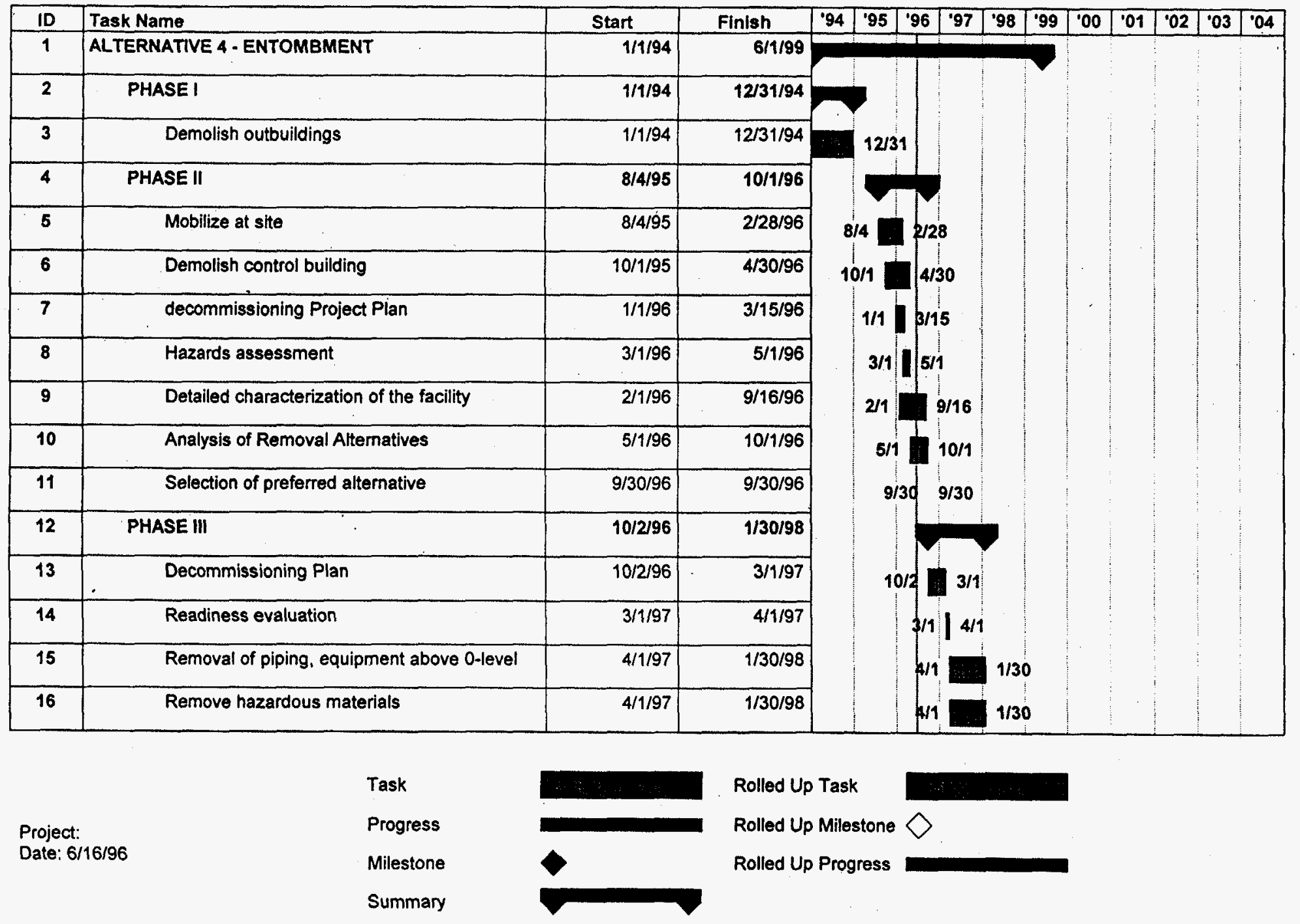


ANALYSIS OF HWCTR REMOVAL ALTERnATIVES

\begin{tabular}{|c|c|c|c|c|c|c|c|c|c|c|c|c|c|c|}
\hline ID & Task Name & Start & Finish & 94 & 95 & 96 & .97 & '98 & .99 & '00 & '01 & 102 & 103 & 04 \\
\hline 17 & Remove refueling machine & $4 / 1 / 97$ & $1 / 30 / 98$ & & & & & & & & & & & \\
\hline 18 & PHASE IV & $2 / 2 / 98$ & $7 / 1 / 98$ & & & & $2 / 2$ & & & & & & & \\
\hline 19 & Remove underground tank, muffler, steam line & $2 / 2 / 98$ & $7 / 31 / 98$ & & & & $2 / 2$ & & & & & & & \\
\hline 20 & Remove dome & $2 / 2 / 98$ & $7 / 1 / 98$ & & & & $2 / 2$ & & & & & & & \\
\hline 21 & PHASE V & $7 / 1 / 98$ & $6 / 1 / 99$ & & & & & & & & & & & \\
\hline 22 & Fill cavity with concrete & $7 / 1 / 98$ & $2 / 1 / 99$ & & & & & & & & & & & \\
\hline 23 & Perform final radiological survey & $2 / 1 / 99$ & $4 / 1 / 99$ & & & & & & & & & & & \\
\hline 24 & Landscaping and project closeout & $4 / 1 / 99$ & $6 / 1 / 99$ & & & & & & & & & & & \\
\hline
\end{tabular}

Task

Project:

Date: $6 / 16 / 96$
Progress

Milestone

Summary
Rolled Up Task

Rolled Up Milestone $\diamond$

Rolled Up Progress 


\section{APPENDIX G - REFERENCES}

No.- Subject

1. Decommissioning Resource Manual. U.S. Department of Energy, Office of Environmental Management Manual DOE /EM-0246, August 1995.

2 Fricke, V. R. Heavy Water Components Test Reactor Decontamination and Decommissioning Project Plan, WSRC Report WSRC-IM-96-144 Revision 0, Savannah River Site, Aiken, SC 29808, March 27, 1996

3 Heavy Water Components Test Reactor Screening Characterization Report, U S Energy Corporation, April 1996.

4 Field, F. R. A Decommissioning Plan for the Heavy Water Components Test Reactor, U. S. Energy Research and Development Administration Report DPST-75-417, Dupont Savannah River Plant, January 1976. 


\section{APPENDIX H - GLOSSARY}

105-C Reactor: An old, graphite-core nuclear weapons materials production reactor located at the Department of Energy's Hanford Site in the state of Washington. The planned "cocooning" of this reactor served as a model for a somewhat similar concept for cocooning of the Heavy Water Components Test Reactor, one of the decommissioning alternatives studied.

Activity: A measure of the rate at which radioactive material is undergoing radioactive decay, usually given in terms of the number of nuclear disintegrations occurring in a given quantity of material over a unit of time. This is also known as Radioactivity. The unit of activity is the curie (Ci).

Air Force Nuclear Engineering Center (AFNEC) Reactor: A small, water-cooled nuclear reactor located at Wright-Patterson Air Force Base in Dayton, Ohio. This reactor, which was entombed in the early 1970 s, served as a model for the entombment decommissioning alternative studied for the Heavy Water Components Test Reactor.

Alpha Particle: A positively charged particle emitted by some radioactive materials undergoing radioactive decay. Alpha particles are the least penetrating of the three common forms of radiation (alpha, beta, gamma); they can be stopped by a sheet of paper and cannot penetrate skin.

Applicable or Relevant and Appropriate Requirements (ARAR): (1) Those cleanup standards, standards of control, and other substantive requirements, criteria, or limitations, promulgated under federal environmental, state environmental, or facility siting laws that specifically address a hazardous substance, pollutant, contaminant, remedial action, location, or other circumstance found at a CERCLA site. Only those state standards that are identified by a state in a timely manner and that are more stringent than federal requirements may be applicable. (2) Requirements promulgated under Federal or state law that specifically address the circumstances at a Superfund site. (3) A requirement that environmental laws other than those under CERCLA, may be either "applicable" or "relevant and appropriate", but not both.

Identification of ARARs must be done on a site-specific basis and involves a two-part analysis:

first, a determination whether a given requirement is applicable; then, if it is not applicable, a determination whether it is both relevant and appropriate.

ASTM: The American Society for Testing and Materials. Society established to provide materials standards and testing procedures.

B-Area: One of the developed areas of the Savannah River Site. Located in the northwest part of the site, B-Area is designated an administrative area in long-term site property use plans. The Heavy Water Components Test Reactor is located in U-Area, which is inside of B-Area. 
Background Radiation: Background radiation is naturally occurring radiation in the human environment. It includes cosmic rays, radiation from the naturally radioactive elements, and manmade radiation from global fallout.

Barytes Concrete: Special high density (13\% iron by weight) concrete used in portions of the biological shield.

Beneficial Reuse: The reactor vessel and steam generators would be removed, the facility would be fully or partially released from radioactive controls, and the facility would be reused for a beneficial purpose, such as storage of radioactive material or equipment.

Beta Particle: An electron emitted from the nucleus during radioactive decay. Beta particles are easily stopped by a thin sheet of metal or plastic.

Biological Shield: The shielding structures consisting of ordinary concrete, Barytes concrete, lead or steel designed to reduce the anticipated radiation levels at various locations in the reactor building to levels ranging generally from $1 \mathrm{mR} / \mathrm{hr}$ to $300 \mathrm{mR} / \mathrm{hr}$ during reactor operation.

Boiling Loop: One of the two isolated coolant loops. In this loop, $\mathrm{D}_{2} \mathrm{O}$ was to be pumped as a liquid to test fuel elements and removed as liquid-steam at reactor pressure. The loop allowed for testing of fuel elements under liquid-steam conditions. It was never used for this purpose.

Characterization Survey: Facility or site sampling, monitoring, and analysis activities to determine the extent and nature of contamination. Characterization provides the basis for acquiring the necessary technical information to develop, analyze, and select appropriate cleanup techniques and characterize materials to be recycled or disposed of as waste.

Chemical Addition System: A part of the purification system used to add deuterium and lithium to maintain proper system chemistry.

Chlorofluorocarbons (CFCs): A family of inert, non toxic and easily liquefied chemicals used in refrigeration, air conditioning, packaging and insulation, or as solvents and aerosol propellants.

Clean Air Act: Passed in 1970, and amended in 1977 and 1990, its purpose is to "protect and enhance the quality of the Nation's air resources. "

Clean Water Act of 1977: This act, which applies to surface water only, is designed to "restore and maintain the chemical, physical and biological integrity of the Nation's waters".

Clean-up: Actions taken to remove a hazardous substance that could affect humans and/or the environment. The term " clean-up " is sometimes used interchangeably with the terms remedial action, remediation, and decontamination. 
Comprehensive Environmental Response, Compensation and Liability Act (CERCLA): A federal statute, also known as Superfund, that provides the statutory authority for clean-up of hazardous substances that could endanger public health, public welfare or the environment. The Heavy Water Components Test Reactor decommissioning project is being performed under this statute by agreement between the U. S. Environmental Protection Agency and the U. S. Department of Energy.

Coolant Sampling System: Part of the purification system. Sample lines from various points run to a hooded sample sink in the monitor room.

Contamination: The presence of residual radioactivity in excess of levels which are acceptable for release of a site or facility for unrestricted use.

Corrosion Coupons: Small test samples of various metals installed in the reactor vessel and $\mathrm{D}_{2} \mathrm{O}$ tank to determine corrosion characteristics of the materials under operating conditions.

Criteria (release criteria): Combination of numerical activity guideline levels and conditions for their application. If criteria are satisfied, the site may be released without restrictions.

Curie: A measure of the rate of radioactive decay. One curie ( $\mathrm{Ci}$ ) is equal to 37 billion disintegrations per second $\left(3.7 \times 10^{10} \mathrm{dps}\right)$, which is approximately equal to the decay of one gram of radium-226. Fractions of a curie are levels typically encountered in the decommissioning process, e. g., picocurie $(\mathrm{pCi})$ or $10^{-12} \mathrm{Ci}$ and microcurie $(\mu \mathrm{Ci})$ or $10^{-6} \mathrm{Ci}$.

$\mathbf{D}_{2}$ O Storage Tank: The 7165 gallon heavy water storage tank located at the $-52^{\prime}$ level which supplied makeup water to the reactor cooling systems and the seal supply system.

Deactivation: The placing of a facility in a safe and stable condition to minimize the long-term cost of a surveillance and maintenance program that is protective of workers, the public and the environment until decommissioning is completed.

Decay: The spontaneous radioactive transformation of one nuclide into a different nuclide or into a lower energy state of the same nuclide. Also, known as radioactive decay.

Decommissioning: The process of removing a facility from operation, followed by decontamination, and license termination.

Decommissioning Plan: A document for a decommissioning project which specifies the work to be done.

Decommissioning Project Plan: The document that defines the decommissioning project and sets the initial cost, schedule, and technical baselines for the project. 
DECON: An acronym for "decontamination".

Decontamination: The removal of unwanted radioactive material from facilities, soils, or equipment. Also, known as remediation, remedial action and clean-up.

Deionizer: A part of the Purification System. One deionizer contained mixed-bed resins which removed dissolved corrosion products and replaced them with lithium hydroxide and deuterium. Another deionizer operated as necessary to maintain alkalinity within limits by removing lithium. Another deionizer is installed in the Spent Fuel Basin purification system.

Dismantlement: The disassembly or demolition and removal of any structure, system, or component during decommissioning and satisfactory interim or long-term disposal of the residue from all or portions of a facility.

Dose Equivalent (Dose): A term used to express the amount of effective radiation when modifying factors have been considered. It is the product of absorbed dose (rads) multiplied by a quality factor and any other modifying factors. It is measured in rem (roentgen equivalent man).

E-Area: One of the developed areas of the Savannah River Site. Located in the northcentral part of the site, E-Area is designated as a waste management area.

E-Area Vaults: The above ground area at SRS expected to be used for disposal of most lowlevel radioactive waste generated by the decommissioning work. The vaults are located in EArea.

Effective Dose Equivalent: See dose equivalent.

Emergency Deluge System: The system designed to condense steam generated by a major reactor leak. The primary component of the system is a 15,000 gallon water tank at the top of the dome of the containment building.

Emergency Poison System: A system, never used, designed for emergency shutdown of the reactor should the safety and control rod systems become inoperable. This system was designed to inject potassium tetra borate into the reactor to suppress the nuclear reaction.

Energy Research and Development Administration: The federal agency which was the predecessor of the Department of Energy.

Entomb: To enclose an object or objects in a strong, durable material such as concrete.

Entombment: The encasement of radioactive materials in concrete or other structural material sufficiently strong and structurally long-lived to ensure retention of the radioactivity until it has decayed to levels that permit restricted release of the site.

WSRC-TR-96-0268 
Environmental Assessment (EA): A written environmental analysis which is prepared pursuant to National Environmental Policy Act to determine whether a federal action would significantly affect the environment and thus require preparation of a more detailed environmental impact statement.

Environmental Impact Statement (EIS): A document required for Federal Agencies by the National Environmental Policy Act for major project or legislative proposals significantly affecting the environment. A tool for decision making, it describes the positive and negative effects of undertaking and lists alternative actions. The statement documents the information required to evaluate the environmental impact of a project. Such a statement informs decision makers and the public of the reasonable alternatives which would avoid or minimize adverse impacts or enhance the quality of the environment.

Exhaust Stack: The 80-foot high steel stack through which the building ventilation system and gaseous radioactivity were vented. It is designated as Building 791-U.

Experimental Boiling Water Reactor (EBWR): The EWBR is located at Argonne National Laboratory and is being considered for conversion for reuse as a long-term waste management facility. EBWR was the first boiling water type nuclear power plant to produce electricity. Decommissioning work was completed in 1996. Radioactive equipment was removed, the reactor vessel was cut into pieces, and the radioactive concrete biological shielding was taken out.

Facility Characterization Screening Report: A detailed report of the results of the process history of the HWCTR facility. Information for the report is drawn from various sources such as health physics logs and interviews with former HWCTR employees. This report forms part of the basis for the scope of the facility characterization work.

Gamma Radiation: Penetrating high-energy, short-wavelength, electromagnetic radiation (similar to $\mathrm{X}$-rays) emitted during radioactive decay. Gamma rays are very penetrating and require dense materials (such as lead or uranium) for shielding.

Half-Life: The time it takes for one-half of the atoms of a quantity of a particular radioactive element to decay into another form. Half-lives of different isotopes vary from millionths of a second or less to billions of years.

Hazardous Substance: Any material that poses a threat to human health or the environment.

Hazardous Waste: Wastes regulated under RCRA that can pose a substantial or potential hazard to human health or the environment when improperly managed.

Heavy Water: Water containing significantly more than the natural proportions of heavy hydrogen (deuterium) atoms to ordinary hydrogen atoms. Heavy water is used as a moderator in WSRC-TR-96-0268 
some reactors because it slows down neutrons effectively and has a low probability for absorption of neutrons.

Helium Gas System: The system used to maintain pressure in the reactor by maintaining a pressurized helium blanket above the heavy water in the reactor vessel.

Instrument Air System: A system designed to supply air to initiate the poison injection into the system.

Interim Safe Storage: The process of placing a nuclear reactor in long-term storage by sealing the reactor core or vessel and removing the other radioactive equipment from the facility. This technique is being used with the 105-C Reactor at the Department of Energy's Hanford Site in the state of Washington.

Ionizing Radiation: Alpha particles, beta particles, gamma rays and other radiation capable of producing ions (electrically charged atoms or molecules). Ionizing radiation does not include visible light, radio waves or microwaves.

Isolated Coolant Loops: Two coolant loops in the primary system. These two loops are the liquid loop and the boiling loop. They were to be used to test fuel elements under a wide variety of operating conditions.

Liquid Loop: One of the two isolated coolant loops. In this loop, the heavy water was circulated at pressures up to $500 \mathrm{psi}$ higher than that in the reactor vessel. This loop was used to test fuel elements at higher pressure conditions than those present under normal operating conditions.

Main Circulating System: (Also known as the Main Coolant System). This system provided cooling water to the reactor core and reactor components. The system consists of two primary loops. $\mathrm{D}_{2} \mathrm{O}$ was circulated in the primary loops by independent pumping systems at about 10,000 gallons per minute. The water was cooled by two steam generators.

Millirem: One-one thousandth $(0.001) \mathrm{rem}$, the unit of effective dose equivalent for ionizing radiation. See $R E M$.

Mixed Waste: Waste which is both radioactive and contains hazardous constituents as defined by $R C R A$.

Monitor Pin Plate: The plate in the reactor bottom where the monitor pins mount.

Muff (shield muff): A fixture at the top of the fuel through which $\mathrm{D}_{2} \mathrm{O}$ entered the fuel assembly. 
Muffler: The 7-foot diameter stainless steel tank which served as a silencer for venting steam to the atmosphere. It is located 100 meters from the reactor building.

National Environmental Policy Act (NEPA): The national charter addressed to federal agencies for protection of the environment. NEPA establishes policy, sets goals, and provides means for carrying out policy. Under NEPA, federal agencies must examine the environmental impact of proposed actions and compare them with reasonable alternatives.

Partial Dismantlement and Beneficial Reuse: Remove all radioactivity except for that in the reactor vessel biological shield, which would be sealed and left in place. The imbedded piping in the biological shield and in the floor drain system would remain in place. The containment dome would remain standing and the structure would be set up for a purpose such as storage of radioactive material, equipment, or waste.

Partial Dismantlement and Cocooning: Placing the reactor in long-term storage by removing all radioactivity except for that in the reactor vessel, the reactor vessel biological shield, and the steam generators, which would be sealed and left in place. The imbedded piping in the biological shield and in the floor drain system would remain in place. The containment dome would remain standing and all openings welded closed.

Person-rem: The common unit for radiation exposure to a group of people. An estimate of four person-rem would be the total expected radiation exposure to all of those exposed to the ionizing radiation of interest. See also REM.

Polychlorinated Biphenyl's (PCBs): A group of persistent, toxic chemicals. PCBs are commonly found in old electrical equipment.

Purification System: A system which continuously removed particulate and dissolved ionic impurities from the heavy water and controlled the chemical composition of the heavy water to minimize corrosion in the high-pressure system.

Radioactive Contaminants: A term used for the radioactivity in the HWCTR facility associated with its operation. Radioactive contaminants include both radioactive contamination and induced radioactivity from neutron activation.

Radiological Buffer Area: An area used to separate an area of known contamination from an uncontrolled area.

Radioisotope: A radioactive isotope, usually artificially produced by the bombardment of naturally occurring atoms with nuclear particles, such as neutrons, electrons, protons and alpha particles utilizing devices like the particle accelerator. They are used in physical and biological research and therapeutic applications 
Radionuclide: An unstable nuclide that undergoes radioactive decay.

Readiness Review: A management review of documents, organizational structure, personnel qualifications, physical preparations and other factors to confirm that decommissioning operations (removal action, if under CERCLA) are ready to proceed. If the facility being commissioned is classified as a nuclear facility per DOE-STD-1027-92, a graded operational readiness review (ORR) may be required in accordance with DOE Order 5480.31 .

Reactor Gas Pressure Relief System: A secondary pressure relief system consisting of two independent groups of self-actuating relief valves that relieve high pressure helium and $\mathrm{D}_{2} \mathrm{O}$ vapor from the gas space of the reactor vessel.

Reactor Gas Purge System: Part of the Helium gas system. Helium was periodically admitted to the reactor to purge the gas space.

Reactor Vessel: The 98 ton, 30-foot high carbon steel pressure vessel which contained the reactor fuel. Clad with stainless steel, it is $3-5 "$ thick.

Receiving Basin for Off-site Fuel: A facility, not located at the HWCTR site, where spent fuel is sent for storage pending processing. All of the spent fuel from the HWCTR reactor was transferred from the HWCTR spent fuel basin to this facility.

Recompression System: A system used to recompress $\mathrm{D}_{2} \mathrm{O}$-He from the storage tank for return to the reactor to make up for gasses discharged in the purge streams.

Refueling Machine (transfer coffin): The heavily-shielded container used to transfer spent fuel from the reactor to the spent fuel basin.

REM (Roentgen Equivalent Man): A quantity used in radiation protection to express the effective dose equivalent for all forms of ionizing radiation. It is the product of the absorbed dose in rads and factors related to relative biological effectiveness (see Dose Equivalent).

Remedial Action: Action taken to remove contaminants from a site. Also known as remediation and decontamination.

Remediation: The removal of contamination from a site. Also known as remedial action and decontamination.

Removable Activity: Surface activity that can be removed and collected for measurement by wiping the surface with moderate pressure.

Removal Action: Under CERCLA, this means "The cleanup or removal of released hazardous substances from the environment, such actions as may be necessarily taken in the event of the WSRC-TR-96-0268 
threat of a release . . . , such actions as may be necessary to monitor, assess, and evaluate the release or threat of release . . ., the disposal of removed material, or the taking of such other actions as may be necessary to prevent, minimize, or mitigate damage to the public health or welfare or to the environment, which may otherwise result from a release or threat of release."

Resource Conservation and Recovery Act (RCRA): The federal law that regulates the management of hazardous waste, solid waste and underground storage tanks to minimize the present and future threat to human health and the environment.

Roentgen (R): Unit of radiation exposure. One roentgen is the amount of gamma rays or x-rays required to produce one electrostatic unit or charge of one sign (either positive or negative) in one cubic centimeter of dry air under standard conditions.

Safe Storage: Those actions required to place and maintain a nuclear facility in such a condition that future risk to public safety from the facility is within acceptable bounds and that the facility can be safely stored for as long a time as desired.

SAFSTOR: An acronym for Safe Storage.

Savannah River Site (SRS): A Department of Energy (DOE) facility for production, reprocessing, and storage of radioactive material and disposal of radioactive waste. SRS is located near Aiken, South Carolina.

Seal Head Tank: Part of the Seal Supply System. The tank is located in the dome of the building and supplies $\mathrm{D}_{2} \mathrm{O}$ to the Seal Supply System. Two other seal head tanks provide $\mathrm{D}_{2} \mathrm{O}$ to the pump seals in the isolated loops.

Seal Supply System: The system which supplies pressurized $\mathrm{D}_{2} \mathrm{O}$ to the pump and rod drive seals.

Shippingport Atomic Power Station: The world's first large-scale nuclear power plant. The plant was located in Beaver County, Pennsylvania and was a pressurized water reactor. It was decommissioned in 1989 and was the first complete decontamination and decommissioning of a power-producing reactor in the nation.

Solid Waste: Non-liquid, non-soluble material ranging from municipal garbage to industrial waste that contains complex, and sometimes hazardous, substances. Solid waste also includes sewage sludge, agricultural refuse, demolition wastes, and residues. Technically, solid waste also refers to liquids and gases in containers.

Solid Waste Disposal Facility: The SRS shallow land burial facility used for disposal of lowlevel radioactive wastes. It is expected that large components such as the reactor vessel and steam generators, if removed, will be disposed of in this facility. 
Spent Fuel Basin: A stainless steel-lined concrete-walled pit used to temporarily store spent fuel on site. The top of the basin is at the 0 level. It is $27^{\prime}$ deep with a cask pit which extends to the -42 ' level.

Spent Fuel Basin Purification System: A recirculating system where water from the spent fuel basin passed through a deionizer and filter to remove radioactivity.

Steam Generators: The major components of the Steam System. Two steam generators are present in the main coolant system. Made of carbon steel, each is about 23 feet high and weighs some 19 tons.

Steam Generator Feedwater System: The system which provides makeup water to the steam generators.

Steam System: The secondary portion of the reactor fluid system where steam is produced in the steam generators and exhausted through the muffler to dissipate heat from the reactor.

Superfund Amendments Rehabilitation Act (SARA): The reauthorization of CERCLA (1986) to provide increased funding and regulations for clean-up of inactive waste sites.

Surface Activity: Radioactivity found on building or equipment surfaces and expressed in units of activity per surface area [typically disintegrations per minute per $100 \mathrm{~cm}^{2}\left(\mathrm{dpm} / 100 \mathrm{~cm}^{2}\right)$ ].

Survey: Evaluation of a representative portion of a population to develop conclusions regarding the population as a whole. In the decommissioning process, several different types of surveys are conducted, including Background, Scoping, Characterization, Remediation Control, Final Status, and Confirmatory surveys.

Thermal Shield: The thermal shield is within the reactor vessel and consists of the top shield which has an 18" thick stainless steel calandria-filled with stainless steel balls and a series of ten, 1 " stainless steel annular rings and the radial and downward (bottom) direction shields made of 3 " stainless steel. The thermal shields are cooled by $\mathrm{D}_{2} \mathrm{O}$.

Toxic Substances Control Act (TSCA): The law and implementing EPA regulations governing the use and management of toxic substances. PCBs are regulated under. TSCA.

Transuranic Waste: Waste that is contaminated with alpha-emitting transuranic nuclides with half-lives greater than 20 years and concentrations greater than 100 nanocuries per gram of waste. Contract-handled TRU waste does not require shielding and has a surface dose rate of less than 200 millirem per hour. Remote-handled TRU waste has a surface dose rate greater than 200 millirem per hour and requires additional shielding because it presents an exposure hazard, the dose rates at the surface or remote-handled TRU waste packages within 200 millirem to 1000 rem WSRC-TR-96-0268 
per hour range. Some TRU waste was buried before these ranges were established.

U-Area: One of the developed areas of the Savannah River Site. Located in the northwest part of the site, U-Area is designated an administrative area in long-term, site property use plans. The Heavy Water Components Test Reactor is located in U-Area, which is inside of B-Area.

Underground Tank: The 8000 gallon waste water collection tank buried on the HWCTR property. Water from the reactor building sump could be pumped directly to the tank. This was done on occasion.

U. S. Atomic Energy Commission (AEC): The commission set up by the Atomic Energy Act of 1954 for the production and control of nuclear materials.

U. S. Department of Energy (DOE): DOE superseded the AEC and has responsibility for the production and control of nuclear materials.

U. S. Environmental Protection Agency (EPA): The U. S. Environmental Protection Agency was established in 1970, bringing together parts of various government agencies involved with the control of pollution. Oversees the investigation and development of remedial actions to reduce the risk of exposure to contaminants.

Volatile Organic Compounds (VOCs): Carbon-containing substances, released by both natural processes and human activities, which readily produce fumes.

Waste Minimization: The reduction, to the extent feasible, of radioactive and hazardous waste that is generated before treatment, storage, or disposal of the waste. Waste minimization includes any source reduction or recycling activity that results in either: 1) reduction of total volume of hazardous waste; 2) reduction of toxicity of hazardous waste; or 3) both.

Water Relief System: A system designed to relieve excessive pressure by allowing escape of heavy water to the storage tank. The primary components of this system were two self-actuating relief valves.

Westinghouse Savannah River Company (WSRC): The prime contractor for operating the Savannah River Site. 


\section{APPENDIX I}

\section{Public Comments and Department of Energy Responses}

\section{Introduction}

On November 19,1996, announcements appeared in five area newspapers concerning the Analysis of Removal Alternatives. These announcements briefly described the document's purpose and scope and solicited comments from members of the public. The deadline for providing comments was set for December 20, 1996. Newspapers in which the notices appeared included four in South Carolina the Aiken Standard, the Allendale Leader, the Barnwell Sentinel and the Columbia State, along with the Augusta, Georgia Chronicle.

A total of 65 comments were received from nine different individuals in response to this request, including one set of comments dated December 27, 1996, which was evaluated even though it was received after the comment deadline.

\section{Summary of the Comments}

The comments, which were mainly technical in nature, are summarized as follows, along with a brief statement (in parentheses) of the DOE-SR response:

- A question about whether removal of the building structure to five feet below grade would satisfy the general end condition criteria. (It would.)

- A suggestion to take more soil samples. (More will be taken.)

- A suggestion that plans for soil remediation be included in the project. (Plans will be included, though little soil contamination is expected.)

- A recommendation to assess the extent of tritium contamination in the facility. (This was done in August and September of 1996 and the levels found to be low.)

- An opinion that dismantlement is the best approach. (This is the preferred alternative.)

- A question about why dismantlement is preferred over the less expensive entombment approach. (For reasons cited in the analysis, along with drawbacks of entombment, such as the fact that the hazardous lifetime of the radioactivity is far longer than the design lifetime of an entombment.) 
- A recommendation to entomb in concrete the activated concrete inside of the reactor biological shield. (This approach was considered, but found not to be technically required to meet the project criteria).

- A question about the future usability of the HWCTR site. (It would be available for any suitable use, although there is other usable property at the Savannah River Site.)

- A question about air monitoring for worker safety during dismantlement. (Various safety measures will include air monitoring for radioactivity when contamination levels make this appropriate.)

- A question about options should more radioactivity than expected be present. (A detailed characterization program completed in September of 1996 showed that amounts of radioactivity present were as expected.)

- A question about radioactivity clean-up standards. (DOE-SR plans to use the standard in DOE Order 5400.5.)

- A question about plans for disposal of mixed waste. (DOE-SR plans to temporarily store the waste on site until treatment options are available.)

- A suggestion that the HWCTR be turned into a museum. (The historical significance of the HWCTR has been evaluated following state and federal guides. The site was found not to have significant historical value.)

- A question about the numerical radiation risk estimate examples of Section 5.4.2. (The examples are accurate, but more explanation was provided for clarification.)

- A recommendation that none of the alternatives evaluated be undertaken at this time. (Because the "no-action alternative" will not meet objectives for the decommissioning, DOE-SR plans to proceed with the preferred alternative.)

- A suggestion to evaluate protective storage. (This approach would not meet objectives for the decommissioning and therefore was not the subject of detailed evaluation.)

- A comment that the study does not state the objectives for the decommissioning project. (These are described in Section 4.1.)

- A comment on the justification for selection of the preferred alternative. (Reasons are detailed in Section 7 and were expanded.)

- A question on selection of the evaluation attributes and their associated weighting factors. 
(They are based primarily on the DOE Decommissioning Resource Mamual, and their weights based on relative importance to the project.)

- A comment on the viability of the HWCTR serving as a prototype for other site reactor decommissioning. (It will serve as a prototype in a broad sense, even though the decommissioning approach for the other reactors has not yet been determined.)

- A comment on the use of the U.S. Environmental Protection Agency (EPA)-DOE decommissioning framework. (The decommissioning framework in the DOE Decommissioning Resource Mamual is being followed for the HWCTR project and will be followed in other site nuclear facility decommissioning work.)

- Suggestions to make revisions and minor corrections, including editorial changes, to the document, including an offer of further information for this purpose. (Such changes were made in revision 1.)

\section{Changes Associated with the Comments}

Changes were made as indicated in the responses to the individual comments.

\section{Detailed DOE-SR Responses to Individual Comments}

Each comment appears below, along with the DOE-SR response. Comments are numbered in the order in which they were received. R1-1 refers to comment 1 of respondent 1 , for example. 
ANALYSIS OF HWCTR REMOVAL ALTERNATIVES

\section{Comments and DOE-SR Responses}

141 Palmetto Avenue North Augusta, SC 29841

December 9, 1996

Mary A. Flora

Public Involvement

Westinghouse Savannah River Company

Aiken, South Carolina

Dear Mrs. Flora:

I am writing to you to submit two comments concerning the DOE's report entitled, Analysis of Removal Alternatives for the Heavy Water Components Test Reactor.

The first comment has to do with the Decommissioning Plan. The 1976

Decommissioning Plan reported for the alternative of dismantlement that the dome and steal and concrete structures down to 16 feet below grade would be removed. The cavity below this level would be backfield with earth and capped with a concrete pad at the -16foot level (page 10 of this report). Now in the 1996 Decommissioning Plan the alternative of dismantlement was changed in that the removal of the concrete structure to the -5-foot level or to the -16-foot level or the removal of all the below ground structure.

My comment is that the latter two options (-16-foot level or removal of all the below ground structure) seem to satisfy the end condition criteria described in section 4.2 of this document, but I see no evidence that -5 -foot level of removal would be sufficient to satisfy the end condition criteria.

My second comment deals with section 3.7.4 of this document. In this section it states that detectable radioactive contamination was present inside of the steam muffler. Also in section 3.7.5 it was stated that traces of radioactive contamination are expected to be present in the underground waste.water storage tank and in the underground piping. Then in this same section it was stated that radioactive contamination in soil on the HWCTR property is expected to be minimal. This conclusion was based on the results of three soil samples taken near the outlet of the steam muffler in April of 1996.

My comment is that I do not believe that three soil samples is enough evidence to base the conclusion of minimal contamination on. One reason being that if the soil was contaminated over 20 years ago and contaminants were released into the soil by the outlet of the steam muffler, chances are they would have leached down into the soil by now or been carried further away from the outlet point. I feel that more studies are needed in order to determine the extent of radioactive contamination in the soil on the HWCTR property. As noted in the document, the HWCTR facility is on two acres of land. It would be beneficial for soil samples to be taken in that two acres radius. 
Thank you for the consideration of my comments. I look forward to hearing back from you in the near future.

Sincerely,

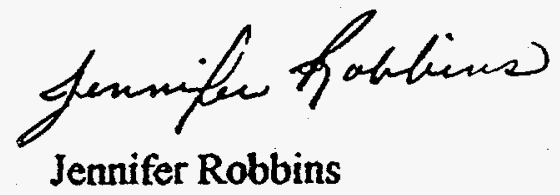

Response to comment R1-1 (whether removing structure to five feet below grade satisfies the end condition criteria)

As noted in Section 5.13, the dismantlement alternative includes the removal and appropriate disposition of structures, systems, and components containing hazardous (radioactive, chemical and toxic) materials. This will enhance the ability to release the property for unrestricted use.

The general end condition criteria of Section 4.2 entails: (1) increased physical security of radioactive equipment and building materials; (2) reduced or eliminated risk of radionuclide migration from the HWCTR property, and, (3) improved ability to release all or most of the HWCTR site for unrestricted use. Removal of the reactor building structure to five feet below grade would satisfy these criteria in the same manner that removal to sixteen feet below grade or removing all of the underground structures. This engineering study revealed that reducing the amount of building material removed (i.e., remove only 5 feet versus 16 feet below grade) is a significant cost savings to the taxpayer and does not present added risks to the safety and health of the worker, public or environment.

Remaining residual radioactivity will be at such a low level that affords minimal increased exposure risk to the health and safety of workers, the public, and the environment. The amount of residual radioactivity will be confirmed during the performance of final radiological surveys and validated during independent verification surveys. Exposure risks have been assessed via computer-aided mathematical modeling of potential exposure pathway. The results of this assessment appear in Section 8 of revision 1 .

DOE-SR believes that your comment is adequately addressed in the Analysis of Removal Alternatives.

\section{Response to comment R1-2 (the need for more soil samples)}

A more rigorous assessment of the soil conditions will be performed prior to major soil disturbing operations. This assessment will provide empirical data on the nature and extent of contaminants so 
that the proper engineered and administrative controls and personal protective equipment are implemented that assures the health and safety of workers during decommissioning operations. This assessment will also facilitate proper disposal of contaminated soils and, to the maximum extent practicable, assures environmental insults are mitigated. In-process and post-decommissioning environmental sampling activities will be performed as well.

It should be noted that sampling is limited to areas disturbed during decommissioning operations and to environmental media newly exposed from the removal of structures, systems and components. Contaminated environmental media beyond the above conditions are expected to be encompassed by a separate environmental restoration effort (e.g., remedial action, removal action, closures, etc.).

Your observation is one with which SR has already considered and is presently working towards a more comprehensive assessment not just of soils, but other environmental media.

December 12, 1996

10 Round Hill $a$.

Aiken, SC29803-5926

Mary Elora

Publiclnvolvement

Westinghouse SavannahRiver Company

Savannah River Site

Building 730-2B, Room 128

Aiken, SC29808

Dear Ms. Flora:

Please include the foll owing issues in the public comment recond for the "Analysis of Removal Altematives for the Heavy Water Components TestReactor at the Savannah RiverSite".

I have one major and several minor issues. Some of the minor issues are only editocial in nature.

\section{MAJOR ISSUE}

The analysis of radioactive constituents in the Heavy Water Components Test Reactor(HWCTR) fails to account for any residual tritium contained in the equipment and structure. The HWCTR facility was a heavy water $\left(D_{2} \mathrm{O}\right)$ moderated reactor which produces tritium atoms as the deuterium is exposed to the nevtrons genecated during the reactor operation. The report does not indicate whether the HWCTR moderator was "virgin" or if was recycled moderator from the other reactors operated at the site. If it was recycled moderator, then the inventory of tritium would have been significant during the operating period. If it was virgin, then the buildup of tritium would have slowly increased during the operating history of the reactor. 
In either case the moderator would leave a legacy of tritum contamination in the reactor vessel, the associated moderatoc piping system, and too a lesser degree the cooling water system from leaks that cocurred. In addition, the discharging of spent fuel and test elements would have also contaminated the spent fuel stocage pool and associated fuel handling equipment with some quantity of tritium contaminated moderator. There may have been spills and leaks of the moderator allowing tritiun to impact other areas of the facility. Until this equipment and the associated concrete structure is assessed for tritium content, the full radiological impact of removing the facility cannotbe fully assessed. The tritium content needs to be assessed for salvage, waste disposal, and worker exposure considerations.

The Savannah River Site has recently seen the consequences of not fully assessing the ability of tritium to contaminate concrete structures. The removal of the 232-F, an old critium processing facility in F-Area, has show that the tritium contamination of concrete structures is poorly understood. The radiological surveys that measured the amount of tritium on concrete surfaces lead to an underestimation of the tritium content deeper within the concrete. After the discovery of the higher tritium concentration, new sampling methods had to be developed to adequately measure the cotaltritiumcontent.

\section{MINOR ISSUES}

1. Section 3.7.1. Table2,SignificantRadioactiveContaminants:
A. Add tritium (T or $\mathrm{H}-3$ ) to the table
B. The half-life of strontium-90 is currently accepted to be 29.1 years, not 28.6
C. The half-life of cesium- 137 is 30.2 years
D. Plutonium-241 primarilyemitsbetaradiation, notalpha
E. Since Fe-55 is listed in Table 3, should it not also be listed in Table 2

2. Section 5. 1.3, First sentence of first paragraph:

It should read. "The DOE Decommissianing.." , not "The Doe Decommissianigg..".

3. Section 5.4.2, First dingbat:

It is noc cocrect to apply theincreased risk of cancerto the naturally occurring radioactivity in the environment, it is reserved to the discussion of increased risk attributed to radiation exposure in excess of natural background. This example should be revised or deleted from the report.

4. Section 5.8.2, First sentence of first paragraph:

Revise sentence to read, "Health and safety of site project personnel would be controlled by adherence to WSRCManuals 4Q. Induserial Hygriene, and 8Q, EmplogreeSafecthanual.

RATIONALE: The industrial hygiene controls for the Savannah River Site are contained in the WSRC4Q Manual. These controls apply to asbestos and other chemical exposures, as well as the physical hazards such as heat stress. The requirements for proper protective clothing and respirators are also contained in the $4 \mathrm{Q} \mathrm{Manual}$. 
5. Section 5.8.5: The WSRC6Q Manual has recently been replaced by the SCD-7 Manual.

Sincerely Yours,

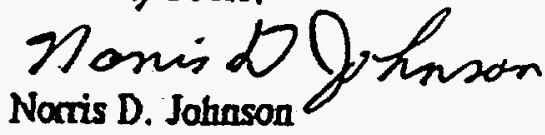

DOE-SR Response to comment R2-1 (The tritium content of the facility needs to be assessed for salvage, waste disposal and worker exposure considerations.)

Your comment is a very legitimate concern. DOE-SR recognized the need for a sound assessment of tritium contamination. Early consideration was given to tritium because of the presence of heavy water in the plant and the potential of the formation of tritium by the mere exposure of moderator and coolant to the reactor's neutron flux (after all, it only requires one more neutron in deuterium nucleus to form tritium). Tritium production is well understood and the actual concentration of tritium in the coolant at final shutdown was available from plant records. Also, special consideration was given to tritium in light of new information, experience and lessons gained from decommissioning SRS's first tritium extraction facility, Building 232-F.

DOE-SR has taken the appropriate measures to qualify and quantify the presence of tritium. Tritium data obtained during facility characterization will be used to assure the health and safety of the workers and protection of the public and environment. This data showed that tritium is estimated to account for only $0.1 \%$ ( 2 curies of 3,000 curies) of the total estimated curie content in the HWCTR facility.

\section{DOE-SR response to comment R2-2 (significant radioactive contaminants)}

Again, please note that tritium is estimated to account for less than $0.1 \%$ ( 2 curies of 3,000 curies) of the total estimated curie content in The HWCTR facility. Although it is a contaminant of concern, it is not a significant radioactive constituent compared to the other radionuclides of Table 2. Therefore, tritium is not listed.

Strontium-90 and Cesium-137. International Council on Radiation Protection publication number 38 of 1983, Radiomuclide Transformations Energy and Interactions of Emissions, lists Sr-90 with a half-life of 29.12 years and Cs-137 with half-life of 30.0 years. The Chart Of Nuclides and Nuclide and Isotopes (14th Edition) published by General Electric (Revised 1989) list Sr-90 with a half-life of 29.1 years and Cs-137 with a half-life of 30.17 years. However, the Health Physics and Radiological Health Handbook (edited by Bernard Sheien, 1992) lists Sr-90 with a half-life of 28.6 and Cs-137 with a half-life of 30.17 years.

Plutonium-241. Plutonium-241 primarily decays by beta- emission with a half life of 14.4 years

WSRC-TR-96-0268 
Iron-55. Iron-55 was listed in Table 2.

DOE-SR response to comment R2-3 (DOE vs. Doe)

"Doe" was changed to "DOE-SR".

DOE-SR response to comment R2-4 (The example in Section 5.4.2 of the cancer risk of background radiation exposure should be deleted.)

Your philosophy on risk is correct. However, there is no single correct conception of risk and, subsequently, mankind can not and has yet to universally accept risk. Traditionally, risk has been viewed as a consequence to the dangers as a result of a certain action, event or condition. In terms of exposure to radiation in the nuclear industry, natural background radiation is an accepted condition and anything beyond that - be it occupational exposure to radioactive materials or exposure to environmental pollutants - is considered to be an increased risk. So, in the context just described, your assessment that is not correct to apply increased risk of cancer or any other hazard or danger for that matter) to naturally occurring radioactivity has technical validity.

Risk can also be viewed as a product of knowledge about the future and acceptance of the most desired prospects. When knowledge is certain and acceptance absolute; then one can effect a preferred outcome. Since it has not been unequivocally concluded that exposure chronic or acute, to low levels of ionizing radiation causes cancer, knowledge in not certain. Since acceptance is based on knowledge, then the desired outcome is at large. Therefore, risk or increased risk to cancer from ionizing radiation is not fully embraced, scientifically or politically.

The discussion presented in Section 5.4.2 was included to portray the increased risk (i.e., that beyond natural background radiation) of cancer as being very low as a result of occupational exposure (i.e., decommissioning HWCTR) to the low levels of radioactivity in the HWCTR facility.

Your comment has been considered and this section was revised for clarity.

DOE-SR response to comment R2-5 (Add reference to the WSRC 4Q manual)

For completeness and to improve the quality of this engineering study, reference to the WSRC Manual 4Q, Industrial Hygiene, was be cited.

DOE-SR response to comment R2-6 (Refer to SCD-7 Manual)

For correctness and to improve the quality of this engineering study, WSRC SCD-7 was cited versus WSRC Manual 6Q. 


\section{Peter L. Gray \\ Post Office Box 968 : \\ Aiken, South Carolina 29802}

December 16, 1996

Mary A. Flora, Public Involvement

Westinghouse Savannah River Company

Savannah River Site, Building 730-2B

Aiken, SC 29808

\section{Analysis of Removal Alternatives for the Heavy Water Components. Test Reactor}

An advertisement in the Augusta Chronicle mentioned the availability of the subject report and requested comments from the public. I read a copy at the USC-Aiken Public Reading Room. The document there was WSRC-TR-96-0268. I'd like to offer some comments.

1. On page 1, it says "all nuclear fuel was removed" but it doesn't say the heavy water was removed. It should say so, because the heavy water was removed.

2. It says only the containment building and a health physics building are still standing. There are actually five HWCTR buildings still standing. They are 770-U (containment building), 735-U (health physics building), 791-U (ventilation stack), 788-B (deluge control bunker), and 704-B (office wing, shops, lunch room, and orange tool room).

3. On page 2, of the four altematives listed, the most favorable one is dismantlement because it takes the reactor vessel with the lion's share of radioactivity away from B Area and potentially places it in a radioactive burial site. I favor this alternative.

4. On page 5, the site description is in error. The area near the HWCTR facility is not "mostly wooded"; it is occupied by the SRS security force headquarters, helicopter facility, and the B Area office complex with about 2500 employees on three sides of U Area (HWCTR).

5. On page 6, figure 2 (actually in appendix A) would have been much more helpful had the SRS roads been shown. The map: only showed streams, but most persons familiar with the site relate much better to roads.

6. Below figure 1 it says the details of the containment building are shown in figures 4 through 27. Actually, considerably more than just the building details are shown; much of the contents of the building are shown.

7. On page 7, the reactor does not have a diameter of about 7 feet. It is about 8 feet in its lower portion and about $51 / 2$ feet in the upper portion.

8. On page 11, the list should include the deluge control bunker (788-B) which is still standing.

9. On page 12, table 2 uses the word "contaminants" in the title and the word "radioisotopes" for the column heading on the left. The proper word in both cases would be "nuclides" or "radionuclides." "Isotopes" exist for only one chemical element (e.g., isotopes of oxygen, or isotopes of uranium, but only one at a time). "Nuclides" covers the different species of all the chemical elements. This wording problem also exists for the last sentencee in 3.7.1. 
10. On page 13. table 3 should include for completeness the induced activity in curies for the zircaloy housing tubes even though the values are, relative to the reactor vessel and its internal shields, quite low. If these values are not given, one might wonder what they are.

11. On page 14, I believe that the radiation levels should be stated as "several hundred R/hr", not "several hundred rem per hour." I believe that instruments read R (and milliR), whereas Rem is a dose to a person (i.e., Roentgen equivalent man).

12. The radiation levels from the control rods should not be "expected to fall within this range" as they are of a much smaller mass. There should be no radiation levels of any significance from the safety rods as they were always out of the neutron flux while the reactor was operating and hence not available to be activated.

13. On page 15 , there is more than just the muffler and steam line leading to it in which some low levels of radioactive contamination might be expected to be found. Between the 770-U building and the muffler there is a whole complex of pipes and valves because one method of ensuring feed water for the steam generators was the steam-driven turbines on some feed water pumps. All steam system equipment below ground should be expected to have contamination if it was found in the muffler.

14. On page 18, the last paragraph certainly argues for dismantlement as it says that "HWCTR lies outside ... the zone ... associated with the central nuclear facilities." This argues strongly for moving the reactor vessel to E Area.

15. On page 20, section 5.1.2 doesn't the author mean "the four decommissioning alternatives", rather than "the four removal altematives"?

16. On page 23, it is nice to hear about the Hanford $105-\mathrm{C}$ reactor, but it seems to have little bearing on the HWCTR case.

E.g., the Hanford reactor weighis 9000 tons yersus 100 tons for HWCTR. The HWCTR vessel can be moved readily whereas moving 9000 tons or even trying to is a task of gigantic proportions. Leave 105-C where it is, but move the HWCTR vessel. By moving HWCTR vessel more than $99+\%$ of the radioactivity is removed from B Area.

E.g. The Hanford reactor is a cube of about 50' on each side, whereas the HWCTR vessel occupies only 938 cubic feet.

E.g., if the dome is cut open, why not remove the vessel? The statement "should funding for complete dismantlement not be forthcoming" seems to mean that the government might save a few percent of the cost and leave behind almost all the radioactivity. If this option costs $\$ 8.7$ million and the vessel can be removed for $\$ 500.000$, that is less than $6 \%$ of the whole cost. Restoring the patch costs $\$ 200,000$ so the net saving by not removing the vessel is a mere $\$ 300,000$. which is less than $31 / 2 \%$ of the cost of this option. I say take the vessel out and restore B Area to a radiation-free zone.

17. Another reason for thinking that the comparison between Hanford and HWCTR is not too closely parallel is that DOE may be shooting for permanent D\&D at HWCTR whereas at Hanford their plan is temporary until such time as the graphite cubes are moved to the 200 Area plateau.

18. On page 23, the first bullet proposes cutting a hole in the carbon steel dome. A search of the construction records might show that the large hole in the dome in 1961 was cut only for 
installation of the reactor vessel itself and virtually everything else came in through the equipment hatch.

19. On page 24, the use of the EBWR building for TRU storage may be acceptable at Chicago, but I would think that at SRS we'd like to keep TRU in the core nuclear areas until it can be shipped to WIPP. As a matter of fact, there are several buildings at SRS that could be reclaimed for beneficial reuse that have much better storage potential and could be readied for such use for much less money. The back end of 777-10A (the old 777-M) comes to mind as one, albeit, the DOE would not wish to store TRU there as the building is almost completely clean (the exception is the SP room).

20. On page 26 and 27, it is suggested that HWCTR be made a monolithic structure. Strictly speaking, I don't believe that can be done. The facility was designed to permit thermal expansion of the vessel as it was heated and there is a gap that would have to be filled to truly make the vessel and the surrounding concrete into one unit, or "monolithic." That seems not possible to do because of the rather soft insulation and air gap for ventilation that surrounds the vessel. This, too, seems to argue for dismantlement.

21. On page 29, the report speaks about radiological criteria that have not yet been established. It seems to me that regulatory matters in past history have gone in only one direction, namely towards more restrictive values. Thus, any alternative that doesn't bring permanent closure to the HWCTR facility now will face. I believe, tougher restrictions to adhere to later towards a final solution. That could wind up costing more than if the DOE closed out the facility with dismantlement right now.

22. On page 30, the report talks about removal of activated concrete after the vessel is removed so as to reduce the exposure rate to less than 0.05 millirem per hour from a buried underground structure which could be conceivably occupied in the future. I think that removing the vessel is the right action to take; however, removing the activated concrete is wrong.

The way to block any occupancy of an underground structure like the HWCTR concrete biological shield is to pour fresh concrete in the hole after the vessel has been removed. This approach is much better than chipping out activated concrete for the following reasons. It would cost far less. The new concrete might cost up to \$3-5,000. The removal would cost $\$ 132,616$ as given in table 6 on page 58. It would also cost something for the B-25 boxes to hold it. It would also cost something to transport these boxes to E Area. And it would cost something for these boxes to be disposed of in E Area, though I don't.know what E Area charges are.

Removing the concrete would also run counter to ALARA because the dose for workers to enter the hole and chip the concrete would be higher than to have them located at the top of the hole and just pour in concrete.

Finally, the question of potential future releases of the activated constituents (Europium-152, I believe) in the concrete needs to be addressed. The pathways for release from the HWCTR facility after filling with new concrete should be compared to pathways for release from the final resting place (and configuration) of the chipped concrete. It seems to me that the newly formed monolith (it truly would become a monolith this time) with the activity deeply buried would seal the activity better than any barriers around the chipped concrete (chipping would place the activation near or at the now much-greater-area surface of that concrete). I'm not sure what regulations would apply to my proposal, but if any blocked it. I would say they ought to be looked at with great skepticism for preventing a good technical solution that also saves money and space in E Area and adheres to the ALARA principle. 
23. On page 31 , first full paragraph, why do this when it leaves $>99 \%$ of all radioactivity at the site? The third sentence doesn't make sense. How does removing all of the radioactive equipment (containing $<1 \%$ of the activity!) but leaving behind the reactor and steam generators (with $>99 \%$ of the activity!) improve the ability to eventually release the site for unrestricted release? You are not coming to grips with the major restriction (the reactor itself) to unrestricted release.

24. As I mentioned before, section 5.3.3 (and page 44) talks about reuse for storage of materials, and suggests that TRU might be stored there. Doesn't DOE wish to remove, rather than add. radioactive materials to B Area? Reuse doesn't sound like a good idea to me.

25. In section 5.3.4, why remove concrete from the building structure down to 5 feet below grade and then fill "with concrete to a level of three feet above the the 0-level reference point"? If you take the building down eight (8) feet below the final level, you only have to build it up 8 feet again. Seems costly to me and doesn't make sense.

26. On page 35, the DOT regulations are discussed along with expected doses rates from HWCIR materials as packaged for transpor. The latter are assumed to be less than 0.001 rem per hour but this might cover all except for the reactor vessel. Its rate might be high enough so that disposal of the vessel on site (not transported through the public domain) is the most sensible thing to do. Besides, it may be very costly to move it away from SRS. The Shippingport reactor was moved to Hanford at a cost. I believe, of about $\$ 7$ million.

27. On page A10, figure 15, some lead shielded casks are shown. They probably are contaminated but that should be only on the carbon steel structure of the cask. The carbon steel should protect the lead against contact with the radioactivity. So they may be mixed waste only if they are not disassembled into their constituent materials. If that is done, the contaminated steel can be handled as LLW and the lead can be recycled for an economic gain. There are probably more than 100 tons of lead in HWCTR which represents some economic asset in today's "recycle-reuse" environment.

28. On page A13, figure 21 , the vessel was moved into the building in 1961 , not 1959 . This photograph was taken on July $3,1961$.

29. On page A13, figure 22 , the opening cut in the containment dome was cut on the south side of $770-U$ near the spent fuel basin. The equipment hatch is on the east side of 770-U. It was not used for reactor installation. But it was used for installation of most all other large equipment. Perhaps only the polar crane came in through the large hole. A larger hole than the $7^{\circ} \times 7^{\prime}$ equipment hatch to permit dismantlement of HWCTR may not be necessary.

30. On page A14, figure 23, the vessel shell contains 25 nozzles, not 24 .

31. On page A16. figure 27. the vessel head is not installed. The head is suspended from the rod drive platform but the platform is not over the reactor, it has been moved aside to the position it occupied during fuel charge-discharge.

Thank you for the opportunity to comment on this report. As you can see, I've made many comments and now I'd like to summarize my thoughts into two general categories. First, the report presents several alternatives, of which I strongly believe that dismantlement is the best because it clears B Area for non-radioactive uses. Second, though I've listed 31 comments where I think some action is needed, I believe the author did a very commendable job.

Thank you. Sincerely,

WSRC-TR-96-0268

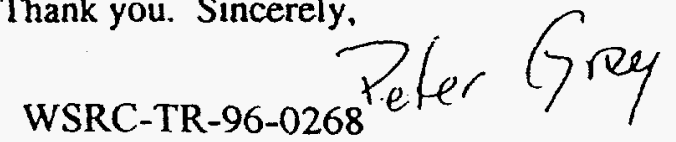




\section{DOE-SR response to comment R3-1 (state that heavy water was removed.)}

In Section 3.4, a description of the end condition of the facility deactivation process is provided. It states that heavy water was drained from the reactor systems. However, your comment refers to the Executive Summary which does not adequately describe the plant's deactivation status.

To improve the quality of this study, your comment was incorporated by expanding on the status of the reactor plant upon the completion of deactivation especially since a concerted effort was made to drain and purge reactor plant systems.

\section{DOE-SR response to comment R3-2 (other HWCTR buildings)}

To improve the accuracy and quality of this study, all structures, systems and components associated with the HWCTR facility and its operations were addressed. This incudes 770-U (containment building), 735-U (health physics building), 791-U (ventilation stack), 788-B (deluge control bunker), and 704-B (administration areas, technical support areas, storage areas).

\section{DOE-SR response to comment R3-3 (favor dismantlement)}

Your support for the dismantlement alternative is appreciated.

\section{DOE-SR response to comment $\mathrm{R3}-4$ (site description)}

To improve the accuracy and quality of this study, your comment was incorporated and the applicable section(s) changed.

DOE-SR response to comment R3-5 (roads on site map would have been helpful)

To improve the usability and quality of this study, your comment was incorporated and the applicable map changed. Site personnel and visitors alike associate with roads and landmarks more readily than streams.

\section{DOE-SR response to comment R3-6 (figures show more than building details)}

To improve the accuracy and quality of this study, your comment was incorporated and the applicable section(s) changed. Figures 4 through 27 in Appendix A contain details of the reactor plant as well.

\section{DOE-SR response to comment $\mathbf{R 3 - 7}$ (reactor vessel diameter)}

To improve the accuracy and quality of this study, your comment was incorporated and the applicable section(s) changed. 


\section{DOE-SR response to comment $\mathbf{R 3 - 8}$ (list should include deluge control bunker)}

This comment is similar to R3-2. Similarly, to improve the accuracy and quality of this study, all structures, systems and components associated with the HWCTR facility and its operations, were addressed. This includes 770-U (containment building), 735-U (health physics building), 791-U (ventilation stack), 788-B (deluge control bunker), and 704-B (administrative areas, technical support areas, storage areas).

\section{DOE-SR response to comment R3-9 (use of terms for radionuclide)}

Table 2 correctly lists the significant radioactive materials foreign to an otherwise "clean" HWCTR facility and which are of interest for decontamination or otherwise management and handling to minimize their exposure to other media or receptors. However, the first column in the table is incorrectly titled as "radioisotopes" when radionuclides are listed.

To improve the technical accuracy and quality of this study, your comment was incorporated and the applicable section(s) changed.

\section{DOE-SR response to comment $\mathrm{R3}-10$ (include activity for housing tubes)}

To improve the technical accuracy and quality of this study, your comment was incorporated and the applicable section(s) changed.

\section{DOE-SR response to comment R3-11 (use of $R /$ hr vs. Rem per hour)}

It is correctly stated that a radiation level of several hundred rem per hour is expected at the point of highest activation inside the reactor vessel. The use of rem (vice Roentgen) is appropriate since, in this context, the concern is the dose equivalent rate to the worker and radiation levels are being expressed in terms of a unit used to describe the radio-biological effects on man.

Respectfully, this comment will not be incorporated for the reason(s) and discussions(s) provided above.

\section{DOE-SR response to comment $\mathbf{R 3 - 1 2}$ (expected radiation levels on control rods)}

The values of table 3 , based on calculations performed in 1976, show a significant amount of radioactivity in the control rods ( 22 curies), despite their relatively low mass. The lower portions of the rods are expected to have significant radiation levels, as stated in the text. Since the control rods are expected to remain contained within and shielded by the reactor vessel, it is reasonable to capture estimated radiation levels within a range. Even for the purposes of transportation and waste disposal, one only needs an upper bound (i.e., a maximum or conservative estimate). 
Respectively, this comment will not be incorporated for the reason(s) and discussion(s) provided above.

\section{DOE-SR response to comment $\mathrm{R3-13}$ ( expected contamination in underground steam lines)}

Facility characterization revealed traces of radioactive contamination in sediment in the steam line near the muffler. Also, the condensate drain line of the ventilation exhaust stack was contaminated with residual radioactivity. There is strong evidence that leaks had occurred between the primary (coolant) side to the secondary (steam and auxiliary) side of the reactor plant. Thus, this potential cross-contaminating has made normally non-contaminated systems and components to be suspected of being contaminated.

Your observation is correct. This factor has been taken into account in other project documents. During actual decommissioning operations, system breaches will be accompanied by supplemental radiological controls and surveys, as deemed appropriate.

Respectfully, this observation will not be incorporated for the reason(s) and discussion(s) provided above.

\section{DOE-SR response to comment R3-14 (favors moving reactor vessel to E-Area)}

This factor was taken into consideration; thus, the dismantlement option was, once again, favored. Please note that final disposition of the reactor vessel has yet to be determined. The site has the capability to dispose of the reactor vessel at the E-Area treatment, storage and disposal facility. However, off-site disposal is still being considered for technical and cost reasons.

Your comment is acknowledged. However, no change to the document will be made for the reason(s) and discussion(s) provided above.

\section{DOE-SR response to comment R3-15 (decommissioning vs. removal alternatives)}

The two terms are used interchangeably in the document, since the Analysis of Removal Alternatives is a study of decommissioning options.

Respectfully, your comment will not be incorporated for the reason(s) and discussion(s) provided above.

\section{DOE-SR response to comment R3-16 (relevance of Hanford 105-C Reactor decommissioning , scenario)}

The Reactor 105-C interim safe storage approach was considered one of several possible approaches for the HWCTR decommissioning. Despite the differences in design between this reactor and the 
HWCTR, evaluation of the Hanford approach was merited because it was a current method of decommissioning a nuclear reactor in the DOE weapons complex and possessed certain advantages. The factors mentioned were among those taken into account as the different removal alternatives were compared.

For each of the decommissioning options presented, an example of a similar reactor project having a somewhat similar approach was provided to help compare and contrast each option. It is acknowledged that variations do occur because of factors such as reactor plant design and facility layout. However, the basic approach at accomplishing the decommissioning and arriving at the end state remain fundamental.

Respectfully, your comment will not be incorporated for the reason(s) and discussion(s) provided above.

\section{DOE-SR response to comment R3-17 (Hanford plan temporary measure)}

As with your previous comment, the basic approach at accomplishing the decommissioning and arriving at the end state remain fundamental. Whether the end-state is temporary, semi-permanent, or permanent, the approach at Hanford warranted investigation and, subsequently, comparison.

Respectfully, your comment will not be incorporated for the reason(s) and discussion(s) provided above.

\section{DOE-SR response to comment R3-18 (Cutting hole in HWCTR dome)}

This factor was taken into account when evaluating the need for a larger opening to facility removal of larger components from the facility. It appears that such a dome-cut would be advantageous.

Your comment is acknowledged. However, no change to the document will be made for the reason(s) and discussion(s) provided above.

DOE-SR response to comment R3-19 (possible transuranic waste storage in the HWCTR facility)

As with one of your previous comments, the basic approach at accomplishing the decommissioning and arriving at the end state remain fundamental. The approach utilized on Argonne National Laboratory-East's Experimental Boiling Water Reactor warranted investigation and, subsequently, comparison. Please note the Section 5.1.5 does not recommend storage of specific waste stream or material. Instead, a generic storage capability was presented as a possible reuse scenario.

Your comment is acknowledged. However, no change to the document will be made for the reason(s) and discussion(s) provided above. 
DOE-SR response to comment $\mathbf{R 3 - 2 0}$ (whether entombment would produce a monolithic structure)

It was recognized that in any entombment process factors such as the ones mentioned may result in small voids. Entombment would inherently require a structurally stable and contained monolith.

Your comment is acknowledge. However, no change to the document will be made for the reason(s) and discussion(s) provided above.

DOE-SR response to comment $\mathrm{R3-21}$ (regulatory criteria may become more restrictive, resulting in higher costs)

Radiological criteria is one of the factors among those considered in the decisions to proceed with the HWCTR decommissioning. However, in terms of the Department's radiological criteria and the ability to release property and material for unrestricted release, those requirements exist in DOE Order 5400.5 wherein de minimus values (through surface and not subsurface) and dose based values are acceptable methodologies.

To improve the technical accuracy and quality of this study, your observation was incorporated and the applicable section(s) changed.

DOE-SR response to comment R3-22 (filling biological shield cavity with concrete in lieu of removing the radioactive concrete)

Your comment is acknowledged. However, no change to the document will be made for the reason(s) and discussion(s) provided above, considering the RESRAD study results which appear in Section 8 of revision 1 .

DOE-SR response to comment $\mathbf{R 3 - 2 3}$ (disadvantages of partial dismantlement and interim safe storage approach)

This approach was evaluated as one of several alternatives for the decommissioning. Removing radioactive systems and components from the site improves the ability to release the site for unrestricted use. However, leaving the reactor vessel precludes unconditional site turnover and reuse. Your observations are correct and further support the alternative of dismantlement.

Your comment is acknowledged. However, no change to the document will be made for the reason(s) and discussion(s) provided above. 
DOE-SR response to comment $\mathbf{R 3 - 2 4}$ (transuranic waste storage in the HWCTR facility would not be appropriate)

As with one of our previous comments, the basic approach at accomplishing the decommissioning and arriving at the end state remains fundamental. The approach utilized on Argonne National Laboratory-East's Experimental Boiling Water Reactor warranted investigation and, subsequently, comparison. Please note the Section 5.1.5 does not recommend storage of a specific waste stream or material. Instead, a generic storage capability was presented as a possible reuse scenario. And, "Yes," the Department does wish to remove vice add radioactive materials to B-Area. Also, please remember that reuse does not imply reuse of radiological purposes.

Your comment is acknowledged. However, no change to the document will be made for the reason(s) and discussion(s) provided above.

DOE-SR response to comment R3-25 (why remove concrete below grade and then pour more concrete to a level three feet above grade)

Your comment is acknowledged. However, no change to the document will be made for the reason(s) and discussion(s) provided above.

DOE-SR response to comment R3-26 (reactor vessel disposal)

Your comment is acknowledged. However, no change to the document will be made for the reason(s) and discussion(s) provided above.

DOE-SR response to comment R3-27 (recycling of lead in shielded casks)

Your comment is acknowledge. However, no change to the document will be made for the reason(s) and discussion(s) provided above.

DOE-SR response to comment $R 3-28$ (date of reactor vessel movement into building)

To improve the accuracy and quality of this study, your comment was incorporated and the applicable section changed.

DOE-SR response to comment R3-29 (location and need for opening in dome)

An opening larger than the present seven foot high by seven foot wide equipment hatch is considered necessary to facilitate removal of larger equipment.

Your comment is acknowledged. However, no change to the document will be made for the reason(s) and discussion(s) provided above.

WSRC-TR-96-0268 


\section{DOE-SR response to comment R3-30 (number of vessel shell nozales)}

To improve the accuracy and quality of this study, your comment was incorporated and the applicable figure narration changed.

\section{DOE-SR response to comment $\mathbf{R 3 - 3 1}$ (vessel head position)}

To improve the accuracy and quality of this study; your comment was incorporated and the applicable figure narrative changed.

Terry M. Wessinger

1534 Dunbar Road

Cayce, SC 29033

December 12,1996

Mary A. Fora, Public Involvement

Westinghouse Savannah River Company

Savannah River Site, Building 730-2B

Aiken, SC 29808

Re: Comments Regarding Analysis of Removal Alternative for the Heavy Water Components Test Reactor

Dear Ms. Flora:

I am writing in response to the Department of Energy Savannah River Site's ("SRS") request for comments: Analysis of Removal Alternative for the Heavy Water Components Test Reactor. I have two (2) questions in regard to this action. Question one is why is this alternative the one being considered over the other ones, especially the entombment alternative. Although dismantlement and reclamation of the land to its original state is by far the most desirable alternative for many sites, the cost is usually going to be prohibitive. The fact this is going to be used as a study site does not mean it will be the alternative used in the future due to the shrinking budget for environmental clean-up. Reading this document it appears to me that the only feasible alternative is to use entombment, since it is a much lower cost and least amount of time, transport, disposal and possible damage to both public and worker health. It seems that the only drawback to the entombment alternative is that the structure would remain radioactive by today's standards and that it would be costly to remove it, if necessary, is probably not going to be a problem since this is a small site, and since the threat it poses to public health and the environment is minimal. 
My second question is related to the first and is how realistic it is that this two acre site will be utilized in the future. With SRS having such a large area of land, there are plenty of other areas in which to use if the need arises. Also, since the commercial development of SRS will probably never occur, there is no danger to the public for the entombment alternative. Furthermore, without more sampling of the groundwater and soil underneath the facility to determine if it is contaminated, the proposed altemative may not remove all of the contamination from the site to its original levels, rendering it useless anyway. It seems to me that, as you stated, entombment would "entail the least number of different activities" which makes it the safest and cheapest alternative. It would also save the public a great deal of money, especially if you plan to do this to the other reactors. Your answers to these questions will be greatly appreciated.

$$
\begin{aligned}
& \text { Sincerely, } \\
& \text { Jenu' } \\
& \text { Terry } M \text {. Wessinger }
\end{aligned}
$$

DOE-SR response to comment R4-1 (why is dismantlement preferred over entombment, which is less expensive?)

Your comment is acknowledged. However, no change to the document will be made for the reason(s) and discussion(s) provided above.

DOE-SR response to comment R4-2 (Is it realistic for the HWCTR site to be used in the future?)

There are indeed large areas of other property available on the Savannah River Site for future development. But whether the two-acre HWCTR property is available for other purposes is only one of many issues to be considered. Please refer to the response to comment R4-1 for concerns about entombment.

Regarding the groundwater under the property, the possibility of radioactive contamination from the HWCTR facility reaching the groundwater is exceedingly small as explained in Section 5.5.1.1. The water table in the area lies more than 30 feet below the bottom of the HWCTR structure. And the levels of radioactive contamination present inside of the HWCTR facility are very low, based on the detailed characterization program completed in September of 1996. (This characterization program is mentioned in Section 3.7.11.)

Regarding soil at the facility, sampling is planned as explained in the answer to comment R1-2. Soil contamination levels are expected to be low, based on the history of the facility and the low levels of contamination inside of the reactor building. 
There are indeed large areas of other property available on the Savannah River Site for future development. And, it is very possible that the property now occupied by the HWCTR facility can be used to supplement the many administrative functions that B-Area now provides to the site. But whether the two-acre HWCTR property is available for the other purposes is one of the may issues considered during the engineering study. Regardless, the dismantlement alternative would maximize the potential for property reuse.

As previously stated, entombment would have been a more viable option had HWCTR been located in one of the other major nuclear industrial areas of the site. However, given its location, entombment greatly restricts reuse options of the property, especially when reuse entails administrative missions or, even commercial development. Again, entombment precludes unrestricted reuse whereas dismantlement promotes it.

Regarding the groundwater, the possibility of radioactive contamination from the HWCTR facility is exceedingly small as explained in Section 5.5.1.1. The water table lies more than 30 feet below the bottom of the HWCTR structure. Given the fact that the containment structure is structurally sound there is no evidence that radioactivity has spread into the environmental from areas of HWCTR below grade.

Since the groundwater is well below even the lowest point of the HWCTR facility and since it appears to be unaffected, there are no plans for groundwater monitoring other that what is already being performed at nearby monitoring wells/points. However, surface water run-off/storm water drainage will need to be assessed routinely since it can serve as a transport mechanism for contamination deposited on the surface.

Regarding the soil, a more rigorous assessment of the soil conditions will be performed prior to major soil disturbing operations. This assessment will provide empirical data on the nature and extent of contaminants so that the proper engineered and administrative controls are implemented that assures the health and safety of working during decommissioning operations, allows for the proper disposal of contaminated soils and, to the maximum extent practicable, assures environmental insults are mitigated. In-process and post-decommissioning environmental sampling activities will be performed as well.

Please note that sampling is limited to areas disturbed during decommissioning operations and to environmental media newly exposed for the removal of structures, systems and components. Contaminated environmental media beyond the above conditions are expected to be encompassed by a separate environmental restoration effort (e.g., remedial action, removal action, closures, etc.)

Your comments are acknowledged. However, no change to the document will be made to the reason(s) and discussion(s) provided above. 
ANALYSIS OF HWCTR REMOVAL ALTERNATIVES

Dear Mary A. Flora,

Enclosed are my comenents concerning the Analysis of Removal Alternatives for the Heavy Water Components Test Reactor at the Savannah River Site. If possible, please respond to me at The University of South Carolina, Dept of Environmental Health sciences, Columbia, SC 29208. Thank you for your time in reviewing my comments.

Dana C. Cresce

1) It was indicated in the report that crevices in the concrete or the concrete itself were significant sources of contamination on the site. It was also stated that the preferred alternative would not pose any threat to workers or the environment with regards to contaminated concrete dust moving off site. After experiences with several building demolitions, I am skeptical that this dust can be effectively contained and am curious what air monitoring will be conducted during the operation to ensure deducting procedures are effective.

2) My second comment concerns the estimated amount of radiation present at the site. What options have been considered if upon beginning the preferred alternative, it is discovered that there has been a gross underestimation of the contamination, and thus cost and worker exposure become much greater than initially calculated.

WSRC-TR-96-0268

[23

Revision 1 


\section{DOE-SR response to comment R5-1 (air monitoring during dismantlement)}

The generation of dust is inherent to the demolition of buildings and other large structures, especially when those made of concrete, brick and other masonry material. The incorporation of dust control and suppression systems that are effective, practical and cost-effective complicate demolition techniques. Demolishing contaminated structures are further challenged with controlling airborne contaminants and minimizing worker and public exposure.

Although the creation of dust can be avoided to a large extent, with exhaustive measures, the generation of contaminated dust can still occur. The most effective method is minimizing the generation of contaminated dust is to remove, to the maximum extent practicable, the contaminant from construction materials prior to building demolition. This has been and remains a common practice in the demolition of nuclear as well as non-nuclear facilities. It is expected that this bestindustry practice will also be followed during actual demolition of the HWCTR facility.

Your concern with exposure of workers, the public and the environment to contaminated dust generated during building demolition can also be answered by a short discussion of safety.

As discussed in Sections 5.4. and 5.5, the potential for personnel exposure to radiological hazards (e.g., ingestion and inhalation of airborne radioactivity) is relatively low. However, the necessary administrative and engineered safety and work controls are needed to assure worker health and safety. There are three underlying factors that will greatly influence the effectiveness of a decommissioning project's ability to provide a safe working environment wherein the exposure to hazards and unnecessary risk are mitigated.

First, all levels of management at the Savannah River Site (DOE and contractors alike) endorse a safety-conscious workforce. Management's attention and expectations are not just limited to operating facilities or construction projects, but to cleanup efforts as well. Accordingly worker health and safety is a priority in decommissioning projects. The Savannah River Site has and will continue to maintain a superior safety record. This safety records is the direct result of a safety management system that protects and preserves. This safety record is a manifestation of a process safety management approach wherein hazards are identified, analyzed and controlled during all phases of work and at all levels of the workforce.

Second, extensive administrative and engineered controls will be used to assure that worker health and safety is not compromised. Similarly, controls will be effected to assure protection of the public and the environment. Since SR is ultimately responsible for the well-being of site workers, site neighbors, and the environment, concerted efforts will be made to verify and validate safety systems and practices via independent oversight and proactive participation in the planning, execution and close-out of the decommissioning project.

Third, radioactive contamination levels in the HWCTR facility are low compared to other nuclear

WSRC-TR-96-0268 
production reactors, research reactors, and test reactors. This is due largely to an extensive deactivation period over the years following shutdown in December 1964 which included removing all spent fuel and all major sources of radiation, dewatering and cleaning the spent fuel storage basin, and maintaining a nitrogen purge on the dewatered reactor plant though November 1971 . Following a detailed characterization program in August and September 1996, it is estimated that more than 99 percent of the residual radioactivity (2,848 of approximately 2850 ) is contained within the reactor vessel that will remain sealed during removal, shipment and disposal. The majority of the remaining residual radioactivity is bound within reactor plant system and components. Even less is found in building structures and construction materials.

Your comments are acknowledged. However, no change to the document will be made for the reason(s) and discussion(s) provided above.

DOE-SR response to comment R5-2 (options if more radioactivity than expected is present)

The information gathered from the recent facility characterization indicates that decommissioning operations can proceed with a very good understanding of the radiological condition at HWCTR It is expected that work will proceed as planned and with few unforeseen or unanticipated conditions and work hazards. Should unexpected conditions be encountered (e.g., higher levels of radiation or radioactivity), a process safety system will be in place to more clearly define, analyze and adjust controls for the safe management of the newly discovered hazard.

Subject: Questions on PAHs.

From: mishra @msgate.ColumbiaSC.NCR.COM at Mailhub

Date: $12 / 18 / 96 \quad 11: 53$ AM

Madam,

I am a student of Environmental Health Sciences and during one of my

class assignments I had the opportunity to read the engineering study on

Analysis of Removal Altematives for the Heavy Water Test Components

Reactor (HWCTR) at SRS. It is surprising that no soil contamination

records were available except one that was done in April 1996 during the

final radiological survey (Analysis of HWCTR Removal Altematives,

section 3.7.5). Also the HWCTR analysis does not take into

consideration the planning and cost of soil remediation and

environmental restoration actions that will be an important aftermath to

a large scale structural demolition due to dismantling altemative.

Section 4.3 further states that there are no present plans for any

remediation of soil or water in the general vicinity of HWCTR property.

According to section 5.5.1.1, minute amounts of radioactivity may be

released to the environment during demolition work. The releases will be

almost exclusively in the form of airborne radioactive particles and very low level of radioactivity contained in concrete dusts. Though the level of radioactive contamination in soil by this process is estimated to be negligible and comparable to background radiation as a result of various control measures not listed in the analysis, the analysis should

WSRC-TR-96-0268 
include an appropriate decontamination and remediation actions that would be required in case such actions become necessary. Also section 5.9 refers to new cleanup standards that is being developed by U.S. EPA. What do these standards include and how do they compare with the current clean up standards for this particular project?

The fact that the low level radwastes from decommissioning work will be disposed of on site makes dismantling an attractive altemative. There were however no clear disposal policies for "mixed wastes". Though the volume of mixed waste ( 280 cubic feet) generated from all the four altematives were estimated to be roughly the same, the method of their disposal is not clearly explained. On page 44 of the report it is mentioned that most of the mixed waste is expected to be shipped to off site facilities which will have treatment capabilities for the waste streams whereas on page 53 section 5.12 .4 it is stated that that mixed waste would be stored at SRS in an approved mixed waste storage facility pending disposition under the Federal Facility Compliance Act and that the HWCTR mixed waste will be processed under the SRS Mixed Waste Approved Site Treatment Plan. I will appreciate if you would clearly state the method of disposal of mixed wastes. It appears, from the analysis, that either dismantling or entombment will be an attractive proposition for the removal of HWCTR since both are ranked very high in the ranking table 7 on page 62. Total points for dismantling and entombment were 103 and 101 respectively as opposed to 92 points for PD\& ISS and 79 points for PD\& reuse.

Please explain why a weight of 3 was given to the ranking attribute number 3 , which emphasizes risk to workers. Also, in my opinion, considering the depth of the water table, entombment should pose no more risk to environment and public than does dismantling and therefore should be ranked 4 for each of the above mentioned ranking attributes. Rather dismantling should entail more environment and worker exposure as it includes demolition of large structure which can result in various forms of airborne radioactive particles and radioactivity contained in concrete dusts. It seems like the major reason in favor of dismantling is that it provides flexibility for future use of the property and provides more information for follow on projects than would entombment.

As stated above the HWCTR study is an important part of my assignment therefore please send your comments and answers to the above questions at your earliest convenience.

Thankyou very much. Meenakshi Mishra 


\section{DOE-SR response to comment R6-I (soil remediation)}

It is recognized that soil data is limited, especially when process history has indicated a small potential for the deposition of residual radioactivity on soil areas immediately adjacent to the HWCTR facility. A more rigorous assessment of the soil conditions will be performed prior to major soil disturbing operations. This assessment will provide empirical data on the nature and extent on contaminants so that the proper engineered and administrative controls are implemented that assures the health and safety of workers during decommissioning operations, allows for the proper disposal of contaminated soils and, to the maximum extent practicable, assures environmental insults are mitigated. In-process and post-decommissioning environmental sampling activities will be performed as well.

Regarding groundwater, the possibility of radioactive contamination from the HWCTR facility is exceedingly small as explained in Section 5.5.1.1. The water table lies more than 30 feet below the bottom of the HWCTR structure. Given the fact that the containment structure is structurally sound there is no evidence that radioactivity has spread into the environmental from areas of HWCTR below grade.

Since the groundwater is well below even the lowest point of the HWCTR facility and since it appears to be unaffected, there are no plans for groundwater monitoring other that what is already being performed at nearby monitoring wells/points. However, surface water run-off/storm water drainage will need to be assessed routinely since it can serve as a transport mechanism for contamination deposited on the surface.

Please note that sampling is limited to areas disturbed during decommissioning operations and it is limited to environmental media newly exposed from the removal of structures, systems and components. Subsequently, in the event contaminated environmental media beyond the above conditions are discovered, it will be managed by a separate environmental restoration effort (e.g., remedial action, removal action, closures, etc.). Please recognize that the scope of facility decommissioning does not generally include environmental restoration.

\section{DOE-SR response to comment R6-2 (radiation clean-up standards)}

The radiation clean-up standards for past DOE nuclear facility decommissioning projects have been set at levels protective of public heath and the environment and approved by DOE for each particular project. Standards used for the clean up of the Shipping port Atomic Power Station in Pennsylvania are typical.

The Shippingport decommissioning project is described on page 22 of the Analysis of Removal Alternatives. The basic standard for this project was in two parts. One was that future users of the unrestricted property would receive no more than 100 millirem per year from residual radioactivity. The second was ALARA, ensuring that any such exposure was as low as reasonably achievable. 
To implement this standard, potential exposure pathways were analyzed. These included pathways associated with residential use of the property, which considered ingestion of radioactive materials and other factors. Secondary limits based on these analyses were used to ensure that the basic standard would be met under the most restrictive pathway scenarios.

As with the Shippingport project, radiation exposure pathway analyses have been performed for the HWCTR project to support implementation of the clean-up standard. The results are discussed in Section 8 of revision 1 of the report. Detailed radiological surveys will be performed, and independently verified, to confirm that the requirements have been met.

Radiological release criteria is one of the factors among those considered in the decisions to proceed with the HWCTR decommissioning. However, in terms of the Department's radiological criteria and the ability to release property and material for unrestricted release, those requirements exist in DOE Order 5400.5 wherein de minimus values (though surface and not subsurface) and dose-based values are acceptable methodologies.

\section{DOE-SR response to comment R6-3 (disposal of mixed waste)}

Mixed waste, waste materials that are both radioactive and hazardous as defined by the Resource Conservative and Recovery Act, will be minimized during decommissioning work. Mixed waste will be managed in accordance with the Sanamah River Site Mixed Waste Approved Site Treatment Plan. Mixed waste may be sent to the site's mixed waste storage facility for temporary storage pending the availability of treatment or permanent disposal options. More information on mixed waste management can be found in the Final Environmental Impact Statement on Waste Management at the Savannah River Site.

To improve the accuracy and quality of this study, your comment was incorporated and the applicable figure narration(s) changed). The discussion on mixed waste treatment, storage and disposal will be clarified and, if necessary, expanded.

\section{DOE-SR response to comment R6-4 (weight given to worker risk in comparative analysis)}

Your comment/question is acknowledged. However, no change to the document will be made for the reason(s) and discussion(s) provided above.

\section{DOE-SR response to comment R6-5 (ranking of entombment attributes)}

An important factor in ranking entombment in protecting the environment and minimizing risk to the public is the longevity of the entombed structure compared to the time required for residual radioactivity to decay to such a low level that it is no longer a significant source of radiation.

The design life of entombment is expected to be 50 years, as in the case of the Wright-Patterson Air

WSRC-TR-96-0268 
Force Base reactor, or even as many as 100 years. As noted in Table 5, one discovers that a relatively large amount of the residual radioactivity would still be a radiation source even after 100 years. This factor precludes assigning the highest ranking to entombment based on these attributes.

Your comment is acknowledged. However, no change to the document will be made for the reason(s) and discussion(s) provided above.

\section{DOE-SR response to comment R6-6 (reasons for favoring dismantlement)}

Your observation is consistent with DOE-SR's selection of the dismantlement option. It is agreed that these factors are important considerations in selection of the dismantlement as the preferred alternative.

Your comment is acknowledged. However, no change to the document will be made for the reason(s) and discussion(s) provided above.

Subject: REMOVAL OF HECTOR(HWCTR)

From: Wayne Ray

Date: 11/20/96 1:01 PM

A POSSIBLE ALTERNATIVE TO THE DESTRUCTION OF HECTOR COULD BE ALLOWING THIS MONUMENT OF NUCLEAR ENERGY TO REMAIN AS IS AND BE UTILIZED AS A MUSEUM OF NUCLEAR ENERGY. WITH ALL THE TOURISTS OUT THERE IN THE PUBLIC DOMAIN, I AM SURE THAT THIS COULD BE TURNED INTO A TOURIST INDUSTRY THAT COULD MAKE MONEY FOR THE SITE.

I REALIZE THATT TODAY PUBLIC ACCESS IS NOT AVAILABLE TO THIS AREA BUT AM ALSO SURE THAT IN YEARS TO COME THIS AREA WILL EVENTUALIY BECOME READILY AVAILABLE TO THE PUBLIC.

JUST MY OPINION.

THANKS

\section{DOE-SR response to comment R7-1 (HWCTR as a museum)}

SR has the responsibility for the preservation of all historic buildings and structures managed by SR which have been determined eligible for listing on the National Register of Historic Places (Register) pursuant to Section 110 of the National Historic Preservation Act (NHPA) as amended (16 USC 470 h-2). SR must assess the effect of any Federal undertaking upon historic buildings and structures included in the eligible for the Register pursuant to Section 106 of NHPA (16 USE $470 \mathrm{f}$ ). Such undertaking can include maintenance, deactivation, alternative, decommissioning, dismantlement, and demolition of the build environment (i.e., buildings and structures). 
Currently, SR is evaluating the historical significance of the HWCTR facility. The SC State Historical Preservation Officer will be consulted as will the Advisory Council on Historical Preservation pursuant to 36 CFR 800.13 .

Prior to accomplishing major decommissioning work, the process for the identification, evaluation and treatment of buildings and historic archeological remains associated with HWCTR will be accomplished through 36 CFR 800.4 and 800.6

A preliminary evaluation has indicated that the HWCTR facility does not possess significant historical value.

Reading through the document I see in section 5.4.2, page 33 that there is a reference to the nature of radiological risks. There is a statement where 2 examples are explained related to the exposure and estimation of cancer risk. I have followed your explanation on the calculations and have recalculated these myself. Somehow I think there a miscalculation in the process. I recommend this page be reviewed because the exposure risk to workers is lower than the exposure risk to the general public. The statement that workers are adults leads me to think that a fair comparison between the cancer risk for workers should be compared to the cancer risk of the adult general population and not all the population because workers are exposed to background levels and they have been exposed as kids too. It sees that workers exposed to background radiation plus exposure to working conditions should have a higher risk factor than the general population (in the same period of time). In the second example the statements may be misleading unless my calculations are wrong. In any case I'd like a clarification on the calculations on the mentioned page. At a glance it seems that 100 radiation workers with an occupational exposure of 1 person-rem over 10 years have a lower cancer risk than 10 people from the general public. My point is, following the example:

100 workers * 1 person-rem * 10 years $* 0.0004$ risk factor $=0.400$ and not 0.040 as the example explains. I guess the term 100 workers should read 10 workers in which case:

10 workers * I person-rem * 10 years *0.0004 risk factor $=0.040$

This would be if a worker were exposed to I person-rem but on page 46 section 5.84 the exposure of a worker in the dismantlement alternative would be 4 person-rem so the cancer risk would be: 
10 workers * 4 person-rem *10 years $* 0.0004$ risk factor $=0.160$

but then; the risk factor in this case would be 0.0016 risk factor (page 46):

10 workers * 4 person-rem * 10 years $* 0.0016$ risk factor $=0.640$ or 1 chance in 1.56

Information on this issue would greatly be appreciated.

Yours sincerely,

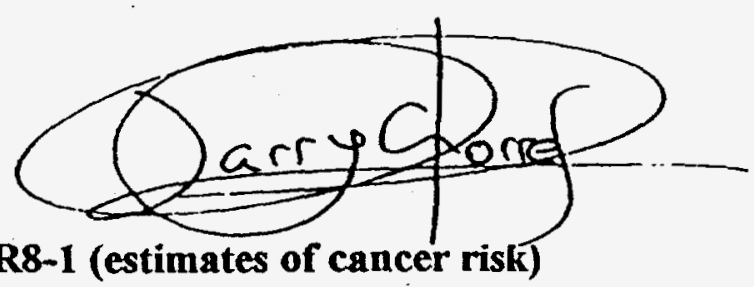

DOE-SR response to comment R8-1 (estimates of cancer risk)

Please note that the example of risk associated with natural background radiation was included only to help place into perspective the risk associated with occupational radiation exposure connected with the HWCTR decommissioning. In the second example, the risk to workers would be an increased risk associated with their occupational radiation exposure. That is, this would be an additional risk beyond that from background radiation. Therefore, the risk to workers would be greater than the risk to the general public.

In the second example, it was assumed that the workers received one rem from their work over a tenyear career; that is, an average of 0.1 rem per year. The calculation is:

100 workers $\times 1 \mathrm{rem} \times 0.0004=0.04$

Using the 4 person-rem estimate for the HWCTR dismantlement, the calculation would be:-

4 person-rem $\times 0.0004=0.0016$

Note that the 4 person-rem exposure is for the entire project, and is not an annual exposure rate. In the above example; the 0.0016 risk would be the total amount for the entire worker population exposed, whether this was 10 persons, 100 persons or somewhere in between.

In regard to differences in cancer risk associated with age - the worker population compared to the general population including children - this factor was not taken into account in the simplified examples used in Section 5.4.2.

Please note that the use of risk estimates such as these is subject to many uncertainties. Excess cancers attributed to radiation exposure can be observed only in populations exposed to high doses and high dose rates. As a consequence, risk estimates derived from high dose studies are extrapolated to low doses. The shape of the dose-effect curve at low doses - that is, the risk of 
cancer from low doses such as one rem per year-continues to be a matter of controversy among scientists:

December 27, 1996

807 E. Rollingwood Rd.

Aiken, SC 29801

WSRC-EM Public Involvement FAX $952-6962$

Westinghouse Savannah River Company

730-2B Room 128

Savannah River Site

Aiken, SC 29808

Atun.: Ms. Mary A Flora Re: Comments on Report, "Analysis of HWCTR Removal Alternatives",
August 1996.

Thank you for the opportunity to comment on the WSRC "Analysis of HWCTR Removal

Altemarives" dated August 1996, as part of the public review. I am sorry that these comments are several days later than requested in the public notice. I hope they will be considered anyway.

After resding the alternatives analysis in the report and reflecting on the contained information, I conclude that none of the altematives analyzed in the report should be nondertaken at this time. My intuitive judgment is that the listed prefecred alternative is probable the correct altemative but che report certainly doesn't make and support that conclusion. The document should be revised and improved before decommissioning should continue. I have listed several areas that need to be improved. They are:

- The report is a "trust me" report that makes a lot of unsubstantiated claims with no baclup justification. Justification should be included for the claims made in the analysis.

- An evaluation of consinued protective storage (the no-action alternative) must be included in the analysis. The text on page 19 lisses off the alternative with the following unsubstanciated words. "Little is to be gained by continuing this condition nor would it meet the objectives set for the decommissioning project." The alternatives report doesn't state the objectives of the decommissioning project.

- The justification for the selection of dismantlement altemative selection (see page 2) seems to rest with the following major parts:

- It ranks highest in the comparative analysis

- It would serve as the best prototype for the site reactor decommissioning program, and

- It would be the most compatible with the site property reuse plans for the future. 
- The ranking analysis is contained in Section 6 of the report. The analysis evaluates elever attributes. These attributes are considerably differint from those used in budget evaluations (which has had significant stakeholder input). There is no support for why the eleven were selected or why they cover the needed territory. The analysis also weights the various attributes. What is the juscification for these weights?

- Table 7. page 62, shows the rank scoring of 103, 101, 92, and 79. Is there a real difference between the 103 and 101? A simple change of the rank order between dismantlement and entomb on protection of the public reverse the cotal ranked value. Neither of these two altematives offer significant risk to the public so my change is not unreasonable. This raises the question of what is a significant difference?

- The justification that dismantiement serves as the best prototype for site reactor decommissioning is one of the three main reasons for making the decision for this alternative. As stated on page 65 , there is no definitive plan for decommissioning the SRS production reactors. One of my major concerns is that with no plan for production reactor decommissioning. HWCTR decommissioning cannot serve as a prototype. If fact without a plan, for how HWCTR can best be accomplished to provide the maximum information for production reactor decommissioning, decommissioning HWCTR now could result in destroying any potential usefulness to the production reactor decommissioning.

- Sections 4.2 and 4.4 discuss the impacts of HWCTR on future land use. The section is pretty good. Several of the alternatives seem to meet the conditions set for in the report since there has been no established future use for that porcion of the site.

Since this removal has been determined to be a CERCLA non-time critical removal action,

the process identified in the DOE-EPA agrecment on May 22, 1995 should be followed. It is not clear from the information in this report where the removal action is relative to the Framework required for a non-ime critical removal actions. (I refer to the framework identified in the May 22, 1995 "U. S. Deparment of Energy Environmental Restoration Program - Decommissioning Implementation Guide.") I infer that this document completes item 10 of that framework. I recommend that the SRS documents in the CERCLA nontime critical removal actions arena utilize this standard framework (as appropriate) and identify where in the process each of these documents are and what the major schedular milestones are for the waste unic. This will facilitate the stakeholder review and understanding of the non-time critical removal. For example key steps in this procedure should be reflected in the time bar charts in Appendices C. D, E, and F. I suspect they may be included but it is not obvious from Task Names.

I have a number of specific comments or points of identification of report weakness marked in the copy of the report I reviewed. If it would be useful in the rework of the report. please have someone phone me and we can discuss them. My phone number is 642-7297.

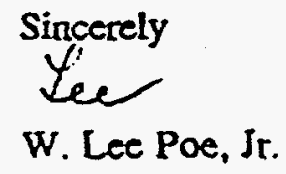




\section{DOE-SR response to comment R9-1 (none of the alternatives analyzed should be undertaken at this time)}

The Savannah River Site has hundreds of surplus facilities that are shutdown, in various stages of deactivation, and are in a variety of plant and system configurations that consume millions of taxpayers dollars in performing routine work activities to keep the facility structurally sound and its materials and contents in a chemically stable and radioactively benign state such that it does not pose unwarranted exposure to workers and such that the threat of an environmental release is mitigated (these activities are commonly referred as surveillance and maintenance). As you may know the SRS has five of DOE's 13 nuclear production reactors; all are shutdown and all are currently surplus. Also, the SRS has enormous chemical processing facilities and tritium processing facilities many of which are becoming surplus.

The SRS has not aggressively pursued decommissioning of the many surplus facilities due in part to the facts that, the site is still an operating facility with great potential of supporting new missions and is not in a "shutdown and cleanup" mode as with many of its sister sites. Site priorities are on environmental restoration of areas that are already contaminated such that the spread of contamination beyond site boundaries is precluded. Facilities that are shutdown still contain many highly radioactive and highly toxic and hazardous materials that require stabilization, treatment and final disposition before its housing facility can be decommissioned.

The "no action" alternative was considered as explain in Section 5.1.1. The conclusion was that continued safe storage - which is effectively a no-action alternative - was not viable. The reasons for this conclusion are stated in Section 5.1.1. They include the fact the HWCTR has been in this condition for some 30 years, and the main benefits associated with safe storage - significantly reduced radiation levels - have already been achieved. Also, continued safe storage would not meet the objectives for the decommissioning, which are described in Section 4.1. Please see also the response to comment R9-4, which lists the decommissioning objectives.

DOE-SR response to comment $\mathbf{R}$-2 (preferred alternative is probably correct, but report does not support this; report should be revised and improved)

The recommendation for dismantlement of the HWCTR facility is contained in Section 7.0 of the report. The organization of the report is designed to compare and contrast the viable decommissioning alternatives and to support such arguments with "case studies" or, demonstrated examples of similar scope and facility end point. The report is designed to provide this information objectively and conclude with recommendation for a "preferred alternative." This "preferred alternative" is based on its "grade" against the criteria specified in the DOE Decommissioning Resource Manual (DOE/EM-0246), its technical merits including regulatory requirements, and its consistency with Departmental and SRS Management programmatic initiatives. 
However, upon further review of the report collectively, Section 7.0 does appear to be anti-climactic. It does not summarize and provide a convincing argument for selection of the preferred alternative (the "sales pitch" is there, but it does not make me want to buy that vacuum cleaner). DOE-SR remains fully supportive with selection of the dismantlement option, but has enhanced Section 7.0. DOE-SR appreciates your comment on this matter.

\section{DOE-SR response to comment $\mathrm{R} 9-3$ (report makes unsubstantiated claims without backup justification)}

The discussions presented in the report are technically sound. A large majority of the information contained is objective in nature and can be easily supported by reference documents. A reason one may perceive such information to be "unsubstantiated claims," is that the presentation of the information lends itself to be qualitative, given the intended audience. Reporting on the results of the engineering study challenges SR to present the information that is understandable to both a nontechnical person and one who is technically competent (in what ever disincline) as you appear to be.

Early revisions of this report included a reference list of some 28 technical references. Many of these supported the information and data provided in the report. However, in an effort to minimize the number of references that were required to be readily available during the public review period, SR cited only the primary references and intentionally deleted the remaining references. Many of those that were omitted were technical in nature. DOE-SR's intention is to honor requests in the event an interest or request is expressed by a member of the public or a stakeholder. Please find the attached list of references. Should you desire a copy, kindly identify each to DOE-SR and we will work to satisfy your request.

DOE-SR response to comment R9-4 (continued protective storage must be evaluated; the alternative report does not state the objectives for the decommissioning project)

The HWCTR facility, in effect, evolved to a protective storage state starting with the 1964 shutdown, moving through nitrogen purge operations which ceased in 1971 and, finally, upon completion of a characterization effort in 1975 . So, the facility has essentially been in a protective storage status for over 20 years with no real benefit other than delaying decommissioning cost.

There are several reasons why the decommissioning of HWCTR is desired. First, this project is serving as a prototype for the site's overall approach for facilities decommissioning. The process is not limited to the production reactors. The rudiments of this decommissioning process bound the framework by which the SRS will handle its nuclear and complex process facilities where radiological and chemical hazards require a disciplined, systematic clean-up approach. This project is also supporting the site's deactivation program which is that portion of a facilities' life-cycle immediately preceding decommissioning. The overall process of managing facilities once it is retired from operations will greatly benefit from this project. 
Second, this project serves as the prototype for planning and executing decommissioning projects using the methods employed in accomplishing CERCLA non-time critical removal actions. This approach is consistent with the policy on decommissioning facilities under the CERCLA endorsed by the EPA and the DOE as documented on May 22, 1996. This approach is embodied in the DOE's Decommissioning Resource Manual (DOE/EM-0246).

Third, this project is serving as a prototype for developing a process wherein facility safety, worker safety, and continued protection of the public and environment are all integrated into a common management framework. This framework focuses on the identification, analysis, mitigation and control of physical, radiological and chemical hazards associated with decommissioning a nuclear or complex process facility.

Finally, the DOE has set aside specific funds to accomplish this project to assist in the development and maturation of a site decommissioning program. These funds do not affect the site's ability to accomplish existing efforts at environmental restoration nor do these funds affect the site's ability to operate existing facilities. The SRS has already removed numerous ancillary buildings and support structures and is fast approaching the final phases of this decommissioning work -- that is, removing the reactor dome and containment structures.

So, in summary, this project is pursued for a variety of reasons and maintaining the facility in safe storage does not support short-range as well as long-term site goals.

The objectives for the decommissioning project are found in Section 4.1. Although this section simply lists the objectives, the supporting arguments are contained throughout the document. However, in light of your comment, the report will be enhanced by including a brief discussion supporting each of the objectives.

\section{DOE-SR response to comment $\mathrm{RS-5}$ (justification for selection of dismantlement alternative)} See the response to comment $\mathbf{R 9 - 4}$.

Please note also the information in Section 7, which describes eleven reasons for selection of dismantlement as the preferred alternative. The drawbacks of the other three alternatives were also important factors in SR's decision for dismantlement. Kindly refer to DOE-SR's response to comment R4-1 for other supporting discussions.

\section{DOE-SR response to comment $R 9-6$ (evaluation attributes and associated weights)}

As noted in Section 6.0, the attributes used in the comparative analysis include those recommended in the DOE Decommissioning Resource Mamual, DOE/EM-0246). These are effectiveness, implementability and costs. Most of the other factors used are those that were addressed throughout the study. Since this project is designed to meet the tenets of the Decommissioning Resource Manual, this engineering study closely followed its recommendations.

WSRC-TR-96-0268 
DOE-SR response to comment R9-7 (significance of small differences in weighted evaluation points of 101 and 103)

It is agreed that the small difference between 101 and 103 are not significant. However, qualitatively, the drawbacks associated with entombment (e.g., limited facility design, continued mortgage burden, gradual facility deterioration, cost escalation over time, etc.) drive the decision for a more immediate approach such as dismantlement.

DOE-SR response to comment R9-8 (HWCTR as a prototype for production reactor decommissioning)

Please note that the statement in the SRS Waste Management Final Environmental Impact Statement of July 1995 is provided in Section 2.1. As stated previously, the HWCTR Decommissioning Project is intended to serve as a prototype for decommissioning other nuclear and complex processing facilities. As explained in Section 6.0, ranking the four alternatives for their value as a demonstrative project required some judgement. Dismantlement was ranked somewhat higher then the other because it involves a broader range of activities.

You are correct in stating that there are no definitive plans for decommissioning the production reactors. SR's Ten Year Plan supports your statement since it focuses on facility deactivation -- that is, stabilizing the nuclear materials and preparing the facilities for long-term surveillance and maintenance period. However, postponement of reactor decommissioning does not preclude SR from decommissioning HWCTR or any other facility. Much information, experience and lessons learned does stand to be gained from decommissioning HWCTR that will ultimately benefit the future decommissioning of the SRS's nuclear facilities. For example, inlet/outlet nozzle cutting, large component removal, packaging and transportation methods, and waste minimization strategies are a few elements of the HWCTR Project that will also be applicable to the production reactors. Please reexamine the approach taken by this report. For each option presented, a case study was also included. It is anticipated the planning for reactor decommissioning will also follow suit and consider data collected, experience gained and lessons learned from the HWCTR project.

\section{DOE-SR response to comment R9-9 (future land use)}

Your positive feedback is appreciated.

DOE-SR response to comment R9-10 (following process of DOE-EPA agreement and decommissioning framework)

The alternative analysis is primarily step 27 of the decommissioning framework outlined in the Decommissioning Resource Manual which implements the DOE-EPA Joint Policy Statement. Step 27 reads as follows: "Identify proposed response and document in Analysis of Removal Alternatives Certain other steps in the framework also pertain to the Analysis of Removal Alternatives such as step

WSRC-TR-96-0268 
20 , "Conduct risk assessment," and step 26, "Evaluate response alternatives."

DOE-SR response to comment R9-11 (recommendation to use standard framework for CERCLA non-time critical removal actions)

As stated previously, SR will follow the decommissioning framework of the Decommissioning Resource Manual. This framework is consistent with the approach described in the DOE-EPA Joint Policy Statement.

Incorporation of the decommissioning framework steps into the schedules of Appendices $\mathrm{C}$ through $F$ was considered. Since the schedules were intended to merely compare and contrast the work tasks associated with each alternative, it was decided not to include the decommissioning framework steps for clarity and simplicity.

\section{DOE-SR response to comment R9-12 (offer to discussed points of report weakness)}

DOE-SR appreciates the responder's offer of assistance. DOE-SR did not contact the responder for further information to use in reworking the report because none of the responder's comments or other public comments affected the DOE-SR conclusions on the preferred alternative or reworking of the report.

NOTE: This second letter from Mr. Porres, who has been identified as respondent R8, was received after his first letter of the same date.

Larry Porres

1850 Atlantic Drive \#621

Columbia SC 29210-7992

$12 / 17 / 96$

Dear Sirs,

As a concerned citizen living in South Carolina, I have reviewed the document Analysis of Removal Alternatives for the Heavy Water Components Test Reactor at the Savanah River Site (Aug. 1996).

I'm interested on the air quality aspect of the document and I see that on page 15 section 3.7.7 you mention the existence of non-nuclear wastes like asbestos, mercury and lead in the facility. My concern is with the mercury present on-site. I quote 'Mercury is expected to be found in electrical equipment such as fluorescent bulbs', asbestos is also mentioned on this page. I don't see any specific information on the type of lighting in HWCTR but I imagine that if it is mentioned in the document, the lighting system must mainly use fluorescent bulbs. 
DOE-SR response to comment $R 8-2$

The characterization study completed in September 1996 showed mercury were to limited to only a few thermometers. These thermometers will be disposed as hazardous waste. Mercury is suspected

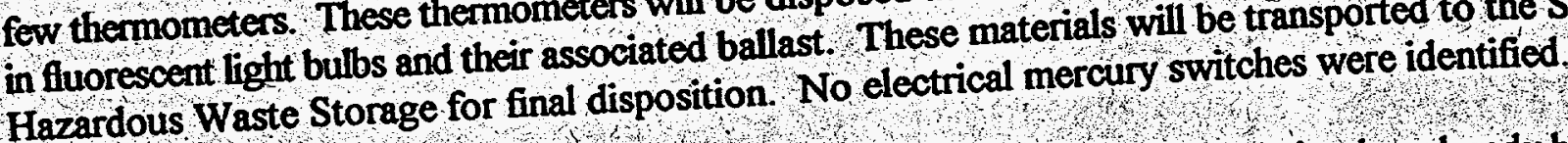

A large quantity of asbestos-containing material in the form of thermal insulation has already been removed. This asbestos abatement activity was performed
asbestos-containing material remain. During decommissioning operations, these residents will be
removed under controlled conditions in such a manner that assures worker health and safety. All asbestos-containing material will be disposed appropriately. 